RAFAEL GUIMARÃES SAVIOLI

ESTUDO EXPERIMENTAL DO COMPORTAMENTO À FRATURA FRÁGIL EM AÇOS ESTRUTURAIS FERRÍTICOS E APLICAÇÕES À DETERMINAÇÃO DA CURVA MESTRA

São Paulo

2016 
RAFAEL GUIMARÃES SAVIOLI

\section{ESTUDO EXPERIMENTAL DO COMPORTAMENTO À FRATURA FRÁGIL EM AÇOS ESTRUTURAIS FERRÍTICOS E APLICAÇÕES À DETERMINAÇÃO DA CURVA MESTRA}

Tese apresentada à Escola Politécnica da Universidade de São Paulo para a obtenção do Título de Doutor em Engenharia.

Área de Concentração:

Engenharia Naval e Oceânica

Orientador: Professor Titular Claudio Ruggieri

São Paulo 
Este exemplar foi revisado e corrigido em relação à versão original, sob responsabilidade única do autor e com a anuência de seu orientador.

São Paulo, de de

Assinatura do autor:

Assinatura do orientador:

Catalogação-na-publicação

Savioli, Rafael

ESTUDO EXPERIMENTAL DO COMPORTAMENTO À FRATURA FRÁGIL EM AÇOS ESTRUTURAIS FERRÍTICOS E APLICAÇÕES À DETERMINAÇÃO DA CURVA MESTRA / R. Savioli -- versão corr. -- São Paulo, 2016.175 p.

Tese (Doutorado) - Escola Politécnica da Universidade de São Paulo. Departamento de Engenharia Naval e Oceânica.

1.Curva Mestra 2.Mecânica da Fratura 3.Transição Dúctil Frágil 4.Aço ASTM A285 Grau C 5.Aço ASTM A515 Grau 65 I.Universidade de São Paulo. Escola Politécnica. Departamento de Engenharia Naval e Oceânica II.t.. 
Aos meus pais Jofre e Marcia e irmãos Daniela e Victor por me apoiarem incondicionalmente. 


\section{AGRADECIMENTOS}

Ao Prof. Dr. Claudio Ruggieri pela orientação;

Aos colegas do NAMEF: Diego Sarzosa, Luís Parise, Leonardo Mathias, Rodolfo Souza e Vitor Scarabeli, pelo companheirismo e amizade;

Ao departamento de Engenharia Naval e Oceânica;

À CAPES pela bolsa concedida. 


\section{RESUMO}

Este trabalho apresenta uma investigação experimental sobre o comportamento à fratura frágil de aços estruturais ferríticos, ASTM A285 Gr C e ASTM A515 Gr 65. Os resultados deste trabalho ampliam a base de dados de propriedades mecânicas utilizadas nas análises de integridade de estruturas pressurizadas tais como vasos de pressão e tanques de armazenamento construídos com esta classe de material. O trabalho tem por objetivo também avaliar a aplicabilidade de corpos de prova de dimensões reduzidas, PCVN, na determinação da temperatura de referência, $T_{0}$, por meio da metodologia da Curva Mestra, a qual define a dependência da tenacidade à fratura do material em função da temperatura. Os ensaios de tenacidade à fratura foram conduzidos utilizando-se corpos de prova solicitados em flexão três pontos com geometria $\mathrm{SE}(\mathrm{B}), \mathrm{PCVN}$ e PCVN com entalhe lateral, extraídos de chapas laminadas. Os resultados dos ensaios foram obtidos em termos de integral $J$ no momento da instabilidade, denotados por $J_{c}$. Dados adicionais de resistência à tração e de Impacto Charpy convencional também foram obtidos para caracterizar o comportamento mecânico dos aços utilizados. Os resultados mostraram uma forte influência da geometria dos corpos de prova sobre os valores de $J_{c}$, evidenciada pela grande variação nos valores de tenacidade à fratura. 


\section{ABSTRACT}

This work presents an experimental investigation on the cleavage fracture behavior of structural ferritic steels, ASTM A285 Grade C and ASTM A515 Grade 65. One purpose of this study is to enlarge a previously reported work on mechanical and fracture properties for this class of steel to provide a more definite database for use in structural and defect analyses of pressurized components, including pressure vessels and storage tanks. Another purpose is to address the applicability of Precracked V-notch Charpy specimens to determine the reference temperature, $T_{0}$, derived from the Master Curve Methodology which defines the dependence of fracture toughness with temperature for the tested material. Fracture toughness testing conducted on single edge bend specimens in three-point loading (SE(B), PCVN Plain Side and PCVN Side Grooved) extracted from laminated plates provides the cleavage fracture resistance data in terms of the $J$-integral at cleavage instability, $J_{c}$. Additional tensile and conventional Charpy tests produce further experimental data which serve to characterize the mechanical behavior of the tested materials. The results reveal a strong effect of specimen geometry on $J_{c}$ values associated with large scatter in the measured values of cleavage fracture toughness. 


\section{ÍNDICE DE FIGURAS}

Figura 1. Representação do micromecanismo de falha da fratura frágil, clivagem transgranular [17]. 8

Figura 2. Esquema representativo da condição de similitude onde corpo de prova e estrutura estão carregados sob mesma condição de intensidade de tensões.

Figura 3. Variação de $K_{I C}$ com a temperatura para o aço ASTM A533B de baixa liga utilizado na construção de vasos de pressão nucleares (adaptado de [20]).

Figura 4. Representação de curva tensão deformação para materiais elasto-plásticos e elásticos não lineares [26].

Figura 5. Representação do contorno arbitrário ao redor da trinca [26].

Figura 6. Limite da validade da mecânica da fratura linear elástica (Dominância $K$ ) e limite da validade da fratura elasto-plástica (Dominância $J$ ) [20]

Figura 7. Definição de área plástica $\left(\boldsymbol{A}_{p l}\right)$ e elástica $\left(\boldsymbol{A}_{e l}\right)$ sob a curva de carga vs. deslocamento (CMOD ou LLD) [35].

Figura 8. Distribuição característica dos dados de tenacidade para aços ferríticos no teste de Impacto Charpy - Patamar inferior: Fratura Frágil; Região de Transição Dúctil-Frágil; Patamar Superior: Fratura Dúctil.

Figura 9. Efeito da espessura sobre os valores de tenacidade à fratura para o aço A285 Grau C. 24

Figura 10. (a) Representação da distribuição uniforme de defeitos na matriz do material; (b) Fratura frágil representada por uma distribuição de valores extremos para tamanho de trinca. Adaptado de [44]

Figura 11. Distribuição de Probabilidade de Weibull (Biparamétrica): (a) Influência do Parâmetro de Forma na distribuição $(\alpha)$; (b) Influência do Parâmetro de Escala $(\beta)$ na distribuição. .......................27

Figura 12. Representação do efeito de espessura baseado na Teoria do Elo Mais Fraco................29

Figura 13. Representação gráfica dos dados de tanacidade à fratura para a determinação do módulo de Weibull.

Figura 14. Dispersão teórica dos dados experimentais para determinação do módulo do Weibull como função do número de testes [49]. (a) Kmin $=10 \mathrm{MPa} \sqrt{\mathrm{m}}$; (b) Kmin $=20 \mathrm{MPa} \sqrt{\mathrm{m}}$. .36

Figura 15. Valores de tenacidade à fratura, $K_{I c}$, para diversas classes de aços ferríticos e a curva de referência ASME estabelecendo o patamar inferior de tenacidade em função da temperatura. [16] 39

Figura 16. Representação esquemática da curva de tenacidade obtida pela Metodologia da Curva Mestra.

Figura 17 Esquema representativo dos pontos para a medição do crescimento estável de trinca....46

Figura 18. Desenho esquemático para retirada dos corpos de tração das chapas laminadas. ........51

Figura 19. Desenho esquemático para retirada dos corpos de pequenas dimensões, Impacto Charpy e PCVN.

Figura 20. Desenho esquemático para retirada dos corpos de tenacidade à fratura com dimensões $1 \mathrm{~T}$.

Figura 21. Corpo de tração para ensaio a temperatura ambiente seguindo os padrões da norma

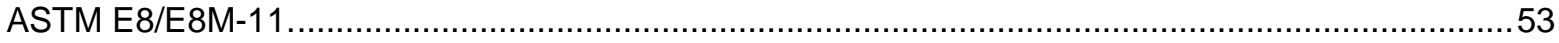

Figura 22. Curva de Tensão vs Deformação para os aços A285 Gr C e A515 Gr 65 a temperatura

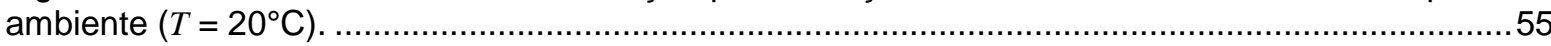

Figura 23. Corpo de prova normalizado para ensaio de impacto Charpy - ASTM E23 - 07 [86]......58

Figura 24. (a) Equipamento de Impacto Charpy Tinius Olsen IT 406; (b) Equipamento de Impacto Charpy Wolpert Tipo PW 30/15; (c) Refrigerador para corpos de prova Charpy. ............................58

Figura 25. Gráficos com os dados de tenacidade ao impacto (Ensaio Charpy) - ASTM A285 Gr C.59 
Figura 26. Gráfico com os dados de tenacidade ao impacto (Ensaio Charpy) - ASTM A515 Gr 65.. 60 Figura 27. Obtenção dos coeficientes da curva de ajuste para os dados experimentais de

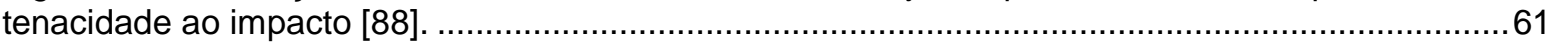

Figura 28. Desenho esquemático com as dimensões geométricas para os espécimes $\mathrm{SE}$ (B) $1 T$ (a) e PCVN (b).

Figura 29. Distribuição dos valores experimentais de tenacidade comparados à distribuição teórica de Weibull $\operatorname{com} \alpha=2$ para o aço A285. 66

Figura 30. Efeito da variação do comprimento de trinca e da temperatura de ensaio nos valores de tenacidade à fratura, $J c$ para 0 aço $\mathrm{A} 285 \mathrm{Gr}$ C.

Figura 31. Efeito da variação da espessura nos valores de tenacidade à fratura, Jc para o aço A285 Gr C.

Figura 32. Efeito dos entalhes laterais e da temperatura de ensaio nos valores de tenacidade à fratura, $J_{c}$ para o aço A285 $\mathrm{Gr}$ C.

Figura 33. Distribuição dos valores experimentais de tenacidade para os espécimes com geometria PCVN comparados à distribuição teórica de Weibull com $\alpha=2$ para o aço A285.

Figura 34. Distribuição dos valores experimentais de tenacidade para o espécime SE(B)-1T, trinca profunda utilizado como referência. e espécimes PCVN com entalhes laterais comparados à distribuição teórica de Weibull com $\alpha=2$ para o aço A285.

Figura 35. Micro e macrografias para os corpos de prova de aço ASTM A285 GR C; (a) CP05; (b) CP12. Os aumentos nas micrografias são de 50x e 1500x, respectivamente. …………................76

Figura 36. Padrão das macrografias obtidas de corpos de prova com trinca rasa e geometria PCVN (aumento de 10X).

Figura 37. Distribuição dos valores experimentais de tenacidade comparados à distribuição teórica

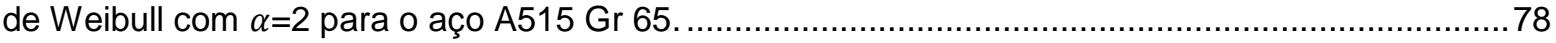

Figura 38. Efeito da variação do comprimento de trinca nos valores de tenacidade à fratura, $J_{c}$ para o aço A515 Gr 65.

Figura 39. Efeito da variação da espessura nos valores de tenacidade à fratura, $J_{c}$ para o aço A515 Gr 65.

Figura 40. Efeito da variação da espessura nos valores de tenacidade à fratura, $J_{c}$ para o aço A515 Gr 65.

Figura 41. Distribuição dos valores experimentais de tenacidade para os espécimes com geometria PCVN comparados à distribuição teórica de Weibull com $\alpha=2$ para o aço A515 Gr 65.

Figura 42. Distribuição da probabilidade de falha dos valores experimentais de tenacidade para o espécime $\mathrm{SE}(\mathrm{B})-1 \mathrm{~T}$, trinca profunda utilizado como referência e espécimes com geometria PCVN com entalhes laterais comparados à distribuição teórica de Weibull com $\alpha=2$ para o aço A515 $\mathrm{Gr}$ 65.

Figura 43. Micro e macrografias para os corpos de prova de aço ASTM A515 GR 65; (a) CP01; (b) CP16. Os aumentos nas micrografias são de 50x e 1500x, respectivamente. ..88

Figura 44. Gráfico representativo da Curva Mestra do aço Aço ASTM A285 Gr C e seus intervalos de confiança, dados experimentais obtidos com corpos de prova $\mathrm{SE}(\mathrm{B})-1 \mathrm{~T}, T_{\text {ensaio }}=-80^{\circ} \mathrm{C}$. . .92

Figura 45. Gráfico representativo da Curva Mestra do aço Aço ASTM A285 Gr C e seus intervalos de confiança, dados experimentais obtidos com corpos de prova PCVN-SG, $T_{\text {ensaio }}=-105^{\circ} \mathrm{C}$. (a) Aço ASTM A285 Gr C.

Figura 46. Gráfico representativo da Curva Mestra do aço ASTM A515 Gr 65 e seus intervalos de confiança, dados experimentais obtidos com corpos de prova $S E(B), B=30 \mathrm{~mm}, T_{\text {ensaio }}=-20^{\circ} \mathrm{C} \ldots . .96$

Figura 47. Gráfico representativo da Curva Mestra do aço ASTM A515 Gr 65 e seus intervalos de confiança, dados experimentais obtidos com corpos de prova PCVN-SG, $T_{\text {ensaio }}=-65^{\circ} \mathrm{C} \ldots \ldots \ldots \ldots \ldots . . . . . . . . .98$

Figura 48. Avaliação dos valores de integral $J$ na frente de trinca. Corpos de prova com geometria

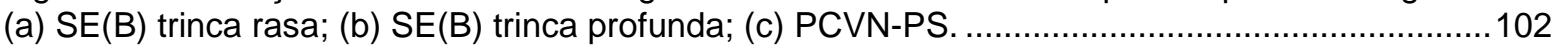

Figura 49. Avaliação de $J$ na frente de trinca PCVN "Side Grooved". ............................................104 
Figura 50. Efeito do raio de ponta sobre os valores locais de $J$ na frente de trinca.

Figura 51. Efeito do raio de ponta e dos ângulos de abertura sobre os valores locais de $\mathrm{J}$ na frente de trinca.

Figura 52. Efeito da temperatura sobre os valores de $J-Q$. Corpo de prova PCVN sem entalhe lateral.

Figura 53. Gráfico comparativo das trajetórias $J-Q$ ao longo da espessura do corpo de prova para as geometrias SE(B)-1T e PCVN. 108

Figura 54. Gráfico comparativo das trajetórias $J-Q$ ao longo da espessura do corpo de prova para as geometrias PCVN sem entalhe lateral ("Plain Side") e PCVN com entalhes laterais ("Side Grooved") e ausência de raio de ponta. 110

Figura 55. Gráfico comparativo das trajetórias $J-Q$ ao longo da espessura do corpo. Geometrias PCVN-SG ("Side Grooved") com e sem raio de ponta. 111

Figura 56. Gráfico comparativo das trajetórias $J-Q$ ao longo da espessura do corpo de prova. Geometrias PCVN-SG ("Side Grooved") variando o ângulo de abertura do entalhe.

Figura 57. Gráfico comparativo das trajetórias $J-Q$ ao longo da espessura do corpo de prova para as geometrias SE(B)-1T e PCVN com entalhes laterais ("Side Grooved"). 113

Figura 58. Imagens representativas das franjas que delimitam a Zona de Processo de Fratura desenvolvidas na frente da trinca para os corpos de prova com a geometria: (a) $S E(B)-1 T$ trinca profunda plano $X Y$ e $X Z$, (b) PCVN sem entalhes laterais plano $X Y$ e $X Z$ e (c) PCVN com entalhes laterais plano XY e XZ. Zona Escuras $M=60$ e Zona Clara $M=30$. 114

Figura 59. Representação da correção pelo efeito de espessura baseado no Weakest Link Model para um componente com espessura $B_{x}$ e três seções menores com espessura $B_{1}$

Figura 60. Corpos de tração para ensaios a baixa temperatura com dimensões reduzidas e previstas

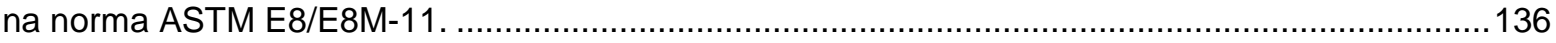

Figura 61. Imagens ilustrativas do ensaio de tração a baixa temperatura sem extensômetro.........138

Figura 62. Tentativa de ensaio de tração do aço A515 em atmosfera refrigerada. 139

Figura 63. (a) e (b) Processo de corte e preservação da frente de trinca; (c) Digitalização das superfícies de fratura para as diferentes configurações de corpos de prova; (d) Estéreo microscópio. 145

Figura 64. Pontos para a medição do comprimento de trinca inicial e verificação de possível crescimento estável da trinca. 146

Figura 65. Modelos computacionais SE(B)-1T e PCVN (a). Representação das dimensões significativas dos corpos de prova (b). 148

Figura 66. Modelos numéricos e representação das configurações geométrica dos corpos de prova com geometria PCVN.

Figura 67. Modelos numéricos das diversas variações de corpos de prova com geometria PCVN.151

Figura 68. Representação da simetria do corpo $S E(B)$ utilizada nos modelos para simulação e representação da ponta da trinca arredondada.

Figura 69. Representação de um corpo de prova com geometria SE(B), (a) solicitado sob Modo I de carregamento. (b) Representação do modelo MBL. 156

Figura 70. Representação da tensão de abertura adimensional vs. distância adimensional para a solução de referência MBL e um componente estrutural genérico [35]. 157 
Tabela 1 Composição química dos aços ASTM A515 Gr 65 e ASTM A285 Gr C (\% massa)...........49

Tabela 2 Propriedades mecânicas em tração para o aço ASTM A285 Gr C ....................................56

Tabela 3 Propriedades mecânicas em tração para o aço ASTM A515 Gr 65 ...................................57

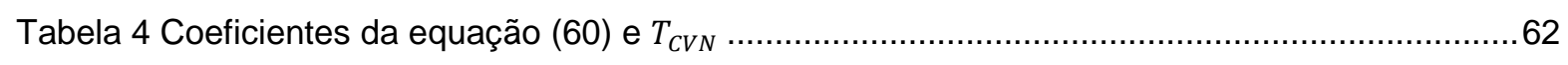

Tabela 5. Matriz de ensaio de tenacidade à fratura para o aço A285 Gr C....................................62

Tabela 6. Matriz de ensaio de tenacidade à fratura para o aço A515 Gr 65 ...................................63

Tabela 7 Valores de tenacidade característica para as diferentes configurações geométricas ensaiadas - Aço ASTM A285.

Tabela 8 Valores de tenacidade característica para as diferentes configurações geométricas ensaiadas utilizando a estimativa de máxima verossimilhança - Aço ASTM A285 ............................68

Tabela 9 Valores de tenacidade, $J_{c}$, obtidos nos ensaios à baixa temperatura, comprimentos de trinca, $a_{0}$ e limite de deformação plástica. Aço A285 Gr C .................................................................74

Tabela 10 Valores de tenacidade característica para as diferentes configurações geométricas

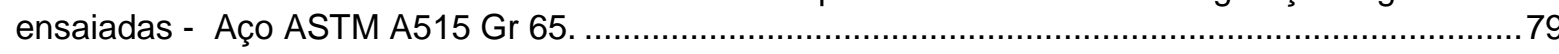

Tabela 11 Valores de tenacidade característica para as diferentes configurações geométricas ensaiadas utilizando a estimativa de máxima verossimilhança - Aço ASTM A515 .............................79

Tabela 12 Valores de tenacidade, $J_{c}$, obtidos nos ensaios à baixa temperatura, comprimentos de trinca, $a 0$ e limite de deformação plástica. Aço A515 Gr 65. .86

Tabela 13 Valores experimentais de tenacidade convertidos para unidades de $\boldsymbol{K}_{\boldsymbol{J c}} ; \boldsymbol{K}_{\boldsymbol{J} \text { _llimite }}$ para 0 corpo de prova SE(B), $1 T$ com $a / W=0,5$ e valor calculado de $\boldsymbol{K}_{\mathbf{J c} \_ \text {med }}$. Aço ASTM A285 [4] ...........91

Tabela 14 Valores experimentais de tenacidade convertidos para unidades de $\boldsymbol{K}_{\boldsymbol{I c}}$ e $\boldsymbol{K}_{\boldsymbol{I c}}-\mathbf{1 T} ; \boldsymbol{K}_{\boldsymbol{I} \_ \text {limite }}$ para o corpo de prova PCVN-SG, $T_{\text {ensaio }}=-105^{\circ} \mathrm{C}$ e valor calculado de $\boldsymbol{K}_{\mathbf{I c} \_ \text {med }}$ sem aplicar censura

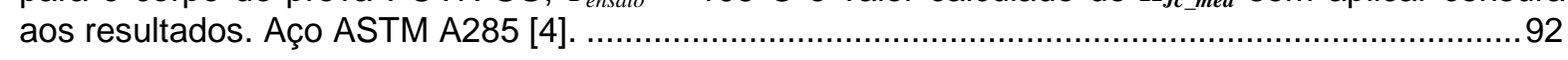

Tabela 15 Temperaturas de ensaio praticadas e temperaturas de referência obtidas para o aço ASTM A285 Gr C.

Tabela 16 Valores experimentais de tenacidade convertidos para unidades de $\boldsymbol{K}_{\boldsymbol{J c}} ; \boldsymbol{K}_{\boldsymbol{J C}_{\mathbf{C}} \text { limite }}$ para $\mathrm{O}$

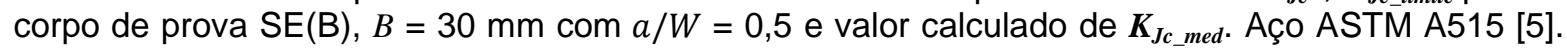

Tabela 17 Valores experimentais de tenacidade convertidos para unidades de $\boldsymbol{K}_{\text {Ic }}$ e $\boldsymbol{K}_{\boldsymbol{I C}}-\mathbf{1 T} ; \boldsymbol{K}_{\boldsymbol{I} \_ \text {limite }}$ para o corpo de prova PCVN-SG, $T_{\text {ensaio }}=-65^{\circ} \mathrm{C}$ e valor calculado de $\boldsymbol{K}_{J_{\_} \text {med }}$ sem aplicar censura aos resultados. Aço ASTM A515 [5].

Tabela 18 Temperaturas de ensaio praticadas e temperaturas de referência obtidas para o aço ASTM A515 Gr 65. . .99

Tabela 19 Valores para a constante $C$. 141

Tabela 20 Taxa de aplicação de carga no ensaio de tenacidade. 142

Tabela 21 Matriz de análise e dimensões dos corpos de prova SE(B) e PCVN. 149 
ECA: "Engineering Critical Assessment" - Análise Crítica de Engenharia.

ASME: "American Society of Mechanical Engineers".

ASTM: "American Society for Testing and Materials".

CMOD: Abertura da boca da trinca ("Crack Mouth Opening Displacement').

$\mathrm{SE}(\mathrm{B})$ : Corpo de prova submetido à flexão 3 pontos com trinca passante lateral centrada.

CTOD: Abertura da ponta da trinca (Crack Tip Opening Displacement).

EPD: Estado Plano de Deformações.

EPT: Estado Plano de Tensões.

FFS: Fitness For Service.

HRR: Solução analítica proposta por Hutchinson, Rice e Rosengren para o campo de tensões e deformações à frente de trincas

LLD: "Load Line Displacement" - deslocamento da linha de carga

LSY: "Large Scale Yieding" - escoamento de grande monta

MBL: Camada de Contorno Limite Modificada ("Modified Boundary Layer")

MFEL: Mecânica da Fratura Elástica Linear

MFEP: Mecânica da Fratura Elasto-Plástica

PCVN-PS: Espécime submetido à flexão com seção de ensaio reduzida e quadrada nas dimensões $10 \mathrm{~mm} \times 10 \mathrm{~mm}$

PCVN-SG: Espécime com entalhes laterais submetido à flexão com seção de ensaio reduzida e quadrada nas dimensões $10 \mathrm{~mm} \times 10 \mathrm{~mm}$

SSY: "Small Scale Yielding" - escoamento de pequena monta

TDF: Transição Dúctil Frágil

TEMF: Teoria do Elo Mais Fraco 


\section{LISTA DE SÍMBOLOS}

a: Comprimento de trinca.

$A_{P}$ : Área plástica sob a curva de carga vs. deslocamento.

$B$ : Espessura do corpo de prova.

$B_{n}$ : Espessura neta do corpo de prova.

b: Ligamento remanescente $(b=W-a)$.

ds: Incremento do arco do contorno fechado.

E: Módulo de elasticidade.

E': Módulo de elasticidade em estado plano de deformação.

F: Trabalho realizado pelas forças externas.

$\mathcal{G}$ : Taxa de liberação de energia.

$I_{n}$ : Constante de integração na solução do campo HRR.

$J$ : Amplitude da singularidade - Integral $J$.

$J_{I c}$ : Valor de integral $J$ que produz a iniciação de crescimento da trinca carregada em modo I.

$J_{E l}$ : Parcela elástica da integral $J$.

$J_{P l}$ : Parcela plástica da integral $J$.

$K_{I}$ : Fator de intensidade de tensões em Modo I de abertura.

$K_{I c}$ : Valor do fator de intensidade de tensões para o qual ocorre fratura sob modo I de carregamento.

M: Limite de deformação plástica.

$n$ : Coeficiente de encruamento.

$P$ : Carga imposta.

$T_{i}$ : Vetor de tração $(i=1,2)$.

$U:$ Energia de deformação armazenada.

$u_{y}$ : Deslocamento vertical da face da trinca.

$u_{i}$ : Vetor de deslocamento $(i=1,2)$.

w: Densidade de energia de deformação.

W: Largura do corpo de prova.

$\varepsilon_{i, j}:$ Tensor de deformação plástica.

$\varepsilon_{y s}$ : Deformação de referência ou escoamento $\left(\sigma_{y s} / E\right)$.

$\sigma_{0}$ : Tensão de referência.

$\sigma_{y s}:$ Tensão de escoamento. 
$\Delta$ : Deslocamento da linha de carga (LLD).

$\Delta_{\mathrm{El}}$ : Deslocamento elástico da linha de carga (LLD EI).

$\Delta_{\mathrm{Pl}}$ : Deslocamento plástico da linha de carga (LLD $\left.\mathrm{Pl}\right)$.

$\Gamma$ : Caminho de integração usado para obtenção de $J$.

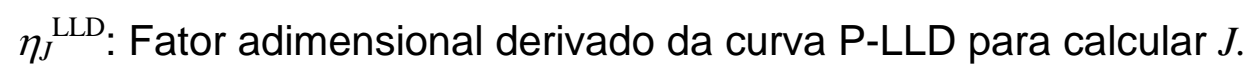

$\eta_{J}{ }^{\mathrm{CMOD}}$ : Fator adimensional derivado da curva P-CMOD para calcular $J$.

$\eta_{\delta}{ }^{\mathrm{CMOD}}$ : Fator adimensional derivado da curva P-CMOD para calcular $\delta$ 


\section{SUMÁRIO}

ÍNDICE DE FIGURAS

LISTAS DE TABELAS

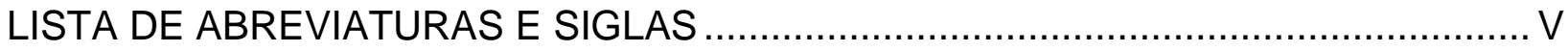

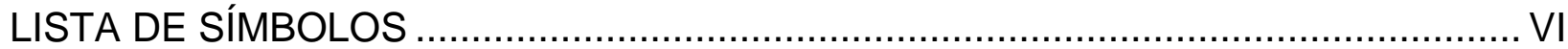

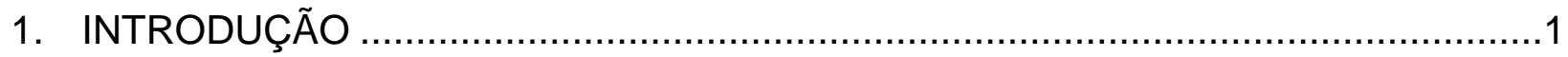

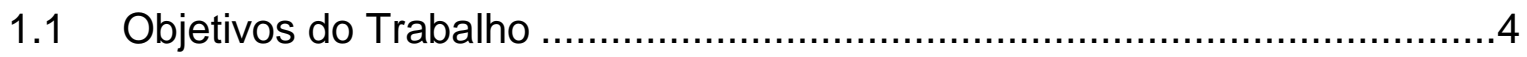

2. REVISÃO BIBLIOGRÁFICA: CONCEITOS ESSENCIAIS ..................................

2.1 Introdução à Fratura Frágil - Clivagem Transgranular ................................6

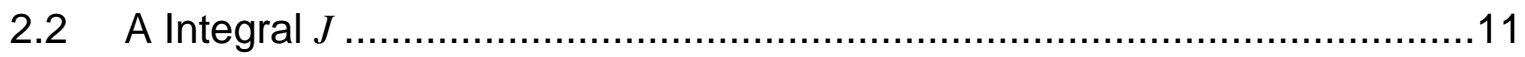

2.2.1 Limitações da Mecânica da Fratura Elasto-Plástica...................................14

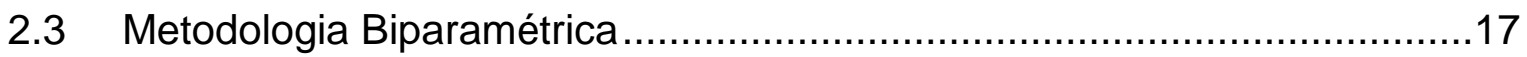

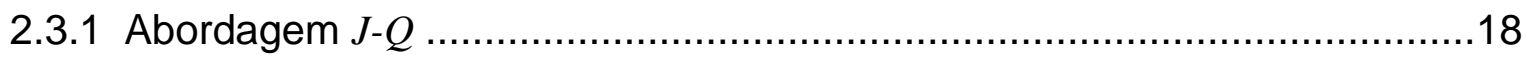

2.4 Procedimento de Avaliação da Integral $J$ Utilizando Medições Experimentais de Carga e Deslocamento - Metodologia ETA ............................20

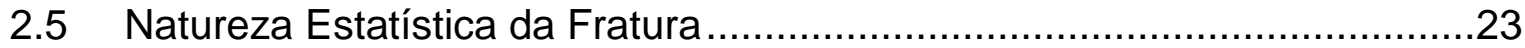

2.6 Tratamento Estatístico de Valores de Tenacidade ...................................26

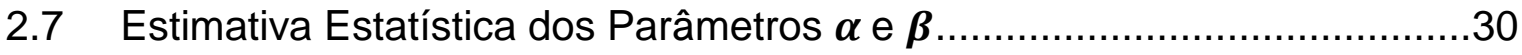

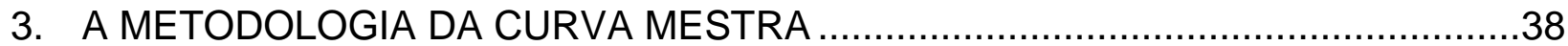

3.1 Curva de Referência ASME ……………...........................................38

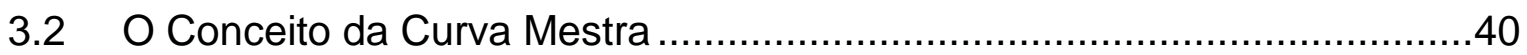

3.3 Roteiro para Determinação da Curva Mestra ............................................43

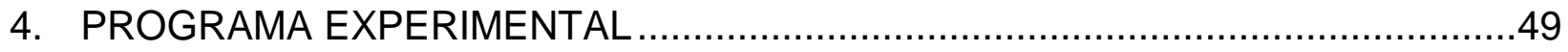

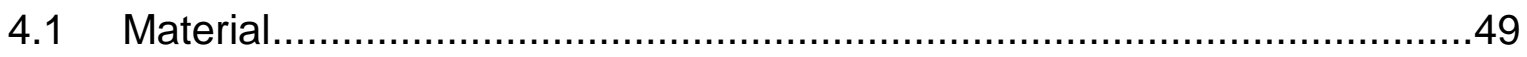

4.2 Preparação das Chapas para Extração dos Corpos de Prova ....................50 


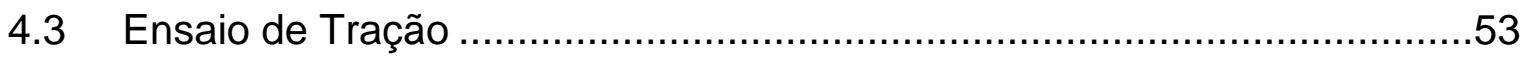

4.4 Ensaio de Impacto Charpy ................................................................

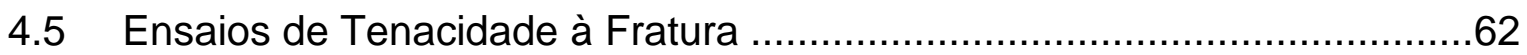

5. EFEITOS GEOMÉTRICOS SOBRE OS VALORES DE TENACIDADE À

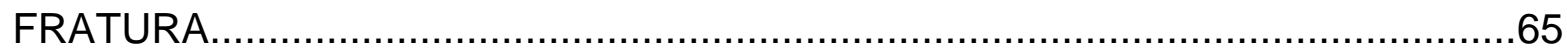

5.1 Aço ASTM A285 Gr C - Ensaios de Tenacidade …..................................65

5.2 Aço ASTM A285 Gr C - Superfícies de Fratura ......................................75

5.3 Aço ASTM A515 Gr 65 - Ensaios de Tenacidade.....................................78

5.4 Aço ASTM A515 Gr 65 - Superfícies de Fratura......................................87

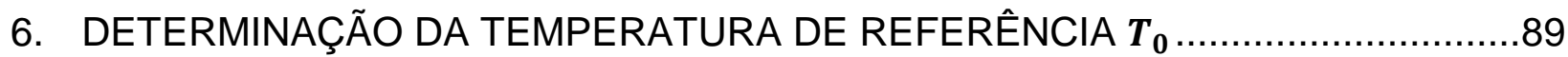

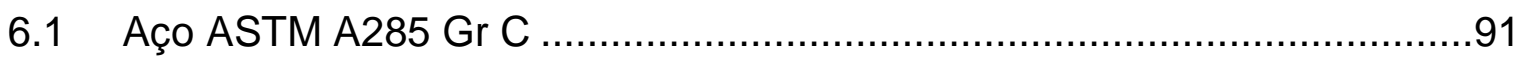

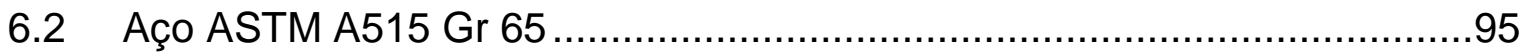

7. IMPLICAÇÕES GEOMÉTRICAS SOBRE OS VALORES DE TENACIDADE .......100

7.1 Avaliação da Integral $J$ na Espessura dos Corpos de Prova .....................101

7.1.1 Avaliação da Integral $J$ na Espessura - Introdução de Entalhes Laterais no Corpo de Prova com Geometria PCVN ...................................................103

7.1.2 Avaliação dos Níveis de Restrição Plástica na Ponta da Trinca -

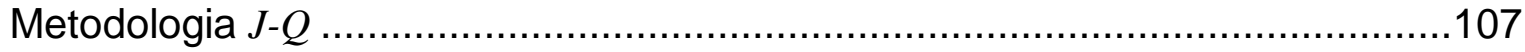

7.1.3 Comparação das Zonas de Processo de Fratura (ZPF).........................113

8. CONCLUSÕES E SUGESTÕES PARA ESTUDOS FUTUROS .........................116

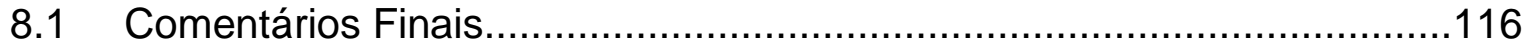

8.2 Sugestões para Estudos Futuros ……………................................118

8.3 Trabalhos Publicados .......................................................................

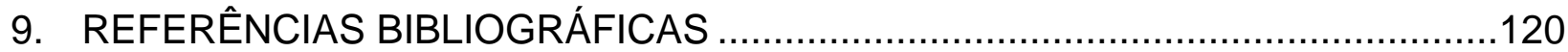

A. Correção da Tenacidade Pelo Efeito de Espessura ..........................................133

B. Ensaios de Tração a Baixa Temperatura .......................................................136

C. Detalhes Operacionais para Execução dos Ensaios de Tenacidade à Fratura .....140

C.1. Processo de Nucleação de Pré-Trinca por Fadiga ..................................140 
C.2. Determinação da Temperatura de Ensaio

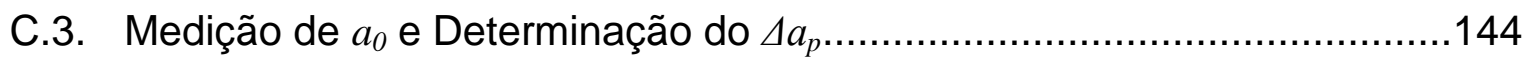

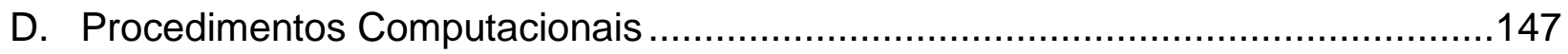

D.1. Modelos Computacionais dos Corpos de Prova................................147

D.2. Análise Pelo Método dos Elementos Finitos .......................................153

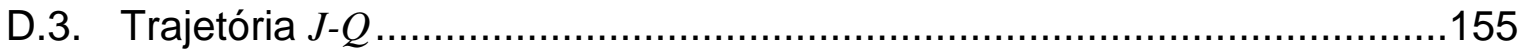





\section{INTRODUÇÃO}

A avaliação precisa do comportamento à fratura por clivagem (fratura frágil) é um tópico de grande relevância nas etapas de projeto e fabricação de estruturas metálicas e nos procedimentos de adequação-ao-uso, comumente conhecidos por Fitness For Service (FFS). Esses procedimentos são aplicados, por exemplo, nos processos decisórios de reparo, manutenção e em programas para extensão de vida de estruturas em serviço que se aproximam do tempo limite de operação previsto em projeto, como vasos de pressão, tanques de armazenamento e tubulações encontradas em plantas de processamento de hidrocarbonetos. Em muitos casos estas estruturas transportam e armazenam substâncias a baixas temperaturas e, em situações adversas, como a rápida despressurização oriunda de vazamento de gás, as temperaturas na região defeituosa podem cair drasticamente e o componente pode entrar em risco de falha catastrófica por fratura frágil [1 - 2].

Metais com microestrutura ferrítica, como aços de baixa liga e aços carbono tipicamente aplicados na construção destas estruturas, têm a tenacidade à fratura fortemente afetada pela variação de temperatura e apresentam curva de tenacidade com uma evidente região de transição dúctil-frágil (TDF).

Essa região, TDF, deve ser evitada na operação, pois nela pode ocorrer a fratura frágil da estrutura por clivagem transgranular disparando a falha catastrófica a níveis relativamente baixos de tensão aplicada. Convencionalmente, vasos de pressão, caldeiras e tanques de armazenamento são projetados para operar em temperaturas intermediárias, de $0^{\circ} \mathrm{C}$ a aproximadamente $430^{\circ} \mathrm{C}$, e são fabricados com aços de baixa liga e de resistência moderada [3] dentre os quais se encontram os dois materiais estudados neste trabalho, ASTM A285 Grau C [4] e ASTM A515 Grau $65[5]$.

O primeiro material, A285 Grau C, é aplicado na fabricação de vasos de pressão que operam à baixas pressão e temperatura nas indústrias químicas e de petróleo. É um aço de baixo custo, boa conformabilidade e boa soldabilidade em processos convencionais. O aço ASTM A515 Grau 65 possui propriedades mecânicas 
ligeiramente superiores, tem soldabilidade inferior e sua aplicação é destinada a vasos de pressão que operam em temperaturas mais elevadas.

Apesar de ser amplamente utilizada na fabricação de vasos de pressão, esta classe de aços pode apresentar significativa variação na composição química, na microestrutura e em outros fatores-chave incluindo o processo de fabricação [6]. Tais variações podem influenciar na tenacidade à fratura destes materiais dificultando a etapa de projeto quando se deseja determinar as temperaturas máximas admissíveis de operação ou no planejamento dos intervalos de inspeção e avaliação crítica de defeitos nos procedimentos de adequação-ao-uso.

Os procedimentos correntes de avaliação de defeitos de grandes estruturas, [7 [8], como vasos de pressão, caldeiras e sistemas de tubulação empregam medidas macroscópicas da tenacidade à fratura frágil como o valor da integral $J$ correspondente ao ponto de instabilidade na clivagem, $J_{c}$, ou a abertura crítica da ponta da trinca, usualmente chamada de Crack Tip Opening Displacement (CTOD, $\left.\delta_{c}\right)$.

Os parâmetros de fratura, $J_{c}$ e $\delta_{c}$, são obtidos por meio de ensaios laboratoriais utilizando-se corpos de prova padronizados. As técnicas normalizadas de ensaios para avaliação de tenacidade à fratura em aços estruturais baseiam-se na medição de valores de carga vs. deslocamento, os quais são obtidos, tradicionalmente com corpos de prova em flexão três pontos $S E(B)$ ou com outras geometrias com trincas passantes e profundas ( $a / W>0,4$ onde $a$ denota a dimensão da trinca ou entalhe e $W$ denota a largura do corpo de prova).

Em particular, a norma ASTM E1820 - 11 [9] adota duas formas para a avaliação de tenacidade à fratura: 1 ) estimando $J$ por meio do trabalho plástico medido a partir da abertura da boca da trinca (CMOD - Crack Mouth Opening Displacement) e 2) estimando o CTOD a partir de valores da componente plástica de $J$, determinada pela área sob a curva do gráfico de carga vs. CMOD, e então convertendo os valores obtidos para o correspondente valor de CTOD plástico.

Para pequenas deformações, onde a zona plástica fica restrita à ponta da trinca e com dimensões pequenas quando comparada às dimensões do corpo de prova, a norma ASTM E1820 [9] tem se provado efetiva em fornecer resultados adequados para caracterizar falhas controladas por tensão para a maioria das aplicações de engenharia. 
Porém, devido às características fenomenológicas do processo de fratura por clivagem na região de transição dúctil-frágil, os valores críticos de tenacidade podem apresentar grande dispersão exigindo a utilização de abordagens estatísticas, dificultando a caracterização da falha do material por meio de um valor único de tenacidade.

Ainda na região de transição dúctil-frágil, aspectos geométricos dos corpos de prova podem também ter grande influência sobre os resultados de tenacidade, ou seja, diferentes configurações geométricas de corpos de prova ou mesmo distintas formas ou profundidades de trinca, proporcionam valores de tenacidade diversos 0 que se deve preponderantemente ao nível de restrição plástica desenvolvido na região da ponta da trinca. $E$, portanto a influência desses efeitos geométricos em conjunto com o comportamento estatístico da fratura devem ser estudados.

Introduzida na década de 80 e normalizada na década de 90 a Metodologia da Curva Mestra [10 - 13] foi proposta como ferramenta de engenharia para descrever de forma simples o comportamento da tenacidade à fratura de aços ferríticos na região de transição dúctil-frágil em função da temperatura. A Curva Mestra possui formato fixo e é posicionada no eixo da abscissa com base no valor da temperatura de referência do material, denominada $T_{0}$, a qual representa o parâmetro chave a ser determinado. A norma ASTM 1921-08 [14] estabelece as diretrizes para a determinação da temperatura de referência e nela também é prevista a utilização de corpos de prova com pequenas dimensões como o Pre-Craked Charpy V-Notch (PCVN).

O PCVN é geometricamente similar ao corpo de prova empregado no tradicional ensaio de Impacto Charpy e é ensaiado em flexão três pontos com aplicação monotônica de carga após a nucleação, por fadiga, de uma pré-trinca na região do entalhe.

O uso de corpos de prova de pequenas dimensões, tais como o PCVN, tem se mostrado um dos principais tópicos de estudo dentro da Metodologia da Curva Mestra. Apesar de apresentar inúmeras vantagens operacionais, ainda há muitas dúvidas sobre sua capacidade de fornecer valores suficientemente precisos para a tenacidade do material com consequente influência destes sobre o valor da temperatura de referência, $T_{0}$. Portanto, um dos objetivos deste trabalho é estudar 
este corpo de prova visando sanar ou diminuir as dúvidas sobre sua utilização na determinação da $T_{0}$.

\subsection{Objetivos do Trabalho}

Motivado pelas observações anteriores, este estudo pretende investigar os efeitos geométricos dos corpos de prova sobre os valores de tenacidade à fratura na região de transição dúctil-frágil e determinar da temperatura de referência, $T_{0}$, para diferentes configurações. Particular atenção é dada à configuração geométrica do corpo de prova padrão adotado em ensaios de Impacto Charpy e adaptado ao ensaio de tenacidade à fratura, PCVN (Pre-Cracked Charpy V-Notch).

Apesar das inúmeras vantagens apresentadas por este espécime como menor consumo de material, menor necessidade de capacidade de máquina e relativa facilidade de manipulação durante a prática experimental, os valores de $T_{0}$ reportados na literatura obtidos por meio do PCVN são geralmente inferiores aos valores obtidos com a geometria padrão $\mathrm{SE}(\mathrm{B})$ com espessura $B=25,4 \mathrm{~mm}(1 \mathrm{~T}) \mathrm{e}$ trinca profunda passante com razão $a / W=0,5$.

As discrepâncias nos valores de tenacidade observadas entre as duas geometrias mencionadas acima são atribuídas geralmente à diferente capacidade de cada configuração de corpo de prova de restringir o desenvolvimento de plasticidade na ponta da trinca. Alguns métodos baseados na correção da restrição plástica dos corpos de prova, ver [15 - 16], foram desenvolvidos para corrigir os dados de tenacidade do PCVN para valores de tenacidade obtidos com corpos de prova padrão $1 \mathrm{~T}$ para, na sequência, determinar a $T_{0}$ do material de forma mais adequada. Entretanto estes métodos geralmente se baseiam em complexas análises computacionais ou em formulações analíticas com grande número de parâmetros prejudicando uma das principais vantagens da Metodologia da Curva Mestra que é a simplicidade de aplicação a partir dos resultados experimentais de $J_{C}$.

Portanto, este trabalho apresenta uma extensa investigação experimental avaliando o comportamento de aços estruturais ferríticos na região de transição dúctil-frágil para diferentes geometrias de corpos de prova. Os experimentos de 
avaliação de tenacidade à fratura foram conduzidos utilizando-se corpos de prova em flexão três pontos, $\mathrm{SE}(\mathrm{B})$, com configuração geométrica convencional $(W=2 B)$, $a / W=0,5$ e $a / W=0,2$, e também a geometria PCVN, com $W=B$ e $a / W=0,5$. Esses últimos (PCVN) foram avaliados nas condições com e sem entalhes laterais e os resultados de tenacidade no momento da clivagem são reportados em termos de integral $J\left(J_{c}\right)$.

O objetivo é avaliar o comportamento da tenacidade decorrente destas variações geométricas combinadas com a natureza estatística da clivagem na região TDF. Adicionalmente, pretende-se propor modificações na prática experimental de forma a corrigir ou, ao menos, diminuir a influência destas diferenças sobre a determinação da temperatura de referência, $T_{0}$, de forma a não prejudicar a simplicidade da Metodologia da Curva Mestra. O trabalho também se propõe a ampliar os dados de propriedades mecânicas e de tenacidade à fratura para a classe de aços estruturais ferríticos, proporcionando assim uma base de dados mais ampla para avaliações de integridade estrutural de componentes estruturais. 


\section{REVISÃO BIBLIOGRÁFICA: CONCEITOS ESSENCIAIS}

\subsection{Introdução à Fratura Frágil - Clivagem Transgranular}

No fenômeno da clivagem transgranular a propriedade do material que controla a sua resistência à fratura possui natureza randômica e apresenta grande variabilidade. Esta grande variabilidade pode fazer com que a resistência à fratura caia a níveis globais de tensão muito inferiores à tensão de escoamento do material. Esse processo pode resultar em uma falha repentina, em uma localização imprevisível no componente, onde a trinca pode se propagar com velocidades próximas à velocidade do som sendo o ligamento remanescente incapaz de suportar o carregamento.

Portando, devido à sua imprevisibilidade e ao seu grande potencial catastrófico que, por vezes, além de acarretar em grandes prejuízos financeiros pode ainda custar vidas humanas, o mecanismo de falha por fratura frágil é de grande importância nos procedimentos de análise de integridade estrutural de componentes fabricados em aço ferríticos, os quais são amplamente utilizados na construção de estruturas e vasos de pressão nas áreas oceânica, nuclear, naval, etc.

A fratura frágil é fortemente dependente da temperatura e sua natureza randômica decorre da presença de defeitos (partículas de segunda fase, inclusões, etc.) aleatoriamente distribuídos na matriz ferrítica do material e de uma série sucessiva de eventos microestruturais que podem ou não ocorrer, [17 - 18]. Resumidamente, para uma estrutura trincada estes eventos, ilustrados pela Figura 1, são:

1. O carregamento aplicado deve ser suficiente para gerar picos de tensão na ponta da trinca superiores à tensão de escoamento do material criando uma zona plástica na frente da trinca. Estas tensões são, em geral, da ordem de $3-5$ vezes a tensão de escoamento $\left(\sigma_{y s}\right)$ do material. 
2. A deformação plástica gerada deve ser suficiente para fraturar as partículas de segunda fase (geralmente carbonetos) gerando microtincas nos contornos de grão.

3. O pico de tensão deve atuar sobre uma distância crítica suficientemente grande para "empilhar" as discordâncias através dos grãos do material gerando tensões de abertura.

4. As tensões de abertura propagam a microtrinca formada para dentro da matriz do material.

5. Rapidamente a microtrinca se estende em direção ao contorno de grão vizinho.

6. O nível de restrição plástica deve ser mantidos alto de forma a impedir o arredondamento da ponta da trinca, o que interromperia o processo de fratura, assim como o carregamento global deve fornecer energia suficiente para a continuidade do processo de fratura transgranular. 

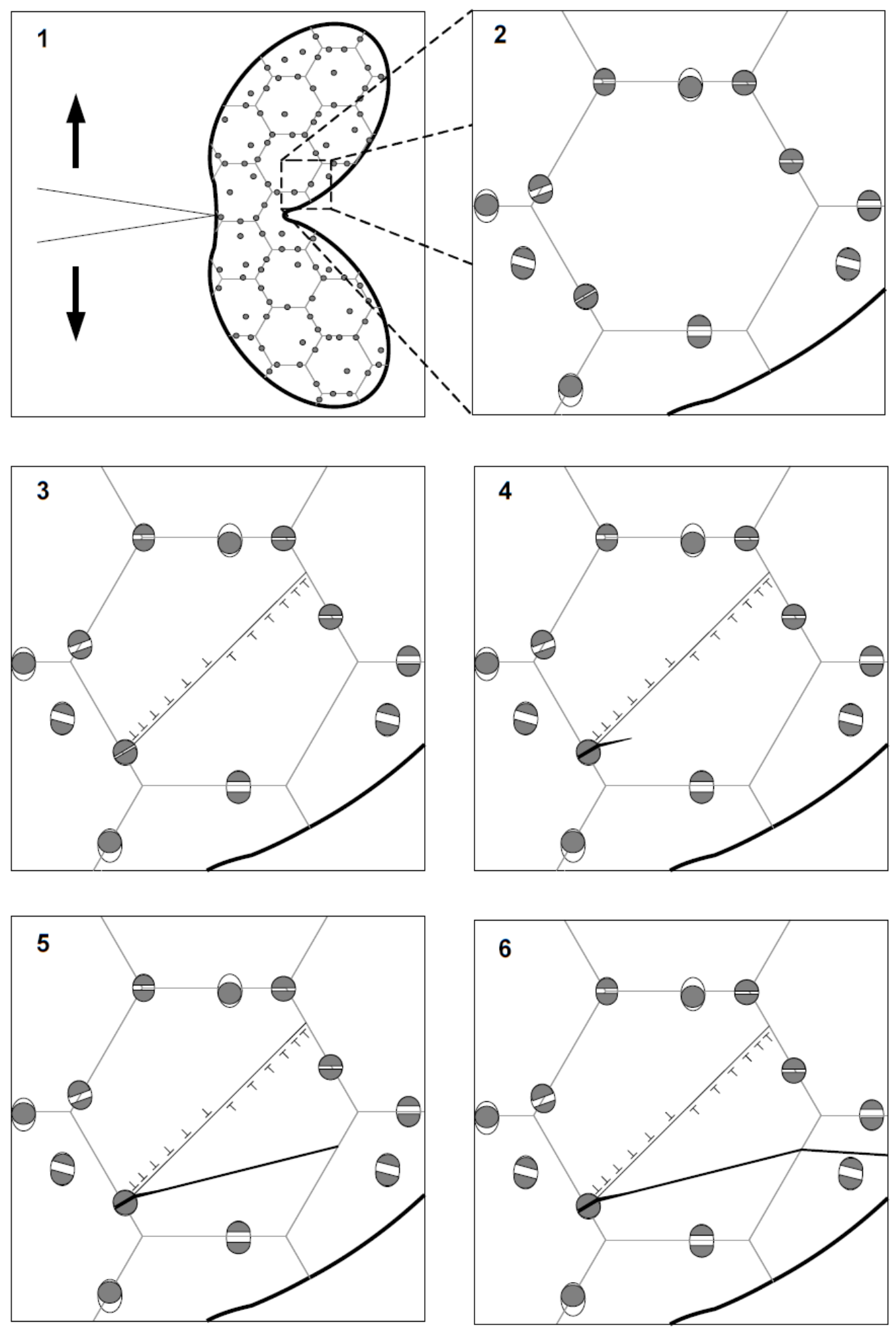

Figura 1. Representação do micromecanismo de falha da fratura frágil, clivagem transgranular [17].

1- Formação da zona plástica na ponta da trinca macroscópica; 2- Fratura das partículas de segunda fase, surgimento de microtincas; 3- A plasticidade local causa o empilhamento de discordâncias gerando tensões de abertura; 4- A microtrinca propaga para o interior do grão; 5Rapidamente a microtinca atinge o contorno de grão oposto; 6- A microtrinca penetra no grão vizinho reiniciando a sequência descrita. 
No passado, quando este mecanismo microestrutural de falha era pouco conhecido, as análises de integridade estrutural baseadas em mecânica da fratura utilizavam metodologias determinísticas em suas abordagens [19]. Nessas análises, o valor crítico do fator de intensidade de tensões, $K_{I c}$, é o principal parâmetro quantitativo a ser determinado.

O fator de intensidade de tensões, $K$, descreve os campos de tensões ao redor de uma trinca dentro do regime elástico da material [20 - 23]. Porém para que este parâmetro tenha validade (regime usualmente definido como dominância $K$ ) garantido o princípio de similitude, ilustrado pela Figura 2, condições geométricas extremamente restritivas devem ser atendidas.

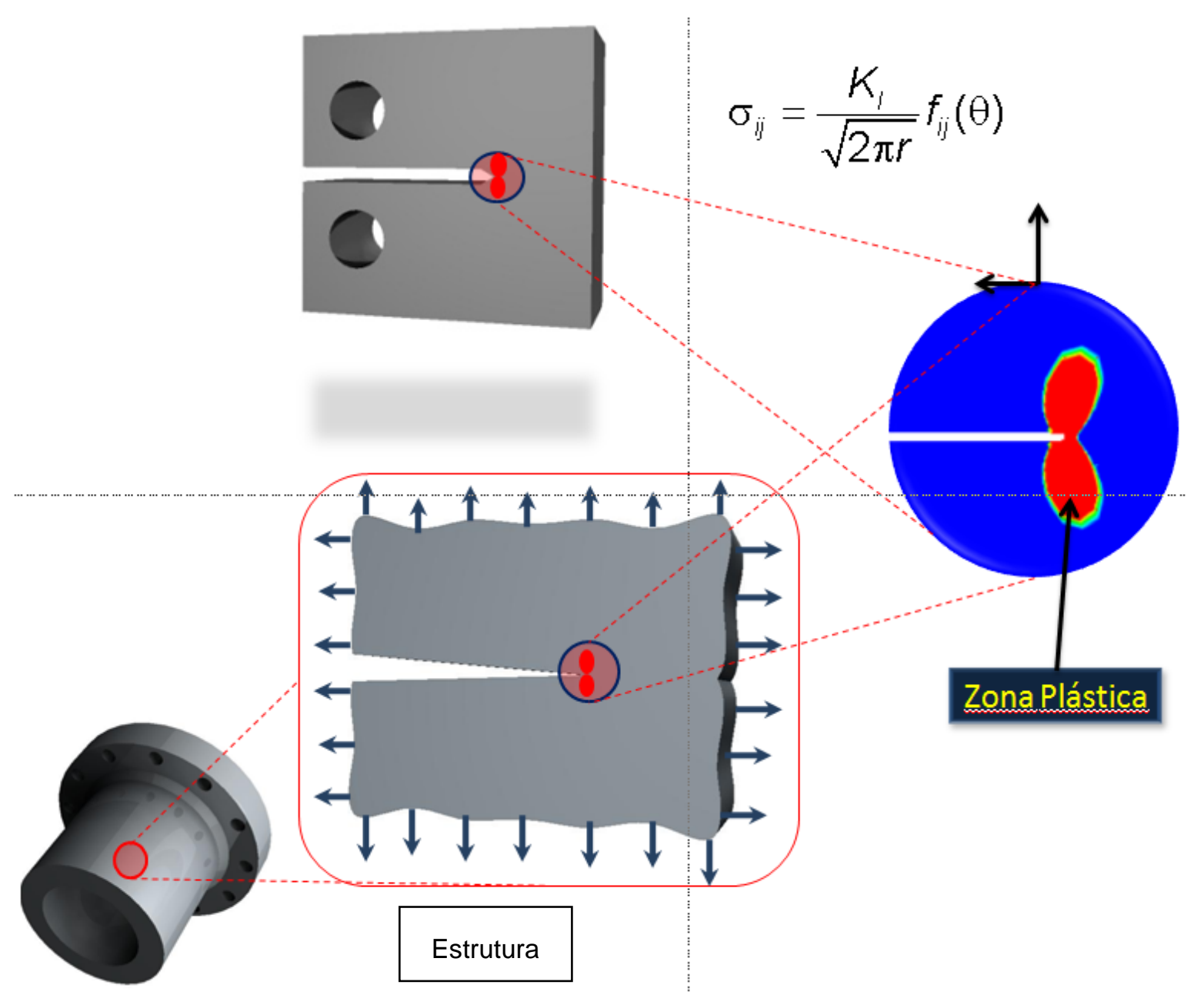

Figura 2. Esquema representativo da condição de similitude onde corpo de prova e estrutura estão carregados sob mesma condição de intensidade de tensões. 
A dominância K é especificada pela norma ASTM E399 [24] a qual estabelece que, para se obter valores válidos de $K_{I c}$, a seguinte relação deve ser atendida:

$$
B, a,(W-a)>2,5\left(\frac{K_{I c}}{\sigma_{Y S}}\right)^{2}, \quad 0,45 \leq \frac{a}{W} \leq 0,55
$$

na qual $B$ é a espessura do corpo de prova, $a$ é o comprimento da trinca e $(W-a)$ é o ligamento remanescente. Os requisitos da ASTM E399 [24], expressos pela equação (1), são extremamente rigorosos e aplicáveis a uma faixa bastante estreita de comprimentos de trinca.

Aços estruturais ferríticos facilmente apresentam valores críticos de tenacidade à fratura, $K_{I c}$, a temperaturas extremamente baixas, porém, ao se elevar a temperatura, a fratura frágil passa a ser precedida de significativo escoamento plástico localizado. Portanto, o fator de intensidade de tensões perde sua validade e não mais descreve os campos de tensão na ponta da trinca exigindo, para tal, a utilização de um outro parâmetro elasto-plástico mais abrangente. A Figura 3 ilustra a variação da tenacidade à fratura de um aço ferrítico comumente utilizado na construção de reatores nuclear.

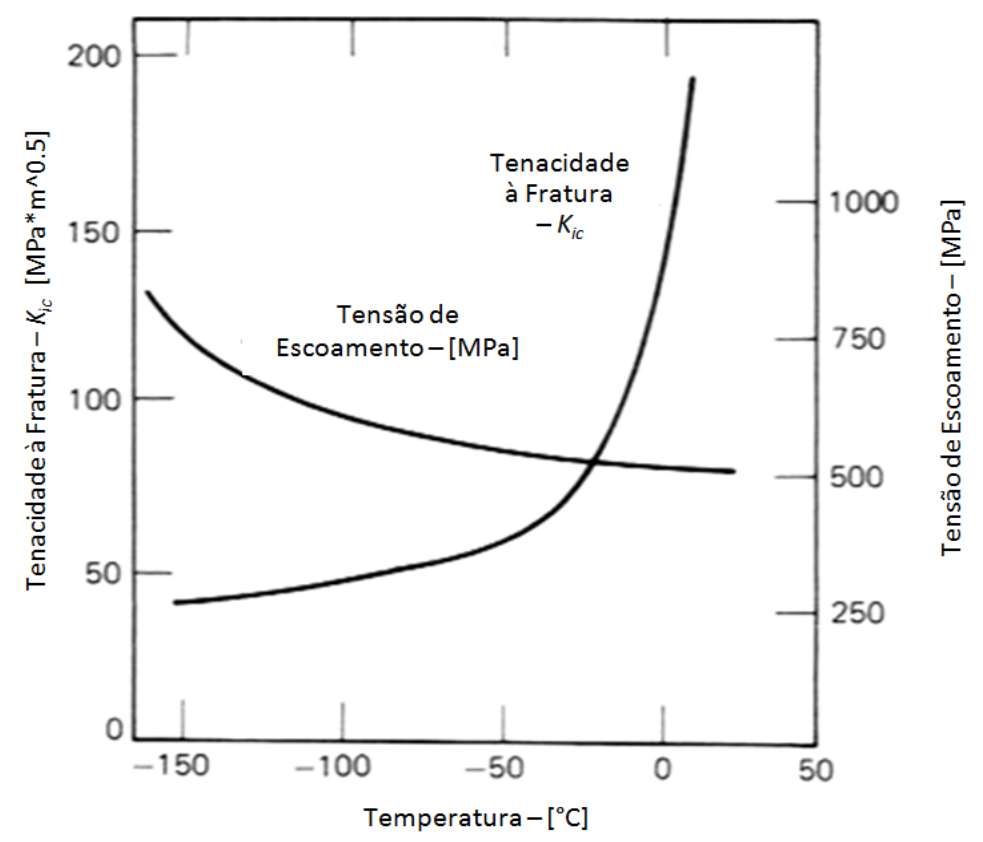

Figura 3. Variação de $K_{\mathrm{I} c}$ com a temperatura para o aço ASTM A533B de baixa liga utilizado na construção de vasos de pressão nucleares (adaptado de [20]). 


\subsection{A Integral $J$}

Sob ocorrência de escoamento e plasticidade limitados, a mecânica da fratura elástica linear permite descrever o comportamento à fratura de diversos materiais e ligas metálicas. Entretanto, com o desenvolvimento de aços de grande resistência e tenacidade, os quais apresentam grande plasticidade antes da fratura frágil, a MFEL encontra dificuldades em relação à sua aplicabilidade para caracterização dos campos de tensão e deformação. Os requisitos dimensionais impostos pela ASTM E399 [24] para estes tipos de aços exigem corpos de prova excessivamente grandes para obtenção de valores válidos de tenacidade à fratura, o que torna os ensaios potencialmente proibitivos.

Isso motivou o desenvolvimento de metodologias que descrevessem com maior precisão o comportamento de materiais dentro do regime elasto-plásticos. Em 1968 James Rice [25], introduziu a integral $J$ como parâmetro de avaliação de tenacidade à fratura utilizando a hipótese de elasticidade não linear, representada esquematicamente na Figura 4. Rice mostrou que a taxa de liberação de energia, denotada por $J$, em um sólido pode ser descrita por uma integral de linha independente do caminho de integração na forma:

$$
J=\int_{\Gamma}\left(W d y-T_{i} \frac{\partial u_{i}}{\partial x} d s\right)
$$

onde $\Gamma$ denota um contorno fechado e anti-horário definido sobre um plano normal à frente da trinca, iniciando na face inferior da trinca e terminando na sua face superior, ilustrado pela Figura $5, W$ denota a energia de deformação por unidade de volume indeformado, $T_{i}$ e $u_{i}$ são as componentes cartesianas do vetor de tração e dos deslocamentos no sistema de coordenadas localizado à frente da trinca, respectivamente. 


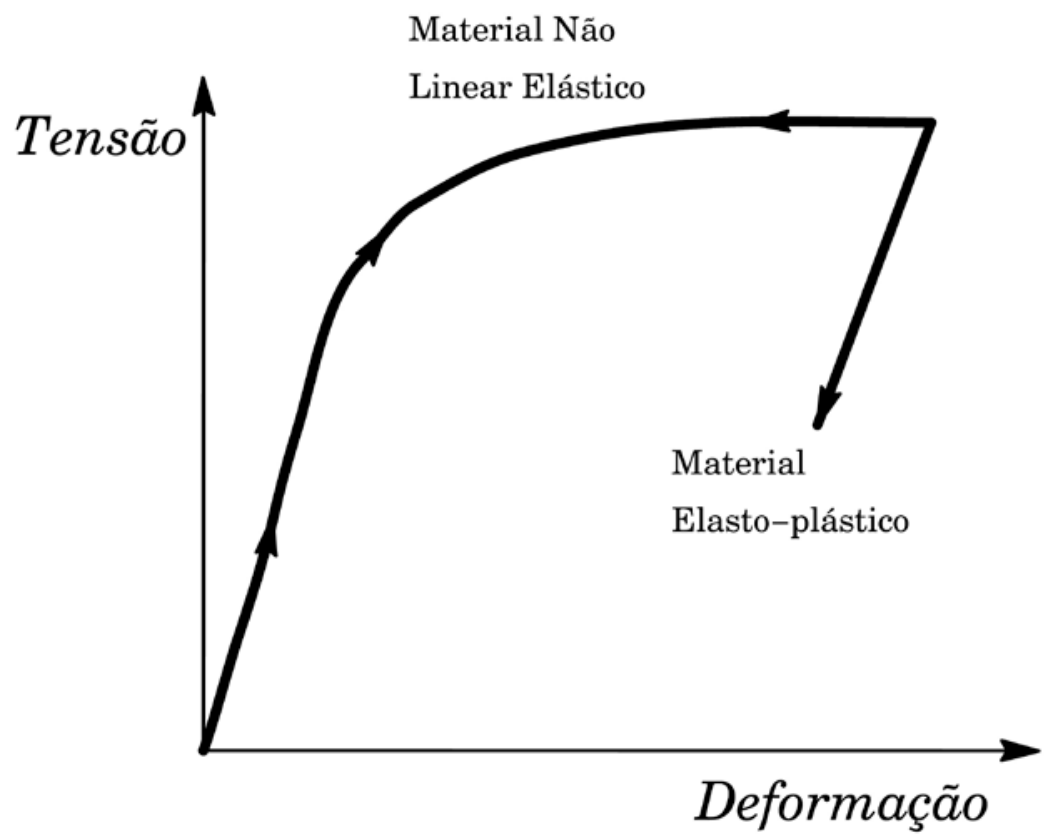

Figura 4. Representação de curva tensão deformação para materiais elasto-plásticos e elásticos não lineares [26].

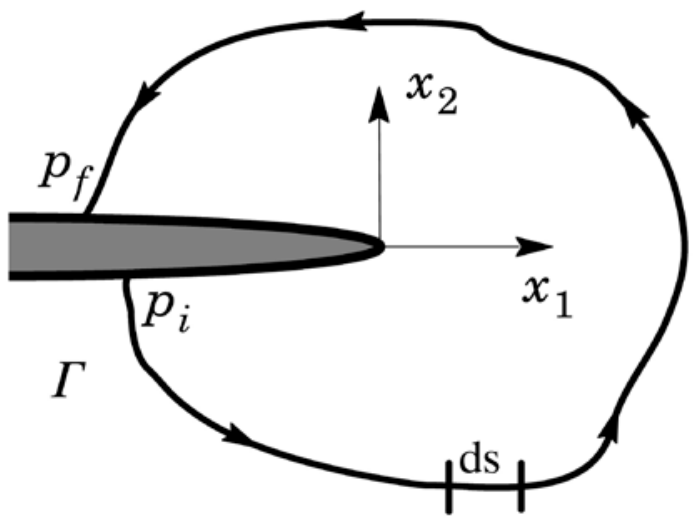

Figura 5. Representação do contorno arbitrário ao redor da trinca [26]. 
Para o caso especial de material com comportamento linear elástico, $J$ é equivalente à taxa de liberação de energia de Griffith [27], isto é, $J=G^{1}$. Esta equivalência permite obter a relação entre o fator elástico de intensidade de tensões e a integral $J$ como

$$
J=K_{I}^{2} / E^{\prime}
$$

onde $E^{\prime}$ é o módulo de elasticidade longitudinal do material ( $E^{\prime}=E$ para EPT, $E^{\prime}=E /\left(1-v^{2}\right)$ para EPD) e $v$ é o coeficiente de Poisson.

Estudos subsequentes de Hutchinson [28] e paralelamente Rice e Rosengren [29] mostraram a relação unívoca entre os campos de tensões e de deformações, atuantes nas vizinhanças de uma trinca contida em sólido elástico não-linear e a integral $J$. Tal abordagem considera que a resposta tensão-deformação obedece à uma lei de potência na forma:

$$
\frac{\varepsilon}{\varepsilon_{0}}=\frac{\sigma}{\sigma_{0}}+a\left(\frac{\sigma}{\sigma_{0}}\right)^{n}
$$

tal que, $\varepsilon$ e $\sigma$ são a deformação e a tensão verdadeira, respectivamente, $a$ é uma constante adimensional e $n$ é o coeficiente de encruamento. O subscrito "0" para a tensão e deformação na equação (4) refere-se a valores de referência, usualmente associados tensão de escoamento $\left(\sigma_{y s}\right)$ e deformação de escoamento $\left(\varepsilon_{y s}\right)$. A equação (4) representa o modelo de Ramberg-Osgood [30[20] amplamente utilizado como modelo constitutivo de materiais metálicos tendo boa aderência ao comportamento mecânico apresentado para aços ferríticos. Hutchinson, Rice e Rosengren mostraram que, para manter a integral de linha independente do caminho de integração, é preciso que as tensões nas vizinhanças da ponta da trinca variem com $(1 / \mathrm{r})^{1 /(n+1)}$. Aplicando condições de contorno apropriadas, os autores citados obtiveram os campos de tensões e deformações na forma:

\footnotetext{
${ }^{1}$ Taxa de liberação de energia, $G$, é a medida de energia disponível para um incremento na extensão de uma trinca.
} 


$$
\begin{gathered}
\sigma=\sigma_{0}\left(\frac{E J}{\alpha \sigma_{0}^{2} I_{n} r}\right)^{\frac{1}{n+1}} \sigma_{i j}^{\prime}(n, \theta) \\
\varepsilon=\frac{\alpha \sigma_{0}}{\varepsilon_{0}}\left(\frac{E J}{\alpha \sigma_{0}^{2} I_{n} r}\right)^{\frac{n}{n+1}} \varepsilon_{i j}^{\prime}(n, \theta)
\end{gathered}
$$

onde $I_{n}$ é uma constante de integração que depende do coeficiente de encruamento $n, \sigma_{i j}^{\prime}$ e $\varepsilon^{\prime}{ }_{i j}$ são funções adimensionais de $\theta, n$ e do estado de tensões (estado plano de tensões ou estado plano de deformações). No caso elástico linear, $n=1$ e as tensões variam com $\sqrt{ }(1 / r)$, recuperando a singularidade caracterizada por $K_{I}$. As equações (5) e (6) são conhecidas como solução HRR (iniciais de Hutchinson, Rice e Rosengren).

Assim a integral $J$ pode ser interpretada tanto como um parâmetro de variação de energia e como também um parâmetro de intensidade de tensões. Esta integral é completamente consistente com o parâmetro $K_{I}$ porque, no caso particular de sólido com comportamento elástico linear, fornece resultados equivalentes.

\subsubsection{Limitações da Mecânica da Fratura Elasto-Plástica}

Sob a mesma lógica na qual se observa a perda de validade do parâmetro elásticolinear $K_{I}$ como unívoco descritor dos campos de tensão e de deformação devido ao aumento da região plástica, o parâmetro elasto-plástico $J$ também perde a sua validade quando grandes deformações plásticas estão presentes na zona de processo de fratura ${ }^{2}$. Isso ocorre porque a dominância $J$ pressupõe a condição de escoamento de pequena monta, conhecido também por Small Scale Yielding (SSY)

\footnotetext{
${ }^{2}$ Camada de material diretamente associada à propagação da trinca macroscópica.
} 
[20]. Portanto, sob grandes deformações, a zona plástica deixa de ter dimensões suficientemente pequenas em relação às dimensões do corpo de prova.

Assim como no caso elástico linear, porém com menores restrições, o limite de $J$ como parâmetro descritor unívoco dos campos de tensões a frente de uma trinca é dado por [20]:

$$
M \leq\left(b \sigma_{\text {Flow }}\right) / J \quad e \quad M \leq\left(B \sigma_{\text {Flow }}\right) / J
$$

sendo $M$ é um parâmetro de deformação adimensional, $b$ é o ligamento remanescente, $B$ é a espessura do espécime e $\sigma_{\text {Flow }}$ é a média aritmética da tensão de escoamento e do limite de resistência à tração do material. O parâmetro adimensional, $M$, depende da geometria do corpo de prova e é fortemente influenciado pelas propriedades do material, principalmente no que se refere ao encruamento. Para o caso do corpo de prova com geometria $\mathrm{SE}(\mathrm{B})$ e trinca profunda, recomenda-se valores de $M=50$ para materiais com alto encruamento (coeficiente de encruamento, $n \sim 5$ ) e $M=175$ para materiais com baixo encruamento (coeficiente de encruamento, $n \sim 20$ ) para que a aderência com a solução HRR seja mantida durante o carregamento [30 - 31].

A sequência que limita as condições de validade da dominância $K$ e da dominância $J$ está representada esquematicamente na Figura 6. Para o primeiro caso, observase que o campo de tensões à frente da trinca pode ser descrito tanto pela solução HRR quanto pela mecânica da fratura elástica-linear (MFEL). Já no segundo caso, a partir do aumento do carregamento e consequente crescimento da zona plástica, nota-se que a MFEL perde a aderência; isto é, não mais descreve o campo de tensões na ponta da trinca. Finalmente, ao se atingir uma deformação plástica de grande monta, observa-se que a solução $H R R$ também não mais descreve os campos de tensão na ponta da trinca (perda da dominância $J$ ) e, consequentemente, a mecânica da fratura monoparamétrica perde a sua validade. 


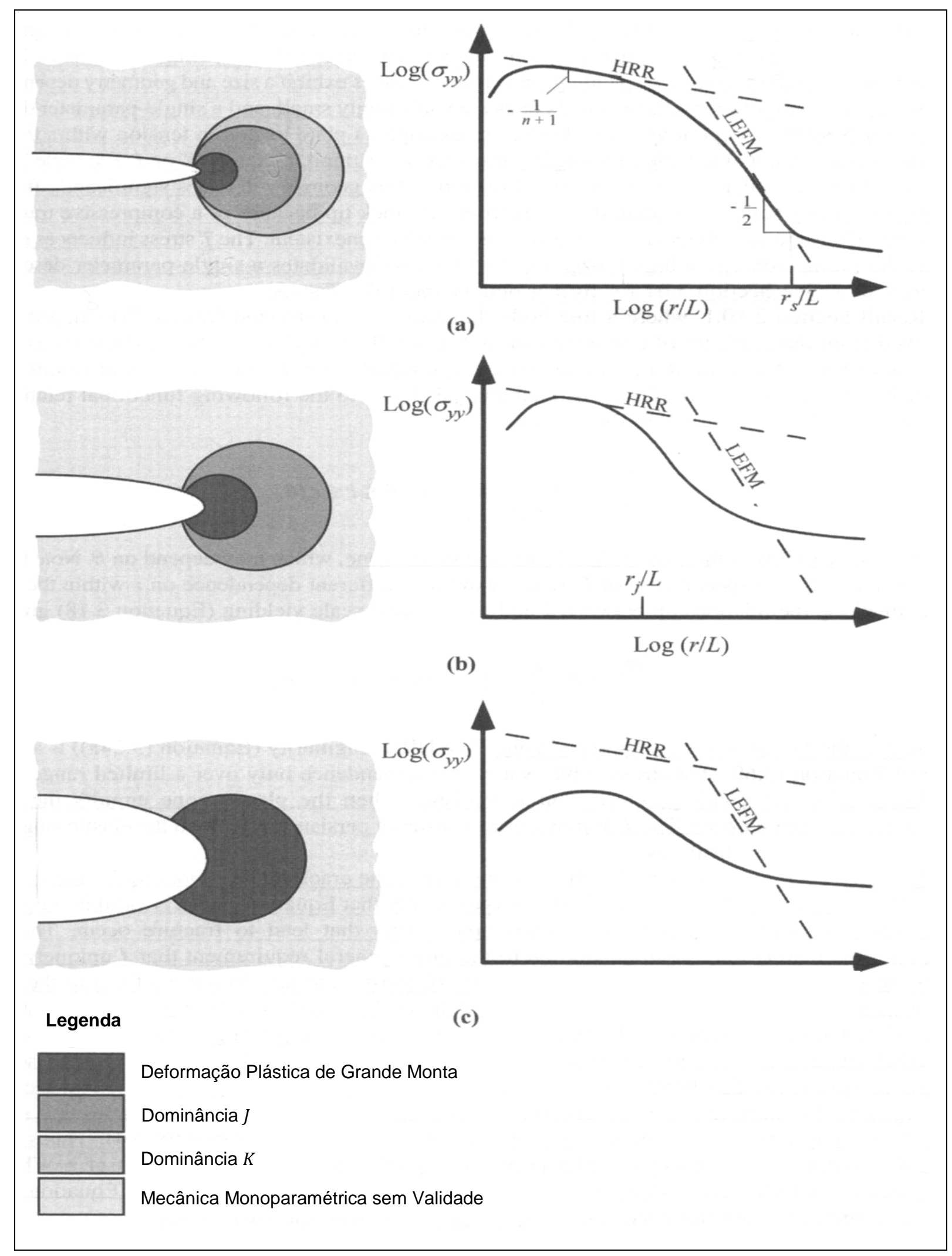

Figura 6. Limite da validade da mecânica da fratura linear elástica (Dominância $K$ ) e limite da validade da fratura elasto-plástica (Dominância $J$ ) [20] 


\subsection{Metodologia Biparamétrica}

Sob plasticidade restrita nas vizinhanças do defeito ou da trinca, garantida pela condição de escoamento de pequena monta (Small Scale Yielding), a mecânica monoparamétrica, representada pelos fatores $J$ e $K$, permite correlacionar de maneira satisfatória os valores de tenacidade à fratura, medidos experimentalmente, com o comportamento à fratura de estruturas sob condições de serviço [32]. Porém, a validade da mecânica da fratura monoparamétrica pode ser violada sob condições de análise onde haja escoamento de grande monta. Variações geométricas dos espécimes ensaiados e condições de plasticidade generalizada causam o relaxamento das tensões nas proximidades da ponta da trinca, podendo invalidar o conceito de parâmetro único para avaliação da tenacidade à fratura [20].

O desenvolvimento da mecânica biparamétrica foi motivado em vista dos argumentos apresentados e da necessidade de uma avaliação precisa dos valores de tenacidade à fratura sob condições de plasticidade generalizada. As metodologias desenvolvidas assumem campos de tensões separáveis, sendo um quantificador do nível de restrição plástica e outro quantificador do nível de tensão ambos na região da ponta da trinca [33 - 34].

Estas metodologias seguem duas abordagens:

- Teoria $J-T^{3}$, construída com base na tensão elástica $T$.

- Teoria $J-Q$, desenvolvida utilizando o parâmetro hidrostático $Q$.

Ambas as teorias utilizam dois parâmetros escalares para descrição do campo elasto-plástico de tensões e quantificação do nível de triaxialidade para trincas estacionárias em materiais homogêneos em relação a uma solução de referência [20]. Assim a integral $J$ mede os campos elasto-plásticos de tensão de alta triaxialidade próximos à trinca enquanto o segundo parâmetro mede o nível de triaxialidade associado à perda de restrição plástica na mesma região.

\footnotetext{
${ }^{3}$ Não é foco deste trabalho a abordagem da metodologia J-T. Para maiores detalhes ver [20] e [35].
} 
Para este estudo, a abordagem $J-Q$ será aplicada com o objetivo de avaliar de forma qualitativa a variação da restrição plástica na ponta da trinca decorrente do efeito de espessura do corpo de prova e comparar como esta variação ocorre para as diferentes geometrias adotadas na parte experimental deste trabalho. Por meio desta abordagem também será possível analisar como o entalhe lateral modifica os níveis de triaxialidade de tensões na ponta da trinca, próximo à superfície livre do corpo de prova com geometria PCVN.

\subsubsection{Abordagem $J-Q$}

O’Dowd e Shih [33 - [34], por meio de análises numéricas identificaram conjuntos de campos elasto-plásticos de tensões parametrizáveis utilizando um parâmetro de triaxialidade, denominados pelos autores por $Q$, aplicável em condições de escoamento generalizado ("Large Scale Yieding" (LSY)). Tal parâmetro é adequado para quantificar os efeitos geométricos do corpo de prova, tamanho de trinca e modo de carregamento, exprimindo a diferença escalar de tensões relativas a um campo de elevada triaxialidade dentro de uma região microestruturalmente significativa (cerca de 5 10 CTOD’s em relação a ponta da trinca) [35] e uma solução de referência expressa por

$$
\sigma_{i j}=\sigma_{o} \hat{f} i j\left(\frac{r}{J / \sigma_{0}}, \theta, Q\right)
$$

na qual $\sigma_{0}$ representa uma tensão de referência, geralmente a tensão de escoamento, e $Q$ define a diferença entre os campos de tensão de um corpo finito e a solução de referência. As componentes de tensão de cisalhamento do campo diferencial são desprezíveis quando comparadas às componentes normais deste mesmo campo, por isso $Q$ é tratado como parâmetro hidrostático [35].

A descrição $J-Q$ dos campos de tensão sob Modo I de carregamento, neste trabalho, deriva da solução MBL (Modified Boundary Layer), ou solução de 
Camada de Contorno Limite Modificada, similar à equação (9), representada por uma placa infinita.

$$
\sigma_{i j}=\left(\sigma_{i j}\right)_{R e f}+Q \sigma_{0} \delta_{i j} ; \text { para } r>\frac{\mathrm{J}}{\sigma_{0}}, \quad|\theta| \leq \frac{\pi}{2}
$$

sendo $\left(\sigma_{i j}\right)_{R e f}=\left(\sigma_{i j}\right)_{S S Y}$, representa o campo de tensões de referência com alta restrição plástica, o segundo termo $Q \sigma_{0} \delta_{i j}$ é uma constante hidrostática independente da distância e ângulo em relação à ponta da trinca, na qual $\delta_{i j}$ é o delta de Kronecker . Portanto, operacionalmente $Q$ é definido como:

$$
Q \equiv \frac{\sigma_{y y}-\left(\sigma_{y y}\right)_{R e f}}{\sigma_{0}} ; \quad r=J \frac{2}{\sigma_{0}}
$$

onde $\sigma_{y y} \mathrm{e}\left(\sigma_{y y}\right)_{\text {Ref }}$ são, respectivamente, as tensões de abertura da trinca do componente (corpo-de-prova) e as tensões de abertura da trinca da solução de referência avaliadas a uma distância $r$. A distância $r$ mostra pouca influência sobre os valores de $Q$ quando mantida no intervalo $J / \sigma_{0} \leq r \leq 5 J / \sigma_{0}$, [33 - [36].

A determinação do parâmetro $Q$ é feita por meio de análises computacionais, aplicando-se o método de elementos finitos, em modelos com geometria idêntica aos corpos de prova adotados na parte experimental, sendo elas: SE(B) 1T, PCVN, PCVN com entalhes laterais ("Side Grooved"). O padrão de refinamento da malha dos modelos foi desenvolvido de forma a ser microestruturalmente representativo e sensível às variações dos campos de tensão decorrentes da variação da espessura e da presença dos entalhes laterais. Deste modo, é possível calcular a diferença entre os campos de tensões desenvolvidos na ponta da trinca para os modelos estudados e o modelo MBL. Mais detalhes do procedimento de análise aplicado serão abordados nas próximas seções. 


\subsection{Procedimento de Avaliação da Integral $J$ Utilizando Medições Experimentais de Carga e Deslocamento - Metodologia ETA}

Esta seção apresenta sucintamente os fundamentos metodológicos para avaliação da integral $J$, seguindo protocolos de ensaio que utilizam medições experimentais de carga e deslocamento em corpos de prova de tenacidade com geometria normalizada.

A metodologia ETA ( $\eta$ ), proposta por Sumpter e Turner [37] em 1976, é amplamente adotada para a avaliação experimental de valores de tenacidade à fratura. Tal abordagem correlaciona por meio de um parâmetro adimensional a energia de deformação, dada pela integral $J$, com o valor da área sob a curva de carga vs. deslocamento obtida experimentalmente, conforme ilustra a Figura 7, para um corpo de prova trincado confeccionado com material homogêneo. Nesta metodologia, $J$ é dividido em duas componentes, uma elástica $\left(J_{E l}\right)$, e outra plástica $\left(J_{P l}\right)$, conforme a equação (11). Normas como ASTM E1820 [9], ASTM E1921 [14] dentre outras, [38 - [40] fazem uso desta metodologia para o cálculo do parâmetro $J$.

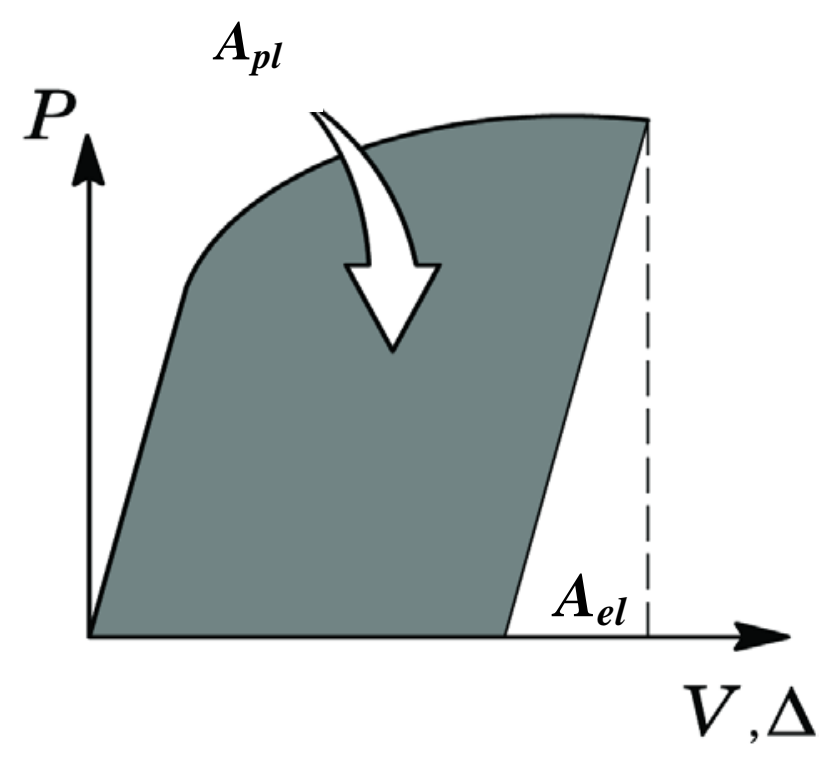

Figura 7. Definição de área plástica $\left(\boldsymbol{A}_{p l}\right)$ e elástica $\left(\boldsymbol{A}_{e l}\right)$ sob a curva de carga vs. deslocamento (CMOD ou LLD) [35]. 


$$
J_{T o t a l}=J_{E l}+J_{P l}
$$

A componente elástica, $J_{E l,}$ é dada por

$$
J_{E l}=\frac{K_{I}^{2}}{E^{\prime}}
$$

sendo o fator de intensidade de tensões, $K_{I}$, é definido analiticamente para o espécime SE(B) [20] como:

$$
K_{I}=\frac{P}{B \sqrt{W}} f\left(\frac{a}{w}\right)
$$

O fator de intensidade de tensões adimensional, $f\left(\frac{a}{w}\right)$, para a geometria SE(B) é dado por:

$$
f\left(\frac{a}{W}\right)=\frac{3 \frac{S}{W} \sqrt{\frac{a}{W}}}{2\left(1+2 \frac{a}{W}\right)\left(1-\frac{a}{W}\right)^{3 / 2}}\left[1,99-\frac{a}{W}\left(1-\frac{a}{W}\right)\left(2,15-3,93\left(\frac{a}{W}\right)+2,7\left(\frac{a}{W}\right)^{2}\right)\right]
$$

Nas equações acima, $P$ é o carregamento aplicado ao corpo de prova, $B$ é a espessura, $W$ é a largura do corpo de prova, usualmente utilizada como $W=2 B$, $a$ é o comprimento da trinca e $S$ é a distância entre os roletes de apoio empregada nos espécimes ensaiados em flexão três pontos.

A componente plástica, $J_{P l}$, pode ser convenientemente avaliada a partir da área plástica sob a curva carga vs. deslocamento como:

$$
J_{p l}=-1 / B \int_{0}^{\Delta_{p}}\left(\frac{\partial P}{\partial a}\right) d \Delta_{p l}=\frac{\eta_{J}}{B b} \int_{0}^{\Delta_{p}} P \Delta_{p l}=\frac{\eta_{J} A_{p l}}{B b}
$$


$A_{p l}$ é a área plástica da curva de carga vs. deslocamento (a qual representa o trabalho plástico, $U_{p}$ ), $P$ denota o carregamento, $\Delta_{p l}$ define a componente plástica do deslocamento, $b$ é o ligamento remanescente inicial do corpo de prova, $B$ é a espessura do espécime e $\eta_{J}$ é o fator adimensional que relaciona a contribuição plástica da curva com a energia de deformação do sólido contendo uma trinca.

A formulação acima apresentada é válida para o caso da medição do deslocamento ser realizada em relação ao deslocamento da linha de carga (LLD) [41] e pode ser denotada na seguinte maneira:

$$
J_{P l}=\eta_{J}^{L L D} A_{p l}^{L L D} / B b_{0}
$$

Analogamente, caso a medição do deslocamento seja realizada pela abertura da boca da trinca, CMOD (V), a componente plástica da integral $J$ passa a ser denotada por:

$$
J_{P l}=\eta_{J}^{C M O D} A_{p l}^{C M O D} / B b_{0}
$$

Neste trabalho as medições de deslocamento foram realizadas por meio do CMOD e, portanto, optou-se por usar valores de $\eta_{J}{ }^{C M O D}$ calculados pela equação abaixo, fornecida pela ASTM 1820 [9].

$$
\eta_{J}^{C M O D}=3,667-2,199\left(a_{0} / W\right)+0,437\left(a_{0} / W\right)^{2}
$$

Esta equação é derivada de simulações computacionais, utilizando métodos de elementos finitos e considerando corpos de prova sob estado plano de deformações. Apesar de reconhecer que essa condição gera valores conservadores para $\eta_{J}^{C M O D}$, trabalhos realizados por Souza e Ruggieri [42] utilizando modelos tridimensionais mostram diferenças inferiores a $10 \%$ para a faixa de comprimento de trinca, $a / W$, utilizada neste trabalho. 


\subsection{Natureza Estatística da Fratura}

A tenacidade à fratura de aços ferríticos sofre forte influência da temperatura, principalmente na chamada região de transição dúctil-frágil (TDF), ilustrada na Figura 8. Tal propriedade decresce rapidamente com a diminuição da temperatura e sob esta condição, o modo de falha de estruturas construídas com estes aços pode passar do rasgamento dúctil para a fratura frágil por clivagem, situação na qual praticamente não há desenvolvimento de plasticidade antes da ruptura causando a falha catastrófica.

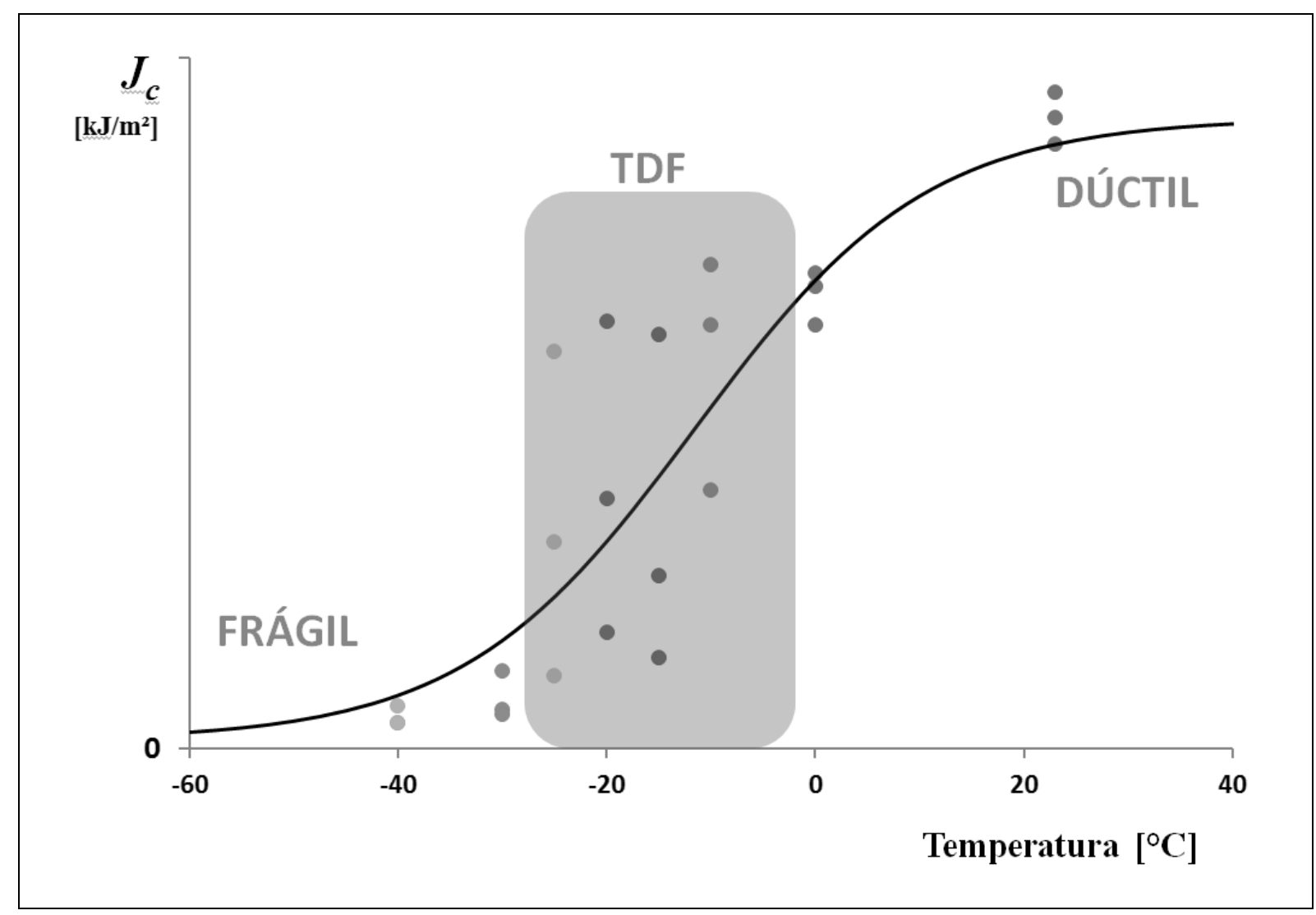

Figura 8. Distribuição característica dos dados de tenacidade para aços ferríticos no teste de Impacto Charpy - Patamar inferior: Fratura Frágil; Região de Transição Dúctil-Frágil; Patamar Superior: Fratura Dúctil.

Nos dois extremos do gráfico da Figura 8 a mecânica da fratura possui metodologias e parâmetros bem estabelecidos para a caracterização adequada da tenacidade à fratura. A avaliação das forças motrizes na região do defeito pode ser feita de forma determinística. Já a região intermediária, TDF, é bastante particular, 
pois nela os valores de tenacidade apresentam grande dispersão que combinada aos efeitos geométricos dos corpos de prova, conforme ilustra a Figura 9, tornam a avaliação da tenacidade à fratura um problema complexo, exigindo abordagens estatísticas para o tratamento adequado dos dados.

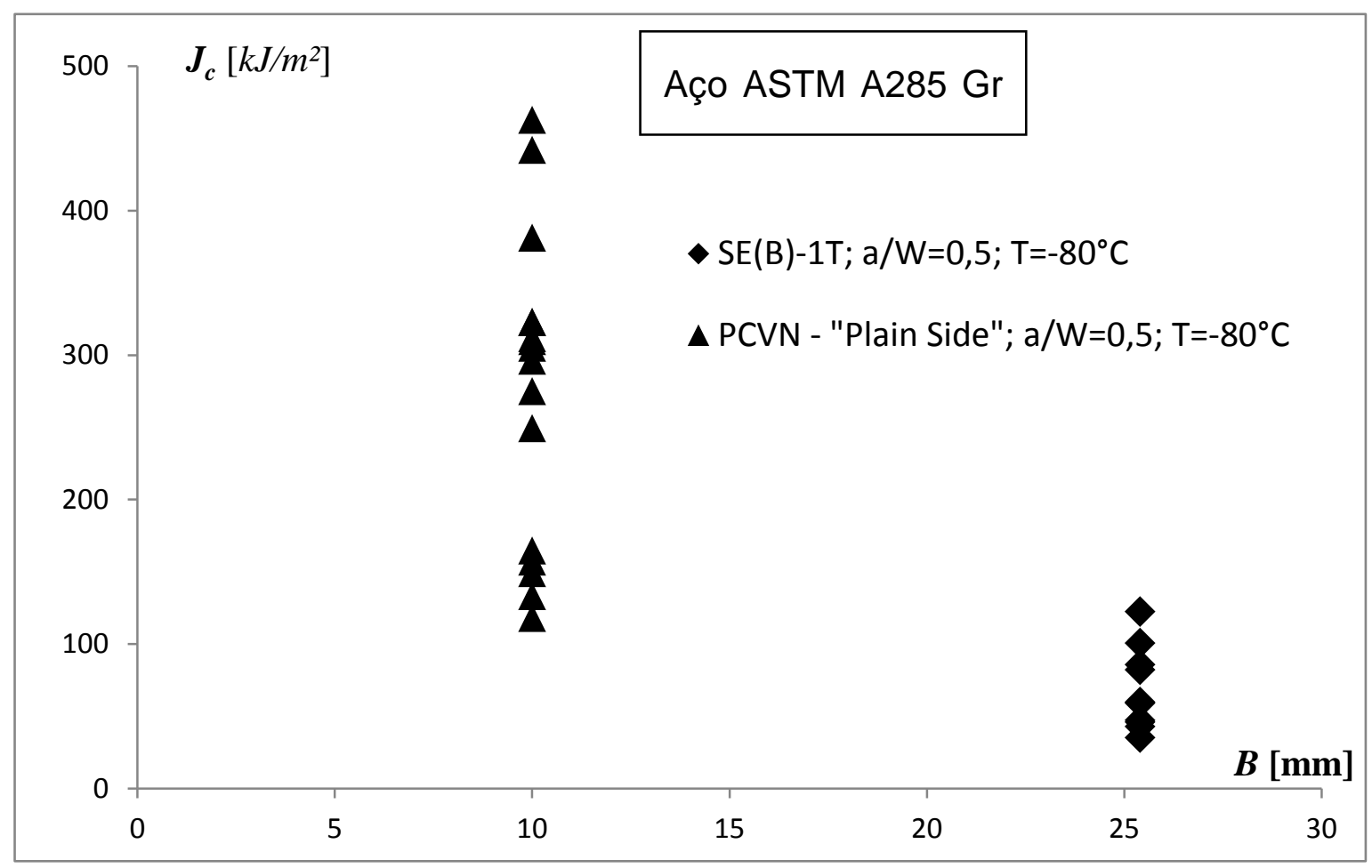

Figura 9. Efeito da espessura sobre os valores de tenacidade à fratura para o aço A285 Grau C.

Localmente o mecanismo de fratura por clivagem é governado pela nucleação e propagação de microtrincas a partir de defeitos microestruturais (neste trabalho consideram-se defeitos os compostos intermetálicos, inclusões, partículas de segunda fase, etc.) presentes nos contornos de grão da matriz ferrítica. Griffith [27], em seu modelo sugere que localmente estas microtrincas geram tensões superiores à suportada pelo material a baixos níveis de carregamento global podendo disparar o processo de fratura.

Esses microdefeitos estão aleatoriamente distribuídos na matriz ferrítica e um pequeno volume do material conterá estes defeitos conforme ilustra a Figura 10 (a). Os modelos estatísticos micromecânicos abordam o fenômeno da fratura frágil 
reduzindo-o a um problema de determinação do tamanho crítico de trinca ou, como exemplifica a Figura 10 (b), a um problema de distribuição de valores de extremo.

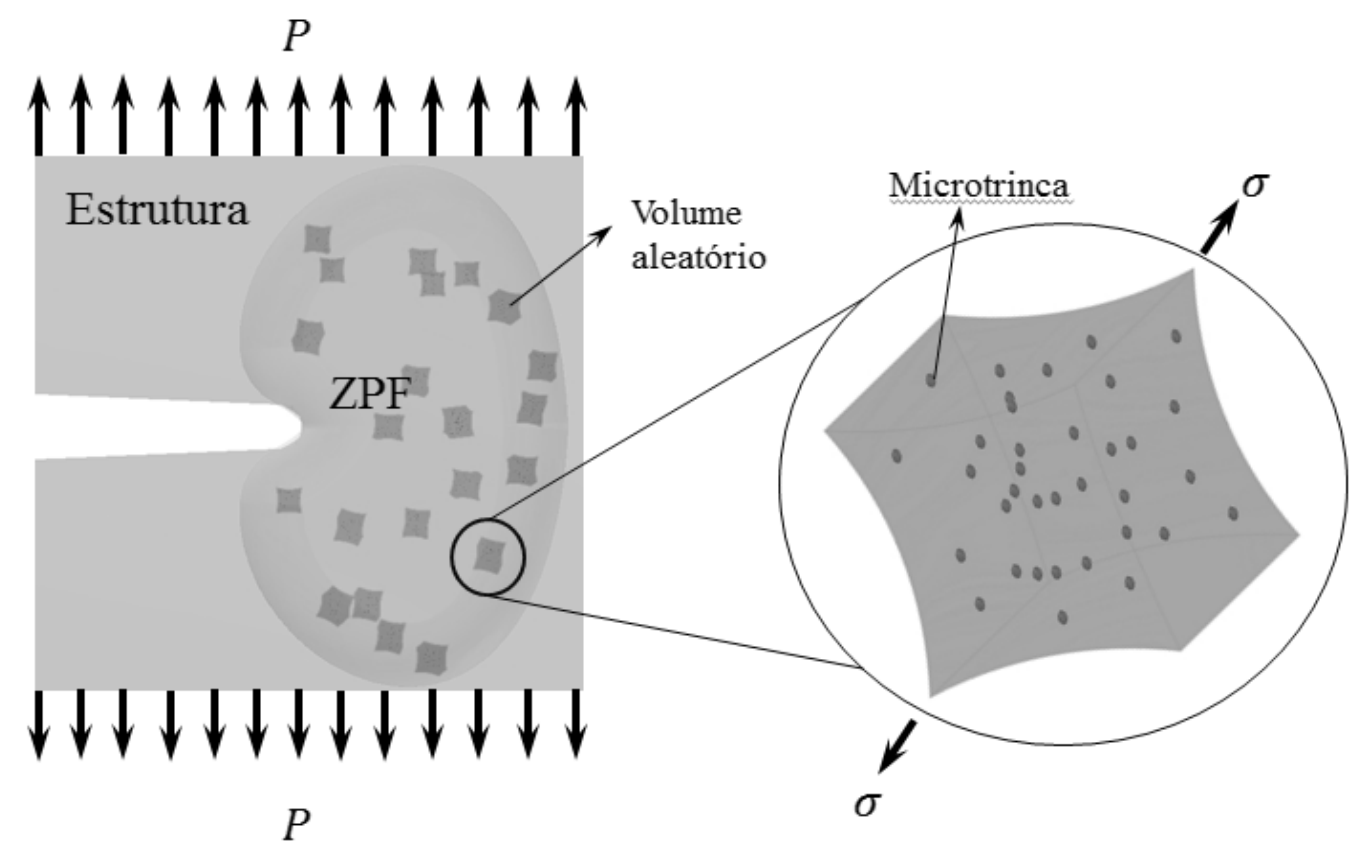

(a)

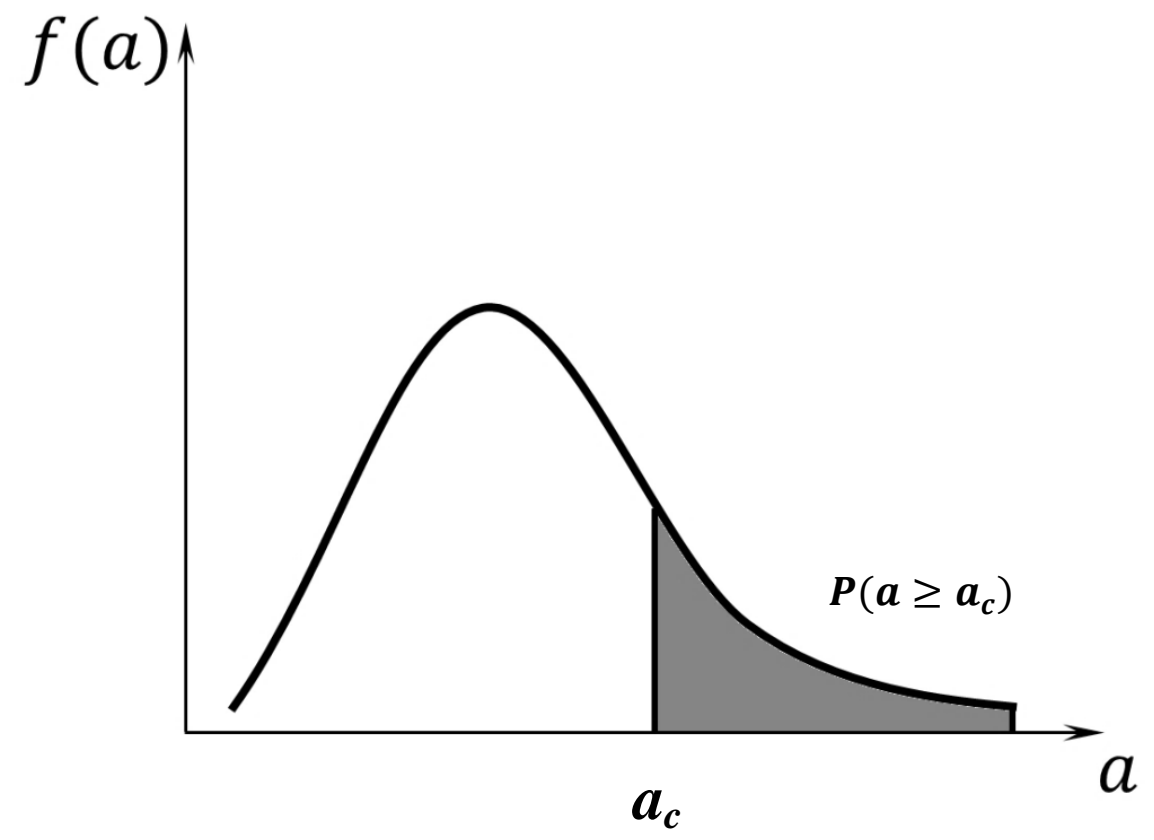

(b)

Figura 10. (a) Representação da distribuição uniforme de defeitos na matriz do material; (b) Fratura frágil representada por uma distribuição de valores extremos para tamanho de trinca. Adaptado de [44] 


\subsection{Tratamento Estatístico de Valores de Tenacidade}

A Teoria de Valores de Extremo [44] consiste na abordagem estatística da ocorrência de eventos que desviam extremamente da média das distribuições de probabilidade, sendo estes eventos valores máximos ou mínimos. Nesta teoria há três possibilidades de distribuição assintótica para o tratamento dos eventos extremos. As distribuições de Gumbel e Fréchet [45], Tipos I e II, respectivamente, são utilizadas na determinação de valores máximos e não se aplicam a este trabalho.

Já a distribuição de probabilidade acumulada Tipo III, representada pela equação (19), proposta por Weibull [46], pode ser aplicada ao tratamento de valores de mínimo associados a problemas de ciência dos materiais. A distribuição teórica de Weibull possui boa aderência aos dados experimentais de tenacidade à fratura na região de TDF e é dada por:

$$
F(x)=1-\exp \left[-\left(\frac{x-\gamma}{\beta}\right)^{\alpha}\right] \quad ; \gamma \geq 0
$$

Na equação acima $F(x)$ é a probabilidade acumulada de falha, $\alpha$ é o parâmetro de forma (ou módulo de Weibull), $\beta$ é o parâmetro de escala, $\gamma$ é o parâmetro de localização e $x$ é a variável aleatória. A Figura 11 mostra como os parâmetros de forma e escala, alteram a distribuição de probabilidade de Weibull quando $\gamma=0$, formato biparamétrico da distribuição. 


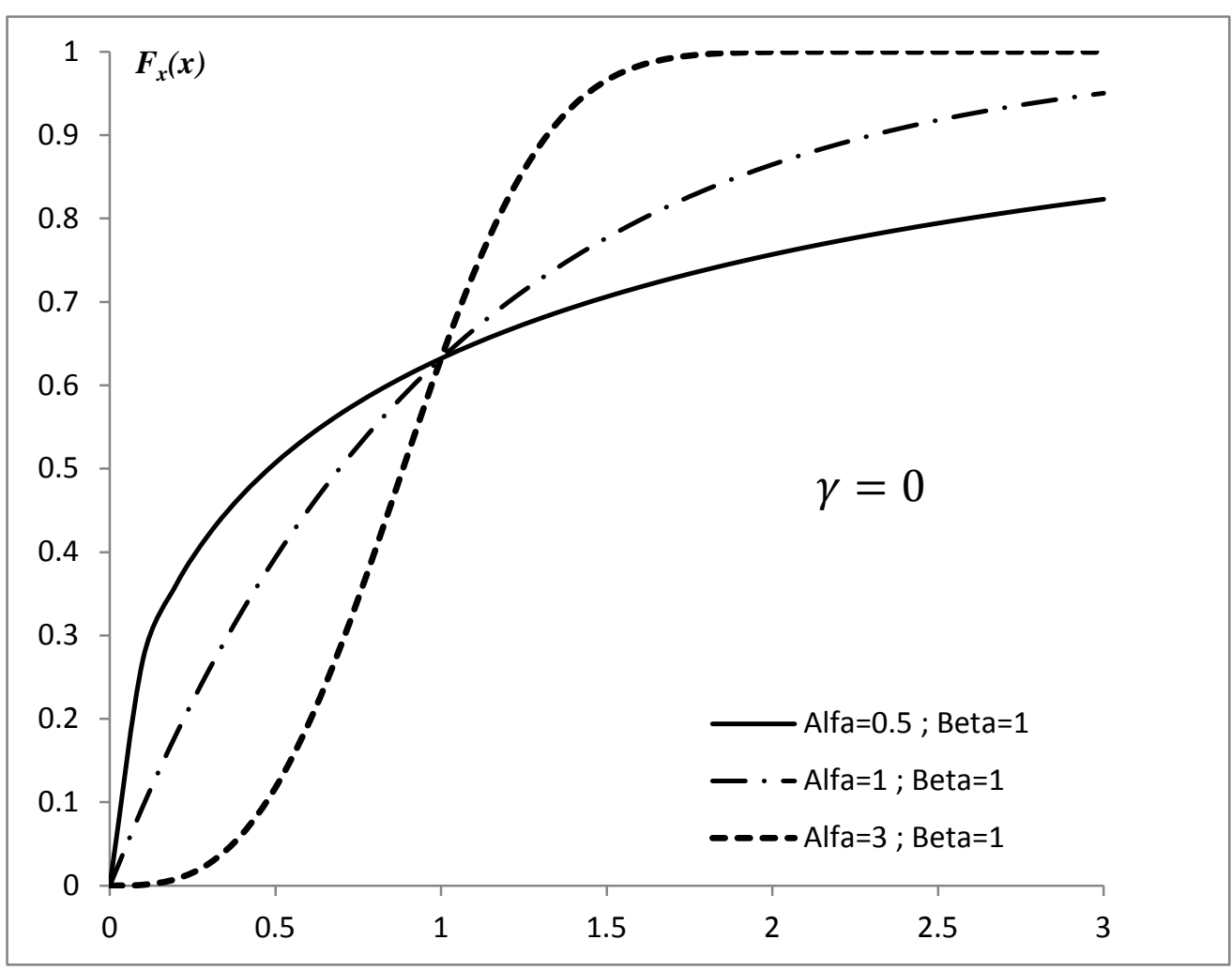

(a)

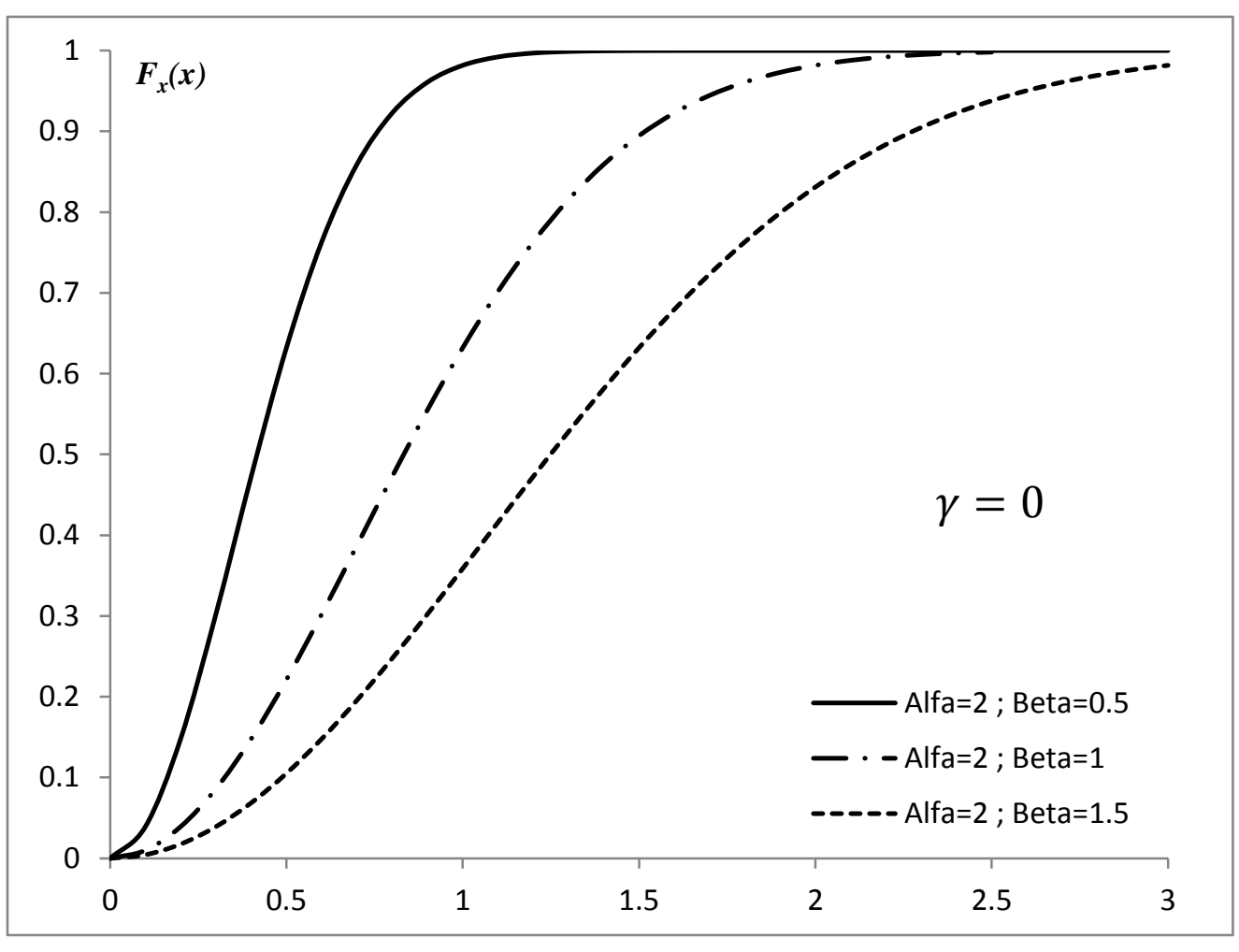

(b)

Figura 11. Distribuição de Probabilidade de Weibull (Biparamétrica): (a) Influência do Parâmetro de Forma na distribuição $(\alpha)$; (b) Influência do Parâmetro de Escala $(\beta)$ na distribuição. 
Observa-se, na Figura 11 (a) que a variação do módulo de Weibull altera significativamente o formato da distribuição levando-a de uma forma hiperexponencial, quando $\alpha<1$, para uma distribuição de formato simétrico, quando $\alpha=3$. Já a variação do parâmetro de escala, Figura 11 (b), apenas altera a sensibilidade da distribuição de Weibull em função da variável aleatória, causando um rápido crescimento dos valores de $F(x)$, quando $\beta<1$, ou uma transição mais suave de $F(x)$ para valores de $\beta \geq 1$. O terceiro parâmetro, $\gamma$, apenas translada a curva de distribuição de probabilidade acumulada no eixo da abscissa e não promove alterações significativas sobre demais parâmetros ou no formato da curva de distribuição de probabilidade, $F(x)$.

Em trabalho pioneiro, Landes e Schaffer [47] propuseram uma abordagem estatística para o tratamento da dispersão dos dados de tenacidade na transição. Suportados por uma ampla base de dados experimentais, avaliaram a probabilidade de falha utilizando a forma biparamétrica da distribuição de Weibull $(\gamma=0)$. Em trabalho posterior Landes e McCabe [48] sugerem a introdução de um terceiro parâmetro, $J_{\min }$, na distribuição de Weibull para corrigir conceitualmente a forma biparamétrica da distribuição. Este parâmetro introduz um valor limiar abaixo do qual a probabilidade de falha é igual a zero, ou seja, a fratura não ocorre, a forma triparamétrica da distribuição é dada por:

$$
F\left(J_{c}\right)=1-\exp \left[-\left(\frac{J_{c}-J_{\min }}{J_{0}}\right)^{\alpha}\right]
$$

na qual:

$F\left(J_{c}\right)=$ Probabilidade acumulada de falha para um espécime carregado com valor de $J_{c}$;

$J_{c}=$ Valor da integral $J$ na instabilidade obtida no ensaio experimental;

$J_{\text {mim }}=$ Valor limiar abaixo do qual a probabilidade de fratura é zero;

$J_{0}=$ Tenacidade característica do material $\left(P_{f}=63,2 \%\right)$ e parâmetro de escala da distribuição de Weibull;

$\alpha=$ Parâmetro de forma da distribuição de Weibull ou módulo de Weibull. 
O valor limiar, $J_{\min }$, geralmente é adotado conforme norma, [14], como 1,77 kJ/m² ou $20 \mathrm{MPa} \sqrt{\mathrm{m}}$ quando em unidade do Fator de Intensidade de Tensões, $K$. Este valor decorre da observação de dados experimentais e Wallin [49] propõe que este valor esteja entre 10 e $20 M P a \sqrt{m}$.

Ainda em [47], os autores também introduziram o conceito de correção da tenacidade à fratura devido aos efeitos de espessura. A correção é baseada na Teoria do Elo Mais Fraco (TEMF) - em uma corrente com $n$ elos, se o mais fraco falhar toda a estrutura falhará. Estendendo esta teoria para estruturas com defeitos tem-se que a falha por fratura frágil será causada pela instabilidade da primeira trinca que atingir o tamanho crítico. Como os defeitos contidos em um volume são aleatoriamente distribuídos, aumentando, por exemplo, a espessura do corpo de prova e mantendo o valor de $J_{c}$ constante diminui-se a probabilidade de sobrevivência do espécime. A Figura 12 ilustra esse processo.

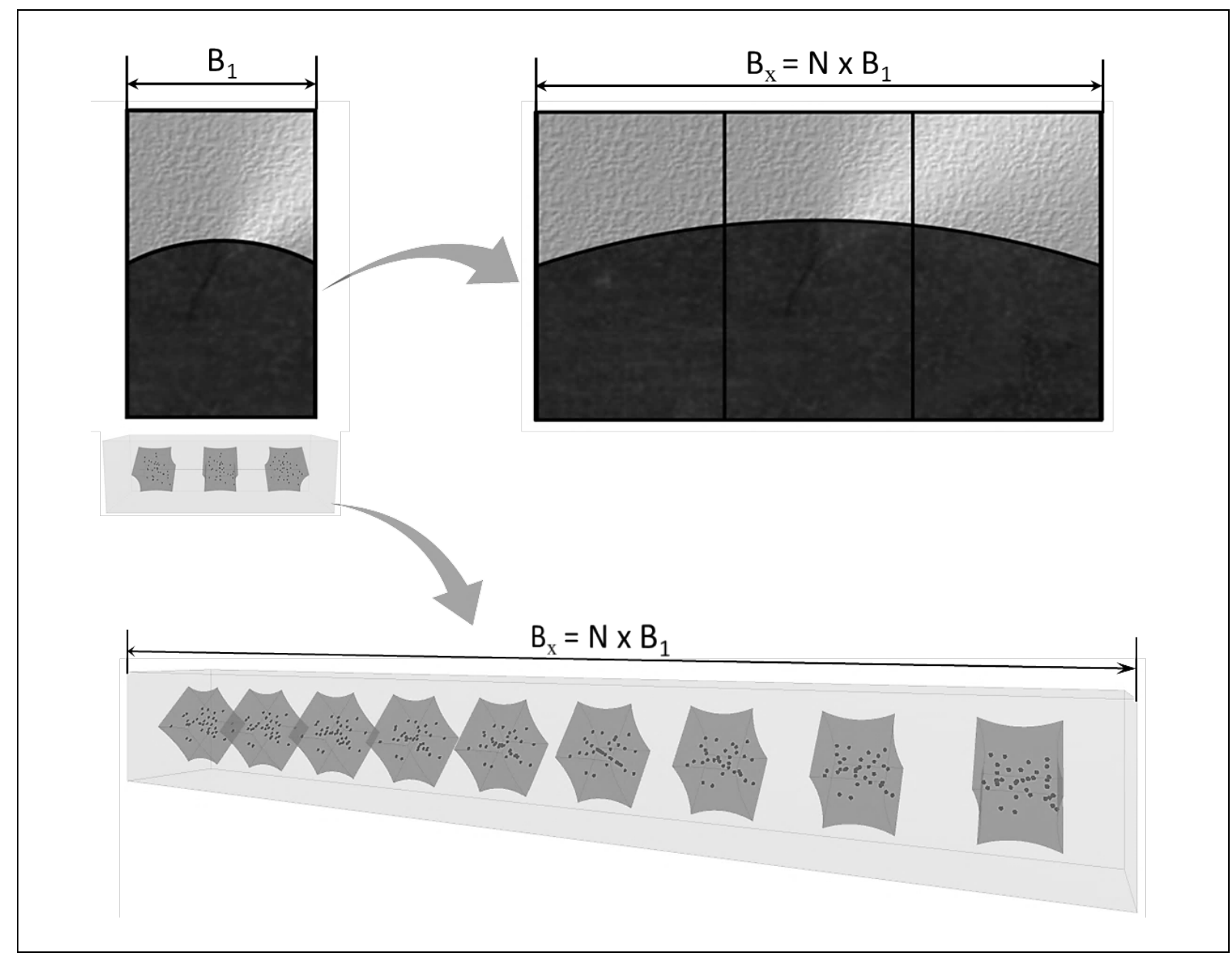

Figura 12. Representação do efeito de espessura baseado na Teoria do Elo Mais Fraco. 
Portanto, mantendo-se agora a probabilidade de sobrevivência $(1-F(x))$ constante é possível correlacionar os valores de $J_{c}$ para dois corpos de prova com espessuras diferentes pela equação abaixo.

$$
J_{C\left(B_{0}\right)}=J_{\min }+\left(J_{C\left(B_{x}\right)}-J_{\min }\right)\left(\frac{B_{x}}{B_{0}}\right)^{1 / \alpha}
$$

onde $B_{0}$ denota uma espessura de referência, no caso deste trabalho $1 \mathrm{~T}(25,4$ $\mathrm{mm}$ ), e $B_{x}$ denota a espessura do corpo de prova para o qual se deseja prever a tenacidade à fratura.

\subsection{Estimativa Estatística dos Parâmetros $\alpha$ e $\beta$}

O Método da Máxima Verossimilhança (MMV) e métodos gráficos são geralmente utilizados na determinação dos parâmetros da distribuição triparamétrica de Weibull, equação (19). O MMV é bastante robusto e à medida que o tamanho da amostra aumenta as estimativas de valor se tornam mais precisas. Porém, no caso inverso, para amostras muito pequenas, observa-se a perda de precisão [50].

O Método da Máxima Verossimilhança [44] consiste em determinar valores $\theta \equiv\left\{\theta_{1}, \theta_{2}, \ldots, \theta_{r}\right\}$ que maximizem a função de máxima verossimilhança, $L$, dada por:

$$
L\left(\theta \mid x_{1}, x_{2}, \ldots, x_{N}\right)=\prod_{i=1}^{N} f_{X i}\left(x_{i} \mid \theta\right)
$$


Na equação acima $\prod_{i=1}^{N}$ denota a operação de produtório e $f(x)$ é a função de densidade de probabilidade da distribuição de Weibull dada pela derivada da função de probabilidade acumulada $(F(x))$, equação (19), na seguinte forma:

$$
\begin{gathered}
f(x)=\frac{d F_{X}(x)}{d x} \\
f(x)=\frac{\alpha}{\beta^{\alpha}}(x-\gamma)^{\alpha-1} e^{-\left(\frac{x-\gamma}{\beta}\right)^{\alpha}}
\end{gathered}
$$

Substituindo a equação (24) na equação (22) temos a função de verossimilhança para a distribuição de Weibull triparamétrica:

$$
L=\prod_{i=1}^{N} \frac{\alpha}{\beta^{\alpha}}\left(x_{i}-\gamma\right)^{\alpha-1} e^{-\left(\frac{x_{i}-\gamma}{\beta}\right)^{\alpha}}
$$

A utilização da forma logarítmica da função de verossimilhança é conveniente, pois permite trabalhar com o somatório das funções, conforme mostrado na equação (26):

$$
\ln [L]=\sum_{i=1}^{N} \ln \left(\frac{\alpha}{\beta^{\alpha}}\left(x_{i}-\gamma\right)^{\alpha-1} e^{-\left(\frac{x_{i}-\gamma}{\beta}\right)^{\alpha}}\right)
$$

Finalmente o estimador de máxima verossimilhança é obtido pela solução da seguinte equação:

$$
\frac{d \ln [L]}{d \theta}=0 ; \quad \theta=\beta \text { ou } \theta=\alpha
$$


E resolvendo esta equação para $\beta$, temos:

$$
\beta=\left[\sum_{i=1}^{N}\left(x_{i}-\gamma\right)^{\alpha} / N\right]^{\frac{1}{\alpha}}
$$

Sendo o parâmetro de escala $(\beta)$ para uma distribuição de Weibull triparamétrica aplicada ao tratamento de dados de tenacidade à fratura dado por $\beta=J_{0}-J_{\min }$, a tenacidade característica do material pode ser obtida de $N$ valores de $J_{c}$ utilizando a equação abaixo:

$$
J_{o}=\left(\frac{\sum_{i=1}^{N}\left(J_{c i}-J_{\min }\right)^{\alpha}}{N}\right)^{1 / \alpha}+J_{\text {min }}
$$

A determinação do parâmetro de forma $(\alpha)$ por meio do Método da Máxima Verossimilhança não é recomendada para o tratamento da dispersão de dados de tenacidade à fratura deste trabalho [50], pois este método pode gerar valores imprecisos do referido parâmetro, uma vez que o número de amostras é reduzido.

A estimativa dos parâmetros da distribuição de Weibull pode também ser realizada de modo mais prático, apesar de menos preciso, utilizando-se de métodos gráficos e regressão linear do conjunto de dados experimentais [50], conforme será apresentado a seguir.

Considerando a função de distribuição acumulada de falha biparamétrica, já apresentada anteriormente, mas repetida por conveniência:

$$
F(x)=1-\exp \left[-\left(\frac{x}{\beta}\right)^{\alpha}\right]
$$


Faz-se a linearização aplicando duas vezes o logaritmo natural na equação acima.

$$
\ln \left(\ln \left(\frac{1}{1-(F(x))}\right)\right)=\alpha \ln x-\alpha \ln \beta
$$

E arranjando os termos na forma:

$$
Y=m X+c
$$

Temos que:

$$
\begin{gathered}
Y=\ln (\ln (1 / 1-(F(x)))) \\
m=\alpha \\
X=\ln x \\
c=-\alpha \ln \beta
\end{gathered}
$$

Na sequência é necessária a estimativa da probabilidade de falha acumulada dada por $F_{(x)}$. Essa estimativa pode ser realizada por diversos métodos, porém em [13] e [44] há a recomendação para o uso do "Estimador do Rank Mediano de Bernard", dado pela equação (37), para o caso de distribuições com grande dispersão de dados, como a apresentada para o tratamento dos dados de tenacidade à fratura de aços ferríticos na região TDF. 


$$
F_{(x)}=(k-0,3) /(N+0,4)
$$

Na equação acima $k$ é o valor da posição da amostra após a ordenação crescente dos valores de tenacidade e $N$ é o tamanho da amostra. A Figura 13 ilustra o procedimento gráfico acima descrito.

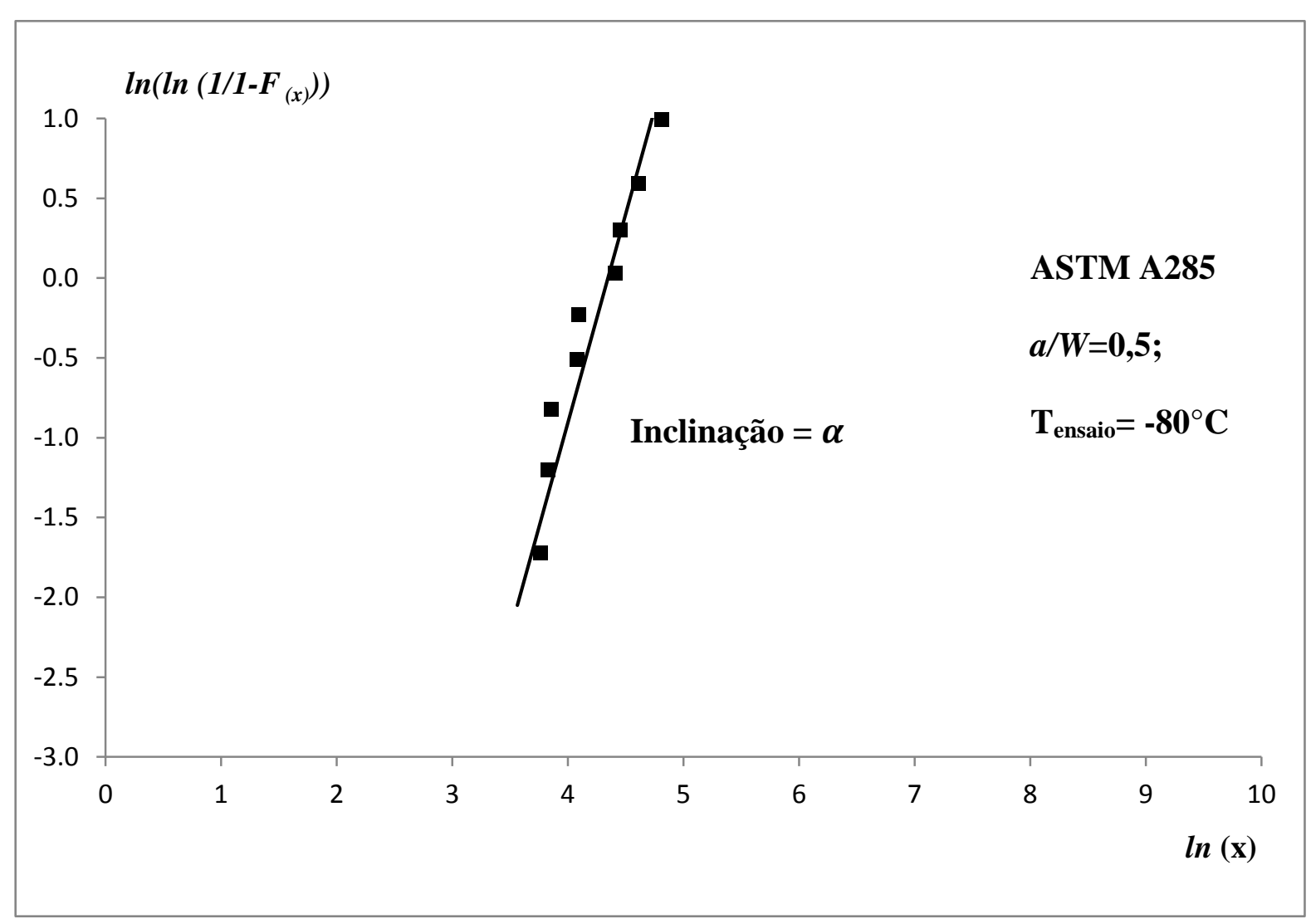

Figura 13. Representação gráfica dos dados de tanacidade à fratura para a determinação do módulo de Weibull.

No gráfico acima os pontos representam os resultados experimentais de tenacidade, o valor do módulo de Weibull, $\alpha$, é aproximado por meio do valor da inclinação da reta de ajuste aos pontos experimentais e o parâmetro de escala, $\beta$, é calculado estabelecendo uma probabilidade de falha acumulada de $63,2 \%$, conforme indica a equação abaixo: 


$$
F(x=\beta)=1-\exp \left[-\left(\frac{x}{\beta}\right)^{\alpha}\right]=1-\exp [-1]=0,632
$$

Baseado em estudos fenomenológicos do processo de clivagem em aços ferríticos Wallin [49] e Wallin et al. [51] demonstram que o parâmetro de forma, $\alpha$, converge para uma dispersão com magnitude teórica igual a 4 quando mantida a condição de escoamento de pequena monta, SSY, dentro do regime de transição dúctil-frágil no qual o processo de falha se dá por nucleação e propagação de defeitos, respeitando o critério de falha de Griffith, a partir de carbonetos esferoidais dispersos na matriz do material [51]. Wallin [49] também demonstrou, utilizando simulações de Monte Carlo, que a escolha do valor de 10 ou $20 \mathrm{MPa} \sqrt{\mathrm{m}}$ para o parâmetro $K_{\min }$ não altera o valor teórico de 4 para o módulo de Weibull, conforme pode ser observado nos gráficos da Figura 14. 


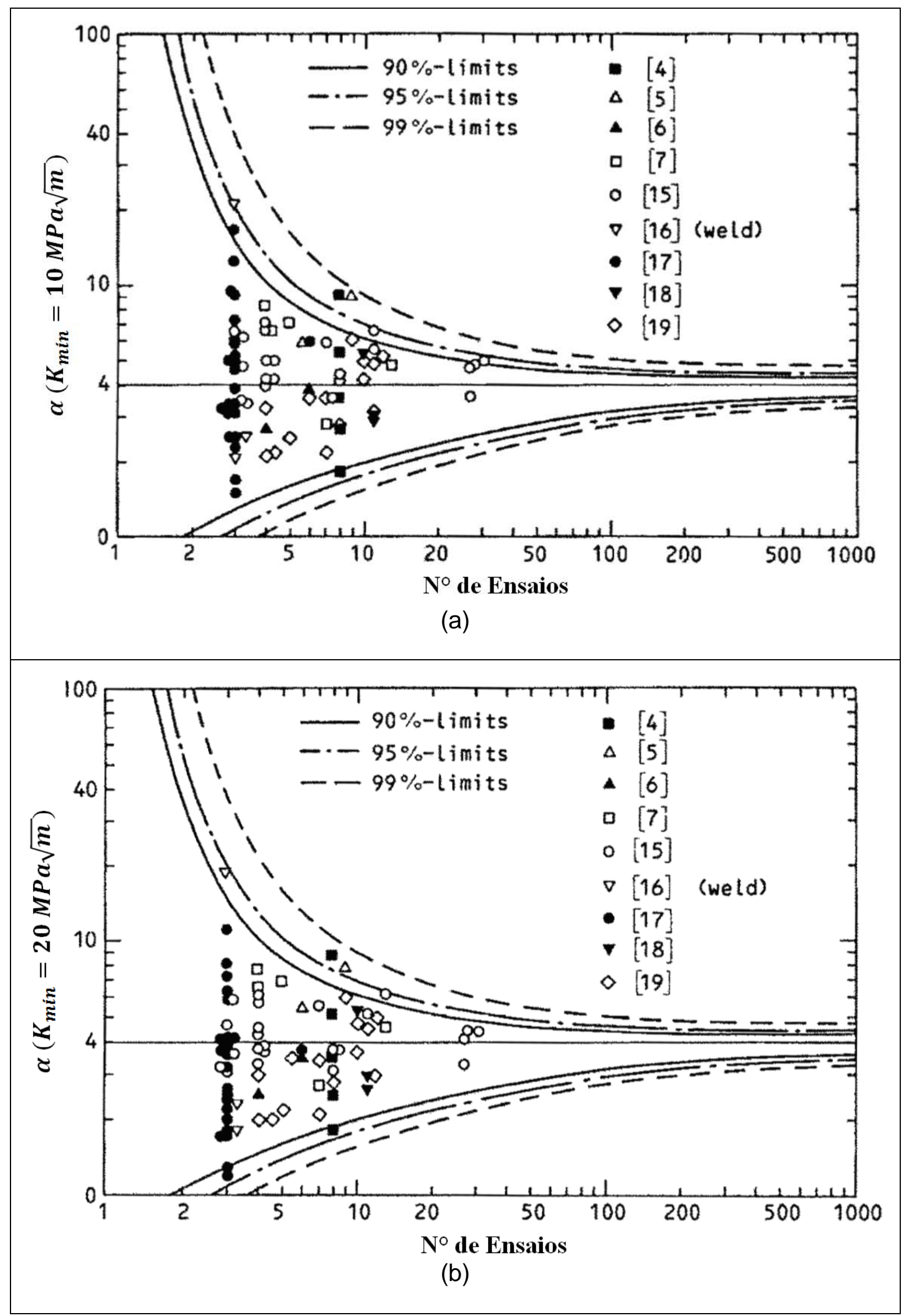

Figura 14. Dispersão teórica dos dados experimentais para determinação do módulo do Weibull como função do número de testes [49]. (a) $K_{\min }=10 \mathrm{MPa} \sqrt{\mathrm{m}}$; (b) $K_{\min }=20 \mathrm{MPa} \sqrt{\mathrm{m}}$. 
Portanto, para a avaliação de tenacidade à fratura de aços ferríticos, em regime de transição dúctil-frágil, dois dos três parâmetros da distribuição de Weibull podem ter seus valores fixos, sendo 10 ou $20 \mathrm{MPa} \sqrt{\mathrm{m}}$ para $K_{\min }$ e 4 para o parâmetro de forma, $\alpha$, restando apenas a determinação do parâmetro de escala, ou tenacidade característica $\left(K_{0}\right.$ ou $J_{0}$ ), obtido por meio dos ensaios experimentais de tenacidade à fratura. Quando os dados de tenacidade à fratura forem denotados em unidades de integral $J,\left[\mathrm{~kJ} / \mathrm{m}^{2}\right]$, o parâmetro de forma, $\alpha$, passa a ter o valor de 2 . 


\section{A METODOLOGIA DA CURVA MESTRA}

\subsection{Curva de Referência ASME}

Na primeira metade do século XX conhecimentos aprofundados sobre mecânica da fratura encontravam-se em estágio inicial de desenvolvimento, as bases de dados experimentais de tenacidade à fratura eram reduzidas e pouco diversificadas. Porém neste período começava a se tornar evidente a importância do conhecimento da tenacidade à fratura dos materiais como um fator de segurança na avaliação da integridade estrutural de vasos de pressão e reatores nucleares.

Devido às consequências catastróficas decorrentes uma falha por clivagem um grande esforço experimental foi realizado para a ampliação destas bases de dados. E em decorrência disto, no início dos anos 70 foi incorporado ao código ASME uma metodologia, baseada em conceitos de mecânica da fratura, para garantir a integridade dos vasos de pressão estabelecendo os limites operacionais de temperatura e pressão na presença de defeitos, tipo trinca, [53 - [55].

Esta metodologia está fundamentada em uma abordagem determinística da mecânica da fratura que por meio de uma curva de referência (curva de referência ASME), procura descrever o patamar inferior de tenacidade à fratura, $K_{I c}$, para aços ferríticos característicos de vasos de pressão de reatores nucleares em uma região de transição dúctil-frágil, conforme ilustra a Figura 15. 


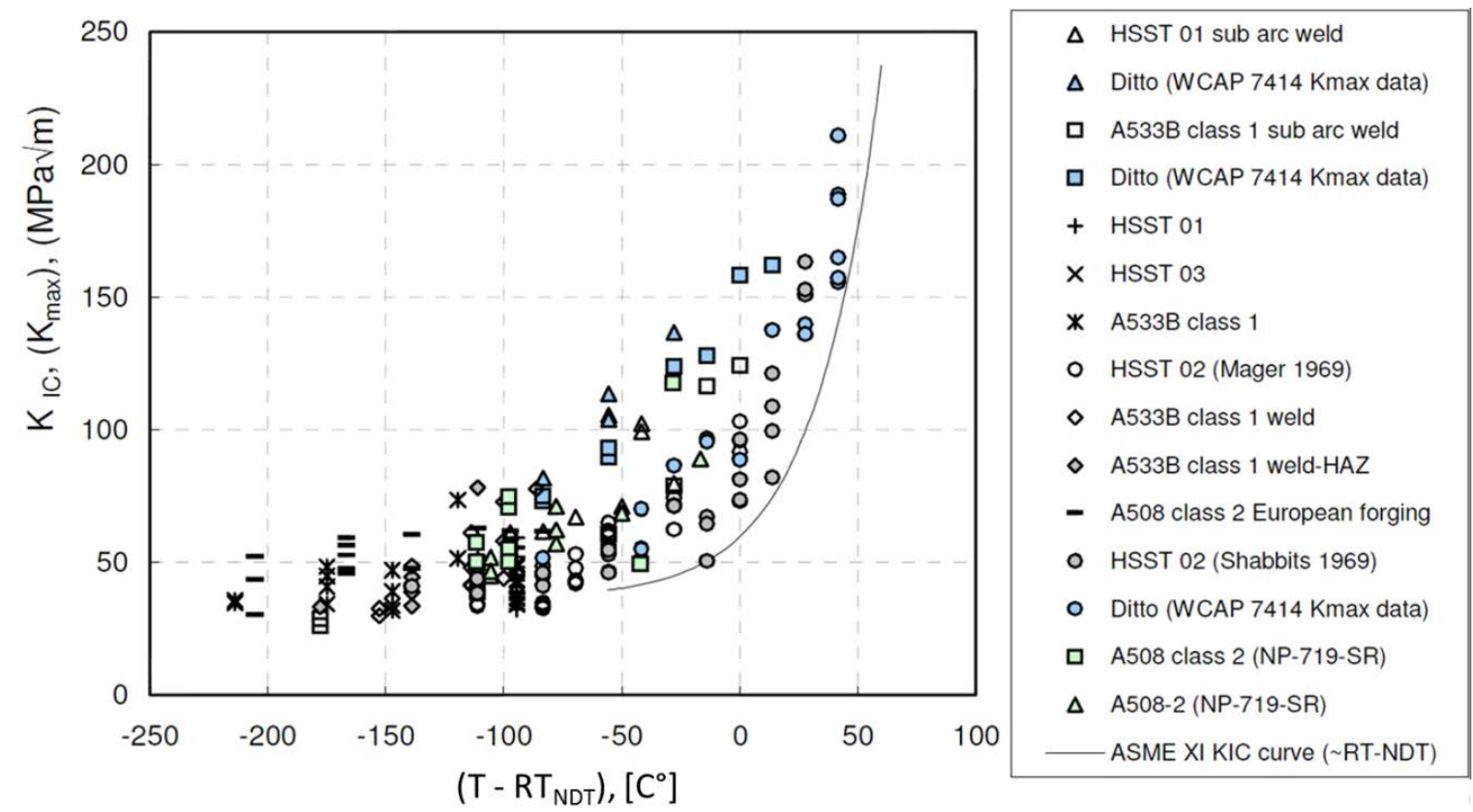

Figura 15. Valores de tenacidade à fratura, $K_{I c}$, para diversas classes de aços ferríticos e a curva de referência ASME estabelecendo o patamar inferior de tenacidade em função da temperatura. [16]

A curva de referência ASME é construída estabelecendo a correlação de $K_{I c}$, $[M P a \sqrt{m}]$, em função da temperatura, $\left[{ }^{\circ} \mathrm{C}\right]$, e é dada pela equação:

$$
K_{I C}=36,5+22,783 \exp \left[0,036\left(T-R T_{N D T}\right)\right]
$$

onde o termo $\mathrm{RT}_{\mathrm{NDT}}$ é uma temperatura de referência obtida por intermédio de ensaios de Impacto Charpy e ensaios de impacto Pellini ${ }^{4}$. A correlação obtida, apesar de possuir baixa precisão devido ao grande espalhamento dos dados, fornece resultados seguros o suficiente para o uso em projeto de vasos de pressão o que fez esta metodologia se perpetuar por 40 anos no código ASME [54].

\footnotetext{
${ }^{4}$ O ensaio de Impacto Pellini, também conhecido como Drop-Weight Test, consiste em utilizar uma massa em queda livre para avaliar a tenacidade de um material havendo como resposta apenas duas possibilidade, ruptura e não-ruptura. Este teste é utilizado na determinação da temperatura de transição de ductilidade nula, Nil-Ductility Transition Temperature. E em conjunto com os valores obtidos dos testes de ensaio Charpy determina-se a temperatura de referência $T_{N D T}$ para ser utilizada nas curvas de avaliação de $K_{I c}$ do código ASME.
} 
Entretanto, por ser baseada em $K_{I c}$, que é um parâmetro elástico e, portanto, muito severo e utilizar fundamentos determinísticos para estabelecer limites inferiores de tenacidade à fratura na região de TDF, na qual claramente se observa grande dispersão dos dados experimentais, tal abordagem introduz demasiado conservadorismo nas análises e acaba por tratar de forma não particular vários tipos de aço.

\subsection{O Conceito da Curva Mestra}

A partir dos conceitos desenvolvidos sobre a mecânica da fratura elasto-plástica juntamente com os entendimentos sobre os fenômenos que regem o micromecanismo de falha por clivagem transgranular e a utilização de modelos estatísticos como os apresentados anteriormente, Wallin propôs uma abordagem de engenharia, conhecida por Metodologia de Curva Mestra [11]. Segundo esta metodologia, a partir de um conjunto reduzido de amostras, é possível caracterizar a tenacidade à fratura frágil por clivagem transgranular de aços ferríticos, na região de transição dúctil-frágil, por uma distribuição de Weibull triparamétrica.

A Metodologia da Curva Mestra foi rapidamente normalizada devido à carência de abordagens baseadas em mecânica da fratura elasto-plástica para o tratamento de dados de tenacidade na região TDF. Outro importante fator que corroborou para a normalização da metodologia foi a possibilidade de caracterizar a tenacidade de um aço específico a partir de uma quantidade reduzida de material, uma vez que na indústria nuclear há pouca disponibilidade de matéria prima, irradiada por exemplo, para a confecção de corpos de prova. Suas diretrizes podem ser encontradas na norma ASTM E1921 [14]

Os conceitos da Curva Mestra baseiam-se na descrição teórica da dispersão de dados, no efeito estatístico sobre os valores tenacidade decorrente da variação da espessura (Teoria do Elo Mais Fraco) e na avaliação empírica da tenacidade à fratura em função da temperatura. Com isso, a avaliação da tenacidade à fratura no regime de transição dúctil-frágil passa a ser descrita por apenas um parâmetro [52], 
a temperatura de referência, $T_{0}$. Esse parâmetro posiciona uma curva de formato fixo no eixo da abscissa do gráfico de $K_{J c} v s\left(T-T_{0}\right)$, conforme ilustra a Figura 16.

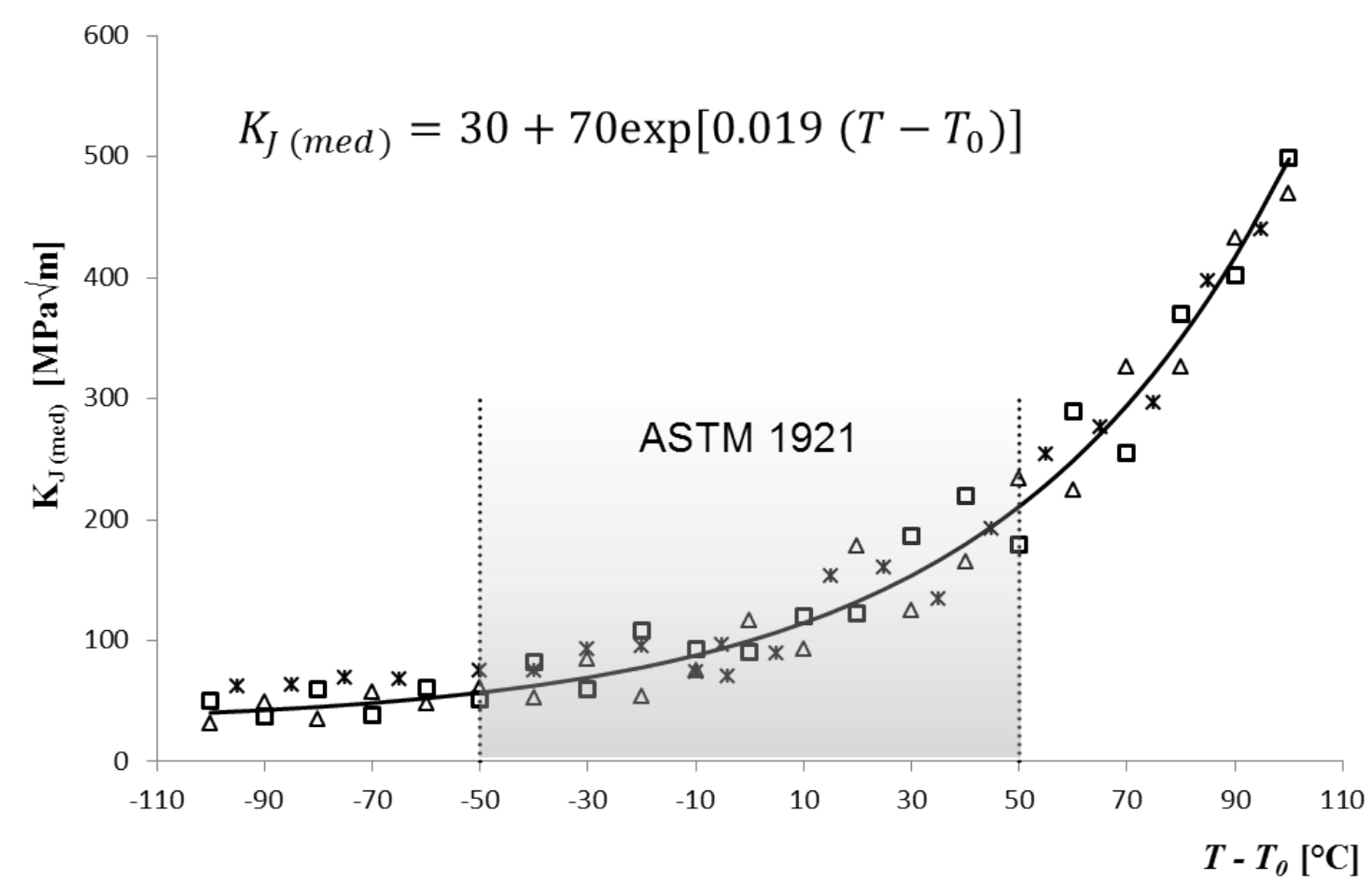

Figura 16. Representação esquemática da curva de tenacidade obtida pela Metodologia da Curva Mestra.

Por anos a Metodologia da Curva Mestra foi mantida no código ASME como forma indireta para obtenção das curvas de tenacidade $K_{I c}$, no projeto e avaliação de integridade de vasos de pressão [55]. Neste período seu uso era previsto e descrito pelo "Code Case N-631" [56] e pelo "Code Case N-629" [57]. A abordagem indireta consiste em substituir a temperatura de referência, $\mathrm{RT}_{\mathrm{NDT}}$, por uma temperatura de referência análoga, $\mathrm{RT}_{\mathrm{TO}}$, na seguinte forma:

$$
\begin{gathered}
R T_{T 0}=T_{0}+19,4{ }^{\circ} \mathrm{C} \\
K_{I C}=36,5+22,783 \exp \left[0,036\left(T-R T_{T 0}\right)\right]
\end{gathered}
$$


A curva de tenacidade gerada por meio da Metodologia da Curva Mestra, para um limite inferior de $5 \%$ de probabilidade de falha, proporciona o mesmo nível de confiabilidade pretendido originalmente com as curvas de referência ASME [58]. Recentemente, em 2013, a Metodologia da Curva Mestra deixou de ser uma abordagem alternativa para o cálculo da tenacidade e foi incorporada como abordagem padrão para a determinação da curva de tenacidade, $K_{I c}$, do código ASME para o projeto de vasos de pressão [55].

Desde sua criação, a Metodologia da Curva Mestra tem sido extensivamente testada e, ao longo dos anos, vem se mostrando uma ferramenta bastante robusta para a avaliação da tenacidade à fratura e da integridade estrutural, principalmente em vasos de pressão de reatores nucleares. Dentre os tópicos de estudo de maior interesse destacam-se:

- Validade da metodologia da Curva Mestra para resultados obtidos de aços severamente fragilizados por radiação neutrônica, [59 - [63].

- Validade da metodologia da Curva Mestra para materiais não homogêneos, [64 - [66].

- Validade da metodologia da Curva Mestra para a região superior da curva de transição dúctil-frágil onde a fratura por clivagem pode ser precedida por uma grande extensão dúctil (rasgamento) da trinca, [67].

- Influência de fatores relacionados às configurações geométricas dos corpos de prova sobre a determinação da temperatura de referência, $T_{0}$, com foco na utilização de geometria PCVN ou "sub-sized", [68 - [83].

Este último tópico é de especial importância, pois nos programas de avaliação de integridade estrutural e extensão de vida de reatores nucleares, por vezes, o único tipo de corpo de prova disponível para ensaios é o PCVN. Portanto, sabendo-se que os efeitos geométricos podem acarretar em variações significativas na temperatura de referência, $T_{0}$, torna-se crucial caracterizar e definir os limites de aplicação do espécime PCVN para este fim.

Na próxima seção serão mostradas as etapas para a determinação da $T_{0}$ e da Curva Mestra com base nas diretrizes da norma ASTM E1921 [14]. 


\subsection{Roteiro para Determinação da Curva Mestra}

Uma vez realizados os ensaios experimentais de tenacidade à fratura na região TDF, a temperatura de referência, $T_{0}$, e a Curva Mestra podem ser determinadas a partir do roteiro descrito a seguir. Os valores de força motriz na instabilidade, $J_{c}$, devem ser convertidos para as unidades do fator de intensidade de tensões, $K[M P a \sqrt{m}]$ que passarão a ser representados por $K_{J c}$ (fator de intensidade de tensões elasto-plástico). A conversão é feita simplesmente utilizando-se a relação convencional entre $K$ e $J$ sob estado plano de deformação [20] na forma:

$$
K_{J c}=\sqrt{\frac{E J_{c}}{\left(1-v^{2}\right)}}
$$

Na qual $E$ é o módulo de elasticidade do material; $J_{c}$ é o valor de tenacidade à fratura na instabilidade e $v$ é o coeficiente de Poisson.

Caso os valores experimentais não tenham sido obtidos de corpos de prova com a espessura padrão de $25,4 \mathrm{~mm}$ (1T) a correção deve ser feita com base na Teoria do Elo Mais Fraco, utilizando a expressão a seguir:

$$
K_{J c(1 T)}=K_{\min }+\left[K_{J c(x T)}-K_{\min }\right]\left(\frac{B_{(x T)}}{B_{(1 T)}}\right)^{\frac{1}{4}}
$$

Sendo:

$K_{J c(1 T)}$ : Tenacidade corrigida para um corpo de prova com espessura $25,4 \mathrm{~mm}$;

$K_{\min }: 20 \mathrm{MPa} \sqrt{m}$;

$K_{J c(x T)}$ : Valor experimental obtido do ensaio com o corpo de prova de espessura $x T$;

$B_{(x T)}$ : Espessura do corpo de prova ensaiado;

$B_{(1 T)}$ : Espessura de $25,4 \mathrm{~mm}$. 
Com os dados experimentais convertido em valores de $K$ e corrigidos para a espessura de 1T, aplica-se Metodologia da Curva Mestra, adotando-se uma distribuição de Weibull triparamétrica na forma da equação (44):

$$
F\left(K_{J c}\right)=1-\exp \left[-\left(\frac{K_{J c}-K_{\min }}{K_{0}-K_{\min }}\right)^{\alpha}\right]
$$

A princípio, na equação acima há três parâmetros a serem determinados, porém, conforme mostrado na seção anterior, dois destes parâmetros passam a ser fixos e pré-definidos se as condições de escoamento de pequena monta, SSY, e o modo de falha por clivagem com nucleação da trinca seguida de propagação forem atendidas. A norma ASTM E1921 [14] estabelece o valor de $20 \mathrm{MPa} \sqrt{\mathrm{m}}$ para $K_{\min } \mathrm{e}$ valor teórico de 4 para o módulo de Weibull. Portanto resta apenas a avaliação da tenacidade característica, $K_{0}$, dada pela equação abaixo:

$$
K_{0}=K_{\min }+\left[\frac{\sum_{i=1}^{N}\left(K_{J c}(i)-K_{\min }\right)^{4}}{N}\right]^{\frac{1}{4}}
$$

Na qual $K_{J c}(i)$ é o valor experimental obtido do ensaio de tenacidade à fratura e $N$ é o número de ensaios experimentais. Na sequência faz-se a conversão de $K_{0}$, que corresponde à probabilidade de $63,2 \%$ de falha, para um valor mediano de $50 \%$, $K_{J c \text { (med) }}$, com a seguinte expressão:

$$
K_{J c(\text { med })}=0,9124\left(K_{0}-20\right)+20
$$

A temperatura de referência, $T_{0}$, pode então calculada por: 


$$
T_{0}=T_{\text {ensaio }}-\left(\frac{1}{0,019}\left(\ln \left(\frac{K_{J c(\text { med })}-30}{70}\right)\right)\right)
$$

E a Curva Mestra de um corpo de prova $1 T$ na região de transição dúctil-frágil passa a ser dada pela equação (48):

$$
K_{J c(m e d)}=30+70 \exp \left[0,019\left(T-T_{0}\right)\right]
$$

Na qual $T$ é a temperatura na qual se deseja avaliar a tenacidade e $T_{0}$ é a temperatura de referência característica de cada material obtida com no mínimo 6 valores válidos de $K_{J c}$.

A norma ASTM E1921 [14] estabelece dois critérios que determinam a validade dos resultados experimentais e caso eles não sejam cumpridos o resultado é então censurado. São eles:

1) Os valores de tenacidade críticos, $K_{J c}(i)$, não devem ultrapassar o limite, determinado por:

$$
K_{J c_{\_} \text {limite }}=\sqrt{\frac{E b_{0} \sigma_{y s}}{M\left(1-v^{2}\right)}} \quad ; \quad K_{J c} \leq K_{J c \text { Limite }}
$$

$\mathrm{Na}$ equação acima $E$ é o módulo de elasticidade do material, $b_{0}$ é o ligamento remanescente inicial, $\sigma_{y s}$ é a tensão de escoamento do material na temperatura de ensaio, $v$ é o coeficiente de Poisson e $M$ é o limite de deformação plástica. Por recomendação da norma o valor de $M=30$ deve ser utilizado quando os ensaios experimentais forem realizados com corpos de prova SE(B) ou PCVN. 
2) Crescimento estável da trinca antes da clivagem, $\Delta a_{p}$.

Para esta segunda avaliação a norma sugere a técnica de medição dos 9 pontos, similar a da norma ASTM E1820 [9] e ilustrada na figura abaixo:

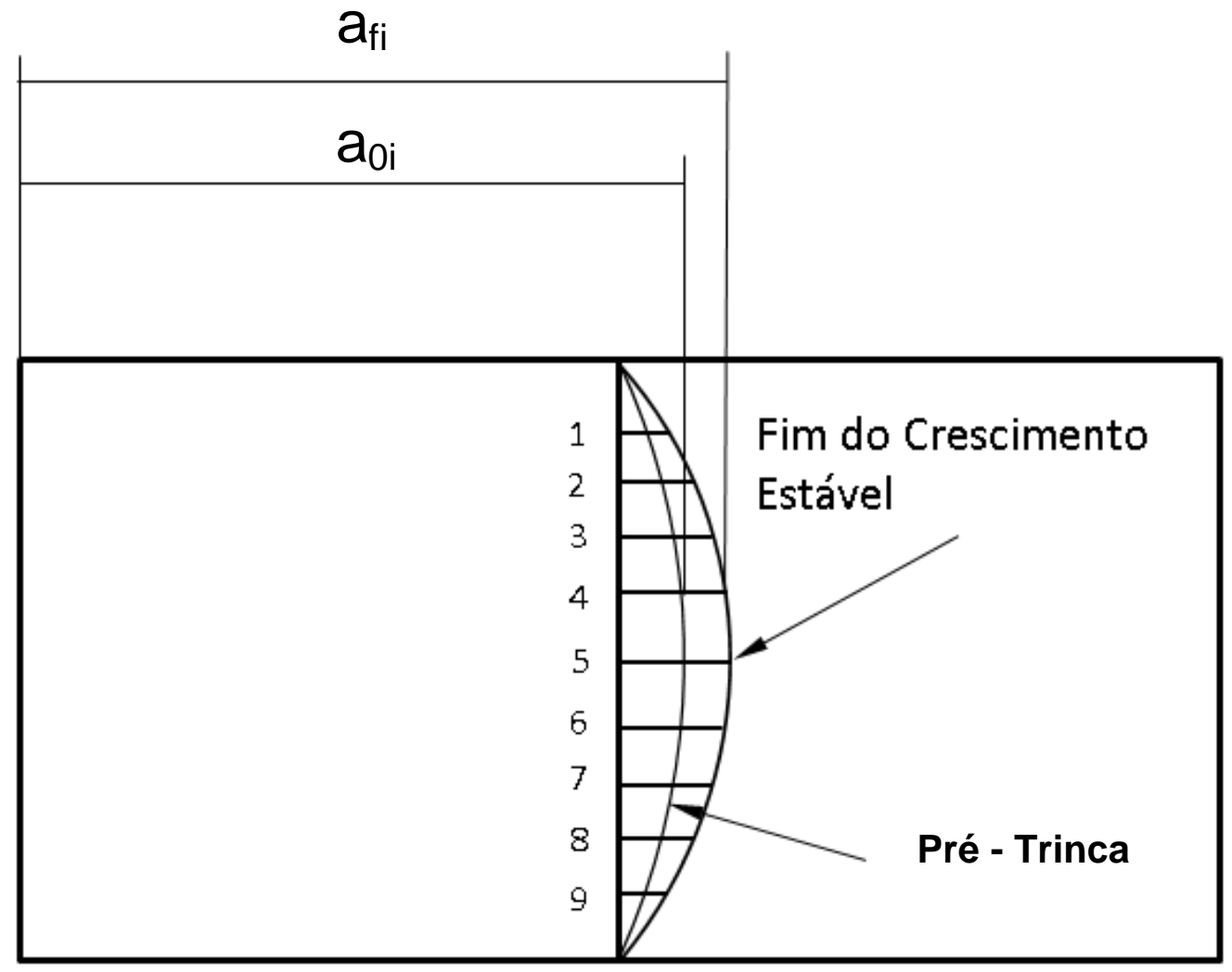

Figura 17 Esquema representativo dos pontos para a medição do crescimento estável de trinca.

Para a medição da pré-trinca propagada por fadiga tem-se:

$$
a_{0}=0,125\left(0,5\left(a_{1}+a_{9}\right)+a_{2} \ldots+a_{8}\right)
$$

E para a medição do fim do crescimento estável tem-se:

$$
a_{f}=0,125\left(0,5\left(a_{f 1}+a_{f 9}\right)+a_{f 2} \ldots+a_{f 8}\right)
$$


Portanto, se a condição dada pela equação (52) não for satisfeita, o ensaio deve ser dado como inválido.

$$
\Delta a_{p}=a_{f}-a_{0} ; \Delta a_{p} \leq 0,05\left(W-a_{0}\right) \text { ou } 1 \mathrm{~mm}
$$

Ainda sobre a medição do comprimento de trinca inicial e a avaliação do crescimento estável, foi utilizado neste trabalho um procedimento análogo ao apresentado, utilizando-se apenas a medição de 5 pontos ao invés de 9 , pois devido às características do fenômeno de clivagem transgranular as frentes de trinca são praticamente planas em toda a sua extensão. Dessa forma a divisão em 5 pontos se mostrou suficiente para a medição desejada. Detalhes sobre o método estão descritos no Anexo C.3.

A norma ASTM E1921 não descarta os resultados experimentais que violaram os critérios mostrados acima e foram classificados como inválidos, mas ela os censura e a tenacidade característica $K_{0}$ passa então a ser calculada pela equação:

$$
K_{0}=K_{\min }+\left[\frac{\sum_{i=1}^{N}\left(K_{J c}(i)-K_{\min }\right)^{4}}{r}\right]^{\frac{1}{4}}
$$

Trata-se de uma equação similar à equação (45), porém sendo $r$ o número de resultados válidos. Portanto, quando houver resultados censurados devido $K_{J c}(i)>K_{J c \text { Limite }}$, então $K_{J c}(i)$ deve ser substituído pelo valor de $K_{J c}$ Limite para a avaliação de $K_{0}$. Ou quando $\Delta a_{p}$ for superior ao limite estabelecido, o valor de tenacidade $K_{J c}(i)$ a ser considerado deve ser igual ao maior valor de $K_{J c}$ da série de dados experimentais que se mantém válido. Uma vez obtido $K_{0}$, retorna-se aos passos descritos anteriormente até a obtenção da temperatura $T_{0}$ e determinação da Curva Mestra. 
Finalmente, define-se o intervalo de confiança para a Curva Mestra obtida. A norma ASTM E1921 fornece a seguinte expressão geral para que este cálculo seja feito:

$$
K_{J c(0, x x)}=20+\left[\ln \left(\frac{1}{1-0, x x}\right)\right]^{1 / 4}\left\{11+77 \exp \left(0,019\left(T-T_{0}\right)\right)\right\}
$$

Por exemplo, caso o novo intervalo desejado seja de $2 \%$, substitui-se $0, x x$ por 0,02. Porém usualmente o intervalo de confiança estabelecido é de 5 a $95 \%$ e este pode ser obtido respectivamente pelas equações (55) e (56).

$$
K_{J c(0,05)}=25,2+36,6 \exp \left(0,019\left(T-T_{0}\right)\right)
$$

$$
K_{J C(0,95)}=34,5+101,3 \exp \left(0,019\left(T-T_{0}\right)\right)
$$




\section{PROGRAMA EXPERIMENTAL}

Nesta seção serão apresentados os aços ferríticos utilizados neste trabalho, os métodos experimentais aplicados para caracterização das propriedades mecânicas e também serão descritas algumas etapas dos procedimentos operacionais para a realização destes experimentos. Alguns destes procedimentos são simples e diretos e, portanto, suas abordagens metodológicas não se fazem necessárias. No entanto, as etapas que envolvem a nucleação de pré-trinca por fadiga e a determinação precisa das temperaturas de ensaio de tenacidade à fratura são detalhadas nos anexos, uma vez que tais procedimentos introduziram grande complexidade experimental neste trabalho.

\subsection{Material}

Os materiais utilizados neste trabalho experimental foram os aços ferríticos ASTM A285 Grau C [4] e o ASTM A515 Grau 65 [5]. Ambos foram fornecidos em chapas laminadas a quente, beneficiadas pela empresa Usiminas, com dimensões de $1420 \mathrm{~mm}$ de comprimento, $290 \mathrm{~mm}$ de largura e espessura de $31,5 \mathrm{~mm}$ para o aço ASTM A285 e espessura de 38,1 mm para o aço ASTM A515.

Pequenas variações na composição química destes aços são permitidas, pois a obtenção dos requisitos de resistência mecânica se faz por meio da adição de elementos de liga. De acordo com a certificação fornecida pelo fabricante da chapa, as composições químicas dos aços utilizados são apresentadas na Tabela 1.

Tabela 1 Composição química dos aços ASTM A515 Gr 65 e ASTM A285 Gr C (\% massa).

\begin{tabular}{ccccccccccccc}
\hline & $\mathbf{C}$ & $\mathbf{M n}$ & $\mathbf{S i}$ & $\mathbf{A l}$ & $\mathbf{M o}$ & $\mathbf{C r}$ & $\mathbf{N i}$ & $\mathbf{N b}$ & $\mathrm{Ti}$ & $\mathbf{V}$ & $\mathbf{P}$ & $\mathbf{S}$ \\
\hline $\begin{array}{c}\text { A285 } \\
\text { (Gr C) }\end{array}$ & 0,14 & 0,77 & 0,24 & 0,029 & 0,001 & 0,01 & 0,01 & 0,002 & 0,001 & 0,001 & 0,01 & 0,006 \\
\hline $\begin{array}{c}\text { A515 } \\
(\text { Gr 65) }\end{array}$ & 0,26 & 0,67 & 0,26 & 0,004 & 0,01 & 0,03 & 0,01 & 0,001 & 0,002 & 0,003 & 0,02 & 0,009 \\
\hline
\end{tabular}


De acordo com a ASTM as únicas quantidades estabelecidas referem-se aos elementos Carbono, Manganês, Fósforo e Enxofre e neste caso todas elas foram atendidas e estão abaixo do limite máximo permitido.

\subsection{Preparação das Chapas para Extração dos Corpos de Prova}

Foram realizados três tipos de ensaios para caracterização dos materiais e para o estudo da tenacidade à fratura. São eles:

- Ensaio de Tração

- Ensaio de Impacto Charpy

- Ensaio de Tenacidade à Fratura

A preparação das chapas e a usinagem dos corpos de prova seguiu basicamente 0 mesmo roteiro para ambos os aços. As dimensões das chapas e o posicionamento dos espécimes foram estabelecidos de forma a facilitar a extração dos corpos de prova, garantir o alinhamento da direção de laminação das chapas com o entalhe dos corpos de prova (direção T-L) e evitar zonas afetadas pelo calor decorrente da etapa de corte por oxi-acetileno. As Figuras 18, 19 e 20 ilustram esquematicamente este posicionamento. 

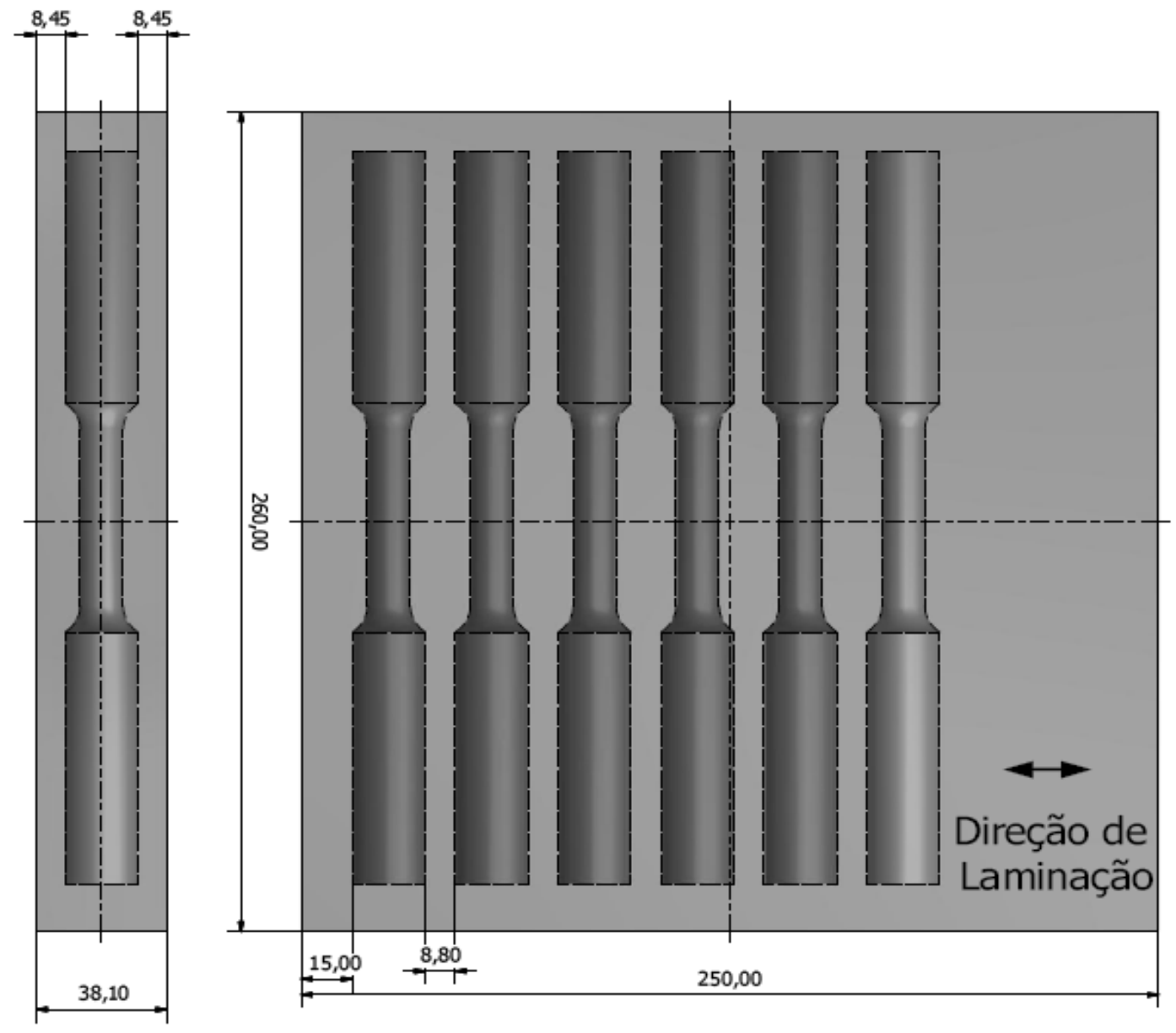

Figura 18. Desenho esquemático para retirada dos corpos de tração das chapas laminadas. 


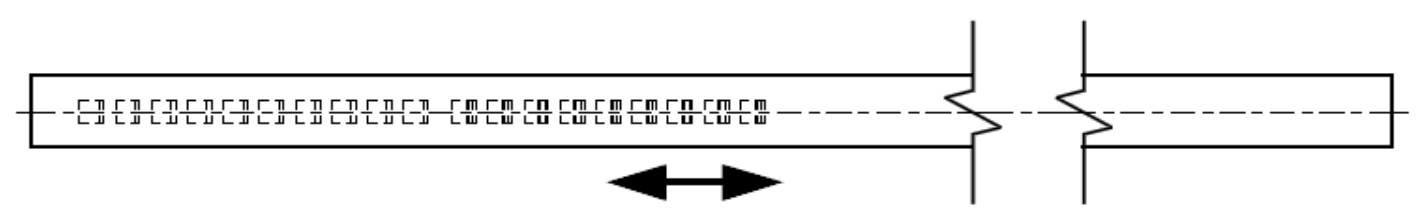

SENTIDO DE LAMINAÇ̃̃o

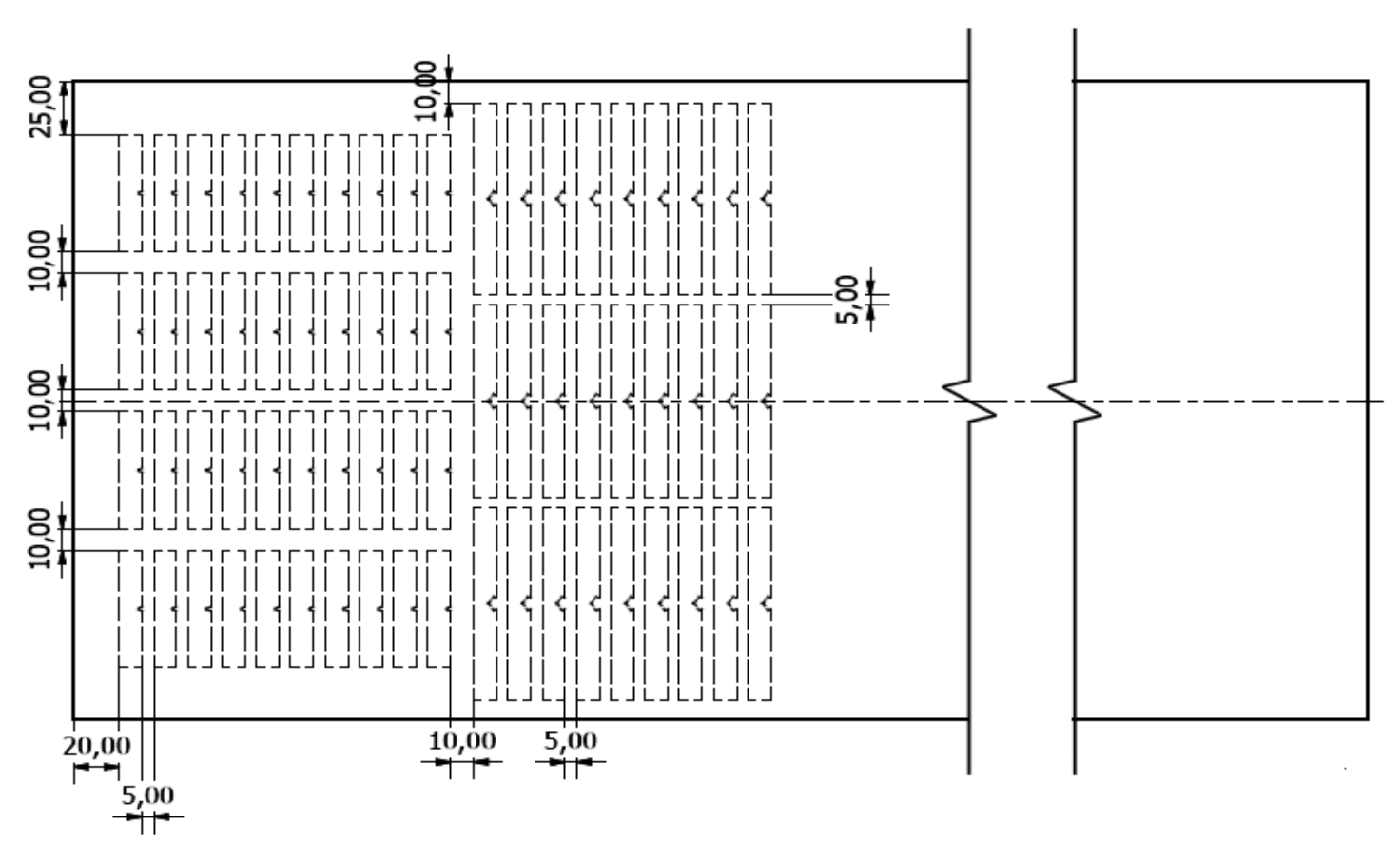

Figura 19. Desenho esquemático para retirada dos corpos de pequenas dimensões, Impacto Charpy e PCVN.

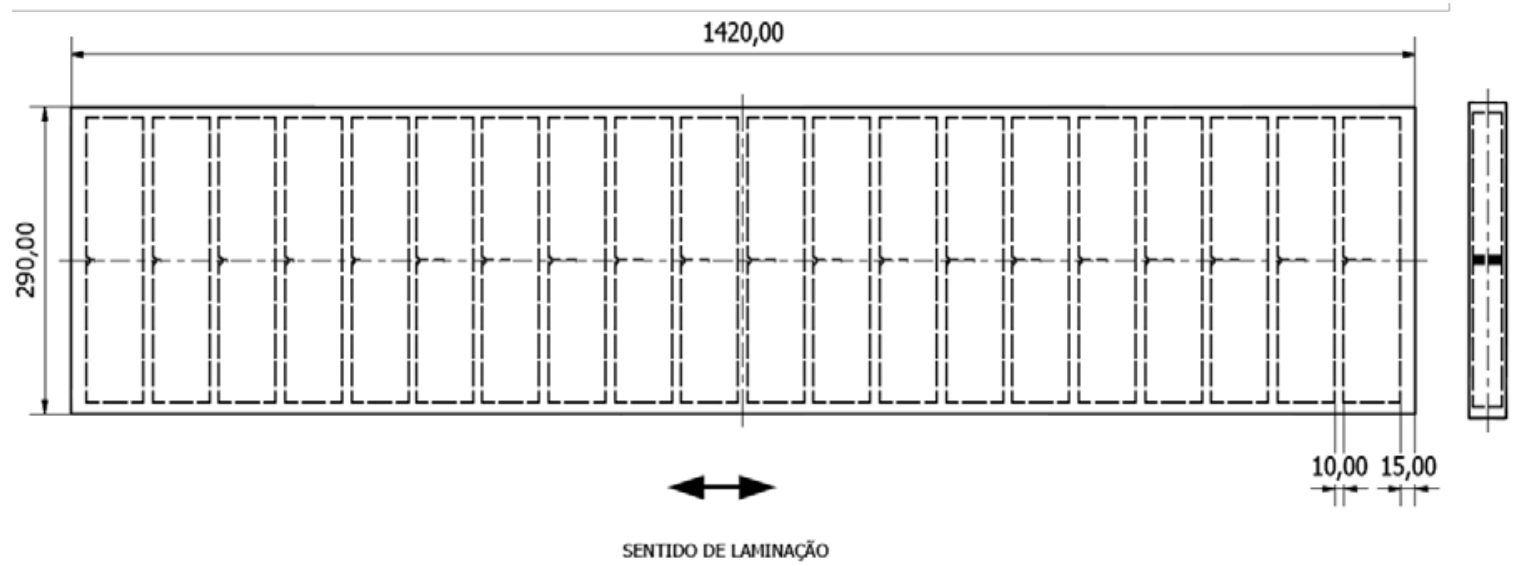

\section{के}

Figura 20. Desenho esquemático para retirada dos corpos de tenacidade à fratura com dimensões $1 \mathrm{~T}$. 


\subsection{Ensaio de Tração}

Os ensaios de tração realizados neste trabalho seguem as recomendações da norma ASTM E8/E8M - 11 [84]. À temperatura ambiente foram utilizados corpos de prova com diâmetro de seção de ensaio de 12,5 mm, conforme ilustra a Figura 21. As propriedades mecânicas são determinadas a partir do ensaio de três corpos de prova para cada uma das temperaturas, $T_{\text {ensaio }}$, praticadas nos testes de tenacidade e alguns testes adicionais foram realizados no intuito de avaliar a anisotropia presente nestes materiais, decorrentes da direção de laminação das chapas.

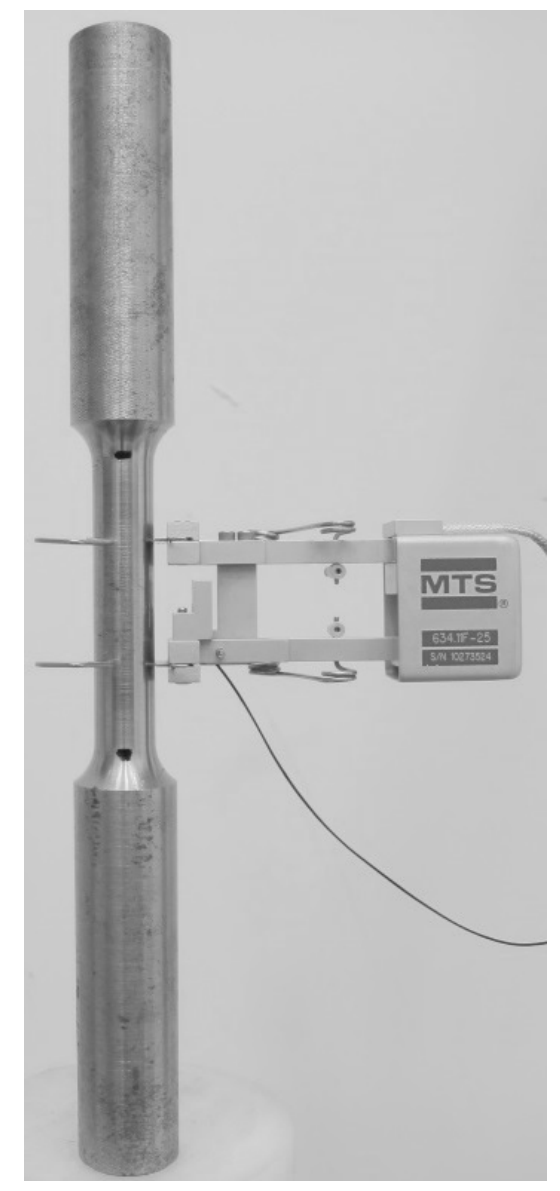

Figura 21. Corpo de tração para ensaio a temperatura ambiente seguindo os padrões da norma ASTM E8/E8M-11.

Para determinar as propriedades de tração a baixas temperaturas foram utilizadas as equações (57) e (58), obtidas do trabalho de Tagawa et al. [85]. Essas equações 
permitem estimar a tensão de escoamento e a tensão de ruptura de engenharia para a temperatura desejada.

$$
\begin{aligned}
\sigma_{y S} & =\sigma_{y S}^{*} \exp \left[8,4810^{-3}\left(\frac{\sigma_{y S}^{*}}{E}\right)^{-1.5}\left(\frac{1}{T+273}-\frac{1}{293}\right)\right] \\
\sigma_{U T S} & =\sigma_{U T S}^{*} \exp \left[7,8310^{-3}\left(\frac{\sigma_{U T S}^{*}}{E}\right)^{-1.5}\left(\frac{1}{T+273}-\frac{1}{293}\right)\right]
\end{aligned}
$$

Nas equações acima tem-se que:

$T=$ Temperatura, $\left[{ }^{\circ} \mathrm{C}\right]$, na qual se deseja estimar a propriedade mecânica.

$E=$ Módulo de Elasticidade (não varia com a temperatura).

$\sigma_{y s}=$ Tensão de escoamento à temperatura desejada.

$\sigma_{y s}^{*}=$ Tensão de escoamento à temperatura ambiente.

$\sigma_{U T S}=$ Limite de resistência à tração à temperatura desejada.

$\sigma_{U T S}^{*}=$ Limite de resistência à tração à temperatura ambiente.

Outra propriedade mecânica de interesse para o trabalho é o coeficiente de encruamento do material. A literatura também fornece algumas relações analíticas para o seu cálculo com base apenas nos valores da tensão de escoamento e do limite de resistência à tração caso a curva completa de Tensão vs. Deformação não esteja disponível. A expressão para o cálculo do coeficiente de encruamento do material adotada neste trabalho é sugerida pela API 579 [8] e dada pela equação (59).

$$
\sigma_{U T S}=\sigma_{y S}\left[\frac{(500 N)^{N}}{\exp (N)}\right] \quad \text { na qual } \quad N=1 / n
$$


Nesse trabalho foi realizada uma tentativa experimental de avaliação das propriedades mecânicas a baixas temperaturas. Protótipos dos dispositivos para estes testes foram desenvolvidos, porém os resultados obtidos não foram confiáveis e alguns pontos do aparato de teste deveriam ser submetidos a melhorias. Detalhes desta tentativa experimental podem ser encontrados no Anexo B.

Os valores das propriedades mecânicas apresentados a seguir referem-se à média do ensaio de três corpos de prova com diâmetro de $12,5 \mathrm{~mm}$, posicionados transversalmente à direção de laminação e ensaiados em temperatura ambiente. Com o objetivo de avaliar a anisotropia do material, corpos de prova usinados no sentido de laminação também foram ensaiados, porém não foram observadas diferenças significativas nos resultados.

A dispersão de resultados entre os 3 corpos de prova foi muito baixa então, para permitir maior clareza na apresentação dos resultados e na comparação entre os dois materiais optou-se por plotar apenas uma das três curvas de Tensão vs. Deformação referente a cada um dos aços, conforme mostra a Figura 22.

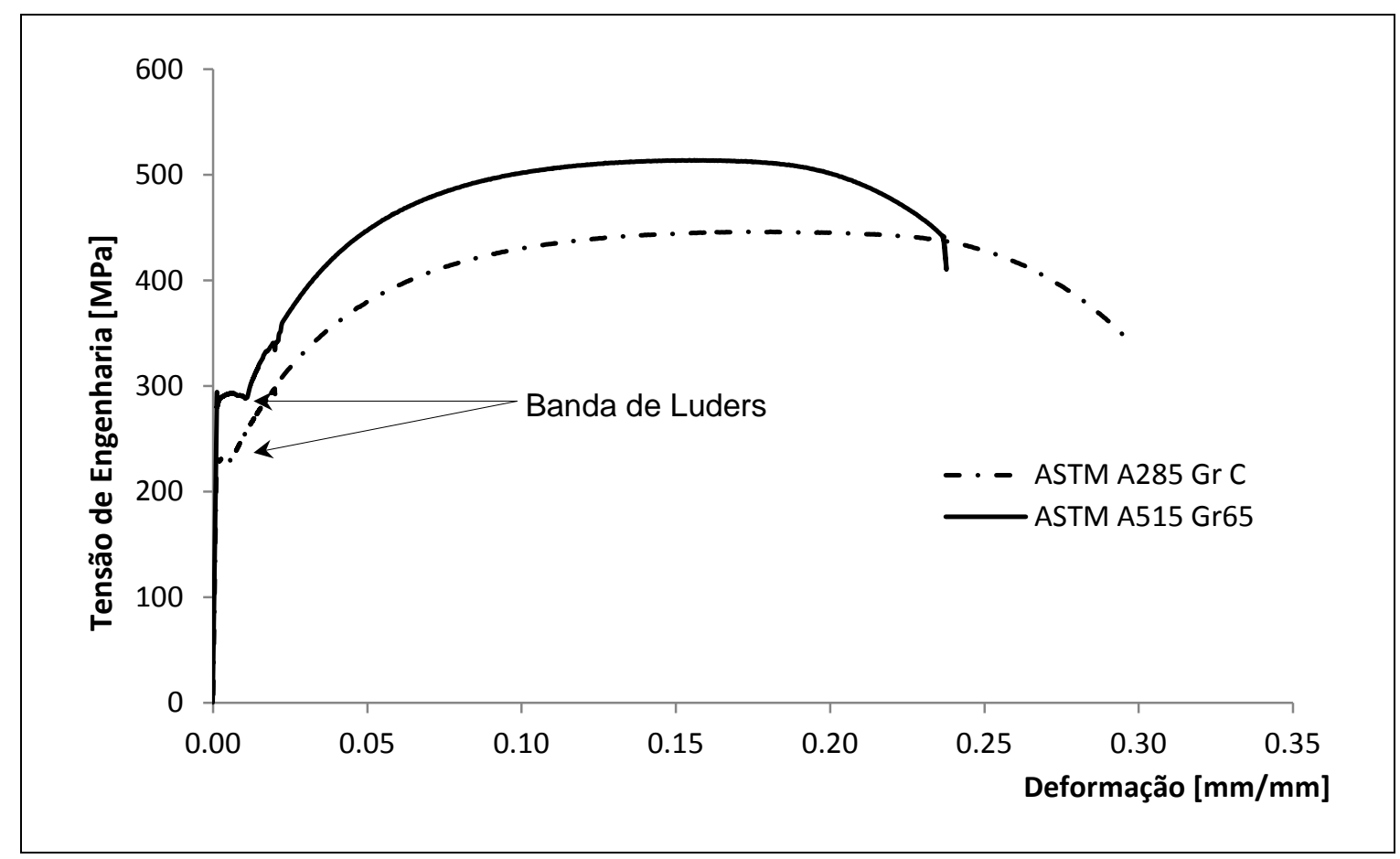

Figura 22. Curva de Tensão vs Deformação para os aços A285 Gr C e A515 Gr 65 a temperatura ambiente $\left(T=20^{\circ} \mathrm{C}\right)$. 
Do gráfico da Figura 22 é possível concluir que o comportamento mecânico em tração de ambos os materiais é muito semelhante. Os valores da tensão de escoamento e do limite de resistência à tração, ambos de engenharia, para o aço A285 são ligeiramente inferiores aos do aço A515. A tensão de escoamento é definida no patamar onde ocorre a Banda de Lüders e o limite de resistência à tração é determinado no pico de maior tensão observada no gráfico.

O aço A285 apresentou um elongamento 6\% superior ao elongamento do aço A515 sendo este determinado na deformação de ruptura. O valor do coeficiente de encruamento de ambos os materiais é bastante próximo e estes aços podem ser classificados como aços de alto capacidade de encruamento com $n$ de aproximadamente 5 .

As Tabela 2 e Tabela 3 compilam os valores para cada uma das propriedades mecânicas, incluindo também os valores dessas propriedades nas temperaturas de ensaio nas quais os testes de tenacidade à fratura foram realizados. As propriedades mecânicas avaliadas à baixa temperatura, conforme dito anteriormente, foram obtidas analiticamente por meio das equações (57), (58) e (59) e, portanto o elongamento não foi possível de ser avaliado uma vez que esta análise necessita de uma curva completa de Tensão vs. Deformação.

Tabela 2 Propriedades mecânicas em tração para o aço ASTM A285 Gr C

\begin{tabular}{|c|c|c|c|c|c|}
\hline \multirow[b]{2}{*}{$\begin{array}{c}\text { Temp. } \\
\text { de } \\
\text { Ensaio }\end{array}$} & \multicolumn{4}{|c|}{ ASTM A285 GR C } & \multirow[b]{2}{*}{$\begin{array}{c}E \\
(G P a)\end{array}$} \\
\hline & $\begin{array}{c}\sigma_{y s} \\
\text { Eng. } \\
(M P a)\end{array}$ & $\begin{array}{c}\sigma_{U T S} \\
\text { Eng. } \\
(\mathrm{MPa})\end{array}$ & $\begin{array}{c}\text { Elongamento } \\
(\%)\end{array}$ & $n$ & \\
\hline $20^{\circ} \mathrm{C}$ & 230 & 446 & 30 & 5,3 & 201 \\
\hline$-60^{\circ} \mathrm{C}$ & 304 & 490 & & 6,9 & \\
\hline$-80^{\circ} \mathrm{C}$ & 339 & 509 & & 7,8 & \\
\hline$-105^{\circ} \mathrm{C}$ & 401 & 539 & & 9,8 & \\
\hline
\end{tabular}


Tabela 3 Propriedades mecânicas em tração para o aço ASTM A515 Gr 65

\begin{tabular}{cccccc}
\hline & \multicolumn{5}{c}{ ASTM A515 GR 65 } \\
\cline { 2 - 6 } $\begin{array}{c}\text { Temp. } \\
\text { de } \\
\text { Ensaio }\end{array}$ & $\begin{array}{c}\sigma_{y s} \\
\text { Eng. }\end{array}$ & $\begin{array}{c}\sigma_{U T S} \\
\text { Eng. }\end{array}$ & $\begin{array}{c}\text { Elongamento } \\
(\%)\end{array}$ & $n$ & $E$ \\
\hline $\mathbf{2 0} \mathbf{C}$ & 294 & 514 & 24 & 6,1 & 210 \\
$\mathbf{- 1 0 ^ { \circ } \mathrm { C }}$ & 313 & 527 & & 6,4 & \\
$\mathbf{- 2 0 ^ { \circ } \mathrm { C }}$ & 321 & 532 & & 6,6 & \\
$\mathbf{- 6 5 ^ { \circ } \mathrm { C }}$ & 368 & 562 & & 7,5 & \\
\hline
\end{tabular}

\subsection{Ensaio de Impacto Charpy}

Não foi encontrada na literatura uma base de dados com valores de tenacidade ao impacto que permitisse determinar a região de transição dúctil-frágil para os aços A285 e A515. Entretanto, a estimativa inicial da temperatura de teste para os ensaios de tenacidade à fratura é imprescindível e esta estimativa é feita com base na curva de tenacidade ao Impacto Charpy.

Desta forma a curva de tenacidade ao impacto foi obtida por meio de testes, seguindo-se a norma ASTM E23 - 07 [86]. Os corpos de prova foram retirados do centro das chapas, com relação à espessura e ao todo foram utilizados neste trabalho 42 espécimes com as dimensões padrão de $55 \mathrm{~mm}$ de comprimento, 10 $\mathrm{mm}$ de largura e $10 \mathrm{~mm}$ de espessura. Na Figura 23 podem ser observados outros detalhes da geometria do corpo de prova utilizado nesse tipo ensaio. 


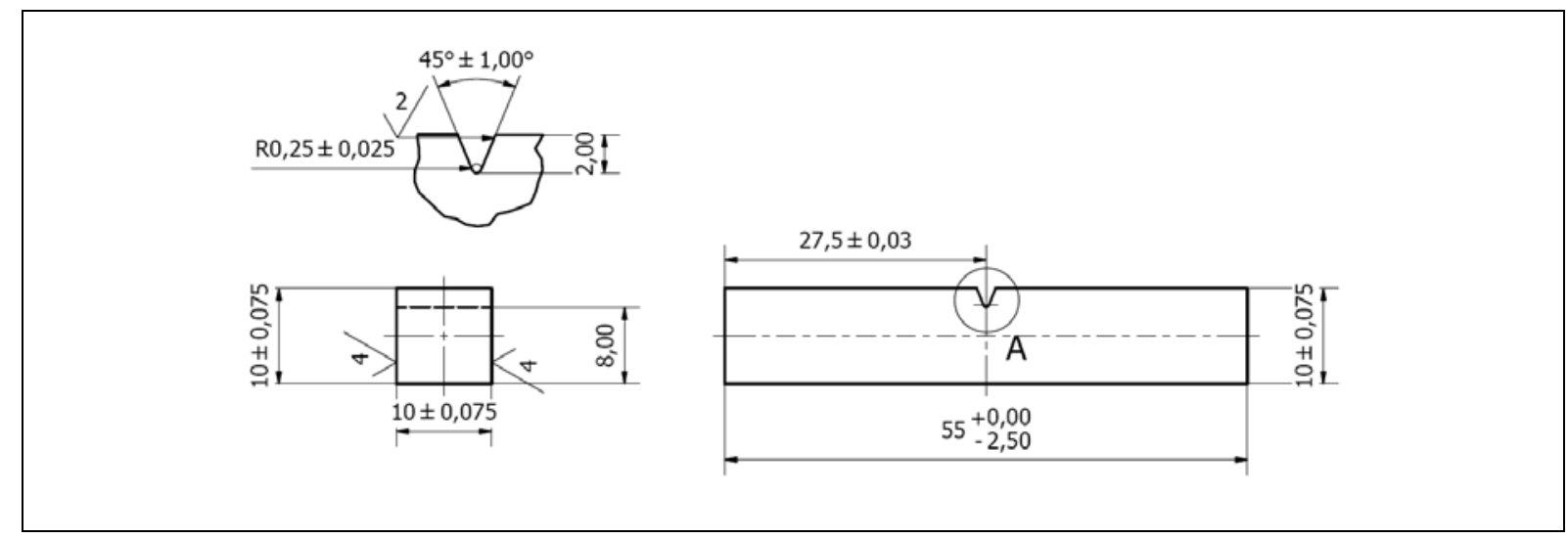

Figura 23. Corpo de prova normalizado para ensaio de impacto Charpy - ASTM E23 - 07 [86]

Os ensaios foram realizados com equipamentos Tinius Olsen IT 406 digital com capacidade de 406 Joules e Wolpert PW30/15 analógico com capacidade 300 Joules, mostrados nas Figura 24 (a) e (b) respectivamente. Os corpos de prova foram refrigerados em banho de álcool etílico com equipamento similar ao da Figura 24 (c) e aquecidos em banho de água quente controlando-se a temperatura com auxílio de um termômetro e uma resistência elétrica.
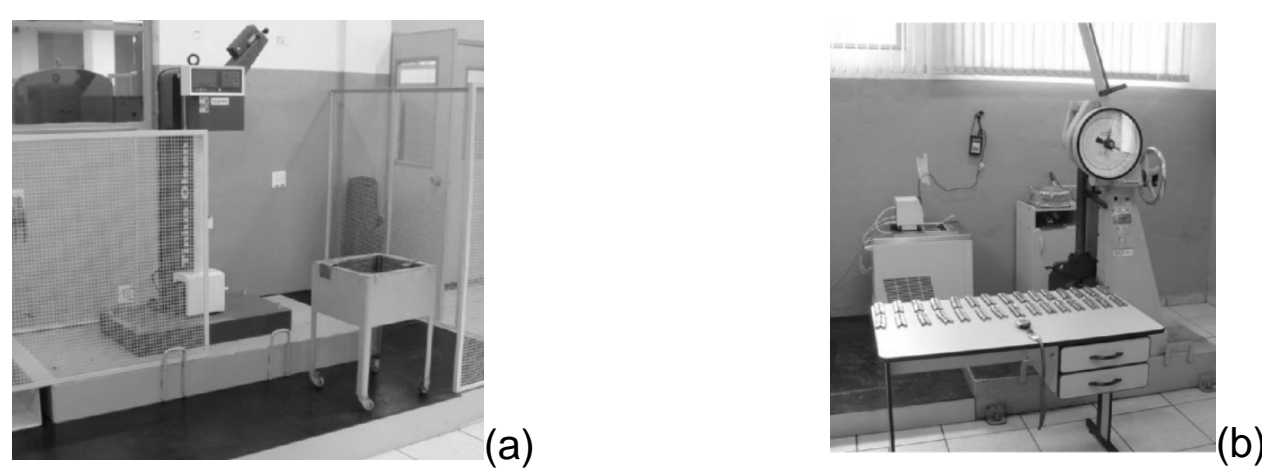

(a)

(b)

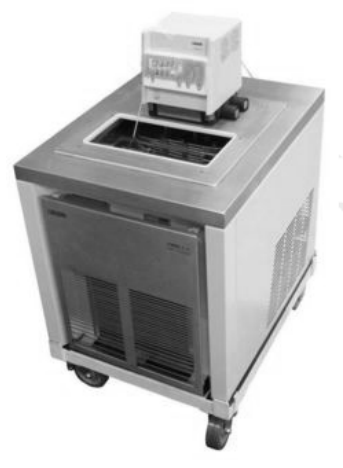

(c)

Figura 24. (a) Equipamento de Impacto Charpy Tinius Olsen IT 406; (b) Equipamento de Impacto Charpy Wolpert Tipo PW 30/15; (c) Refrigerador para corpos de prova Charpy. 
As Figura 25 e Figura 26 apresentam os valores experimentais de energia absorvida em função da temperatura de ensaio para os dois materiais testados. Nesses gráficos os símbolos apresentam as medições experimentais e a linha sólida corresponde à curva de ajuste aos dados de ensaio.

Ambos os materiais apresentaram o comportamento padrão, esperado para aços ferríticos, com queda abrupta da energia absorvida para fraturar com a diminuição da temperatura. Conforme citado em seções anteriores, aços ferríticos apresentam dispersão nos valores de tenacidade à fratura (ou energia absorvida) decorrente das características fenomenológicas do processo de clivagem transgranular no regime de transição dúctil-frágil.

Para o aço A285, Figura 25, foi observada uma grande dispersão dos dados na região de transição, conforme era esperado, ficando esta compreendida no intervalo de temperatura de $-25^{\circ} \mathrm{C}$ a aproximadamente $-10^{\circ} \mathrm{C}$, o limite superior de energia absorvida é de aproximadamente 140 Joules e a $T_{C V N}(28 J)$ é de $-28^{\circ} \mathrm{C}$. Esta temperatura é bastante importante, pois a partir dela será estabelecida a estimativa inicial para os ensaios de tenacidade à fratura para esse material, seguindo o protocolo de ensaio da norma ASTM 1921 [14].

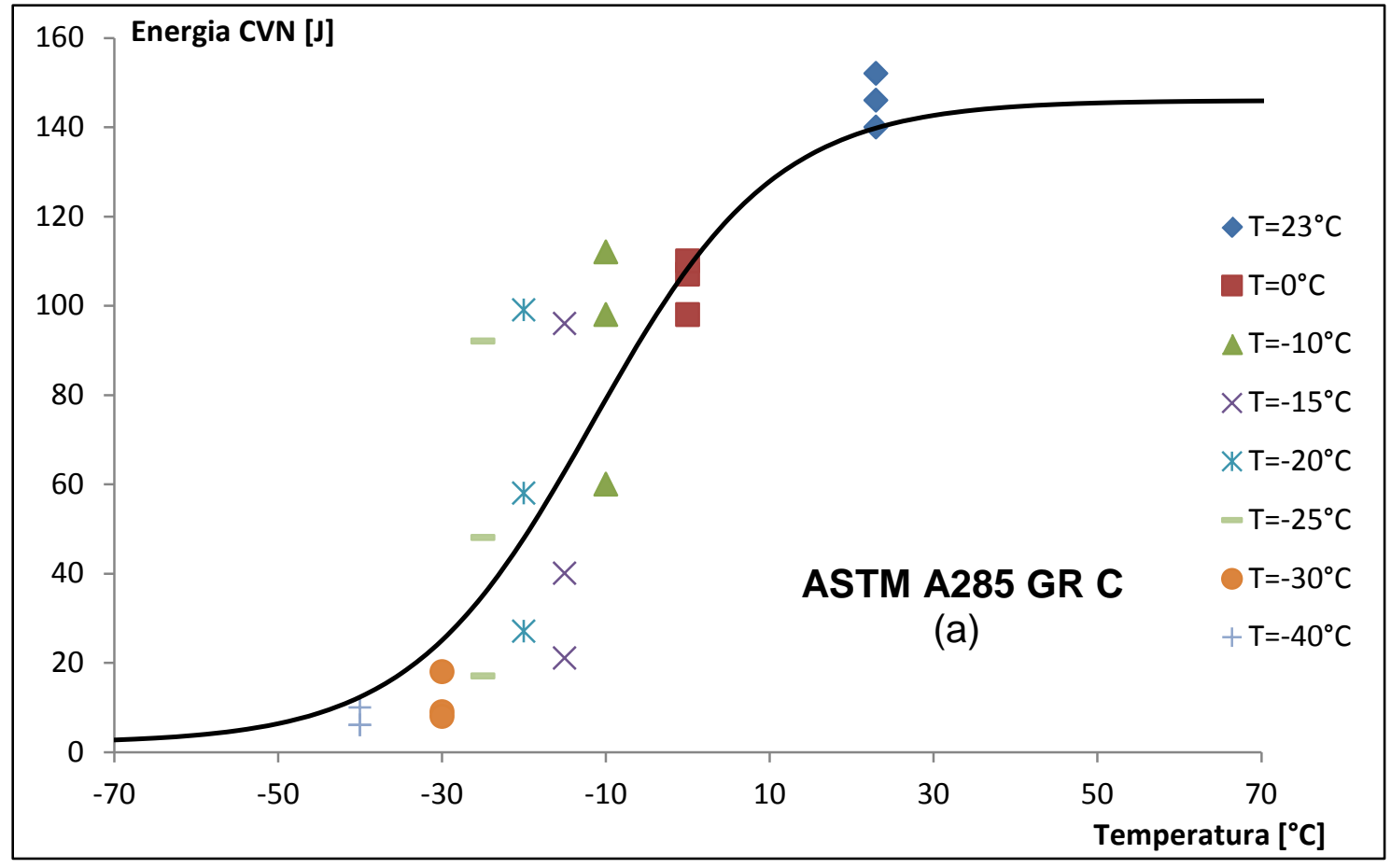

Figura 25. Gráficos com os dados de tenacidade ao impacto (Ensaio Charpy) - ASTM A285 Gr C. 
O aço A515, Figura 26, também sofreu a variação esperada na tenacidade em função da temperatura. Entretanto comparado ao aço A285, este material não mostrou dispersão significativa de energia absorvida na região de transição dúctilfrágil. A curva de ajuste apresentou uma transição mais suave entre as regiões frágil e dúctil indicando que a tenacidade do aço A515 sofre menor influência devido às variações de temperatura. A energia máxima absorvida foi de aproximadamente 80 Joules, sendo este material muito menos tenaz do que o aço A285 e a $T_{C V N}(28 J)$ é de $6^{\circ} \mathrm{C}$.

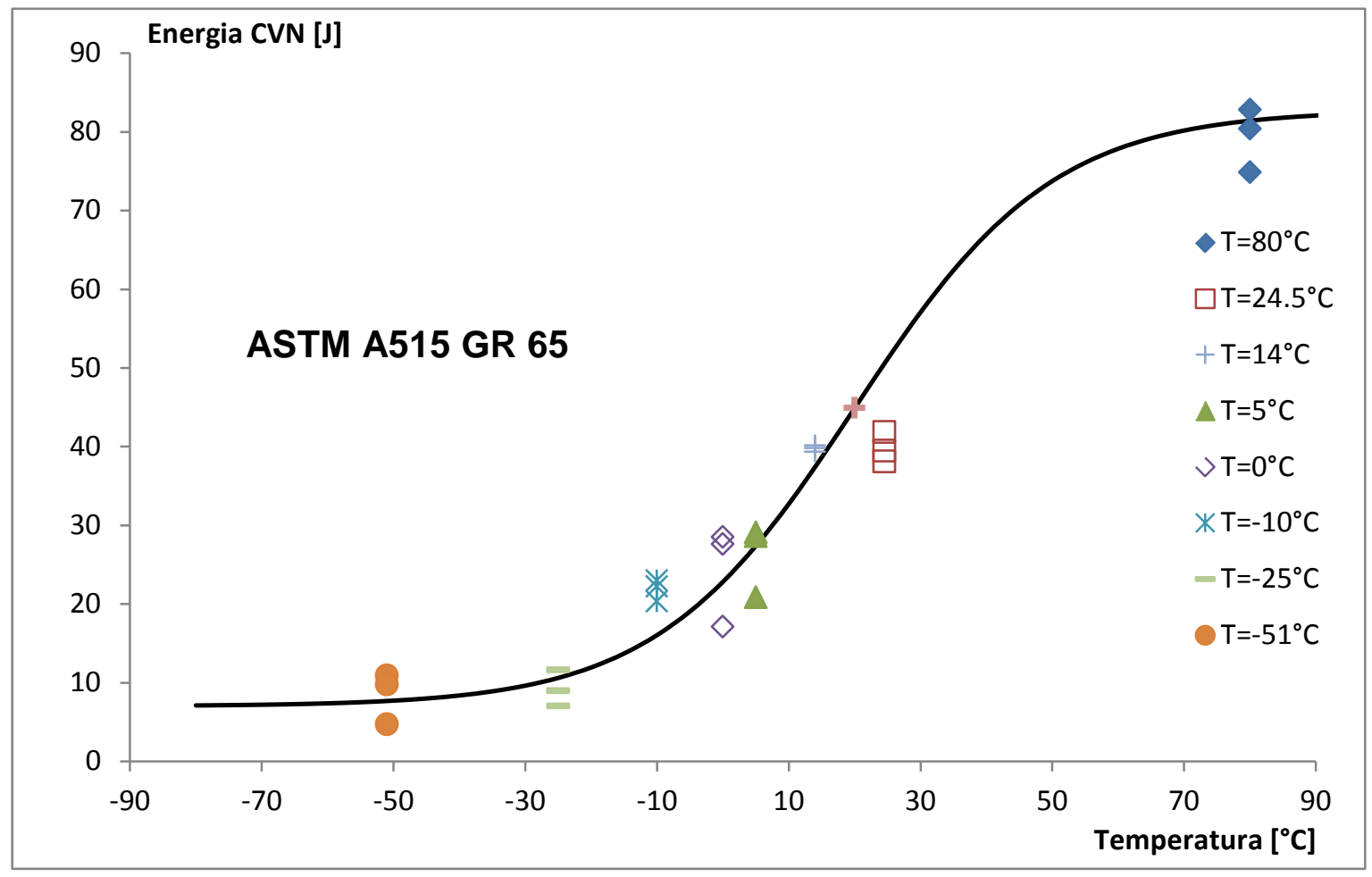

Figura 26. Gráfico com os dados de tenacidade ao impacto (Ensaio Charpy) - ASTM A515 Gr 65.

Uma hipótese para este comportamento aborda a microestrutura do material, particularmente o refino de grão e a quantidade de carbono podem ter forte influência sobre as propriedades de tenacidade à fratura. Curry e Knott [87] mostraram, experimentalmente, que quanto fino for o grão da microestrutura do material maior é a sua tenacidade à fratura. Portanto, isso poderia explicar a baixa tenacidade ao Impacto Charpy para o aço A515, pois pelos requisitos estabelecidos na norma A515/A515M [5] o tamanho de grão da sua microestrutura 
deve ser de 1 a 5 (classificação ASTM), característico de grãos grosseiros. Porém, como não faz parte do escopo deste trabalho, as características microestruturais desses materiais não são abordadas.

A função da curva de ajuste para determinação da região de transição dúctil-frágil utilizada nos gráficos acima foi proposta por Ericksonkirk et al. [89]. A curva é obtida a partir de uma função hiperbólica na forma da equação (60).

$$
E_{\text {Charpy }}=A+B \tanh \left(\frac{T-D}{C}\right)
$$

Os coeficientes desta equação são obtidos de medições no gráfico de Energia Charpy vs. Temperatura, como ilustra o gráfico da Figura 27, e a Tabela 4 apresenta os coeficientes que proporcionaram o melhor ajuste da curva aos dados experimentais de cada um dos materiais ensaiados.

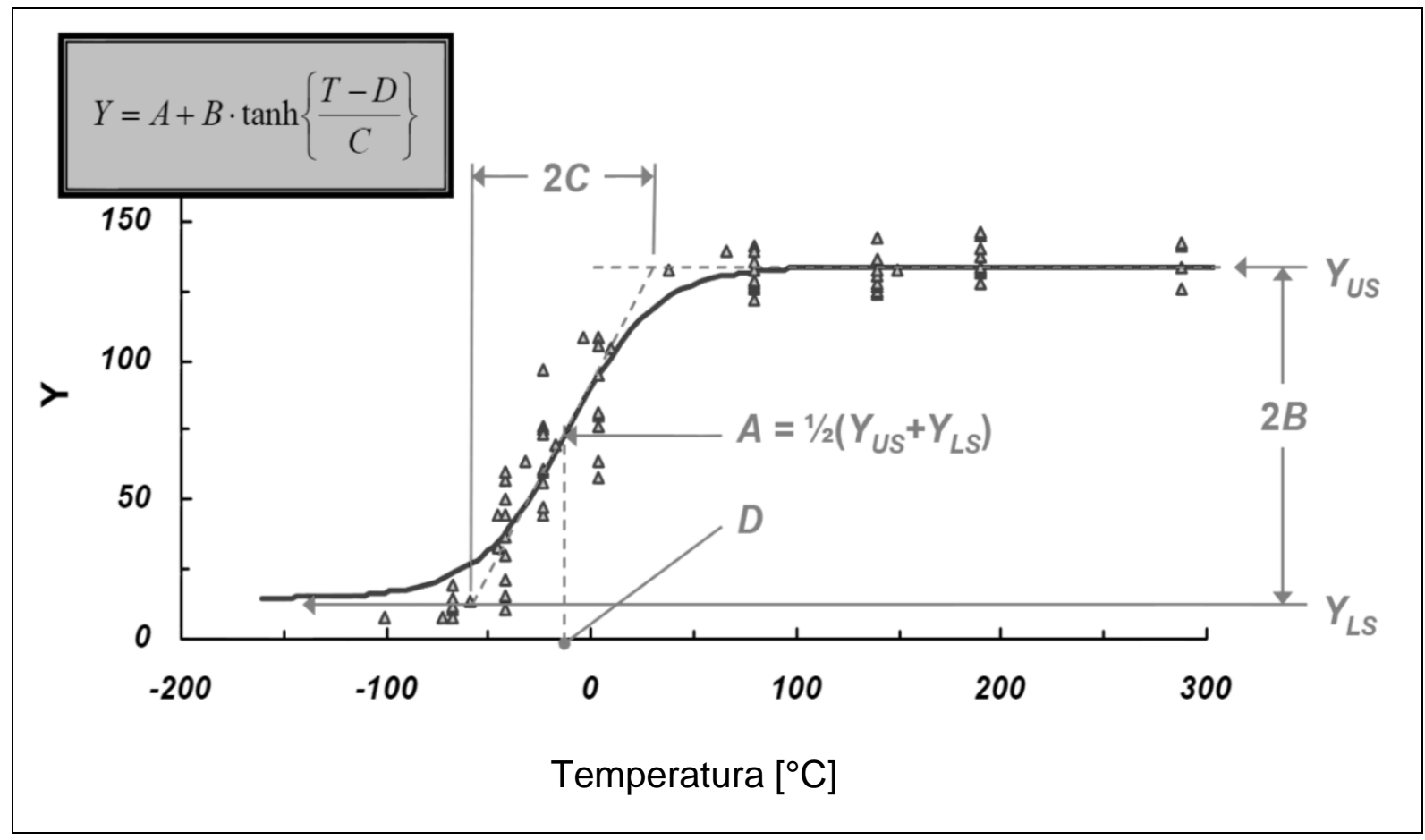

Figura 27. Obtenção dos coeficientes da curva de ajuste para os dados experimentais de tenacidade ao impacto [88]. 
Tabela 4 Coeficientes da equação (60) e $T_{C V N}$

\begin{tabular}{cccccc}
\hline & A & B & D & C & T $_{\text {CVN (28J) }}$ \\
\cline { 2 - 6 } A285 & 74 & 72 & $-11,57$ & 22,25 & $-28^{\circ} \mathrm{C}$ \\
A515 & 44,90 & 37,87 & 20 & 30 & $6^{\circ} \mathrm{C}$ \\
\hline
\end{tabular}

\subsection{Ensaios de Tenacidade à Fratura}

Grande parte do esforço realizado neste trabalho de pesquisa foi dedicado à obtenção da temperatura de referência, $T_{0}$, e à avaliação dos efeitos da geometria dos corpos de prova sobre a tenacidade do material. Foi realizada uma grande quantidade de experimentos na região de transição dúctil-frágil, totalizando 133 ensaios divididos entre os dois materiais já apresentados. As Tabelas 5 e 6 mostram as quantidades de corpos de prova ensaiadas para cada temperatura e sua respectiva geometria.

Tabela 5. Matriz de ensaio de tenacidade à fratura para o aço A285 Gr C

\begin{tabular}{ccccc}
\hline $\begin{array}{c}T_{\text {ensaio }} \\
\left({ }^{\circ} \mathrm{C}\right)\end{array}$ & $\begin{array}{c}a / W=0,5 \\
\text { (un.) }\end{array}$ & $\begin{array}{c}a / W=0,2 \\
\text { (un.) }\end{array}$ & $\begin{array}{c}\text { PCVN } \\
\text { "Plain Side" } \\
\text { (un.) }\end{array}$ & $\begin{array}{c}\text { PCVN } \\
\text { "Side } \\
\text { Grooved" } \\
\text { (un.) }\end{array}$ \\
\hline$-50^{\circ} \mathrm{C}$ & 1 & & & \\
$-60^{\circ} \mathrm{C}$ & 1 & 8 & & \\
$-70^{\circ} \mathrm{C}$ & 1 & & & \\
$-80^{\circ} \mathrm{C}$ & 10 & 6 & 18 & 6 \\
$-105^{\circ} \mathrm{C}$ & & & & 7 \\
\hline
\end{tabular}


Tabela 6. Matriz de ensaio de tenacidade à fratura para o aço A515 Gr 65

\begin{tabular}{ccccc}
\hline $\begin{array}{c}T_{\text {ensaio }} \\
\left({ }^{\circ} \mathrm{C}\right)\end{array}$ & $\begin{array}{c}a / W=0,5 \\
\text { (un.) }\end{array}$ & $\begin{array}{c}a / W=0,15 \\
\text { (un.) }\end{array}$ & $\begin{array}{c}\text { PCVN } \\
\text { "Plain Side" } \\
\text { (un.) }\end{array}$ & $\begin{array}{c}\text { PCVN } \\
\text { "Side } \\
\text { Grooved" } \\
\text { (un.) }\end{array}$ \\
\hline-10 & 11 & 11 & 2 & 6 \\
-20 & 11 & & 13 & \\
-35 & 13 & 3 & 2 & \\
-50 & 1 & & & 6 \\
-60 & 1 & & & \\
-65 & & & & \\
-70 & 1 & & & \\
\hline
\end{tabular}

Os ensaios de tenacidade à fratura seguiram as recomendações da norma ASTM E1921 [14]. Novamente, os corpos de prova foram retirados do centro das chapas em relação à espessura para evitar que as heterogeneidades da superfície das chapas, decorrentes do processo de laminação a quente e do resfriamento acelerado do material nesta região, tivessem influência sobre os resultados dos ensaios.

Seis variações de geometria foram previstas para os corpos de prova ensaiados em flexão três pontos, SE(B):

1. Comprimento adimensional de trinca $a / W=0,5$; seção retangular $\mathrm{e}$ espessura padrão de 25,4 mm ou 1T.

2. Comprimento adimensional de trinca $a / W=0,2$; seção retangular $\mathrm{e}$ espessura padrão de 25,4 mm ou $1 \mathrm{~T}$.

3. Comprimento adimensional de trinca $a / W=0,5$; seção retangular $\mathrm{e}$ espessura de $30 \mathrm{~mm}$.

4. Comprimento adimensional de trinca $a / W=0,15$; seção retangular $\mathrm{e}$ espessura de $30 \mathrm{~mm}$.

5. Comprimento adimensional de trinca $a / W=0,5$; seção quadrada e espessura de 10 mm com superfície livre plana. (Geometria PCVN "Plain Side").

6. Comprimento adimensional de trinca $a / W=0,5$; seção quadrada e espessura de $8 \mathrm{~mm}$ na seção da trinca, com entalhes laterais. (Geometria PCVN "Side Grooved"). 
Para cada material caracterizado, quatro destas geometrias foram adotadas:

- A285 (Geometrias: $1 ; 2 ; 5 ; 6)$

- A515 (Geometrias: 3; 4; 5; 6)

A Figura 28 abaixo mostra esquematicamente as dimensões dos corpos de prova. Para maiores detalhes sobre a geometria do entalhe, acabamento superficial e tolerância geométrica consultar a referência [14].

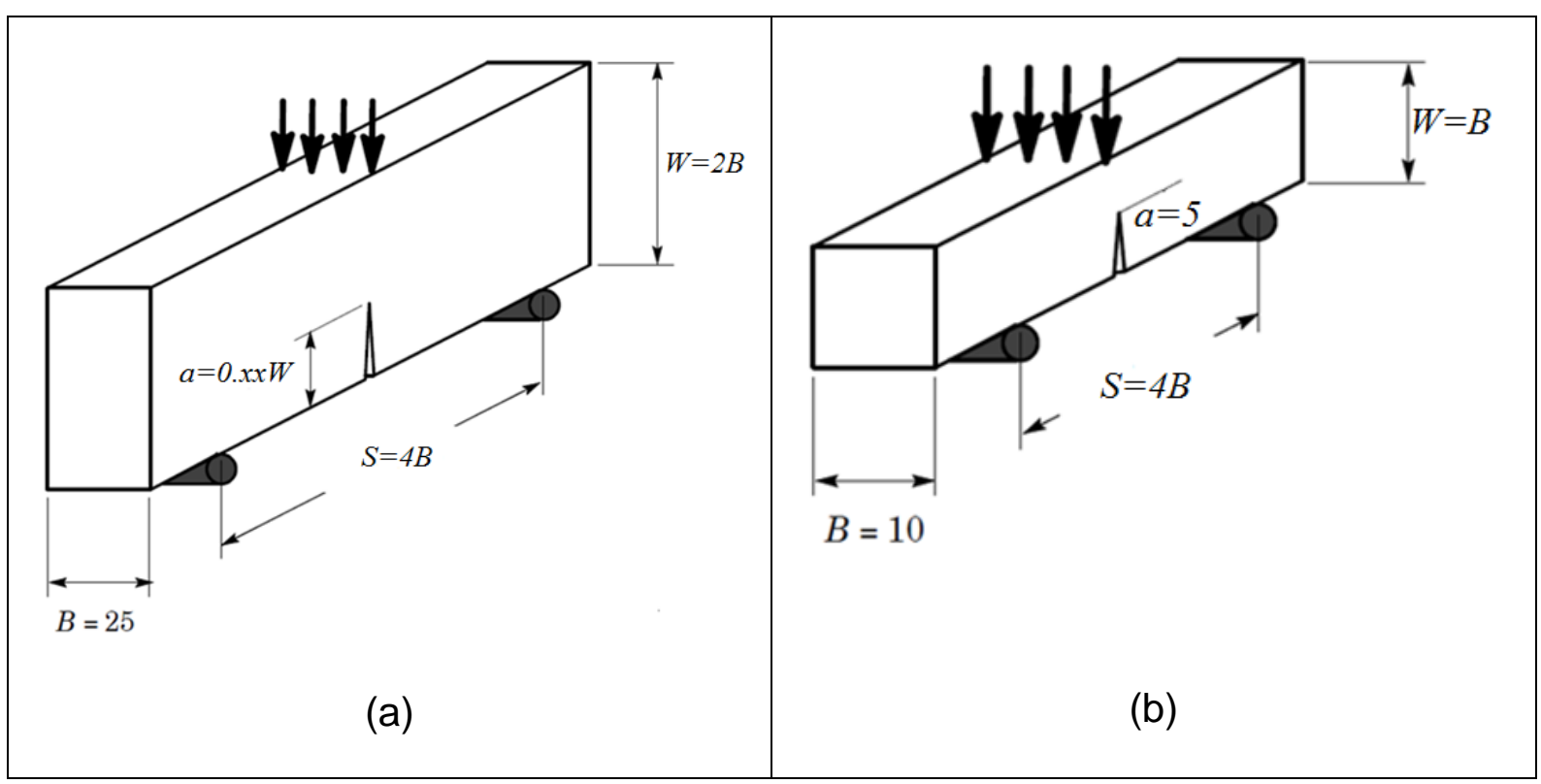

Figura 28. Desenho esquemático com as dimensões geométricas para os espécimes $\mathrm{SE}(\mathrm{B}) 1 \mathrm{~T}$ (a) e PCVN (b). 


\section{EFEITOS GEOMÉTRICOS SOBRE OS VALORES DE TENACIDADE À FRATURA}

Visando avaliar os efeitos geométricos (dimensão de seção, tamanho do entalhe e entalhes laterais) sobre os valores de tenacidade à fratura na região de transição dúctil frágil e posteriormente, a aplicação da metodologia da Curva Mestra para a determinação da temperatura de referência $T_{0}$, uma ampla etapa de ensaios experimentais foi realizada em diversas temperaturas, de acordo com a norma ASTM E1921 [14].

O processo para a determinação correta das temperaturas de ensaio, $T_{\text {ensaio }}$, consumiu grande quantidade de corpos de prova. Porém, essa determinação da temperatura correta, a mais próxima possível da temperatura de referência, $T_{0}$, foi essencial para que as variações de tenacidade decorrentes dos efeitos de geometria combinados com a natureza estatística da clivagem na região TDF ficassem evidentes e pudessem ser observadas e avaliadas.

Nos próximos tópicos serão apresentados e analisados os resultados de toda essa etapa para os dois aços já apresentados, ASTM A285 Gr C e ASTM A515 Gr 65.

\subsection{Aço ASTM A285 Gr C - Ensaios de Tenacidade}

O primeiro material ensaiado foi o aço A285. A estimativa inicial da temperatura de teste seguindo o protocolo recomendado na norma ASTM E1921 [14], foi de $-46^{\circ} \mathrm{C}$ para o corpo de prova com comprimento de trinca $a / W=0,5$. Porém, seguindo-se o roteiro experimental descrito no Anexo $\mathrm{C}$ verificou-se que a $T_{\text {ensaio }}=-80^{\circ} \mathrm{C}$ proporcionava valores de $J_{c}$ para o $\mathrm{SE}(\mathrm{B})-1 \mathrm{~T}, a / W=0,5$, com boa aderência à distribuição teórica de Weibull ( $\alpha=2$ ), equação (19), conforme ilustra o gráfico da Figura 29. Isso foi um bom indicativo de que esta temperatura de ensaio estaria próxima à temperatura de referência, $T_{0}$, do material e grande parte dos ensaios restantes ocorreram nesta temperatura. 


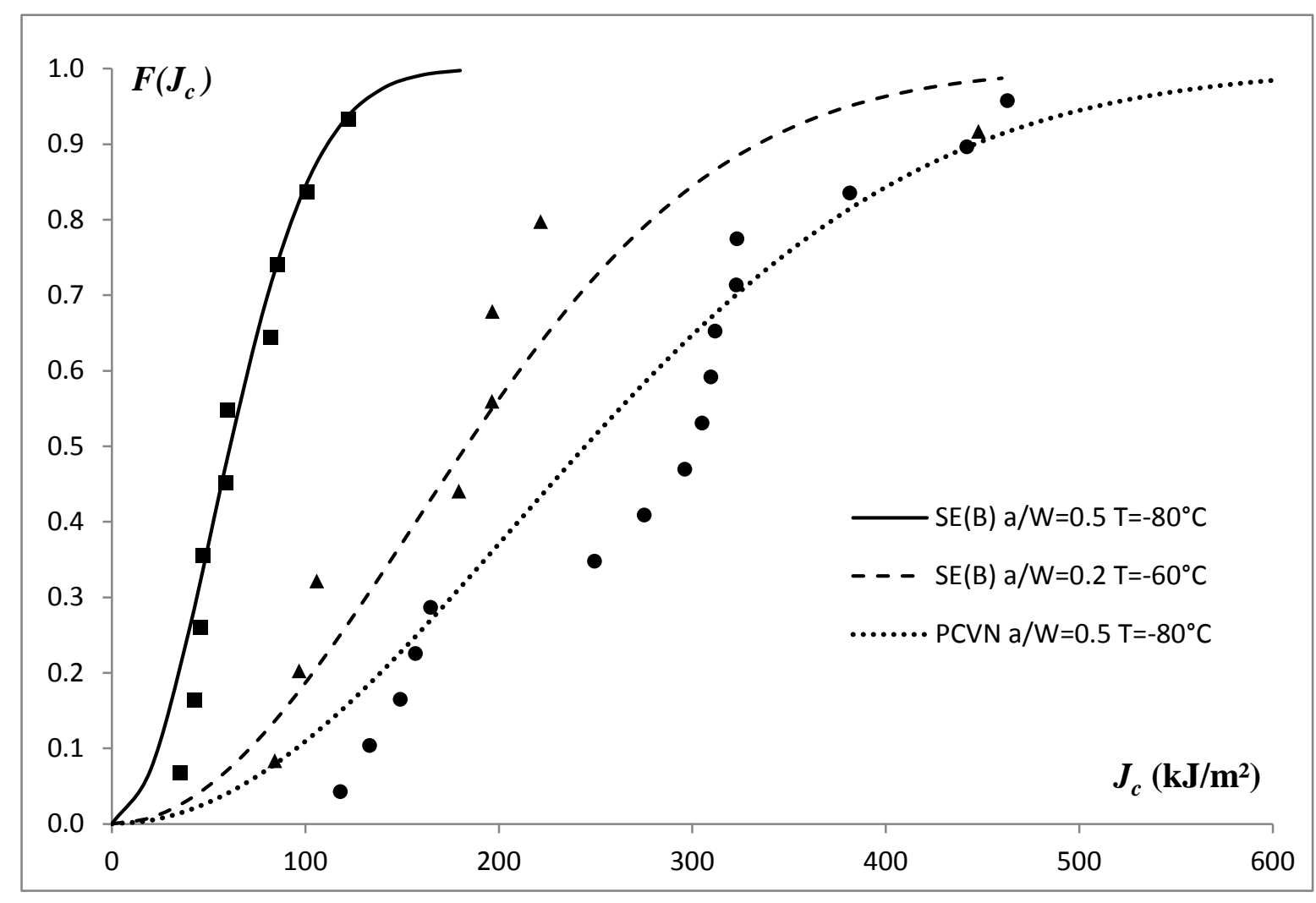

Figura 29. Distribuição dos valores experimentais de tenacidade comparados à distribuição teórica de Weibull com $\alpha=2$ para o aço A285.

Para os corpos de prova com razão de trinca adimensional $a / W=0,2$, repetiu-se a temperatura de $-80^{\circ} \mathrm{C}$. Entretanto, esta temperatura de ensaio revelou-se ser muito baixa uma vez que não foi evidenciado um aumento esperado da tenacidade à fratura, decorrente do relaxamento das tensões na ponta da trinca a baixos níveis de carregamento, causado justamente, pela diminuição do comprimento de trinca.

Portanto, para que os efeitos geométricos sobre a tenacidade do material pudessem ser observados, a temperatura de ensaio foi elevada em vinte graus Celsius, passando a ser $-60^{\circ} \mathrm{C}$. Comparando apenas os valores de tenacidade característica para estes dois comprimentos de trinca, $J_{o}^{a / w=0,5}=77 \mathrm{~kJ} / \mathrm{m}^{2}$ e $J_{o}^{a / w=0,2}=214 \mathrm{~kJ} / \mathrm{m}^{2}$, tem-se a impressão de que um pequeno aumento na temperatura de ensaio impactou fortemente na tenacidade à fratura para os espécimes com trinca rasa $(a / W=0,2)$, pois $J_{o}^{a / w=0,2} / J_{o}^{a / w=0,5}=2,8$.

Entretanto, ao se observar o gráfico da Figura 30, referente aos valores experimentais de $J_{c} v s$. $a / W$, pode-se concluir que o aumento da temperatura de 
ensaio combinado com a diminuição do comprimento de trinca proporcionou 0 aumento dos valores de tenacidade, mas este aumento não foi da magnitude inicialmente obtida na relação dos valores de tenacidade característica, $J_{o}^{a / w=0,2} / J_{o}^{a / w=0,5}$.

Plotando-se cada um dos pontos experimentais, nota-se no gráfico uma pequena dispersão dos resultados próximos aos valores de 100 e 200 kJ/m² e um único ponto com valor de $J_{c}$ superior a $400 \mathrm{~kJ} / \mathrm{m}^{2}$. Esse ponto causou grande elevação na tenacidade característica do material, de tal forma que a análise considerando apenas a relação $J_{o}^{a / w=0,2} / J_{o}^{a / w=0,5}$ poderia levar a uma conclusão errada sobre o real efeito da temperatura e da geometria sobre a tenacidade à fratura do aço A285.

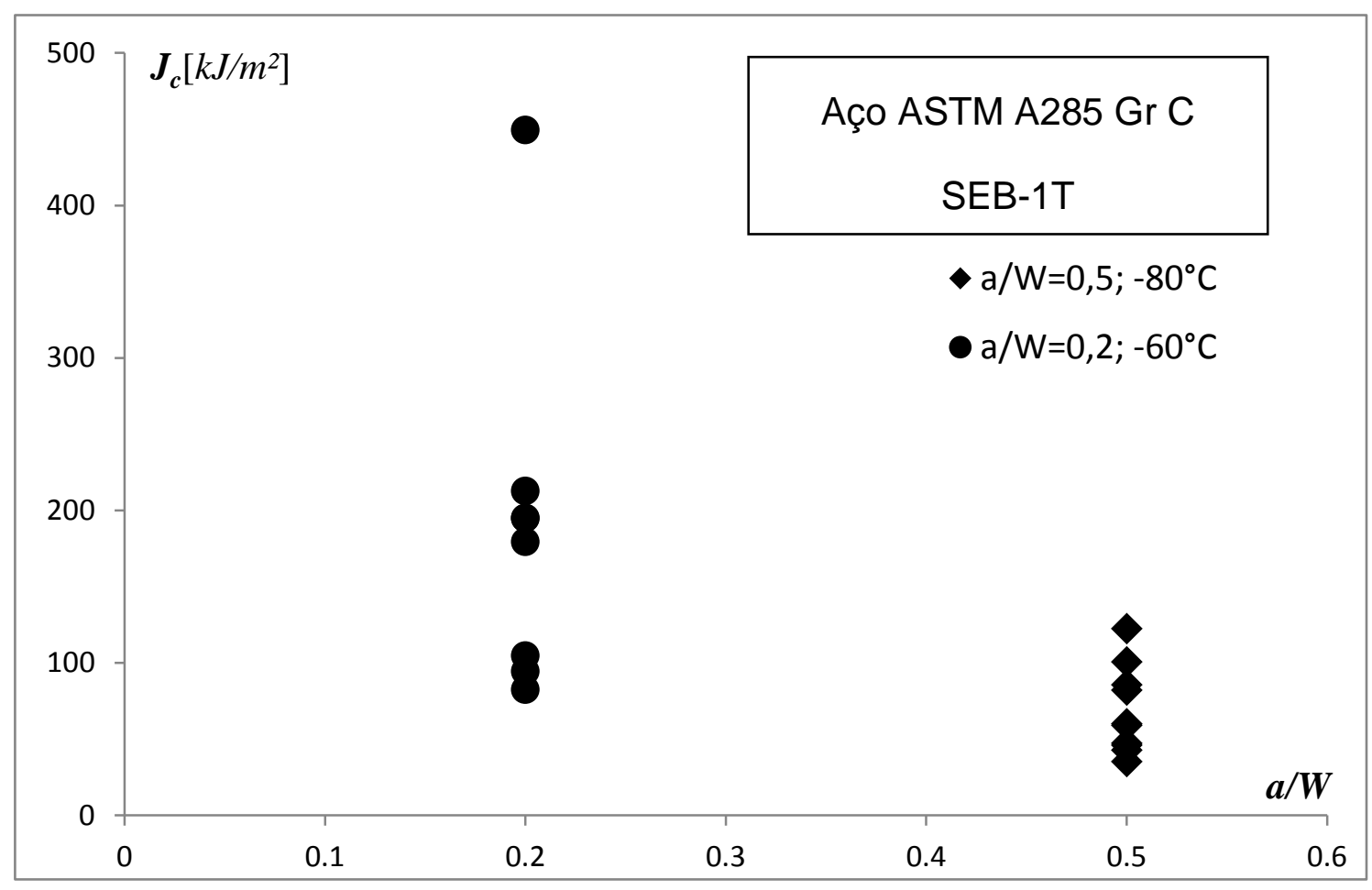

Figura 30. Efeito da variação do comprimento de trinca e da temperatura de ensaio nos valores de tenacidade à fratura, $J_{c}$ para o aço A285 Gr C.

Para os corpos de prova com geometria PCVN-PS, esperava-se um efeito mais acentuado na elevação da tenacidade decorrente da variação geométrica do corpo de prova e por isso a temperatura de $-80^{\circ} \mathrm{C}$ foi repetida. A tenacidade característica 
observada para o PCVN-PS foi aproximadamente 4 vezes maior que a tenacidade característica do corpo de prova $\mathrm{SE}(\mathrm{B}) a / \mathrm{W}=0,5$, sendo esta igual a $J_{o}^{P C V N}=309$ $\mathrm{kJ} / \mathrm{m}^{2}$. As Tabelas 7 e 8 compilam os dados de tenacidade característica e os parâmetros para a distribuição de Weibull biparamétrica para o aço ASTM A285 incluindo todas as geometrias de corpo de prova adotadas na etapa experimental.

Tabela 7 Valores de tenacidade característica para as diferentes configurações geométricas ensaiadas - Aço ASTM A285.

\begin{tabular}{cccccc}
\hline A285 Gr C & $\begin{array}{c}\text { Trinca } \\
\text { Rasa } \\
\left(\mathrm{T}=-60^{\circ} \mathrm{C}\right)\end{array}$ & $\begin{array}{c}\text { Trinca } \\
\text { Profunda } \\
\left(\mathrm{T}=-80^{\circ} \mathrm{C}\right)\end{array}$ & $\begin{array}{c}\text { PCVN } \\
\text { Plain Side } \\
\left(\mathrm{T}=-80^{\circ} \mathrm{C}\right)\end{array}$ & $\begin{array}{c}\text { PCVN } \\
\text { "Side Grooved" } \\
\left(\mathrm{T}=-80^{\circ} \mathrm{C}\right)\end{array}$ & $\begin{array}{c}\text { PCVN } \\
\text { "Side Grooved" } \\
\left(\mathrm{T}=-105^{\circ} \mathrm{C}\right)\end{array}$ \\
\hline$J_{0}\left[\mathrm{~kJ} / \mathrm{m}^{2}\right]$ & 214 & 77 & 309 & 185,5 & 63 \\
\hline
\end{tabular}

Tabela 8 Valores de tenacidade característica para as diferentes configurações geométricas ensaiadas utilizando a estimativa de máxima verossimilhança - Aço ASTM A285.

\begin{tabular}{|c|c|c|c|c|c|}
\hline \multirow{2}{*}{$\begin{array}{l}\text { A285 Gr C } \\
\text { Geometria }\end{array}$} & \multirow[b]{2}{*}{$\begin{array}{c}\text { Temp. } \\
{\left[{ }^{\circ} \mathrm{C}\right]}\end{array}$} & \multicolumn{2}{|c|}{$\begin{array}{c}\text { Estimativa de MV com } \\
\text { Alpha Fixo }\end{array}$} & \multicolumn{2}{|c|}{ Estimativa de MV } \\
\hline & & $\alpha$ & $\begin{array}{c}J_{0} \\
{\left[\mathbf{k J} / \mathbf{m}^{2}\right]}\end{array}$ & $\alpha$ & $\begin{array}{c}J_{0} \\
{\left[\mathbf{k J} / \mathbf{m}^{2}\right]}\end{array}$ \\
\hline $\begin{array}{c}S E(B)-1 T- \\
a / W=0,2\end{array}$ & $-60^{\circ} \mathrm{C}$ & 2 & 218 & 1,9 & 214 \\
\hline $\begin{array}{l}\mathrm{SE}(\mathrm{B})-1 \mathrm{~T}- \\
\mathrm{a} / \mathrm{W}=0,5\end{array}$ & $-80^{\circ} \mathrm{C}$ & 2 & 73 & 2,7 & 77 \\
\hline $\begin{array}{l}\text { PCVN - "Plain } \\
\text { Side" }\end{array}$ & $-80^{\circ} \mathrm{C}$ & 2 & 294 & 2,9 & 309 \\
\hline $\begin{array}{l}\text { PCVN - "Side } \\
\text { Grooved" }\end{array}$ & $-80^{\circ} \mathrm{C}$ & 2 & 174 & 3,6 & 185 \\
\hline $\begin{array}{l}\text { PCVN - "Side } \\
\text { Grooved" }\end{array}$ & $-105^{\circ} \mathrm{C}$ & 2 & 63,0 & 2,0 & 63 \\
\hline
\end{tabular}


O gráfico da Figura 31 apresenta os valores experimentais de $J_{c}$ vs. B (espessura do corpo de prova) para as geometrias PCVN-PS e SE(B) trinca profunda, ambos ensaiados a $-80^{\circ} \mathrm{C}$. É possível observar claramente a grande dispersão nos resultados experimentais e valores, no geral, muito maiores de $J_{c}$ para o corpo de prova PCVN-PS evidenciando uma forte variação nos valores de tenacidade, parte dela decorrente do efeito de geometria do corpo de prova. Estes resultados de $J_{c}$ para o PCVN-PS apesar de esperados merecem atenção, pois por serem muito discrepantes daqueles obtidos com o SE(B)-1T trinca profunda, a uma mesma temperatura, acabam por gerar dúvidas sobre a capacidade do PCVN-PS medir confiavelmente valores de tenacidade à fratura para aplicação da metodologia da Curva Mestra.

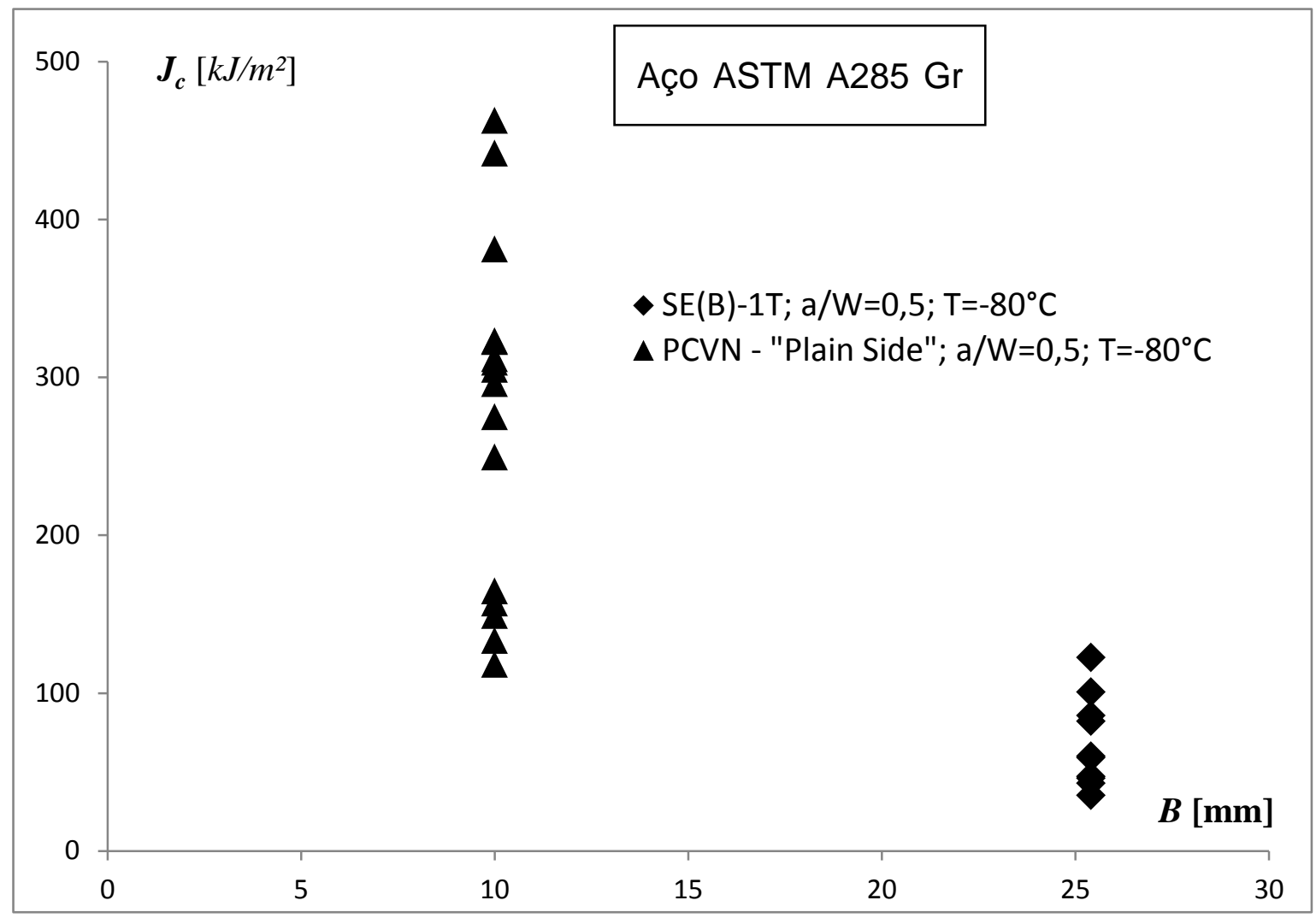

Figura 31. Efeito da variação da espessura nos valores de tenacidade à fratura, $J_{c}$ para 0 aço A285 Gr C.

Os altos valores de $J_{c}$ para o PCVN-PS são um indício do desenvolvimento de plasticidade na ponta da trinca, o que viola a condição SSY e, possivelmente, 
compromete o modo de falha desejado, o qual é precedido da nucleação da trinca seguida da sua propagação. A perda da condição SSY e a alteração do modo de falha devido à elevada plasticidade, violam as condições básicas nas quais a distribuição teórica de Weibull $\operatorname{com} \alpha=2$ descreve a probabilidade de falha do material. Esse comportamento pode ser observado no gráfico da Figura 29 onde os dados experimentais para o PCVN-PS não possuem aderência com a curva teórica de probabilidade de falha.

Portanto a falta de aderência dos dados experimentais com a distribuição teórica de Weibull para o PCVN-PS e a grande discrepância entre os valores de tenacidade crítica deste corpo de prova e o SE(B) trinca profunda, indicam um possível comprometimento da temperatura de referência, $T_{0}$, caso esta seja avaliada por meio de corpos com dimensões reduzidas.

Resultados como os apresentados acima são conhecidos na literatura [89]. No entanto, devido à importância tecnológica que esta geometria de corpo de prova possui, foram realizadas outras etapas de ensaios experimentais para avaliar os efeitos da introdução de entalhes laterais no corpo de prova. O objetivo deste procedimento é obter resultados de tenacidade à fratura adequados à avaliação do fenômeno de fratura frágil por clivagem transgranular na região de TDF e, consequentemente, permitir a sua aplicação na metodologia da Curva Mestra.

Algumas configurações de entalhes laterais foram analisadas computacionalmente (ver Anexo D) e a geometria com $10 \%$ de profundidade da espessura por lado, ângulo de abertura de $45^{\circ}$ e raio de ponta de $0,5 \mathrm{~mm}$ foi definida como sendo a mais promissora para a obtenção de resultados de tenacidade à fratura válidos. Maiores detalhes das implicações geométrica sobre a tenacidade serão expostos na Seção 5. Os resultados de $J_{c}$ vs. $B$ (espessura do corpo de prova) e das distribuições acumuladas de falha para as análises experimentais a diferentes temperaturas de teste com essa configuração de entalhe estão nos gráficos das Figuras 32 e 33 . 


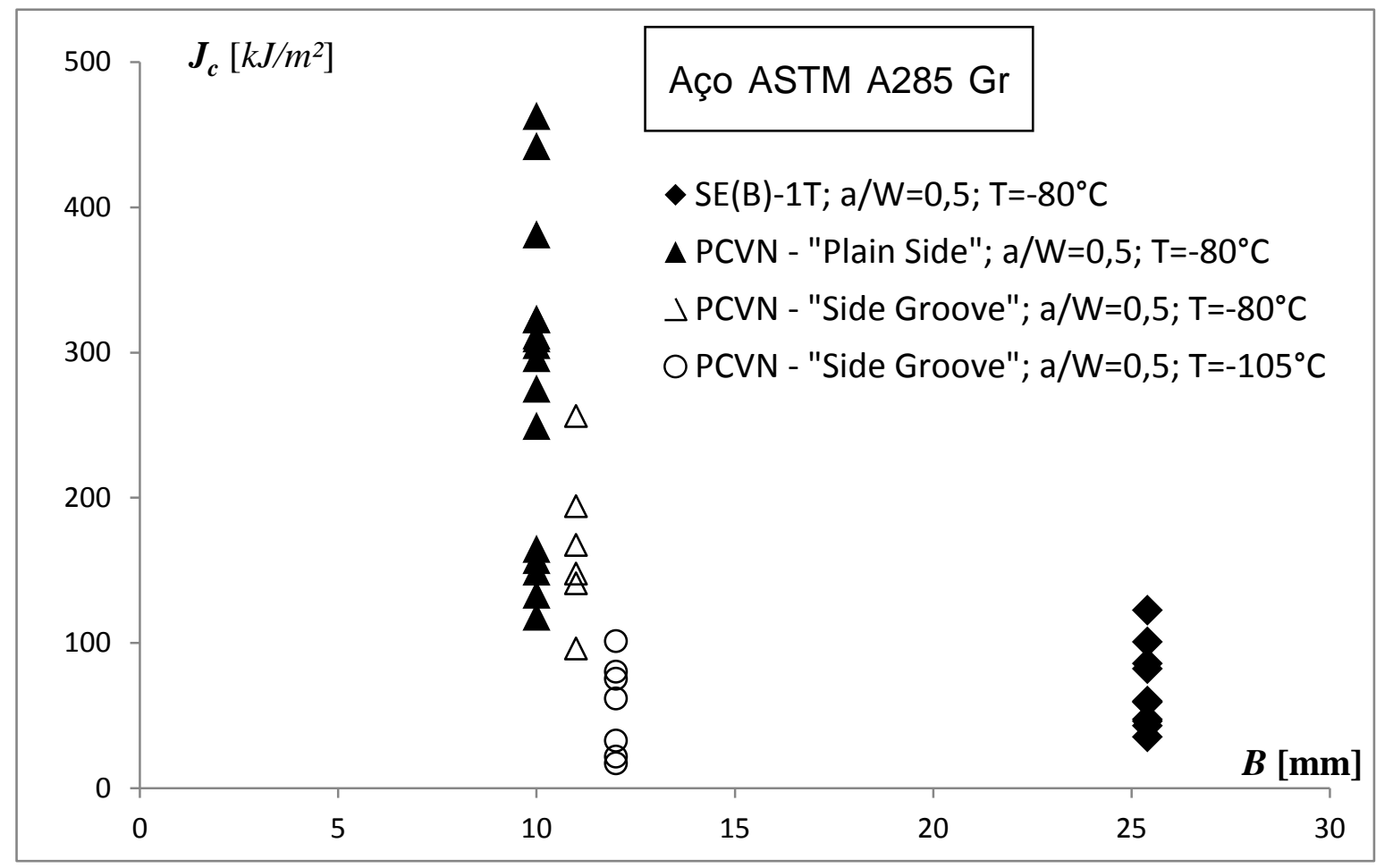

Figura 32. Efeito dos entalhes laterais e da temperatura de ensaio nos valores de tenacidade à fratura, $J_{c}$ para o aço A285 Gr C.

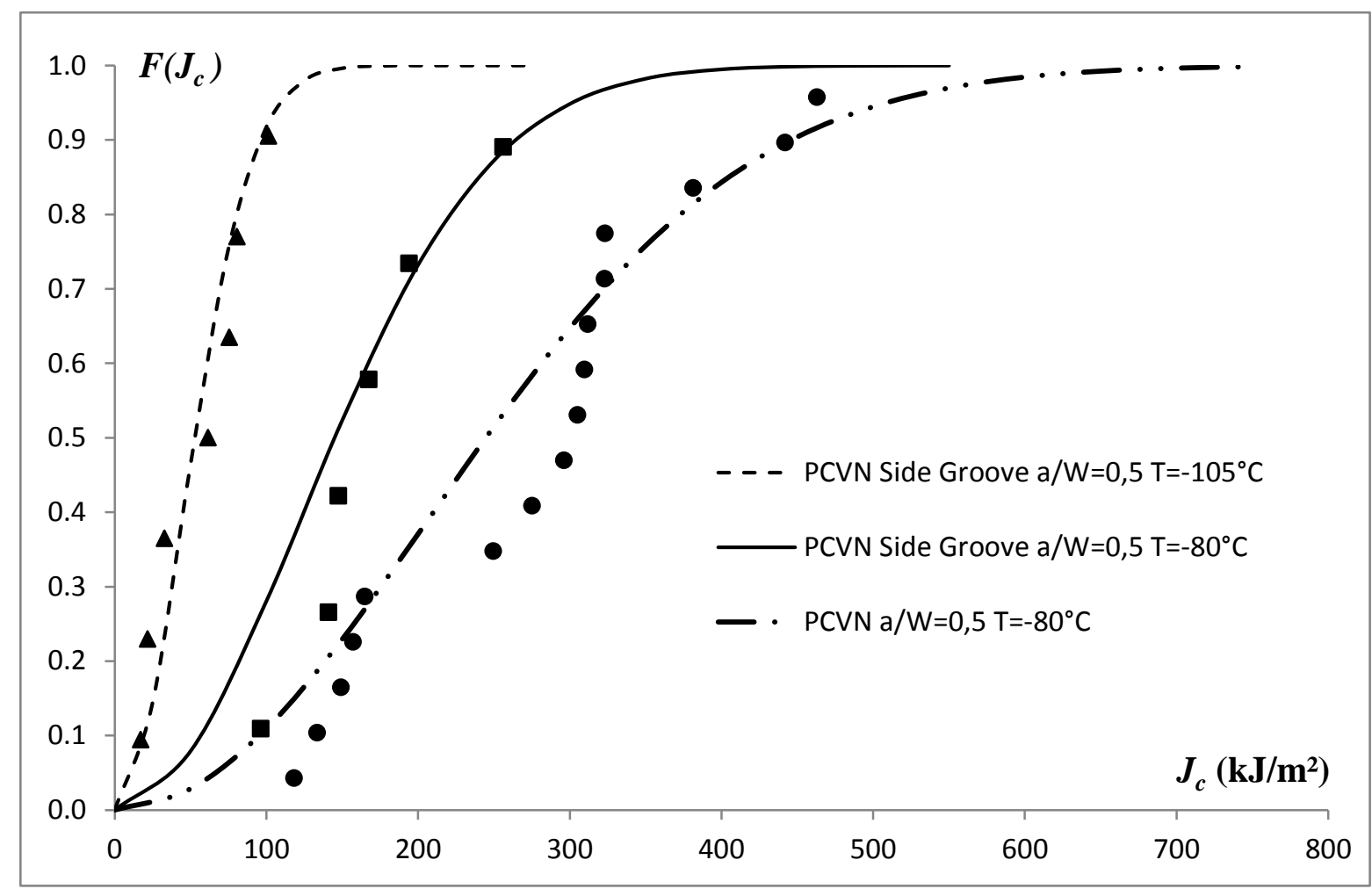

Figura 33. Distribuição dos valores experimentais de tenacidade para os espécimes com geometria PCVN comparados à distribuição teórica de Weibull com $\alpha=2$ para o aço A285. 
Com o intuito inicial de avaliar somente o efeito do entalhe lateral sobre os valores de tenacidade à fratura a temperatura de ensaio foi mantida em $-80^{\circ} \mathrm{C}$. A partir da análise do gráfico da Figura 32, observa-se que os entalhes laterais resultaram no abaixamento dos valores de tenacidade e também reduziram o tamanho da dispersão entre os pontos. Tomando como referência à configuração padrão de PCVN, introdução dos entalhes laterais promoveu uma redução de aproximadamente $40 \%$ na tenacidade aparente, $J_{o}^{P C V N_{-} S G ; T_{\text {ensaio }}=-80^{\circ} \mathrm{C}} / J_{o}^{a / w=0,5}=$ 2,4 , entretanto os valores de $J_{C}$ obtidos à $-80^{\circ} \mathrm{C}$ ainda são altos.

Porém, analisando o gráfico da Figura 33 nota-se que há uma melhoria na aderência dos valores experimentais de $J_{c}$ à curva de distribuição teórica de Weibull, $(\alpha=2)$, principalmente na porção superior da curva (linha contínua, símbolo quadrado). Portanto para um mesmo tamanho de trinca e temperatura, os entalhes laterais promoveram, simultaneamente, diminuição da tenacidade, redução da dispersão e melhor ajuste à curva de distribuição de probabilidade teórica de Weibull.

Como último recurso para aproximar os valores experimentais de $J_{c}$ à curva de distribuição teórica de Weibull e, ao mesmo tempo, diminuir a média dos valores de tenacidade à fratura, optou-se por abaixar a temperatura de ensaio para $-105^{\circ} \mathrm{C}$. Os efeitos da redução em $25^{\circ} \mathrm{C}$ na temperatura de ensaio sobre a tenacidade à fratura ficam evidentes nos gráficos das Figuras 32 e 33 . Os pontos experimentais dispostos nos gráficos (triângulos) indicam uma diminuição significativa tanto dos valores de tenacidade quanto na dispersão dos mesmos, comparativamente temos: $J_{o}^{P C V N-S G-T_{\text {ensaio }}=-105^{\circ} \mathrm{C}} / J_{o}^{a / w=0,5}=0,8$ vs. $J_{o}^{P C V N_{-} S G ; T_{\text {ensaio }}=-80^{\circ} \mathrm{C}} / J_{o}^{a / w=0,5}=2,4$.

A redução na relação $J_{o}^{P C V N}-S G-T_{\text {ensaio }}=-105^{\circ} \mathrm{C} / J_{o}^{a / w=0,5}$ para valores inferiores a 1 é um ponto de atenção, pois pode indicar uma condição onde as hipóteses básicas adotadas para tratar o fenômeno da fratura frágil por clivagem na região TDF são violadas. A baixa temperatura estaria reduzindo a tenacidade da matriz ferrítica a níveis similares aos dos defeitos (carbonetos, compostos intermetálicos, etc.). Dessa forma a fratura passaria então a ser governada apenas por propagação, eliminando as características estatísticas do fenômeno e, portanto este não mais estaria ocorrendo na região de transição dúctil frágil, mas sim na região do patamar inferior de tenacidade e região onde as equações para a determinação da Curva Mestra tendem a ser imprecisas [71]. 
Entretanto, mesmo à temperatura de $-105^{\circ} \mathrm{C}$, os dados de tenacidade apresentam dispersão e o tratamento estatístico ainda é aplicável. No gráfico da Figura 34 as distribuições estatísticas para as geometrias com entalhe lateral e suas respectivas curvas teóricas são comparadas à geometria SE(B)-1T. Observa-se que os resultados do PCVN-SG ensaiados a $-105^{\circ} \mathrm{C}$ mostram uma boa aderência com a sua curva teórica $(\alpha=2)$ e com os valores experimentais obtidos com corpos de prova padrão, SE(B)-1T.

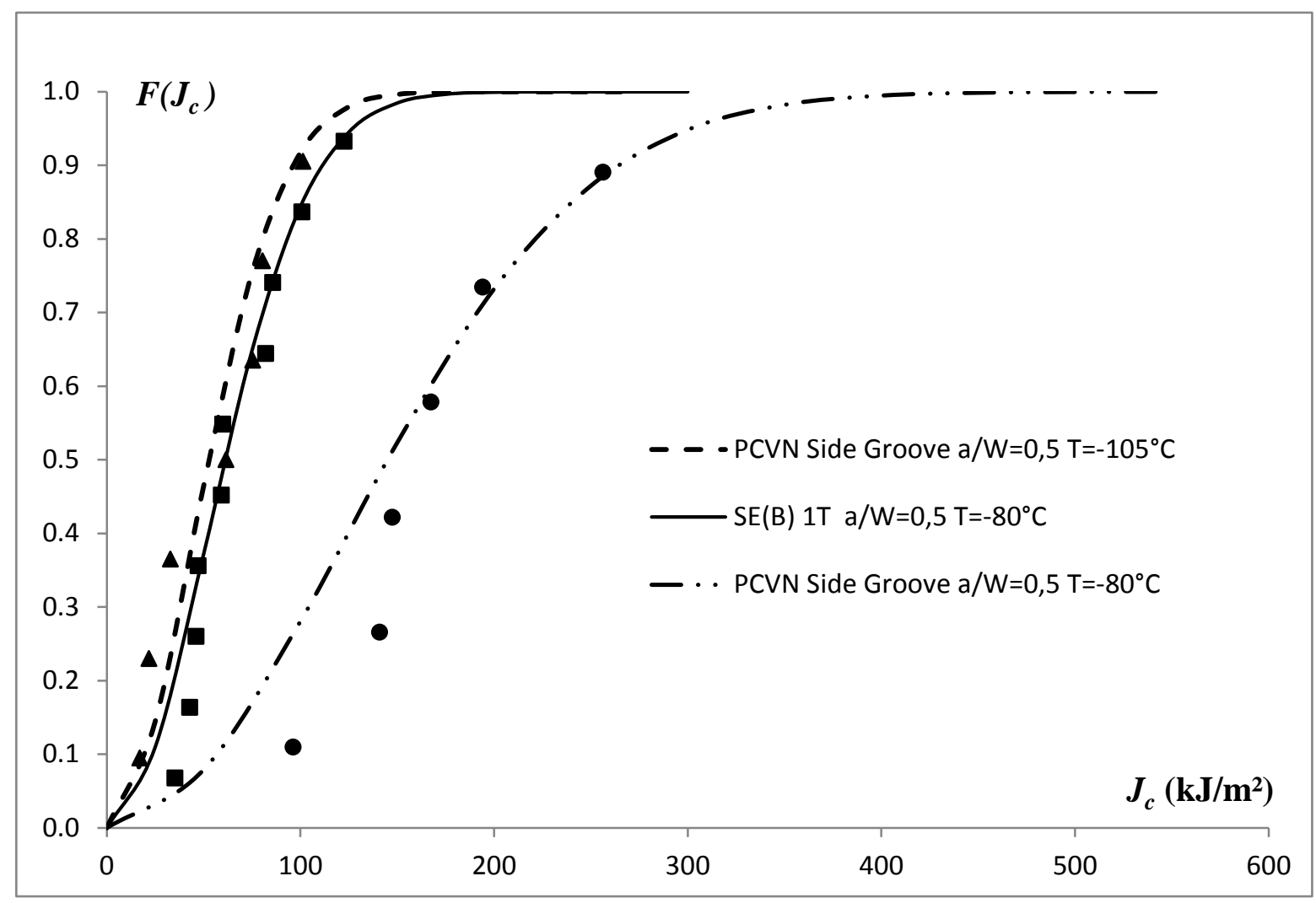

Figura 34. Distribuição dos valores experimentais de tenacidade para o espécime SE(B)-1T, trinca profunda utilizado como referência. e espécimes PCVN com entalhes laterais comparados à distribuição teórica de Weibull com $\alpha=2$ para o aço A285.

Finalmente, na Tabela 9 são mostrados os valores críticos de tenacidade $\left(J_{c}\right)$ e comprimento inicial de trinca $\left(a_{0}\right)$ para cada um dos ensaios de tenacidade realizados com o aço A285 e suas respectivas temperaturas de ensaio. Por motivo de rastreabilidade, a coluna referente à identificação do espécime (" $\mathrm{N}^{\circ}$ do CP") possui os números que estão gravados nas frentes de trinca, permitindo desta maneira a identificação e correlação futura do valor calculado de tenacidade com a respectiva superfície de fratura. 
Tabela 9 Valores de tenacidade, $J_{c}$, obtidos nos ensaios à baixa temperatura, comprimentos de trinca, $a_{0}$ e limite de deformação plástica. Aço A285 Gr C.

\begin{tabular}{|c|c|c|c|c|c|c|c|c|c|c|}
\hline \multirow[b]{2}{*}{ Geometria } & \multirow[b]{2}{*}{$\begin{array}{c}\mathrm{N}^{\circ} \\
\text { do } \mathrm{CP}\end{array}$} & \multicolumn{3}{|c|}{$-60^{\circ} \mathrm{C}$} & \multicolumn{3}{|c|}{$-80^{\circ} \mathrm{C}$} & \multicolumn{3}{|c|}{$-105^{\circ} \mathrm{C}$} \\
\hline & & $\begin{array}{c}J_{c} \\
{\left[k J / m^{2}\right]}\end{array}$ & $\begin{array}{c}a_{0} \\
{[m m]}\end{array}$ & $M$ & $\begin{array}{c}J_{c} \\
{\left[k J / m^{2}\right]}\end{array}$ & $\begin{array}{c}a_{0} \\
{[m m]}\end{array}$ & $M$ & $\begin{array}{c}J_{c} \\
{\left[k J / m^{2}\right]}\end{array}$ & $\begin{array}{c}a_{0} \\
{[m m]}\end{array}$ & $M$ \\
\hline & 7 & 82,44 & 9,1 & 154 & & & & & & \\
\hline & 8 & 449,39 & 9,7 & 28 & & & & & & \\
\hline & 9 & 194,94 & 9,2 & 65 & & & & & & \\
\hline SE(B) & 10 & 104,76 & 9,4 & 120 & & & & & & \\
\hline$a / W=0,2$ & 11 & 212,52 & 9,8 & 59 & & & & & & \\
\hline & 12 & 179,29 & 9,6 & 70 & & & & & & \\
\hline & 13 & 94,38 & 8,9 & 135 & & & & & & \\
\hline & 14 & 194,82 & 9,3 & 65 & & & & & & \\
\hline
\end{tabular}

\begin{tabular}{ccccc} 
& 4 & 42,92 & 24,4 & 209 \\
& 5 & 59,97 & 25,9 & 141 \\
& 6 & 100,79 & 26,7 & 81 \\
$\mathbf{S E}(\mathbf{B})$ & 7 & 85,74 & 26,5 & 96 \\
$\boldsymbol{a} / \mathbf{W}=\mathbf{0 , 5}$ & 8 & 47,22 & 25,8 & 179 \\
& 9 & 122,56 & 26,8 & 66 \\
& 10 & 46,05 & 27,3 & 173 \\
& 11 & 82,15 & 26,3 & 101 \\
& 12 & 59,13 & 25,8 & 143 \\
& 13 & 35,21 & 26,5 & 234 \\
\hline
\end{tabular}

\begin{tabular}{ccccc} 
& 3 & 309,70 & 5,5 & 5 \\
& 4 & 462,91 & 5,4 & 3 \\
& 5 & 441,99 & 5,3 & 4 \\
& 6 & 118,21 & 5,2 & 14 \\
& 7 & 305,17 & 5,1 & 5 \\
PCVN & 8 & 275,20 & 5,3 & 6 \\
Plain Side & 10 & 133,38 & 5,3 & 12 \\
& 11 & 323,21 & 5,2 & 5 \\
& 12 & 322,81 & 5,3 & 5 \\
& 13 & 311,88 & 5,2 & 5 \\
\hline "Side & 14 & 149,20 & 5,6 & 10 \\
Grooved" & 1 & 381,41 & 5,3 & 4 \\
\hline
\end{tabular}




\begin{tabular}{|c|c|c|c|c|c|c|c|}
\hline & 3 & 147,52 & 5,0 & \multicolumn{4}{|c|}{12} \\
\hline & 4 & 194,14 & 5,0 & \multicolumn{4}{|l|}{9} \\
\hline & 5 & 167,42 & 4,8 & \multicolumn{4}{|c|}{10} \\
\hline & 7 & 256,14 & 4,6 & \multicolumn{4}{|l|}{7} \\
\hline \multirow{7}{*}{$\begin{array}{c}\text { PCVN } \\
\text { "Side } \\
\text { Grooved" }\end{array}$} & 9 & & & & 17,1 & 5,0 & 117 \\
\hline & 10 & & & & 32,84 & 5,2 & 59 \\
\hline & 11 & & & & 75,42 & 4,9 & 27 \\
\hline & 12 & & & & 101,26 & 5,0 & 20 \\
\hline & 13 & & & & 21,75 & 4,9 & 95 \\
\hline & 14 & & & & 61,58 & 5,0 & 33 \\
\hline & 15 & & & & 80,21 & 5,0 & 25 \\
\hline
\end{tabular}

\subsection{Aço ASTM A285 Gr C - Superfícies de Fratura}

Apesar do distanciamento dos pontos experimentais, em relação à distribuição teórica, obtidos com espécimes $\mathrm{SE}(\mathrm{B})$ trinca rasa e PCVN indicarem 0 desenvolvimento de plasticidade excessiva na região do defeito, nas análises das frentes de trinca dos três tipos de corpos de prova não foi observado crescimento subcrítico da trinca e visualmente constata-se que a falha se deu por clivagem devido ao aspecto brilhante da superfície de fratura, característico deste modo de falha.

Apesar da norma ASTM E1921 recomendar apenas a análise visual da superfície fraturada, sem o auxílio de equipamentos de aumento, foram feitas também macro e micrografias com estéreo microscópio e análise por MEV (microscopia eletrônica de varredura) respectivamente, com o objetivo de verificar indícios de crescimento estável da trinca, indicando assim a perda da condição SSY e possíveis alterações no modo de falha por clivagem. A Figura 35 ilustra o padrão encontrado nas frentes de trinca para corpos de prova com relação $a / W=0,5$ que tiveram valores de $J_{c}$ mais próximos ao valor de $J_{0}$. 


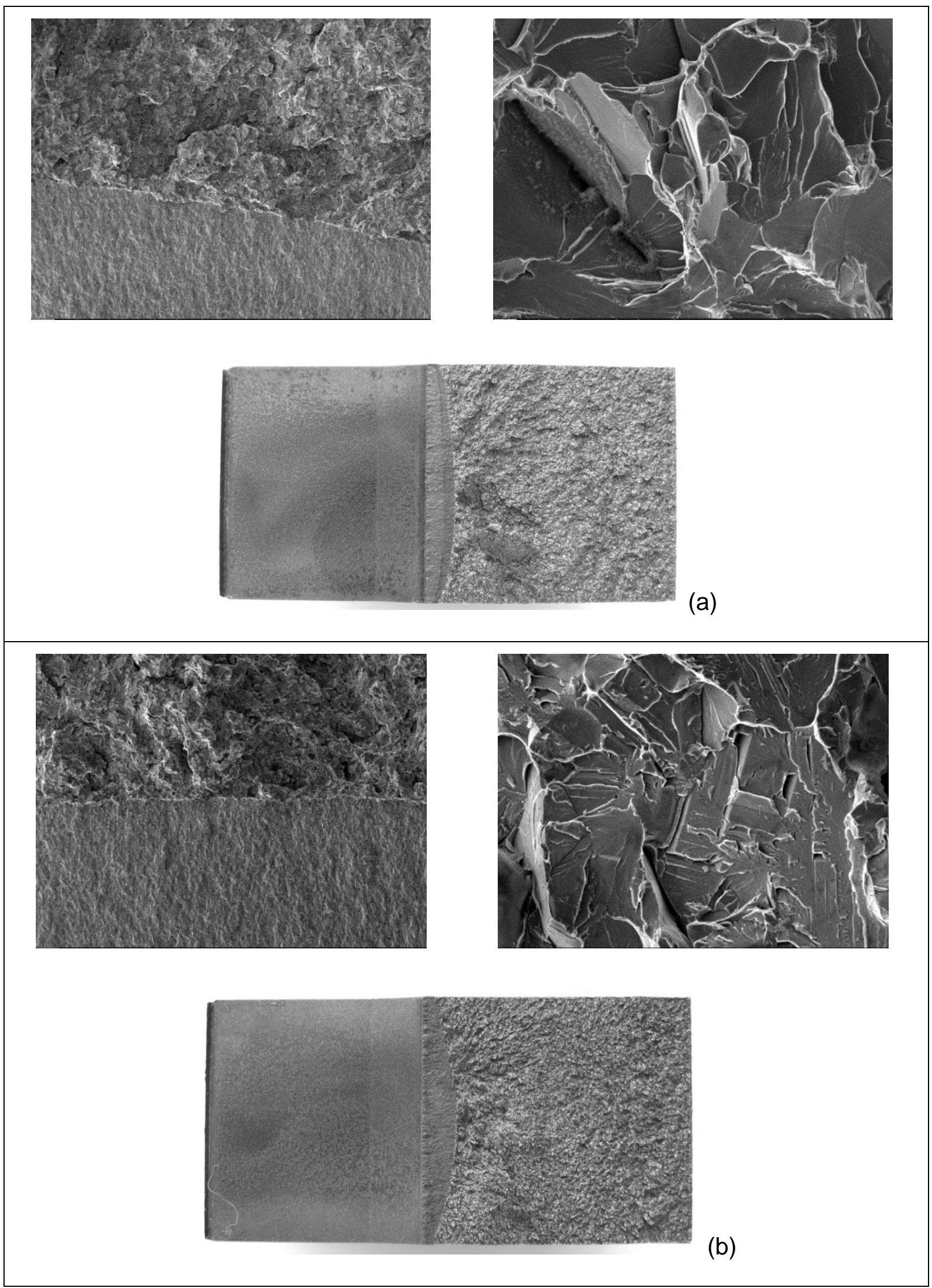

Figura 35. Micro e macrografias para os corpos de prova de aço ASTM A285 GR C; (a) CP05; (b) CP12. Os aumentos nas micrografias são de 50x e 1500x, respectivamente. 
Nota-se claramente o padrão característico da clivagem transgranular na superfície de fratura desses corpos de prova. Infelizmente não foi possível a realização de análises por MEV para os corpos de prova de menor restrição plástica (SE(B) $a / W=$ 0,2 e PCVN), porém as macrografias destes corpos de prova mantém o padrão das imagens da Figura 36, onde também não se observam indícios de propagação estável da trinca.

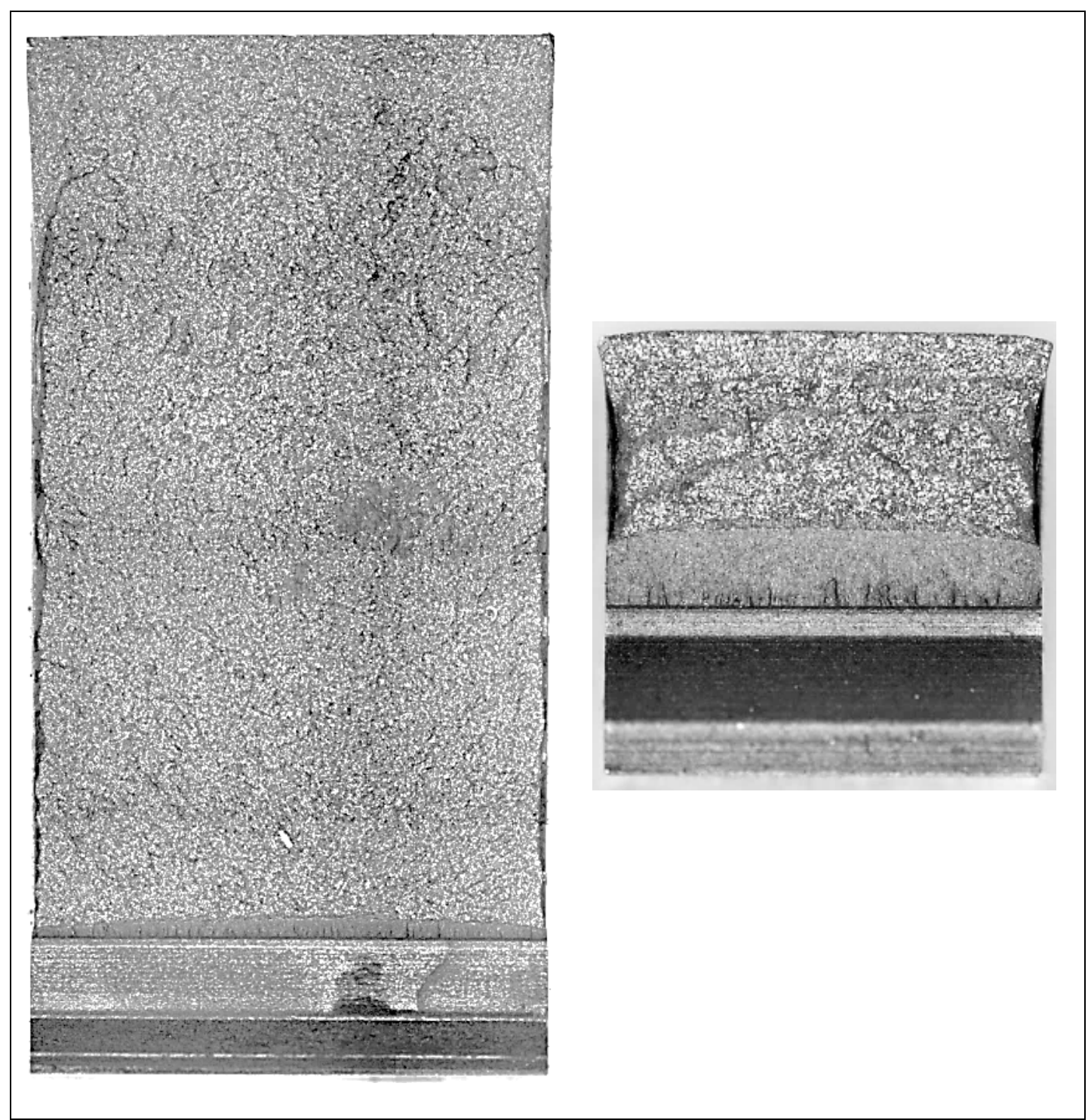

Figura 36. Padrão das macrografias obtidas de corpos de prova com trinca rasa e geometria PCVN (aumento de 10X). 


\subsection{Aço ASTM A515 Gr 65 - Ensaios de Tenacidade}

O segundo material avaliado foi o aço A515. A geometria dos espécimes maiores diferiu ligeiramente da geometria utilizada para o aço A285, sendo neste caso um pouco mais espessa, $30 \mathrm{~mm}$ de espessura, e para o $\mathrm{SE}(\mathrm{B})$ trinca rasa a relação $a / W$ utilizada foi de 0,15 .

A determinação das temperaturas de ensaio para o A515 exigiu 28 corpos de prova de um total de 63. Por não apresentar claramente a dispersão característica nos valores de tenacidade, esperada para a região de TDF com a variação da temperatura, o processo exigiu muitas iterações, reduzindo o conjunto aproveitável de dados para a determinação da temperatura de referência, $T_{0}$.

No gráfico da Figura 37 é possível observar o pequeno distanciamento entre os valores de tenacidade obtidos com as diferentes geometrias de corpos de prova. As tenacidades características não sofreram grandes variações e a maior diferença de tenacidade é observada entre o $\mathrm{SE}(\mathrm{B})$ trinca profunda e o $\mathrm{SE}(\mathrm{B})$ trinca rasa, $J_{o}^{a / w=0,15} / J_{o}^{a / w=0,5}=1,7$.

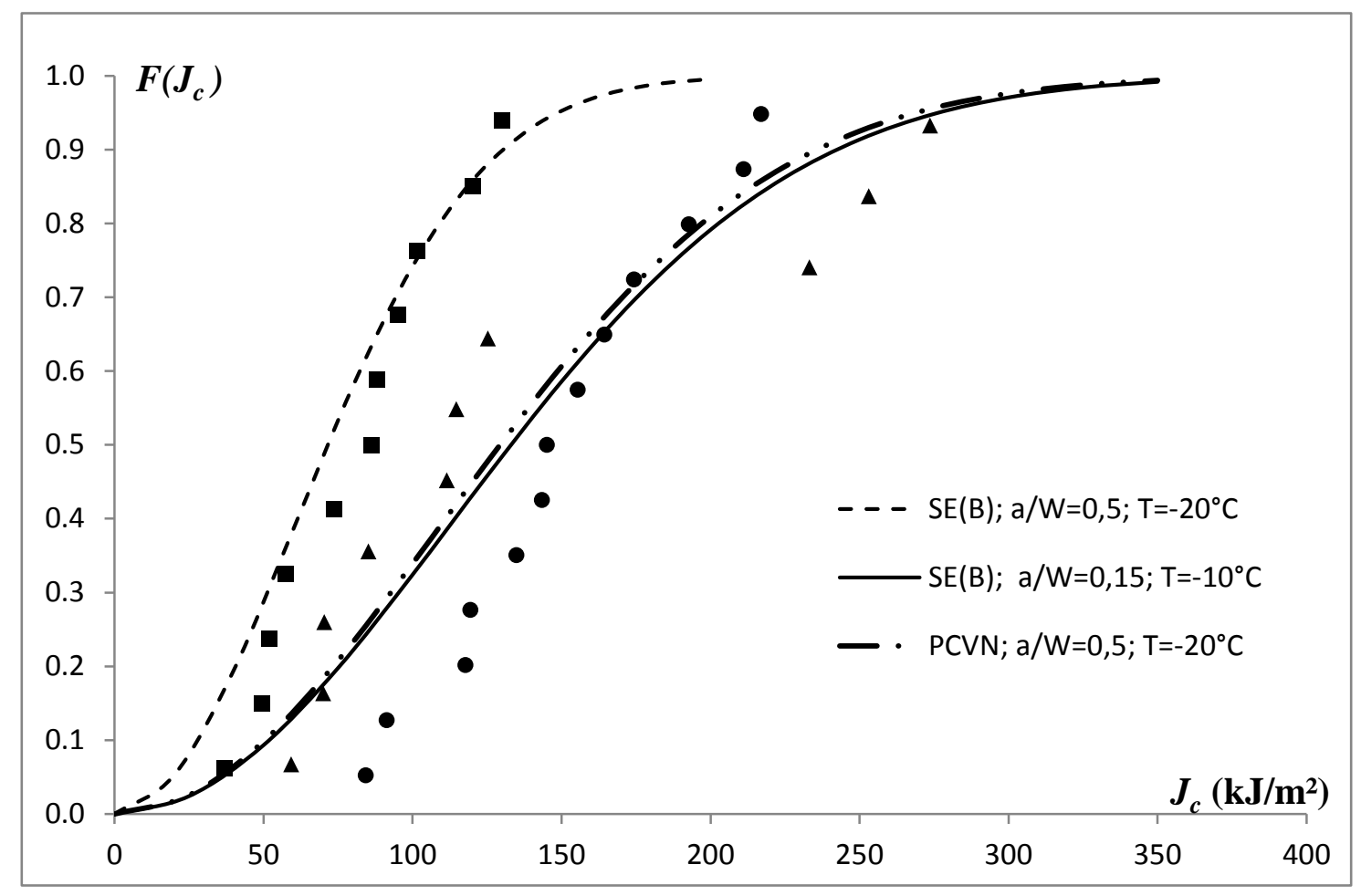

Figura 37. Distribuição dos valores experimentais de tenacidade comparados à distribuição teórica de Weibull com $\alpha=2$ para o aço A515 Gr 65. 
Nas Tabelas 10 e 11 são encontrados os resultados de tenacidade característica e os parâmetros da distribuição de Weibull biparamétrica para as geometrias de corpos de prova ensaiadas.

Tabela 10 Valores de tenacidade característica para as diferentes configurações geométricas ensaiadas - Aço ASTM A515 Gr 65.

\begin{tabular}{cccccc}
\hline A515 GR 65 & $\begin{array}{c}\text { Trinca } \\
\text { Rasa } \\
\left(\mathrm{T}=-10^{\circ} \mathrm{C}\right)\end{array}$ & $\begin{array}{c}\text { Trinca } \\
\text { Profunda } \\
\left(\mathrm{T}=-20^{\circ} \mathrm{C}\right)\end{array}$ & $\begin{array}{c}\text { PCVN } \\
\text { Plain Side } \\
\left(\mathrm{T}=-20^{\circ} \mathrm{C}\right)\end{array}$ & $\begin{array}{c}\text { PCVN } \\
\text { "Side Grooved" } \\
\left(\mathrm{T}=-20^{\circ} \mathrm{C}\right)\end{array}$ & $\begin{array}{c}\text { PCVN } \\
\text { "Side Grooved" } \\
\left(\mathrm{T}=-65^{\circ} \mathrm{C}\right)\end{array}$ \\
\hline$J_{0}\left[\mathrm{~kJ} / \mathrm{m}^{2}\right]$ & 158 & 91 & 165 & 133,5 & 67 \\
\hline
\end{tabular}

Tabela 11 Valores de tenacidade característica para as diferentes configurações geométricas ensaiadas utilizando a estimativa de máxima verossimilhança - Aço ASTM A515.

\begin{tabular}{|c|c|c|c|c|c|}
\hline & & & & & \\
\hline A515 Gr & & $\begin{array}{r}\text { Estimat } \\
\mathrm{A}\end{array}$ & $\begin{array}{l}\text { MV com } \\
\text { kO }\end{array}$ & Esti & de MV \\
\hline Geometria & $\begin{array}{c}\text { Temp. } \\
{\left[{ }^{\circ} \mathrm{C}\right]}\end{array}$ & $\alpha$ & $\begin{array}{c}J_{0} \\
{\left[\mathrm{~kJ} / \mathrm{m}^{2}\right]}\end{array}$ & $\alpha$ & $\begin{array}{c}J_{0} \\
{\left[\mathrm{~kJ} / \mathrm{m}^{2}\right]}\end{array}$ \\
\hline $\begin{array}{c}\mathrm{SE}(B)- \\
a / W=0,15\end{array}$ & $-10^{\circ} \mathrm{C}$ & 2 & 160 & 1,9 & 158 \\
\hline $\begin{array}{l}\text { SE(B) - } \\
a / W=0,5\end{array}$ & $-20^{\circ} \mathrm{C}$ & 2 & 86 & 3,1 & 91 \\
\hline $\begin{array}{l}\text { PCVN - "Plain } \\
\text { Side" }\end{array}$ & $-20^{\circ} \mathrm{C}$ & 2 & 155 & 4,2 & 165 \\
\hline $\begin{array}{c}\text { PCVN - "Side } \\
\text { Grooved" }\end{array}$ & $-20^{\circ} \mathrm{C}$ & 2 & 126 & 3,4 & 133 \\
\hline $\begin{array}{l}\text { PCVN - "Side } \\
\text { Grooved" }\end{array}$ & $-65^{\circ} \mathrm{C}$ & 2 & 64 & 3,1 & 67 \\
\hline
\end{tabular}


Ao contrário da tendência esperada, o espécime com trinca rasa apresentou tenacidade característica muito próxima à tenacidade característica do espécime PCVN-PS. Apesar de nesta série de ensaios com o aço A515 o espécime com trinca rasa ter razão $a / W=0,15$, inferior à razão utilizada nos espécimes trinca rasa de aço A285, os mesmos eram ligeiramente mais espessos e, portanto, esperavase que os efeitos sobre a tenacidade, decorrentes da variação destes dois parâmetros, se compensassem.

Ou seja, diminui-se a triaxialidade de tensões na ponta da trinca diminuindo-se a relação $a / W$ (redução de $25 \%$ no comprimento de trinca), mas por outro lado há uma tendência em aumentar esta mesma triaxialidade com a utilização de corpos de prova mais espessos (aumento de aproximadamente 18\% na espessura). Entretanto, geometricamente, as variações nos parâmetros citados acima foram muito pequenas e provavelmente não são elas as responsáveis pelas tendências observadas, restando atribuir à microestrutura do A515 o comportamento observado para a tenacidade deste material. Não faz parte do escopo do trabalho abordar aspectos microestruturais para explicar os comportamentos à fratura observados e, portanto isto ficará como sugestão para próximos trabalhos.

O gráfico das Figuras 38 e 39 apresentam os valores experimentais de $J_{c}$ em função do comprimento de trinca adimensional e em função da espessura do corpo de prova $S E(B)$, respectivamente. 


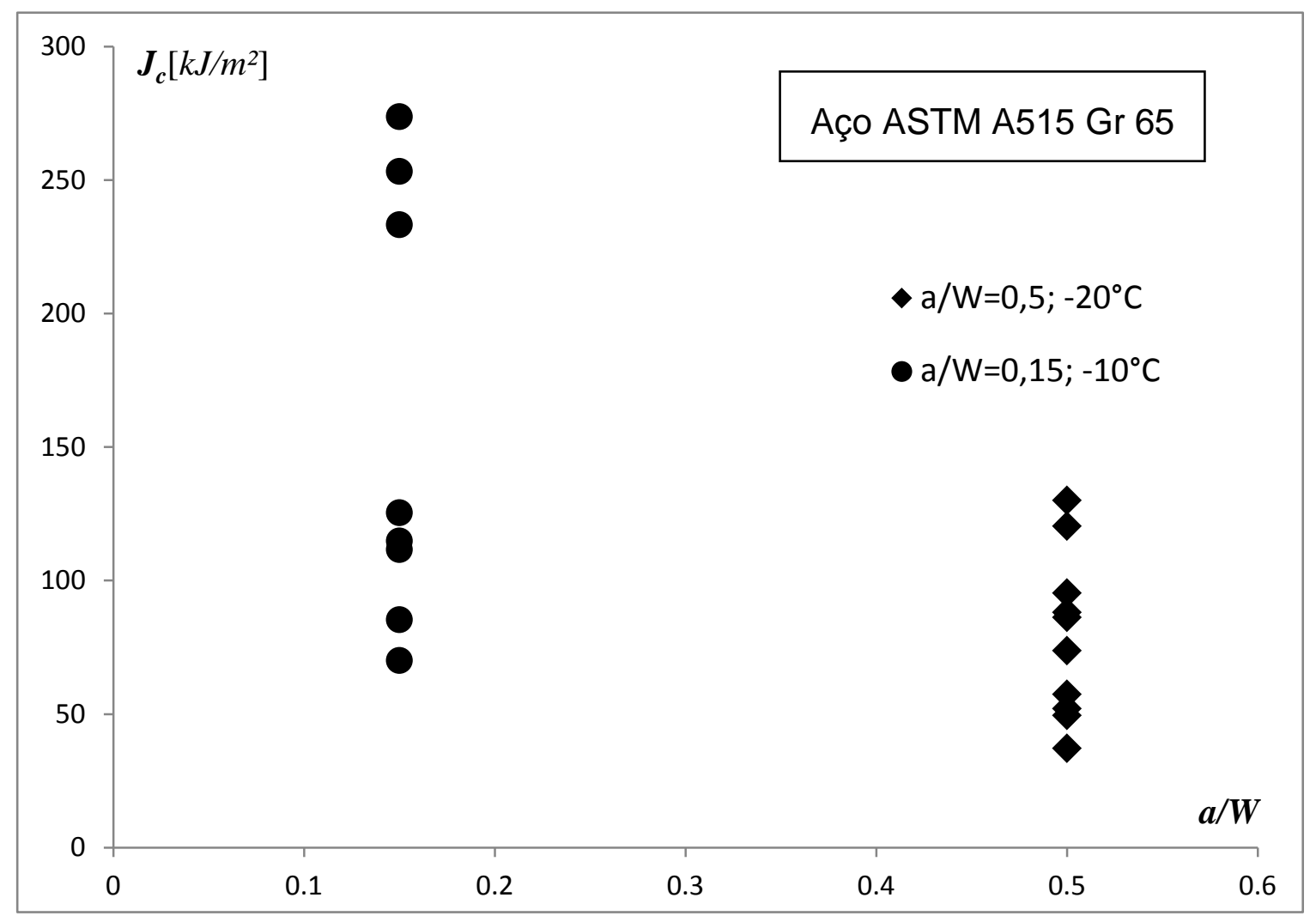

Figura 38. Efeito da variação do comprimento de trinca nos valores de tenacidade à fratura, $J_{c}$ para o aço A515 Gr 65.

Nesse gráfico observa-se que a dispersão dos pontos experimentais para o corpo de prova com trinca rasa novamente apresenta dois grupos de valores distintos de tenacidade, porém estes não são muito distantes dos valores obtidos para o SE(B) trinca profunda. Como não houve nenhum valor extremamente discrepante na série de dados, a comparação dos valores de tenacidade característica para os diferentes espécimes, neste caso, não induz a conclusões equivocadas e qualitativamente a tendência dos dados está em acordo com o esperado, mostrando haver aumento da tenacidade para um menor comprimento de trinca.

Analisando-se o gráfico da Figura 39, conjuntamente com os dados de tenacidade apresentados anteriormente na Tabela 10, pode-se concluir que a tenacidade do aço A515 possui menor sensibilidade a variações de geometria dos corpos de prova. A dispersão nos dados de tenacidade para o PCVN-PS foi praticamente da mesma ordem de grandeza da observada para o corpo de prova $\mathrm{SE}(\mathrm{B})$ trinca profunda e os valores de tenacidade foram, em geral, superiores. 


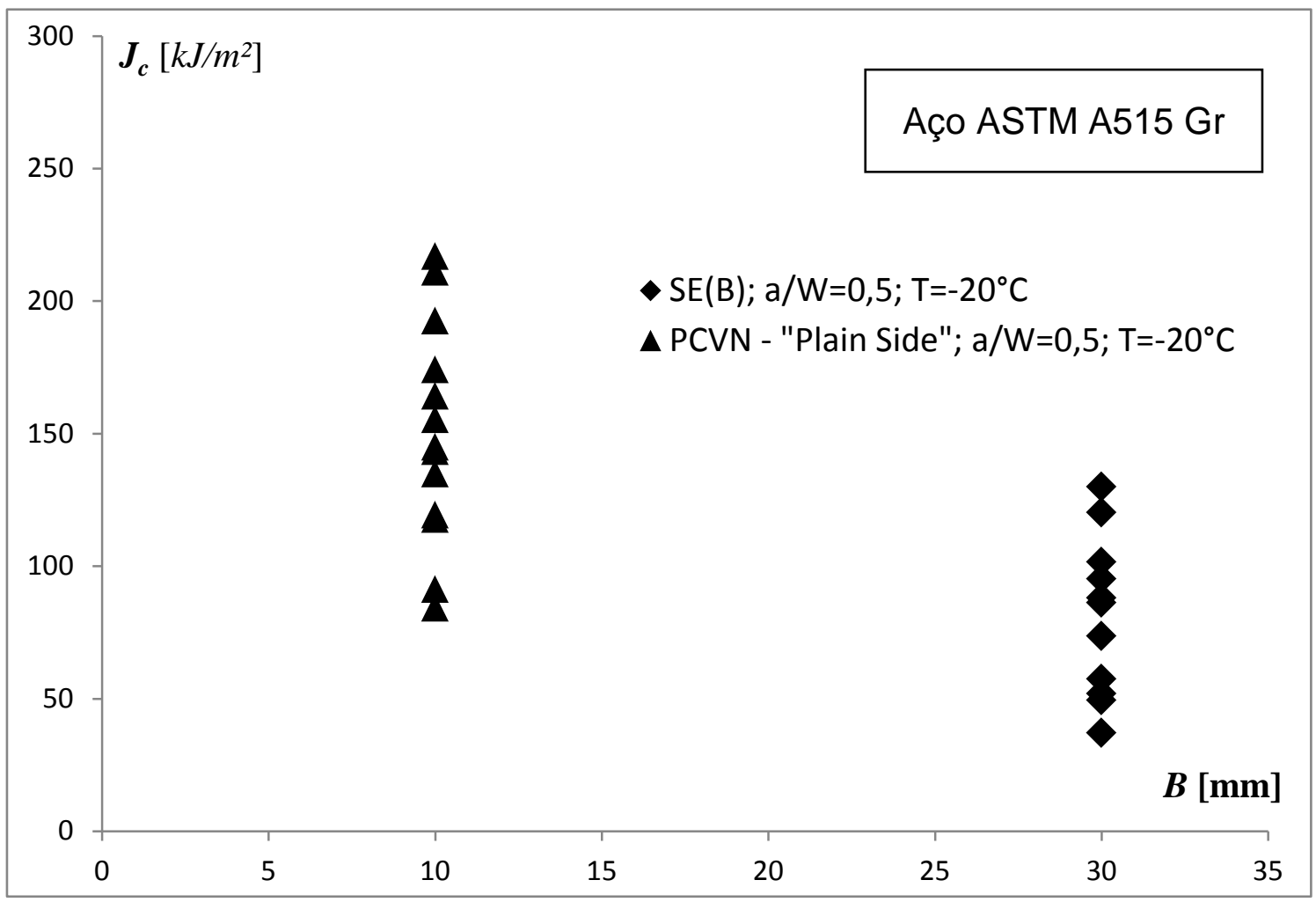

Figura 39. Efeito da variação da espessura nos valores de tenacidade à fratura, $J_{c}$ para o aço A515 Gr 65

Porém, mesmo não apresentando grande dispersão ou grandes desvios em relação aos valores experimentais de $J_{c}$ obtidos com o SE(B) trinca profunda, os valores experimentais de tenacidade para o $P C V N$ e para o $S E(B)$ trinca rasa não demonstraram ter boa aderência à distribuição teórica de Weibull. Pelas mesmas razões descritas anteriormente, na análise do aço A285, a utilização de corpos de prova PCVN-PS novamente mostrou poder comprometer a determinação da temperatura de referência, $T_{0}$.

Na tentativa de reduzir a elevação da tenacidade à fratura dos corpos de prova PCVN-PS, foram realizados ensaios experimentais introduzindo entalhes laterais nos corpos de prova com geometria reduzida. As tendências observadas nos resultados experimentais foram muito similares às obtidas com aço A285 e, portanto, a análise para o aço A515 será breve.

O aço A515, no início da etapa experimental, havia apresentado menor sensibilidade da tenacidade à fratura em função da variação de temperatura. Esta menor sensibilidade se manteve com a introdução dos entalhes laterais, com isso a 
redução da temperatura de ensaio para a obtenção de valores válidos de $J_{c}$, respeitando os requisitos da norma ASTM E1921, teve de ser mais acentuada, sendo esta redução de $45^{\circ} \mathrm{C}$ e, portanto, a $T_{\text {ensaio }}=-65^{\circ} \mathrm{C}$.

A análise da tenacidade em função da espessura para os corpos PCVN-SG, mantendo-se a temperatura de teste de $-20^{\circ} \mathrm{C}$, Figura 40 , mostra uma redução geral dos valores quando comparado ao seu similar sem entalhe. Observa-se também que o tamanho da dispersão dos dados é similar, porém mesmo com a redução no valor de $J_{0}$, para o espécime com entalhes laterais, ensaiado a $-20^{\circ} \mathrm{C}$, este ainda apresenta tenacidade aparente bastante superior a do espécime $\mathrm{SE}(\mathrm{B})$ com trinca profunda, $J_{o}^{P C V N_{-} S G ; T_{\text {ensaio }}=-20^{\circ} \mathrm{C}} / J_{o}^{a / w=0,5}=1,4$.

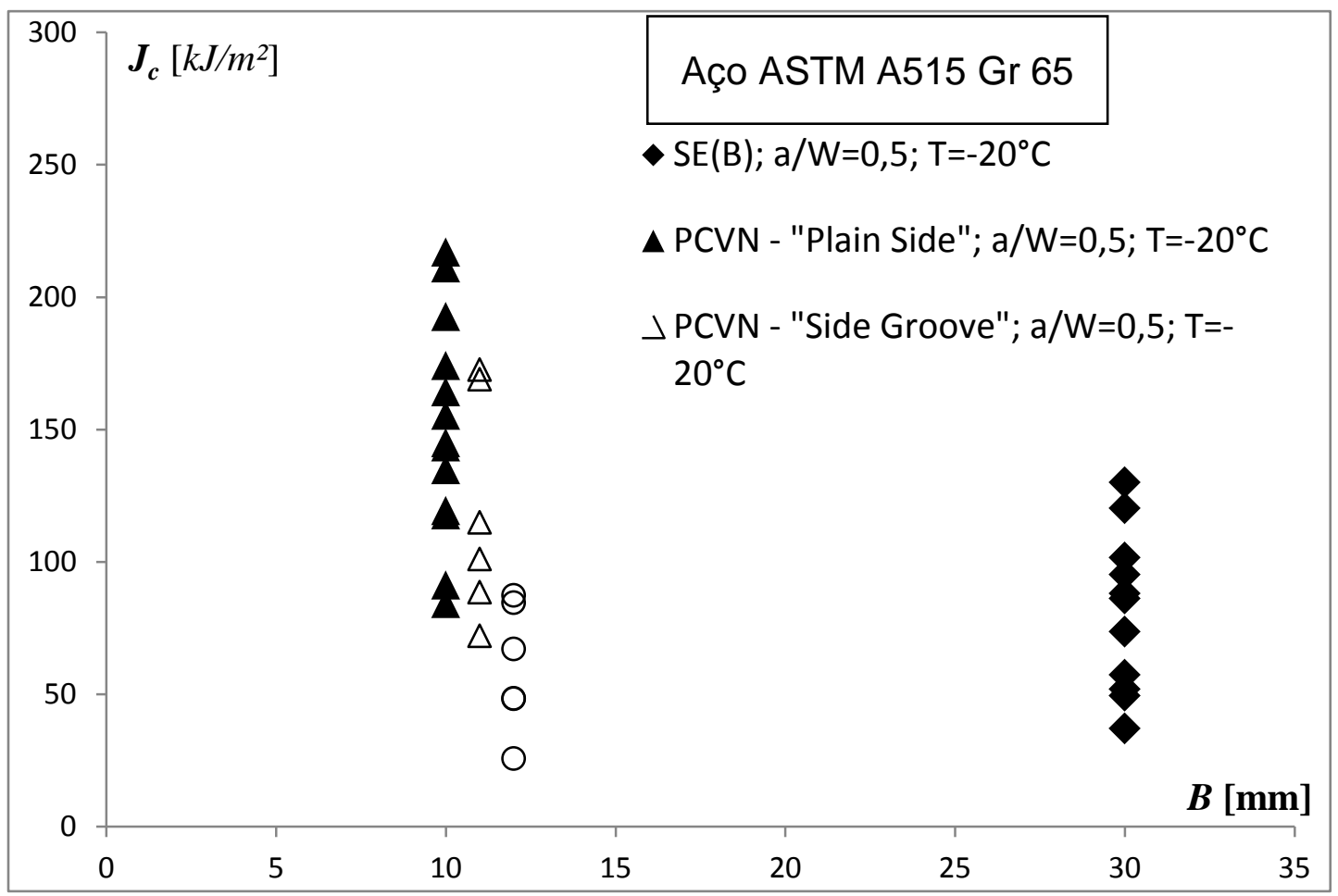

Figura 40. Efeito da variação da espessura nos valores de tenacidade à fratura, $J_{c}$ para o aço A515 Gr 65

Comparado com o corpo de prova de referência, $\mathrm{SE}(\mathrm{B})$ trinca profunda, é possível afirmar que os entalhes laterais foram menos efetivos na redução da tenacidade à fratura para 0 aço A515, pois $J_{o}^{P C V N_{-} P S ; T_{\text {ensaio }}=-20^{\circ} \mathrm{C}} / J_{o}^{a / w=0,5}=1,8 \mathrm{e}$ $J_{o}^{P C V N \_S G ; T_{\text {ensaio }}=-20^{\circ} \mathrm{C}} / J_{o}^{a / w=0,5}=1,4$. Essa redução de aproximadamente $20 \%$ entre os valores apresentados é significativamente menor do que a observada para o aço A285 que para a mesma relação apresenta variação de 40\%. 
O gráfico da Figura 41 mostra a baixa aderência dos dados experimentais para o PCVN-SG, ensaiado à temperatura de $-20^{\circ} \mathrm{C}$, com a curva teórica da distribuição de Weibull biparamétrica. Este comportamento é um indicativo de que a validade dos valores de tenacidade, segundo os critérios da norma ASTM 1921, pode ser comprometida. Com a redução da temperatura de ensaio para o valor de $-65^{\circ} \mathrm{C}$ nota-se uma redução acentuada na tenacidade à fratura e uma aproximação dos pontos experimentais à curva teórica.

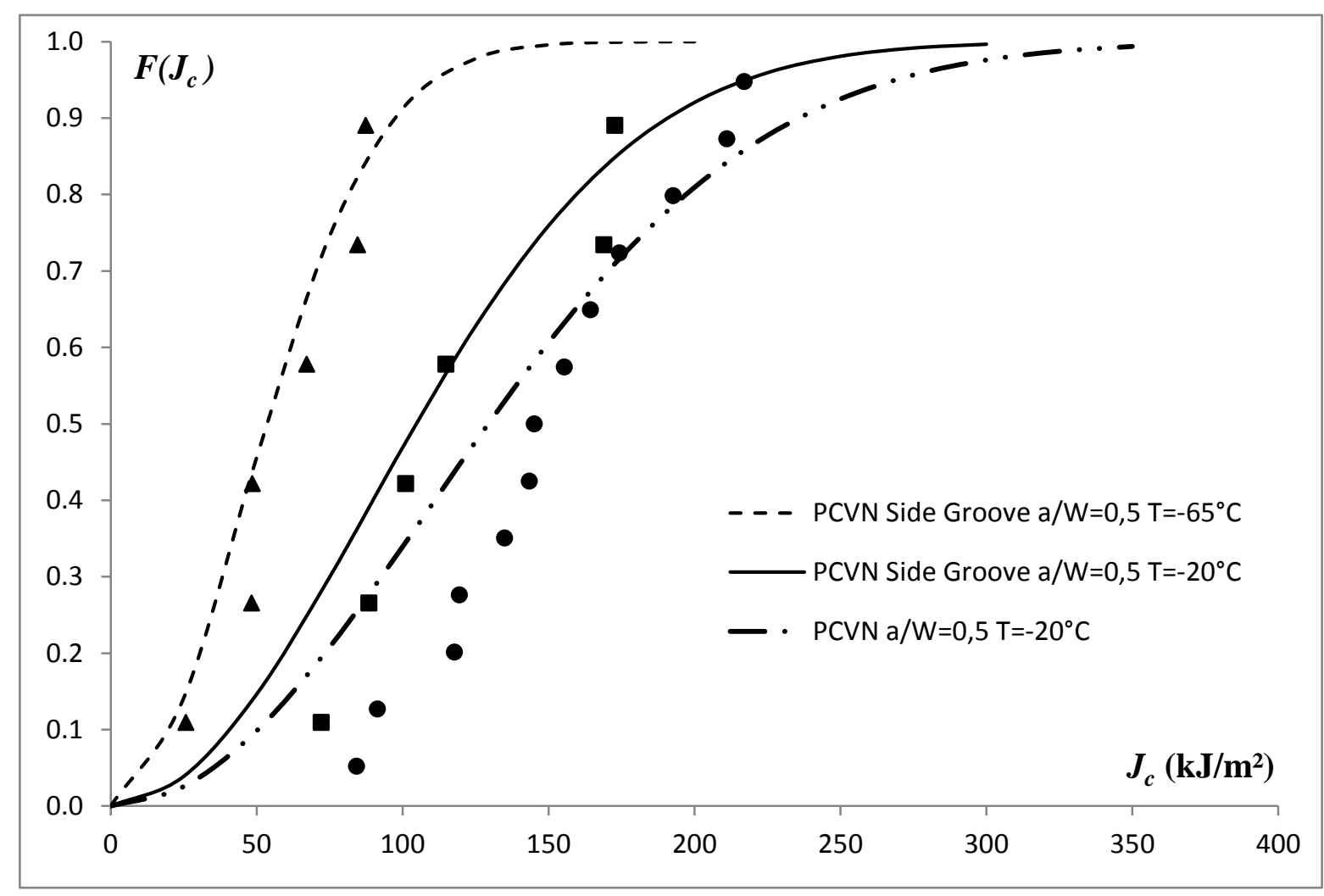

Figura 41. Distribuição dos valores experimentais de tenacidade para os espécimes com geometria PCVN comparados à distribuição teórica de Weibull com $\alpha=2$ para o aço A515 Gr 65.

A Figura 42 mostra, para efeito comparativo, as distribuições obtidas para os espécimes $\mathrm{SE}(\mathrm{B})$ com $a / W=0,5$ e para os PCVN's com entalhes laterais a $-20^{\circ} \mathrm{C}$ e a $-65{ }^{\circ} \mathrm{C}$. Observa-se que a redução da temperatura, somada ao efeito da introdução dos entalhes laterais, reduziu os níveis de tenacidade à fratura do PCVN-SG, resultando em um comportamento similar ao do espécime SE(B). Portanto, novamente se verificou que o uso de entalhes laterais e o ajuste da 
temperatura de ensaio proporcionaram resultados satisfatórios, para a avaliação da temperatura de referência $T_{0}$.

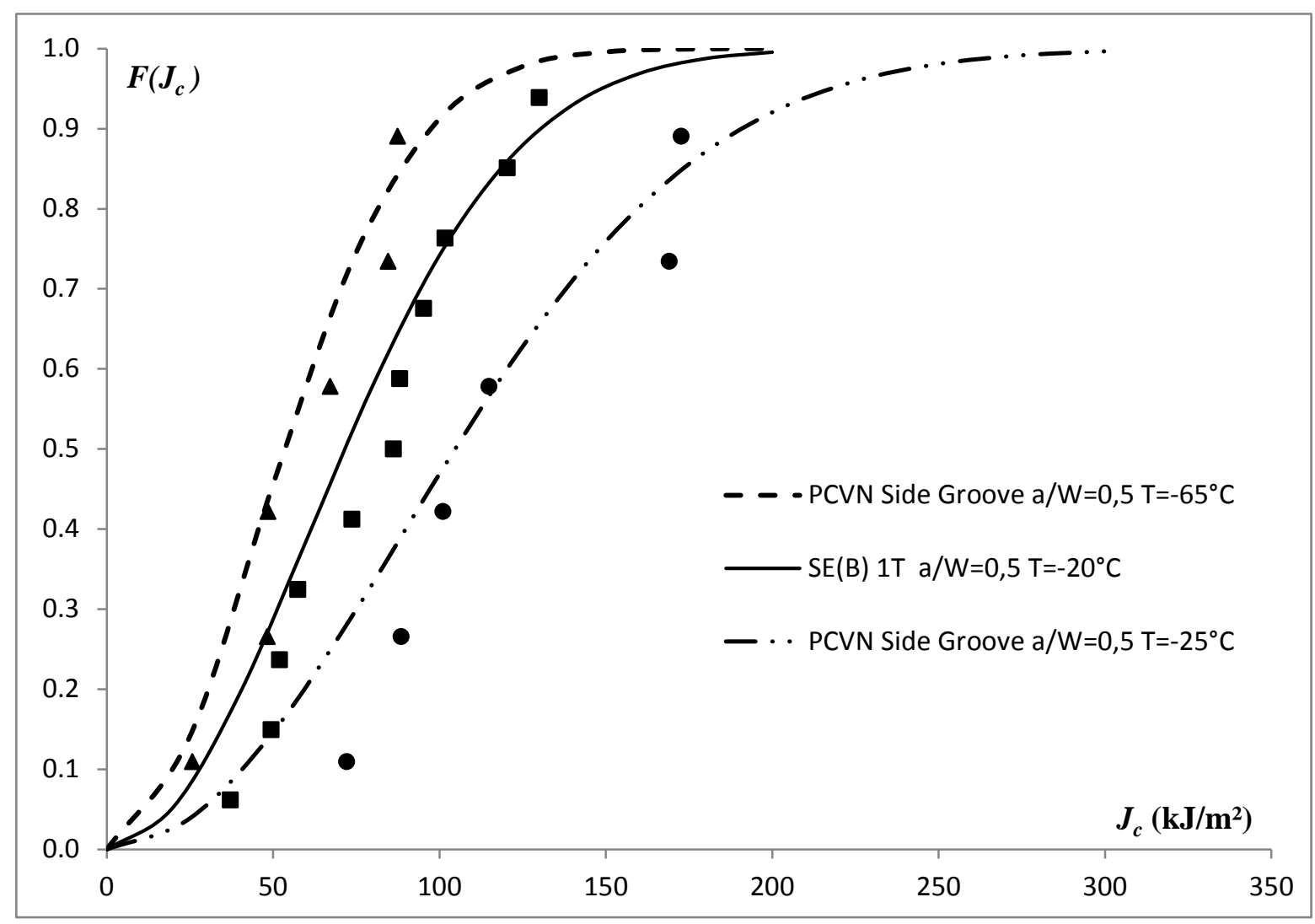

Figura 42. Distribuição da probabilidade de falha dos valores experimentais de tenacidade para o espécime SE(B)-1T, trinca profunda utilizado como referência e espécimes com geometria PCVN com entalhes laterais comparados à distribuição teórica de Weibull com $\alpha=2$ para o aço A515 $\mathrm{Gr}$ 65.

Finalmente, a Tabela 12 apresenta os valores de tenacidade à fratura obtidos para os três tipos de corpos de prova ensaiados no programa experimental deste trabalho e suas respectivas temperaturas de ensaio. Nessa tabela também são mostrados os valores do comprimento inicial trinca, $a_{0}$, medidos após o término do ensaio para fim de obtenção de valores precisos de $J_{c}$. 
Tabela 12 Valores de tenacidade, $J_{c}$, obtidos nos ensaios à baixa temperatura, comprimentos de trinca, $a_{0}$ e limite de deformação plástica. Aço A515 Gr 65.

\begin{tabular}{|c|c|c|c|c|c|c|c|c|c|c|}
\hline \multirow[b]{2}{*}{ Geometria } & \multirow[b]{2}{*}{$\begin{array}{c}\mathrm{N}^{\circ} \\
\text { do } \mathrm{CP} \\
\end{array}$} & \multicolumn{3}{|c|}{$-10^{\circ} \mathrm{C}$} & \multicolumn{3}{|c|}{$-20^{\circ} \mathrm{C}$} & \multicolumn{3}{|c|}{$-65^{\circ} \mathrm{C}$} \\
\hline & & $\begin{array}{c}J_{c} \\
{\left[k J / m^{2}\right]}\end{array}$ & $\begin{array}{c}a_{0} \\
{[m m]}\end{array}$ & M & $\begin{array}{c}J_{c} \\
{\left[k J / m^{2}\right]}\end{array}$ & $\begin{array}{c}a_{0} \\
{[m m]}\end{array}$ & $M$ & $\begin{array}{c}J_{c} \\
{\left[\mathbf{k J} / \mathbf{m}^{2}\right]}\end{array}$ & $\begin{array}{c}a_{0} \\
{[m m]}\end{array}$ & $M$ \\
\hline \multirow{10}{*}{$\begin{array}{c}S E(B) \\
a / W=0,15\end{array}$} & 10 & 125,32 & 8,29 & 129 & & & & & & \\
\hline & 11 & 253,16 & 7,75 & 65 & & & & & & \\
\hline & 12 & 114,67 & 7,96 & 142 & & & & & & \\
\hline & 13 & 111,47 & 8,00 & 146 & & & & & & \\
\hline & 15 & 85,25 & 8,19 & 190 & & & & & & \\
\hline & 16 & 273,67 & 8,55 & 59 & & & & & & \\
\hline & 17 & 233,16 & 8,54 & 69 & & & & & & \\
\hline & 18 & 69,99 & 8,13 & 232 & & & & & & \\
\hline & 19 & 59,29 & 7,58 & 277 & & & & & & \\
\hline & 20 & 70,38 & 8,38 & 230 & & & & & & \\
\hline \multirow{11}{*}{$\begin{array}{c}S E(B) \\
a / W=0,5\end{array}$} & 1 & & & & 130,00 & 30,36 & 73 & & & \\
\hline & 2 & & & & 88,06 & 30,23 & 109 & & & \\
\hline & 3 & & & & 51,98 & 30,40 & 183 & & & \\
\hline & 4 & & & & 95,25 & 30,17 & 101 & & & \\
\hline & 5 & & & & 73,71 & 31,20 & 125 & & & \\
\hline & 6 & & & & 120,34 & 30,49 & 79 & & & \\
\hline & 13 & & & & 37,12 & 30,78 & 253 & & & \\
\hline & 14 & & & & 86,19 & 30,35 & 110 & & & \\
\hline & 15 & & & & 57,41 & 29,57 & 170 & & & \\
\hline & 16 & & & & 49,46 & 30,87 & 189 & & & \\
\hline & 17 & & & & 101,68 & 30,57 & 93 & & & \\
\hline \multirow{13}{*}{$\begin{array}{l}\text { PCVN } \\
\text { "Plain } \\
\text { Side" }\end{array}$} & 1 & & & & 91,37 & 5,43 & 16 & & & \\
\hline & 2 & & & & 217,02 & 5,10 & 7 & & & \\
\hline & 3 & & & & 145,11 & 5,14 & 11 & & & \\
\hline & 4 & & & & 134,92 & 4,98 & 12 & & & \\
\hline & 5 & & & & 192,70 & 5,49 & 8 & & & \\
\hline & 6 & & & & 211,09 & 5,33 & 7 & & & \\
\hline & 7 & & & & 164,33 & 5,41 & 9 & & & \\
\hline & 8 & & & & 117,81 & 5,12 & 13 & & & \\
\hline & 9 & & & & 174,27 & 5,21 & 9 & & & \\
\hline & 10 & & & & 155,40 & 5,22 & 10 & & & \\
\hline & 11 & & & & 84,29 & 5,28 & 18 & & & \\
\hline & 12 & & & & 119,41 & 5,27 & 13 & & & \\
\hline & 13 & & & & 143,41 & 5,16 & 11 & & & \\
\hline \multicolumn{11}{|l|}{ PCVN } \\
\hline “Side & 14 & & & & 114,91 & 4,75 & 15 & & & \\
\hline Grooved" & 15 & & & & 72,13 & 4,64 & 24 & & & \\
\hline
\end{tabular}




\begin{tabular}{|c|c|c|c|c|c|c|c|}
\hline & 16 & 101,07 & 4,75 & 17 & & & \\
\hline & 17 & 172,66 & 4,68 & 10 & & & \\
\hline & 18 & 169 & 4,63 & 10 & & & \\
\hline & 19 & 88,47 & 4,97 & 18 & & & \\
\hline & 9 & & & & 48,3 & 4,98 & 38 \\
\hline PCVN & 10 & & & & 25,8 & 4,99 & 71 \\
\hline "Side & 11 & & & & 48,49 & 4,98 & 38 \\
\hline Grooved" & 12 & & & & 87,44 & 5,00 & 21 \\
\hline & 13 & & & & 84,56 & 5,00 & 22 \\
\hline & 14 & & & & 67,13 & 5,00 & 27 \\
\hline
\end{tabular}

\subsection{Aço ASTM A515 Gr 65 - Superfícies de Fratura}

As análises macro e micrográficas para o aço A515 são mostradas na Figura 43. Foram usados os mesmos métodos descritos anteriormente e, novamente, não foi observado crescimento estável de trinca para nenhum dos espécimes. Por apresentarem valores de $J_{c}$ relativamente altos, todos os corpos de prova com trinca rasa e PCVN tiveram suas frentes de trinca medidas e analisadas no estéreo microscópio com aumento de 10X, porém não foi possível identificar indícios de rasgamento dúctil e o padrão das imagens foi similar ao apresentado anteriormente na Figura 36. 


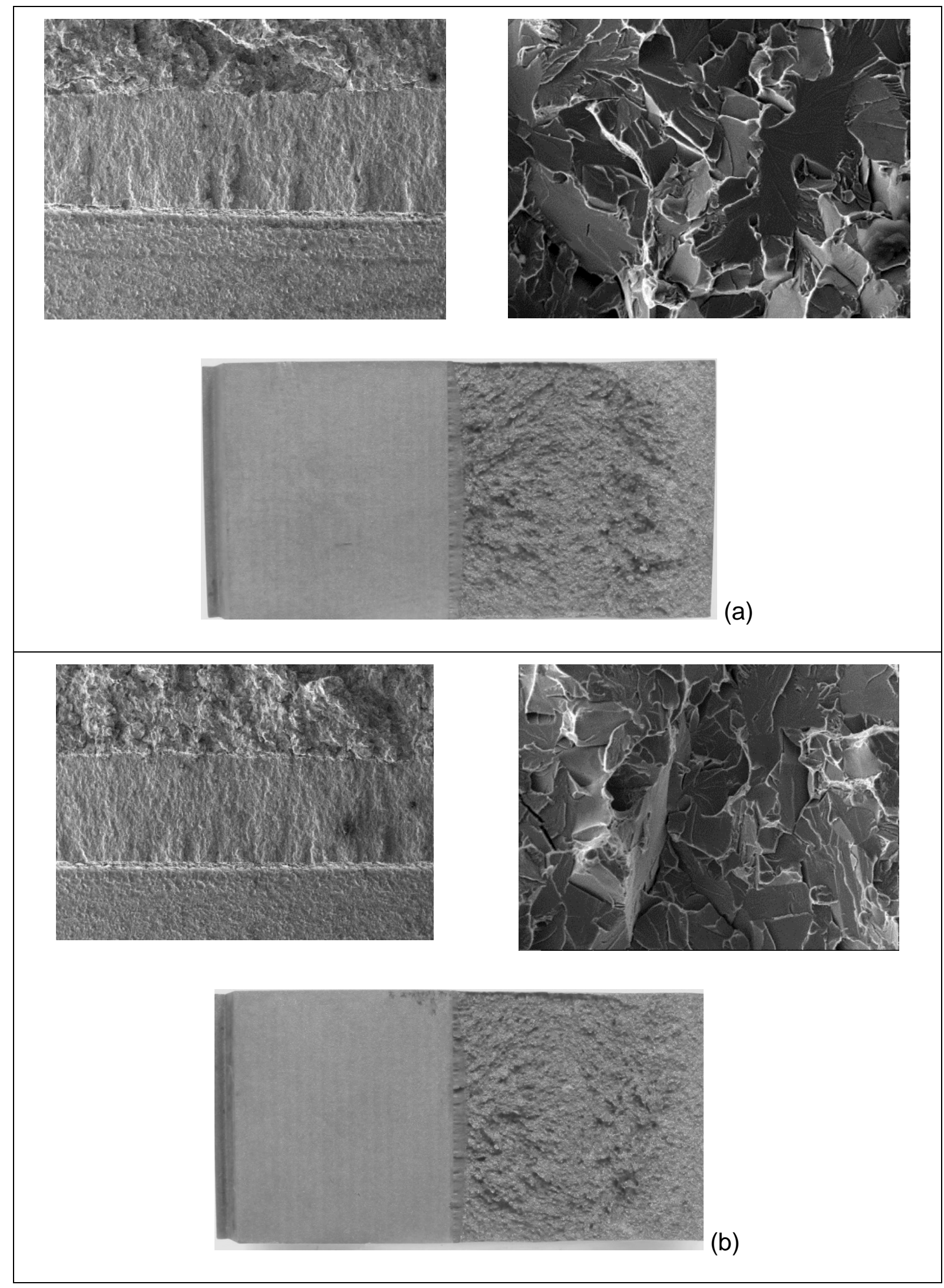

Figura 43. Micro e macrografias para os corpos de prova de aço ASTM A515 GR 65; (a) CP01; (b) CP16. Os aumentos nas micrografias são de 50x e 1500x, respectivamente. 


\section{DETERMINAÇÃO DA TEMPERATURA DE REFERÊNCIA}

\section{$T_{0}$}

A determinação da temperatura de referência, $T_{0}$, realizada nesta seção segue o procedimento da norma ASTM E1921 [14] apresentado na seção 3.3. Todos os valores de $J_{c}$ foram convertidos em valores de $K_{J c}$ usando a equação (42) e corrigidos para a espessura de uma polegada (1T) pela equação (43).

Além de não poder haver crescimento estável de trinca superior ao limite estabelecido pela equação (52), cada geometria de corpo de prova possui um valor limite de $K_{J c}$ dado pela equação (49). Este valor limite determina a máxima capacidade de carga permitida para cada geometria, garantindo assim a condição de escoamento de pequena monta, SSY, a aderência com a solução HRR e consequentemente mantendo $K_{J c}$ como descritor dos campos de tensão na ponta da trinca.

$$
K_{\text {Jc_limite }}=\sqrt{\frac{E b_{0} \sigma_{y s}}{30\left(1-v^{2}\right)}}
$$

A equação (61) é exatamente igual à equação (49), sendo o parâmetro $M$ substituído pelo valor de 30, conforme recomendação da norma ASTM E1921 [14] para a geometria $\mathrm{SE}(\mathrm{B})$.

Algumas observações devem ser feitas em relação ao limite de deformação plástica, M. Apesar da norma ASTM E1921 [14] prever a utilização de corpos de prova com dimensões diferentes da dimensão padrão $1 T$ e trinca profunda ( $a / W \geq 0,5$ ), esta norma não altera ou corrige o valor do limite de deformação plástica, $M$. Trabalhos como os apresentados nas referências [30] e [31] mostram que o valor de $M$ varia significativamente em função da geometria do espécime e em função das propriedades mecânicas do material, no caso o encruamento. Portanto, o uso de um valor fixo, não é adequado quando a temperatura de referência, $T_{0}$, é avaliada por meio de corpos de prova com trinca rasa ( $\left.a / W \leq 0,3\right)$ e pode também não ser aplicável à geometria PCVN. 
Como exemplo disso, o simples exercício de substituir os valores de ligamento remanescente, $b_{0}$, na equação (61) mostraria, equivocadamente, que o corpo de prova com trinca rasa possui $K_{J c-l i m i t e}$ superior ao corpo de prova com trinca profunda, significando assim maior capacidade do espécime com trinca rasa de manter a restrição plástica na ponta da trinca o que não é correto. Portanto neste trabalho não será feita a avaliação da $T_{0}$ a partir dos resultados de tenacidade obtidos com os corpos de prova com trinca rasa apesar de todos os valores de $K_{J c}$ obtidos nos ensaios experimentais terem sido válidos pelo critério de $K_{J c-l i m i t e}$ para $M=30$.

Quanto à determinação da $T_{0}$, utilizando-se os valores de tenacidade obtidos nos ensaios com PCVN-PS, esta também não foi possível, pois todos os valores obtidos nos ensaios foram superiores a $K_{J c-l i m i t e}$ não havendo a possibilidade de ser aplicado o modelo de censura para o cálculo de $K_{0}$. Portanto a $T_{0}$ foi avaliada somente com base nos resultados dos corpos de prova $S E(B)$, trinca profunda, com comprimento de trinca adimensional $a / W=0,5$ e PCVN com entalhes laterais.

Nos corpos de prova com trinca profunda, não foi observado crescimento estável de trinca e os valores de tenacidade $K_{J c}$ foram válidos em sua totalidade. Portanto, o modelo sem censura, no qual $r=N$, foi adotado no cálculo de $K_{0}$ e seguiu-se o roteiro para cálculo da $T_{0}$ apresentado na seção 3.3 .

Já para o espécime PCVN-SG apesar de não serem evidentes os indícios de crescimento estável de trinca (análise sem auxílio de equipamentos ópticos para ampliação, conforme sugere a norma ASTM E1921) em alguns casos estes violaram o valor limite estabelecido pela equação (61) exigindo a aplicação do modelo de censura para o tratamento da série de dados na determinação da Curva Mestra. 


\subsection{Aço ASTM A285 Gr C}

Para o aço A285 a Tabela 13 mostra os valores experimentais de tenacidade à fratura, o valor de $K_{\text {Ic_limite }}$ para o corpo de prova $\mathrm{SE}(\mathrm{B})-1 \mathrm{~T}$ com comprimento adimensional de trinca $a / W=0,5$ e o valor da tenacidade mediana.

Tabela 13 Valores experimentais de tenacidade convertidos para unidades de $\boldsymbol{K}_{\boldsymbol{J}} ; \boldsymbol{K}_{\boldsymbol{J}{ }_{\_} \text {limite }}$ para 0 corpo de prova SE(B), 1T com $a / W=0,5$ e valor calculado de $\boldsymbol{K}_{\boldsymbol{J c \_} \text { med. }}$. Aço ASTM A285 [4].

\begin{tabular}{|c|c|c|c|c|c|c|c|c|c|c|}
\hline $\begin{array}{l}\text { Corpo } \\
\text { de } \\
\text { Prova }\end{array}$ & 4 & 5 & 6 & 7 & 8 & 9 & 10 & 11 & 12 & 13 \\
\hline${ }_{[M P a V m]} K_{J c}$ & 97,3 & 115,0 & 149,2 & 137,6 & 102,1 & 164,5 & 100,8 & 134,7 & 114,2 & 88,1 \\
\hline $\begin{array}{l}K_{\text {Jc_limite }} \\
\text { [MPaVm] }\end{array}$ & 251,8 & & & & & & & & & \\
\hline $\begin{array}{c}K_{J c_{-} \text {med }} \\
{[M P a V m]}\end{array}$ & 119,0 & & & & & & & & & \\
\hline
\end{tabular}

A análise da tabela acima mostra que todos os valores experimentais ficaram bastante distantes do limite estabelecido para a configuração de corpo de prova empregada. E com base nestes 10 valores de $K_{J c}$ a temperatura de referência para o aço ASTM A285 Gr C é:

$$
T_{0}=-93,5^{\circ} \mathrm{C}
$$

Esse valor de temperatura $T_{0}$ aos ser aplicado na equação (48) estabelece a Curva Mestra deste material dada pela equação (62).

$$
K_{J c(m e d)}=30+70 \exp [(0,019(T+93,5))]
$$

E é representada pelo gráfico da Figura 44. 


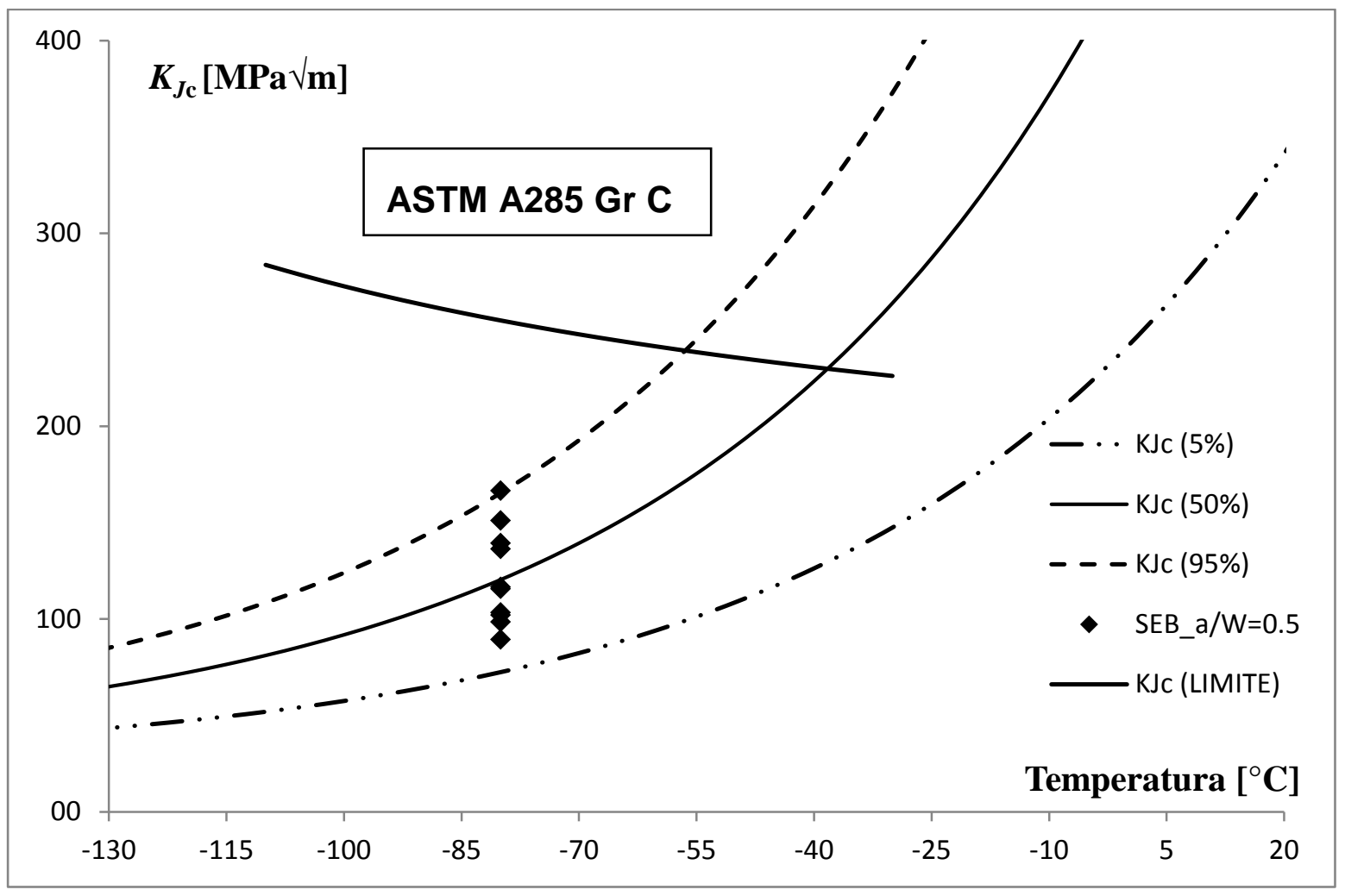

Figura 44. Gráfico representativo da Curva Mestra do aço Aço ASTM A285 Gr C e seus intervalos de confiança, dados experimentais obtidos com corpos de prova $\mathrm{SE}(\mathrm{B})-1 \mathrm{~T}, T_{\text {ensaio }}=-80^{\circ} \mathrm{C}$.

O mesmo roteiro foi seguido na determinação da temperatura de referência, $T_{0}$, e da Curva Mestra para corpos de prova PCVN-SG. Conforme comentado na seção 5 Os ensaios experimentais realizados na temperatura de teste de $-80^{\circ} \mathrm{C}$ não geraram valores válidos e a série de resultados de tenacidade à fratura obtida com o PCVN-SG, ensaiado a temperatura de $-105^{\circ} \mathrm{C}$, foi parcialmente válida, o que exigiu a aplicação do modelo de censura. Na Tabela 14 encontra-se este conjunto de dados experimentais.

Tabela 14 Valores experimentais de tenacidade convertidos para unidades de $\boldsymbol{K}_{\boldsymbol{J c}}$ e $\boldsymbol{K}_{\boldsymbol{J c}}-\mathbf{1 T}$; $\boldsymbol{K}_{J_{\_} \text {limite }}$ para o corpo de prova PCVN-SG, $T_{\text {ensaio }}=-105^{\circ} \mathrm{C}$ e valor calculado de $\boldsymbol{K}_{\boldsymbol{J} \_ \text {med }}$ sem aplicar censura aos resultados. Aço ASTM A285 [4].

\begin{tabular}{cccccccc}
\hline $\begin{array}{c}\text { Corpo de } \\
\text { Prova }\end{array}$ & $\mathbf{9}$ & $\mathbf{1 0}$ & $\mathbf{1 1}$ & $\mathbf{1 2}$ & $\mathbf{1 3}$ & $\mathbf{1 4}$ & $\mathbf{1 5}$ \\
\hline $\boldsymbol{K}_{\boldsymbol{J c}}[\mathrm{MPaVm}]$ & 61,5 & 85,1 & $\underline{129}$ & $\underline{149,5}$ & 69,3 & 116,6 & $\underline{133,3}$ \\
$\boldsymbol{K}_{\boldsymbol{J c}}-\mathbf{1 T}[\mathrm{MPaVm}]$ & 51 & 68 & 101 & 117 & 56,9 & 92,3 & 104,9 \\
$\boldsymbol{K}_{\boldsymbol{J c}}$ limite $[\mathrm{MPaVm}]$ & 121,5 & & & & & & \\
$\boldsymbol{K}_{\boldsymbol{J c} \text { med }}[\mathrm{MPaVm}]$ & 98,7 & & & & & & \\
\hline
\end{tabular}


Três dos sete resultados de tenacidade foram censurados por exceder o valor de $K_{J c_{-} l i m i t e}$ e a temperatura de referência foi avaliada sob duas condições:

1. Considerando a espessura, $B$, igual a $10 \mathrm{~mm}$ (mesmo com os entalhes laterais):

$$
T_{0}=-100^{\circ} \mathrm{C}
$$

2. Considerando a espessura, $B=B_{n}$, onde $B_{n}=8 \mathrm{~mm}$ (espessura real da frente de trinca).

$$
T_{0}=-96,5^{\circ} \mathrm{C}
$$

Esse valor de temperatura $T_{0}$ aos ser aplicado na equação (48) estabelece a Curva Mestra deste material dada pela equação ((63).

$$
K_{J c(m e d)}=30+70 \exp [(0,019(T+96,5))]
$$

E está representada no gráfico da Figura 45 


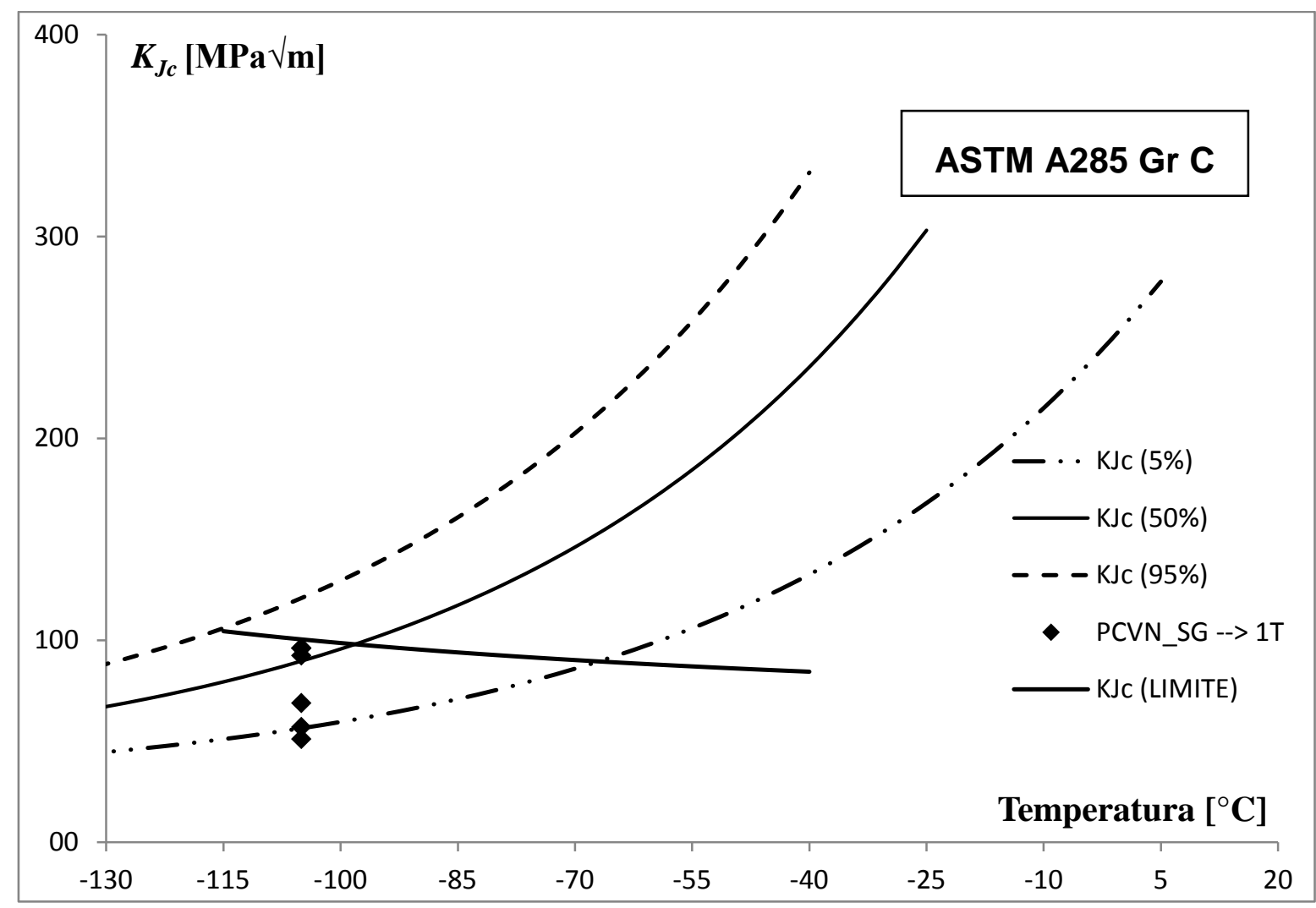

Figura 45. Gráfico representativo da Curva Mestra do aço Aço ASTM A285 Gr C e seus intervalos de confiança, dados experimentais obtidos com corpos de prova PCVN-SG, $T_{\text {ensaio }}=-105^{\circ} \mathrm{C}$. (a) Aço ASTM A285 Gr C

A utilização do valor efetivo de $8 \mathrm{~mm}$ para a espessura do corpo de prova, apesar de ferir a norma ASTM E1921 [14], que recomenda adotar $B_{n}=10 \mathrm{~mm}$ para a correção pelo efeito de espessura, produz uma estimativa de $T_{0}$ mais próxima à estabelecida com o corpo de prova SE(B)-1T. Tal procedimento proporcionou uma previsão mais adequada da temperatura de referência e portanto foi adotada para a determinação da Curva Mestra, a mesma norma ainda sugere um número mínimo de 6 resultado válidos de tenacidade, em decorrência de algumas limitações este número não pode ser atendido, porém isto apenas reduz a precisão, mas não invalida os resultados apresentados. A Tabela 15 reúne as temperaturas de ensaio praticadas e as temperaturas de referência $T_{0}$ obtidas com as geometrias de corpos de prova ensaiadas para o aço ASTM A285 Gr C. 
Tabela 15 Temperaturas de ensaio praticadas e temperaturas de referência obtidas para o aço ASTM A285 Gr C.

\begin{tabular}{ccc}
\hline Geometria & $\boldsymbol{T}_{\text {ensaio }}$ & $\boldsymbol{T}_{\boldsymbol{0}}$ \\
\hline SE(B) - 1T & $-80^{\circ} \mathrm{C}$ & $-93,5^{\circ} \mathrm{C}$ \\
PCVN-PS & $-80^{\circ} \mathrm{C}$ & $\times$ \\
PCVN-SG & $-80^{\circ} \mathrm{C}$ & $\times$ \\
PCVN-SG $(B=10 \mathrm{~mm})$ & $-105^{\circ} \mathrm{C}$ & $-100^{\circ} \mathrm{C}$ \\
PCVN-SG $(B n=8 \mathrm{~mm})$ & $-105^{\circ} \mathrm{C}$ & $-96,5^{\circ} \mathrm{C}$ \\
\hline
\end{tabular}

\subsection{Aço ASTM A515 Gr 65}

Os mesmos procedimentos adotados para o aço A285 foram repetidos para o aço ASTM A515 Gr 65. A Tabela 16 mostra os valores experimentais de tenacidade à fratura em unidades de $K_{J c}$ obtidos para o SE(B) trinca profunda.

Tabela 16 Valores experimentais de tenacidade convertidos para unidades de $\boldsymbol{K}_{J \boldsymbol{c}} ; \boldsymbol{K}_{J_{c} \_ \text {limite }}$ para 0 corpo de prova SE(B), $B=30 \mathrm{~mm}$ com $a / W=0,5$ e valor calculado de $\boldsymbol{K}_{\boldsymbol{J C}_{\mathbf{n}} \boldsymbol{m e d}}$. Aço ASTM A515 [5].

\begin{tabular}{|c|c|c|c|c|c|c|c|c|c|c|c|}
\hline $\begin{array}{c}\text { Corpo de } \\
\text { Prova }\end{array}$ & 1 & 2 & 3 & 4 & 5 & 6 & 13 & 14 & 15 & 16 & 17 \\
\hline $\begin{array}{c}K_{J c} \\
{[M P a V m]} \\
K_{J c \_l i m i t e}\end{array}$ & 173,2 & 142,5 & 109,5 & 148,2 & 130,4 & 166,6 & 92,5 & 141,0 & 115,1 & 106,8 & 153,1 \\
\hline $\begin{array}{c}{[M P a v m]} \\
K_{J c \_m e d} \\
{[M P a v m]}\end{array}$ & 272,2 & & & & & & & & & & \\
\hline
\end{tabular}

Devido às dimensões do corpo de prova $(B=30 \mathrm{~mm})$ e às propriedades mecânicas do A515, o valor de $K_{J c \_l i m i t e}$ acaba por ser ligeiramente superior ao apresentado para o aço A285. Os valores experimentais de $K_{J c}$ novamente ficaram distantes do 
limite estabelecido. E com base nos 11 ensaios válidos de tenacidade (corrigidos para a espessura 1T) a temperatura de referência para o aço ASTM A515 Gr 65 é:

$$
T_{0}=-41^{\circ} \mathrm{C}
$$

De posse do valor da temperatura de referência do aço A515, a expressão da Curva Mestra e o seu respectivo gráfico são dados, respectivamente, pela equação (64) e pela Figura 46.

$$
K_{J c(m e d)}=30+70 \exp [(0,019(T+41))]
$$

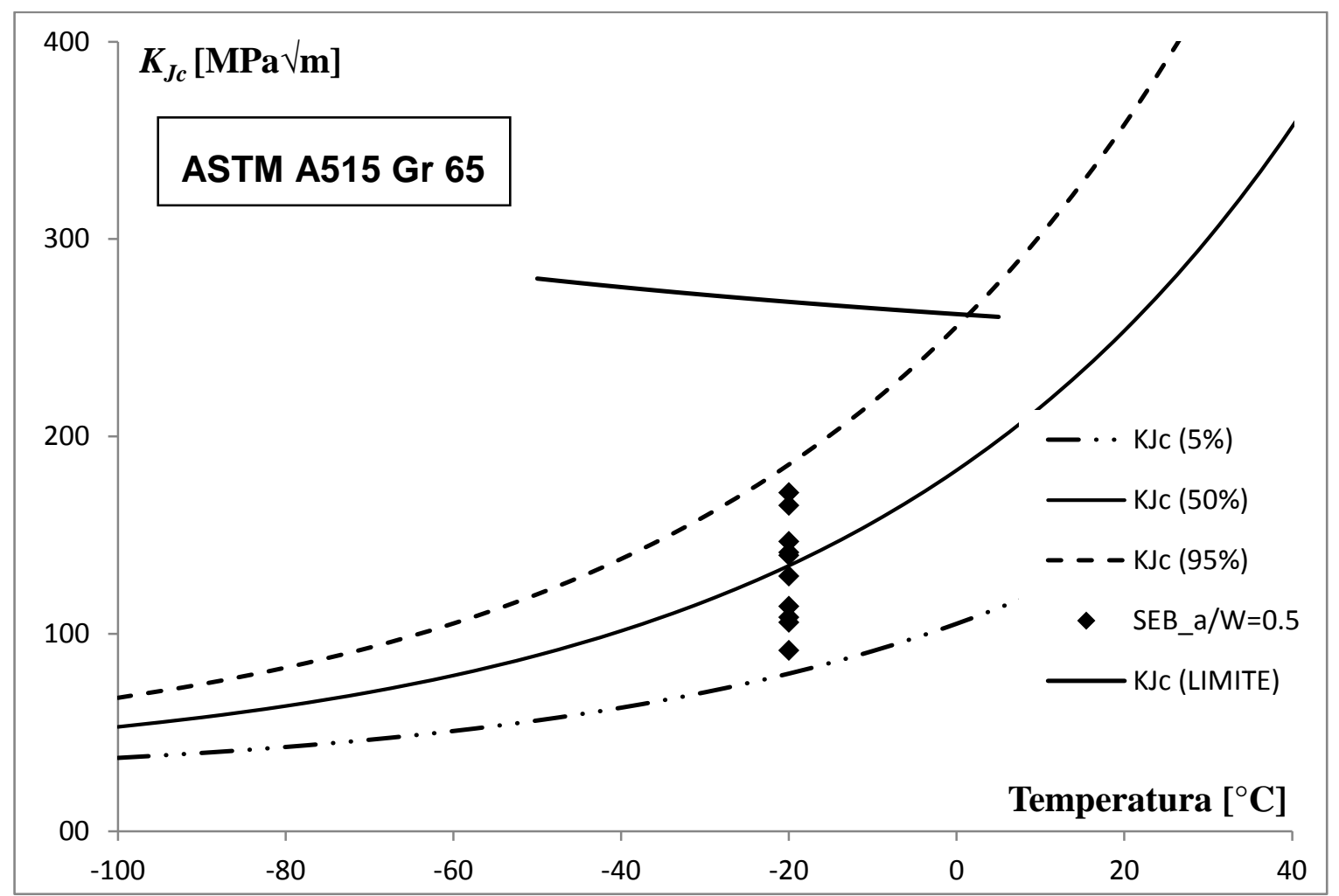

Figura 46. Gráfico representativo da Curva Mestra do aço ASTM A515 Gr 65 e seus intervalos de confiança, dados experimentais obtidos com corpos de prova $\mathrm{SE}(\mathrm{B}), B=30 \mathrm{~mm}, T_{\text {ensaio }}=-20^{\circ} \mathrm{C}$.

$\mathrm{Na}$ Tabela 17 é mostrado o conjunto de dados experimentais para o aço A515 utilizando corpos de prova com geometria PCVN-SG ensaiados à 
$T_{\text {ensaio }}=-65^{\circ} \mathrm{C}$. Apenas nessa temperatura foram obtidos valores válidos de tenacidade à fratura.

Tabela 17 Valores experimentais de tenacidade convertidos para unidades de $\boldsymbol{K}_{\boldsymbol{J c}}$ e $\boldsymbol{K}_{\boldsymbol{J c}}-\mathbf{1 T}$; $\boldsymbol{K}_{J_{c_{-} \text {limite }}}$ para o corpo de prova PCVN-SG, $T_{\text {ensaio }}=-65^{\circ} \mathrm{C}$ e valor calculado de $\boldsymbol{K}_{\boldsymbol{J c}_{\_} \text {med }}$ sem aplicar censura aos resultados. Aço ASTM A515 [5].

\begin{tabular}{|c|c|c|c|c|c|c|}
\hline $\begin{array}{c}\text { Corpo de } \\
\text { Prova }\end{array}$ & 9 & 10 & 11 & 12 & 13 & 14 \\
\hline$K_{J c}[M P a V m]$ & 105,3 & 76,9 & 105.5 & $\underline{141,7}$ & $\underline{139,3}$ & $\underline{124,1}$ \\
\hline$K_{J c}-1 T[M P a V m]$ & 83,9 & 62,6 & 84,0 & 111,1 & 109,4 & 98,0 \\
\hline$K_{J c}$ limite $[M P a v m]$ & 118,8 & & & & & \\
\hline 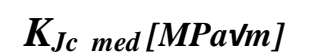 & 131,0 & & & & & \\
\hline
\end{tabular}

Três dos seis resultados de tenacidade, sublinhados na Tabela 17, foram censurados por exceder o valor de $K_{\text {J__limite }} \mathrm{e}$, portanto, a temperatura de referência novamente foi avaliada sob duas condições:

1. Considerando a espessura $B$ igual a $10 \mathrm{~mm}$ (mesmo com os entalhes laterais):

$$
T_{0}=-63,5^{\circ} \mathrm{C}
$$

2. Considerando a espessura, $B=B_{n}$, onde $B_{n}=8 \mathrm{~mm}$ (espessura real da frente de trinca).

$$
T_{0}=-60^{\circ} \mathrm{C}
$$

A curva de tenacidade média em função da temperatura, Curva Mestra, deste material, para $T_{0}=-60^{\circ} \mathrm{C}$ é dada pela equação (65)

$$
K_{J c(m e d)}=30+70 \exp [(0,019(T+60))]
$$

E está representada no gráfico da Figura 47. 


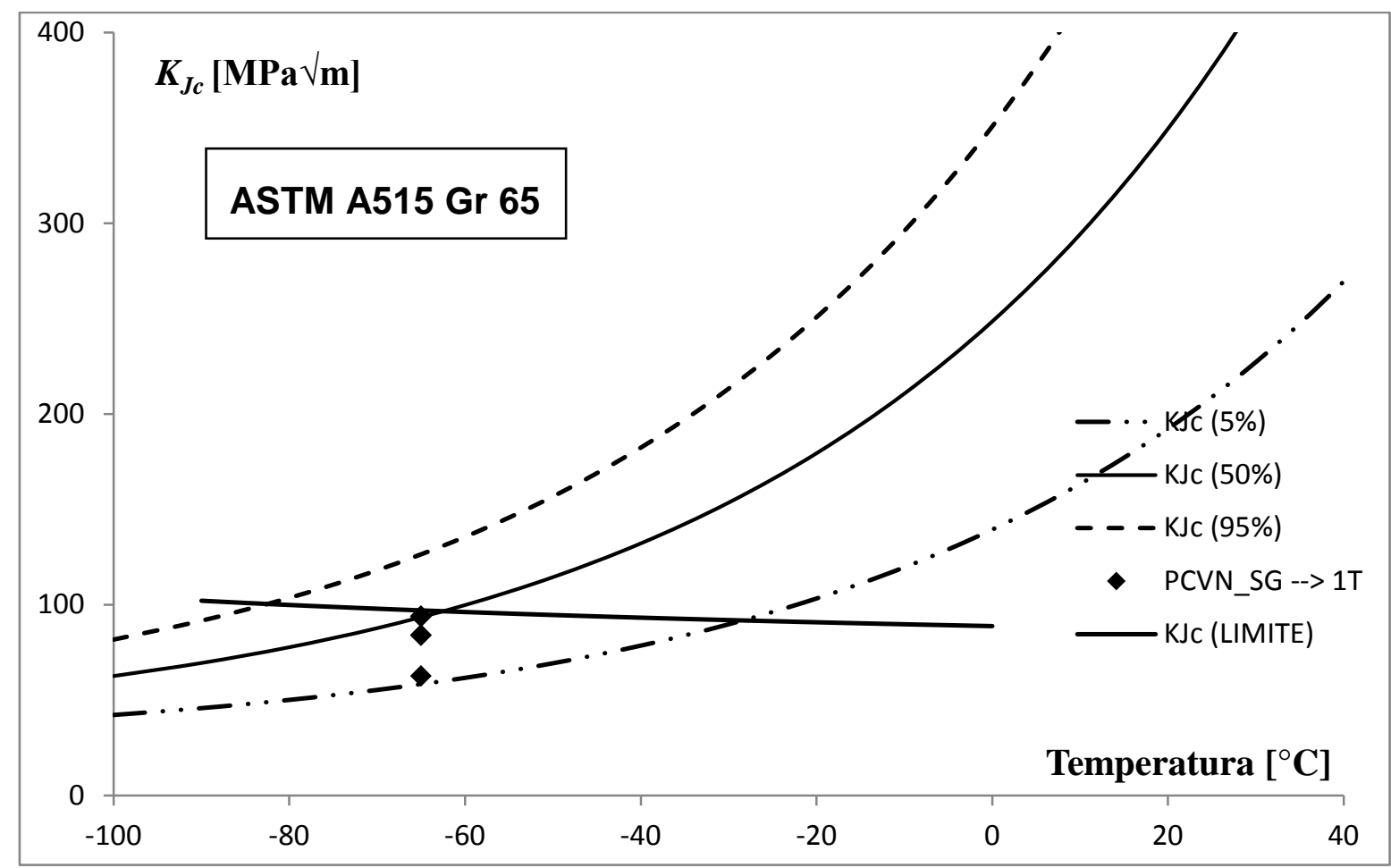

Figura 47. Gráfico representativo da Curva Mestra do aço ASTM A515 Gr 65 e seus intervalos de confiança, dados experimentais obtidos com corpos de prova PCVN-SG, $T_{\text {ensaio }}=-65^{\circ} \mathrm{C}$.

Com base nos resultados obtidos para o aço A515 pode-se concluir que a previsão da temperatura de referência, utilizando corpos de prova com geometria PCVN e entalhes laterais, mesmo à temperatura de ensaio de $-65^{\circ} \mathrm{C}$, não foi precisa. Pois, comparada à referência, $T_{o}^{S E(B)_{-} 1 T}$, a diferença é grande e próxima a $20^{\circ} \mathrm{C}$, para 0 resultado obtido com $B_{n}=8 \mathrm{~mm}$.

Por outro lado, mesmo não sendo uma previsão precisa, essa diferença de valores era provável e esperada, uma vez que resultados semelhantes são reportados em [78 - 80]. A Tabela 18 reúne as temperaturas de ensaio praticadas e as temperaturas de referência $T_{0}$ obtidas para o aço A515 Gr 65. 
Tabela 18 Temperaturas de ensaio praticadas e temperaturas de referência obtidas para o aço ASTM A515 Gr 65.

\begin{tabular}{ccc}
\hline Geometria & $\boldsymbol{T}_{\text {ensaio }}$ & $\boldsymbol{T}_{\boldsymbol{0}}$ \\
\hline SE(B) - 1T & $-20{ }^{\circ} \mathrm{C}$ & $-41{ }^{\circ} \mathrm{C}$ \\
PCVN-PS & $-20{ }^{\circ} \mathrm{C}$ & $\times$ \\
PCVN-SG & $-20{ }^{\circ} \mathrm{C}$ & $\times$ \\
PCVN-SG $(B=10 \mathrm{~mm})$ & $-65^{\circ} \mathrm{C}$ & $-63,5{ }^{\circ} \mathrm{C}$ \\
PCVN-SG $(B n=8 \mathrm{~mm})$ & $-65^{\circ} \mathrm{C}$ & $-60{ }^{\circ} \mathrm{C}$ \\
\hline
\end{tabular}




\section{IMPLICAÇÕES GEOMÉTRICAS SOBRE OS VALORES DE TENACIDADE}

O fenômeno da clivagem transgranular na região de transição dúctil frágil em aços ferríticos é de natureza mecânico-estatística. Entretanto, diversos trabalhos, [74 [80], dão ênfase à perda da restrição plástica na ponta da trinca para justificar a elevação dos valores de tenacidade à fratura por clivagem, geralmente observada em corpos de prova com geometria reduzida, como é o caso do espécime PCVN, em comparação a espécimes de maior espessura.

A perda de restrição plástica eleva a força motriz, integral $J$, necessária para causar a fratura, porém o fenômeno da fratura transgranular na região TDF também depende do tamanho da zona de processo de fratura desenvolvida em cada uma das geometrias ensaiadas, pois é neste local onde há maior probabilidade do surgimento de microtrincas críticas responsáveis por disparar a falha macroscópica. Portanto, é plausível dizer que a perda de restrição plástica não é exclusivamente responsável pela elevação da tenacidade à fratura em corpos de prova PCVN [83].

Apesar de não ser o objetivo principal deste trabalho de pesquisa, foram realizadas análises computacionais, em caráter exploratório, para avaliar a parcela mecânica do fenômeno, com o objetivo de se obter um entendimento maior de como os campos de tensão se comportam para cada uma das geometrias de interesse.

Isolando a resposta mecânica dos corpos de prova é possível observar que a introdução de entalhes laterais adequados altera o perfil de tensões na ponta da trinca dos espécimes PCVN. Desta forma, este espécimes apresentam um comportamento mecânico similar ao observado para o corpo de prova SE(B)-1T com trinca profunda, utilizado neste trabalho como a referência para o cálculo da $T_{0}$.

As propriedades mecânicas utilizadas nas análises numéricas são referentes às do aço ASTM A285 Gr C medidas na temperatura ambiente. Como ambos os aços estudados neste trabalho têm propriedades mecânicas similares (tensão de 
escoamento e encruamento) e as análises computacionais para estudo dos campos de tensão têm viés qualitativo, a repetição das análises utilizando as propriedades mecânicas do aço ASTM A515 Gr 65 não acrescentariam informações relevantes. Detalhes mais aprofundados sobre a abordagem computacional encontram-se nos Anexo D.

\subsection{Avaliação da Integral $J$ na Espessura dos Corpos de Prova}

Inicialmente foi avaliado o desenvolvimento dos níveis de integral $J$ em toda a frente de trinca, para cada uma das configurações de corpo de prova utilizadas na parte experimental do trabalho. Os valores de integral $J$ foram calculados localmente cobrindo toda a espessura dos espécimes desde a simetria em $Z=0$ até a superfície livre, $Z=B / 2$, com incrementos de $20 \%$, conforme mostram os gráficos da Figura 48. 


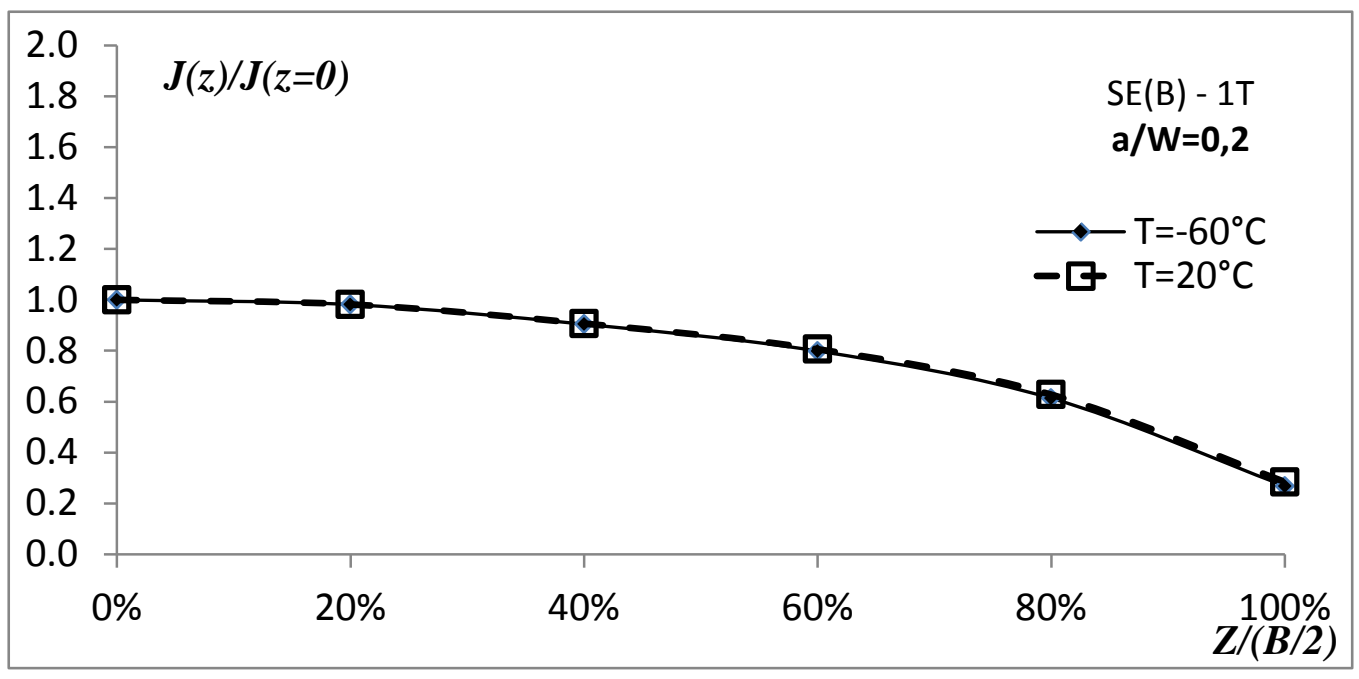

(a)

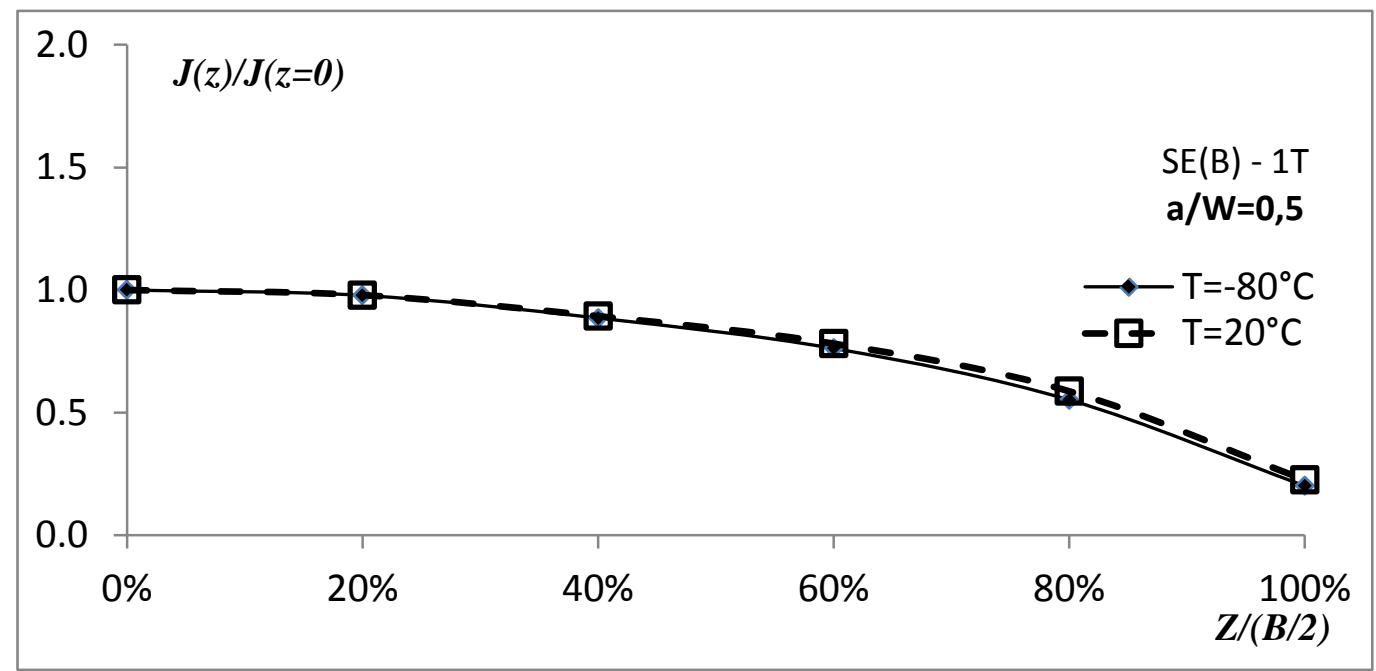

(b)

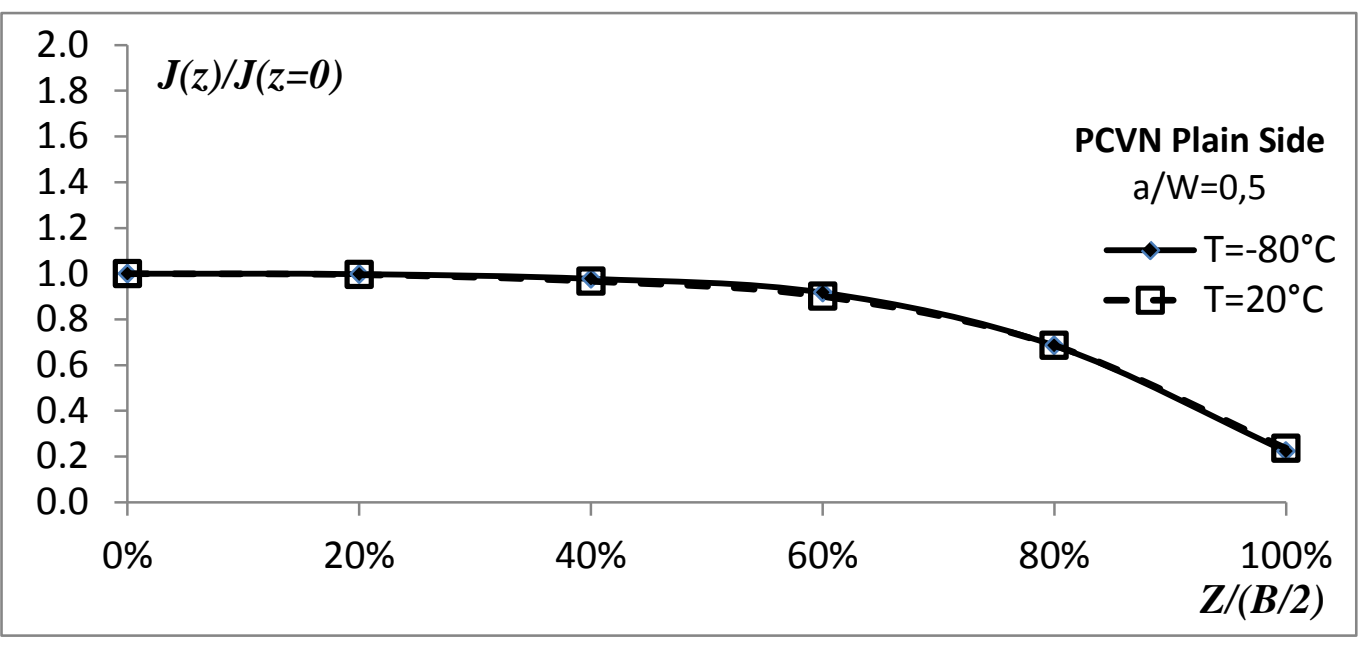

(c)

Figura 48. Avaliação dos valores de integral $J$ na frente de trinca. Corpos de prova com geometria (a) SE(B) trinca rasa; (b) SE(B) trinca profunda; (c) PCVN-PS. 
Os valores locais adimensionalizados de integral $J,\left[J_{(\mathrm{z})} / J_{(\mathrm{z}=0)}\right]$, foram muito similares para os dois espécimes com espessura de 25,4 mm (1T). Pode-se observar que na frente de trinca, até $40 \%$ da espessura, os níveis de $J$ adimensionalizados se mantiveram acima de 0,8 com ligeira tendência de queda. A redução nos valores de $J$ com o distanciamento em relação ao centro está em acordo com a literatura, porém inicialmente acreditava-se que, para o corpo de prova com trinca profunda, esta redução seria observada de forma acentuada somente nas proximidades da superfície livre, conforme Anderson [20].

O corpo de prova PCVN, por outro lado, apresentou um resultado contra intuitivo, mostrando valores de integral $J$ constantes em uma grande extensão de sua espessura. Os valores de $J$ se mantiveram constantes e acima de $80 \%$ do valor de referência $(J$ em $Z /(B / 2)=0)$ em uma extensão superior a $60 \%$ de sua espessura total. Este resultado preliminar é bastante promissor, pois embasa a hipótese inicial de que a elevação aparente da tenacidade à fratura em corpos de prova PCVN não é exclusivamente causada pela perda da restrição plástica na frente de trinca e reforça a possibilidade de recuperação da triaxialidade por meio de alterações de geometria, com a introdução de entalhes laterais.

Também, como resultado destas análises, é possível observar que variações nas propriedades mecânicas decorrentes do abaixamento da temperatura, neste caso simulando a condição encontrada nos ensaios experimentais, não exercem influência significativa nos valores de força motriz. Portanto, decidiu-se por realizar todas as demais análises numéricas com as propriedades do material a temperatura ambiente de $20^{\circ} \mathrm{C}$.

\subsubsection{Avaliação da Integral $J$ na Espessura - Introdução de Entalhes Laterais no Corpo de Prova com Geometria PCVN}

Com o objetivo de uniformizar os valores de $J$ na espessura do corpo de prova PCVN, entalhes laterais com diferentes profundidades foram incorporados aos modelos computacionais mantendo-se o ângulo de abertura de $90^{\circ}$. Por motivos de simplicidade na construção dos modelos de elementos finitos, os entalhes foram 
simulados inicialmente sem raio de ponta e com duas profundidades diferentes, removendo-se $10 \%$ e $20 \%$ de material por lado do corpo de prova, os valores de $J$ locais na frente de trinca podem ser vistos no gráfico da Figura 49.

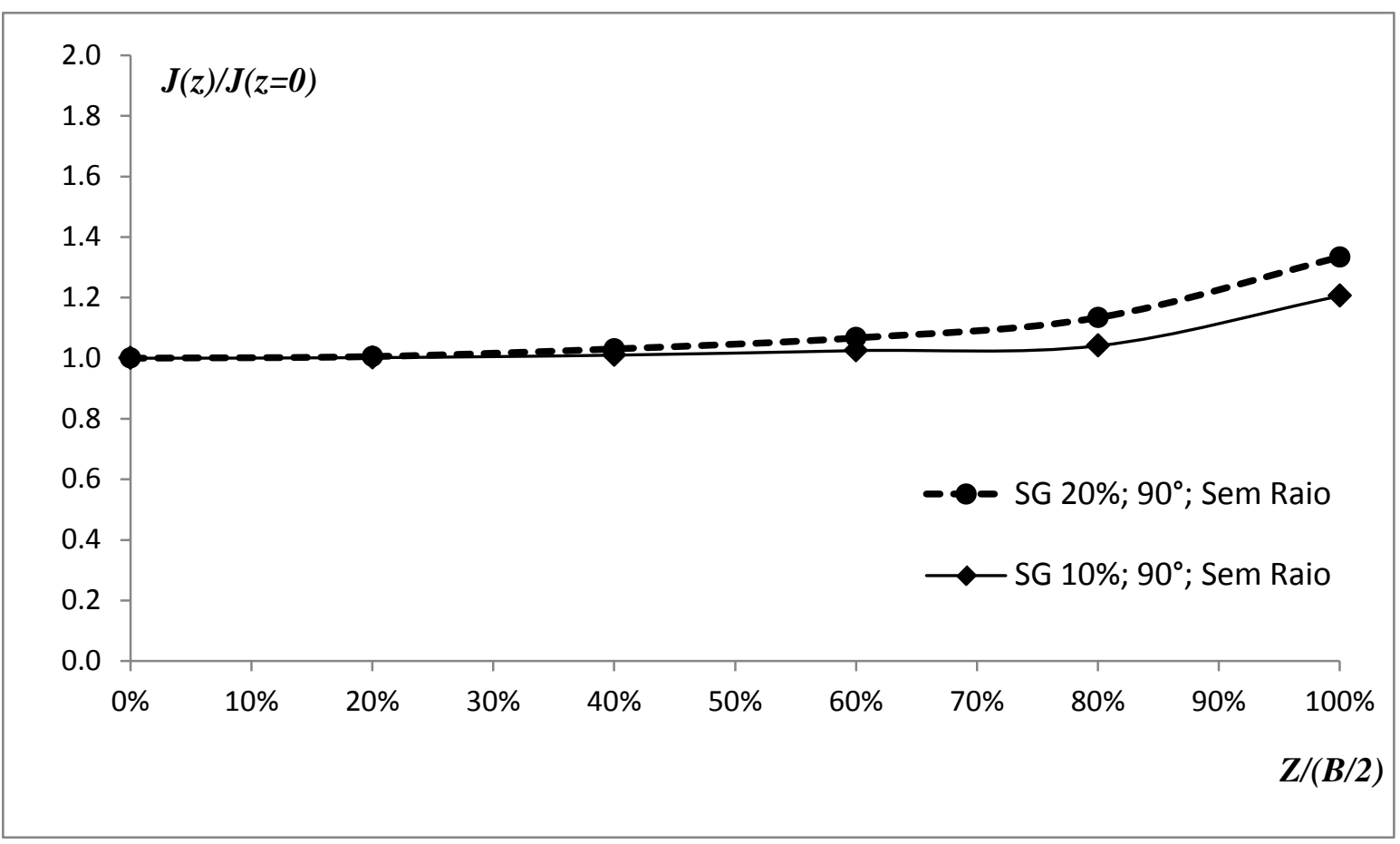

Figura 49. Avaliação de $J$ na frente de trinca PCVN "Side Grooved".

Esse gráfico mostra que apesar da pequena diferença entre as duas configurações o entalhe com $10 \%$ de profundidade por lado e ângulo de abertura de $90^{\circ}$ apresenta resultados ligeiramente melhores, pois gera valores estáveis de $J$ em uma extensão maior da frente de trinca, até aproximadamente $80 \%$ da espessura total em comparação aos $60 \%$ observados para o entalhe mais profundo. E para 0 entalhe mais raso o máximo valor de $J$ obtido, próximo à ponta do entalhe, apesar de estar 20\% acima da referência $(J$ em $Z=0)$ ainda é menor do que o seu comparativo, com valor de $J 30 \%$ superior ao observado no centro do espécime.

O processo de fratura por clivagem transgranular deve ser controlado por tensão e geralmente inicia-se próximo ao centro do corpo de prova onde os níveis de triaxialidade de tensões são mais altos. Porém, a configuração com entalhes sem raio de ponta, pela análise do gráfico, concentra tensão em uma região não desejada do ponto de vista do fenômeno estudado. 
Sem a realização de ensaios experimentais e as devidas análises fractográficas não se pode afirmar que a fratura seria iniciada próxima aos entalhes. Porém, os resultados numéricos apresentam esta possibilidade e, portanto, o modelo de elementos finitos foi refinado de forma a incorporar um raio de ponta de $0,5 \mathrm{~mm}$, uma vez que essa dimensão foi escolhida por ser sugerida por norma. No gráfico da Figura 50 é possível observar o efeito da introdução deste raio de ponta no entalhe lateral.

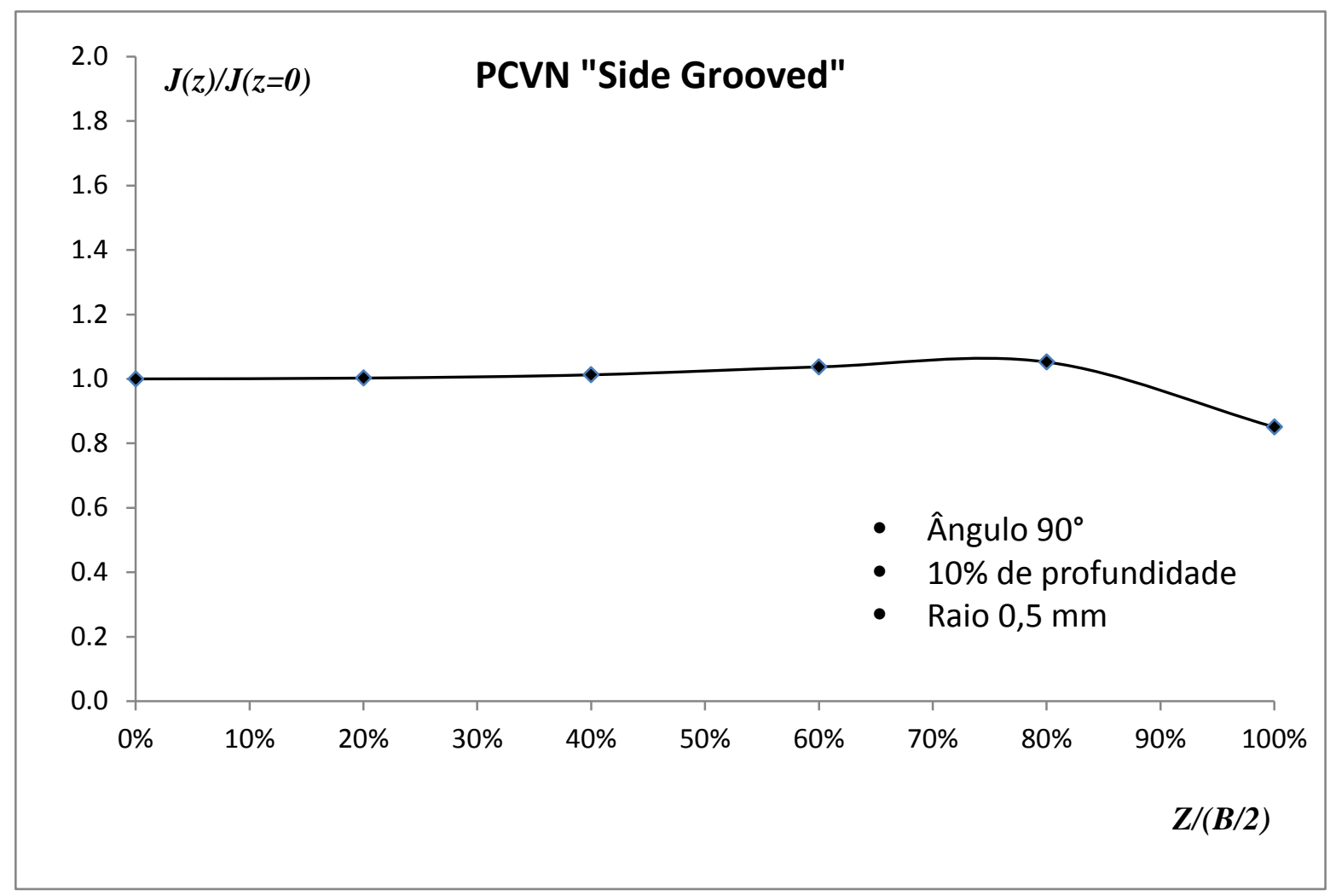

Figura 50. Efeito do raio de ponta sobre os valores locais de $J$ na frente de trinca.

Conforme esperado o raio de ponta reduz localmente a concentração de tensões provocada pelo entalhe lateral, proporcionando uma distribuição uniforme e bastante próxima aos níveis de $J$ obtidos no centro do corpo de prova. Finalmente para encerrar estas análises exploratórias sobre o efeito do entalhe lateral na distribuição da força motriz próximo à frente de trinca, outras configurações com diferentes profundidades e ângulo de abertura foram simuladas. No gráfico da Figura 51 é possível ver o resultado para cada uma delas. 


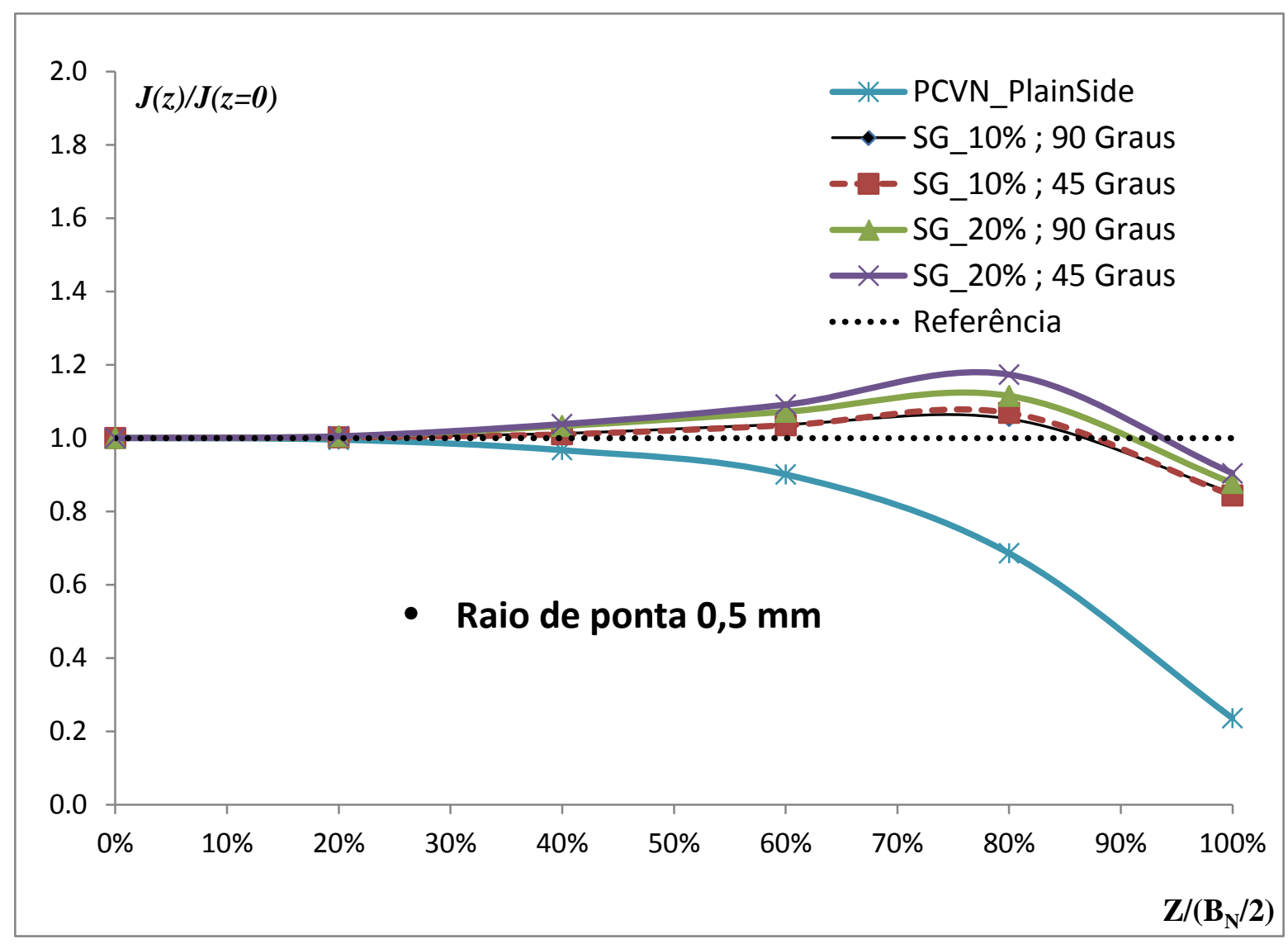

Figura 51. Efeito do raio de ponta e dos ângulos de abertura sobre os valores locais de $\mathrm{J}$ na frente de trinca.

A análise do gráfico acima mostra que as duas configurações de entalhe lateral com profundidade de $10 \%$ por lado são as mais adequadas para serem adotadas, pois geram valores de $J$ constantes em uma grande porção da extensão da frente de trinca, até $60 \%$ da espessura, com pequeno desvio, não superior a $10 \%$ da referência a partir de $80 \%$ da espessura até a superfície livre do corpo de prova.

Portanto, os entalhes laterais são eficientes em equalizar os valores de força motriz em praticamente toda a extensão da frente de trinca e indicam ser uma solução promissora para evitar a perda de restrição plástica comumente observada em corpos de prova de tamanho reduzido. 


\subsubsection{Avaliação dos Níveis de Restrição Plástica na Ponta da Trinca - Metodologia $J-Q$}

Uma vez avaliada e confirmada a possibilidade de modificar o perfil de distribuição dos valores de força motriz na frente de trinca por meio de alteração geométrica da seção de ensaio dos corpos de prova PCVN com a introdução de entalhes laterais, foi possível avançar à etapa de avaliação dos campos de tensão de cada uma das configurações simuladas, utilizando a metodologia $J$-Q (para maiores detalhes ver Anexo D.3). Nessas análises foi possível determinar comparativamente os níveis de triaxialidade de tensão desenvolvidos nas frentes de trinca, para cada espécime em diferentes pontos da espessura e, assim, definir a configuração mais adequada de entalhe lateral com o intuito de se obter, em média, valores experimentais mais baixos de tenacidade à fratura.

Inicialmente foi avaliado o efeito da temperatura sobre os valores de $J$ - $Q$, conforme ilustra o gráfico da Figura 52.

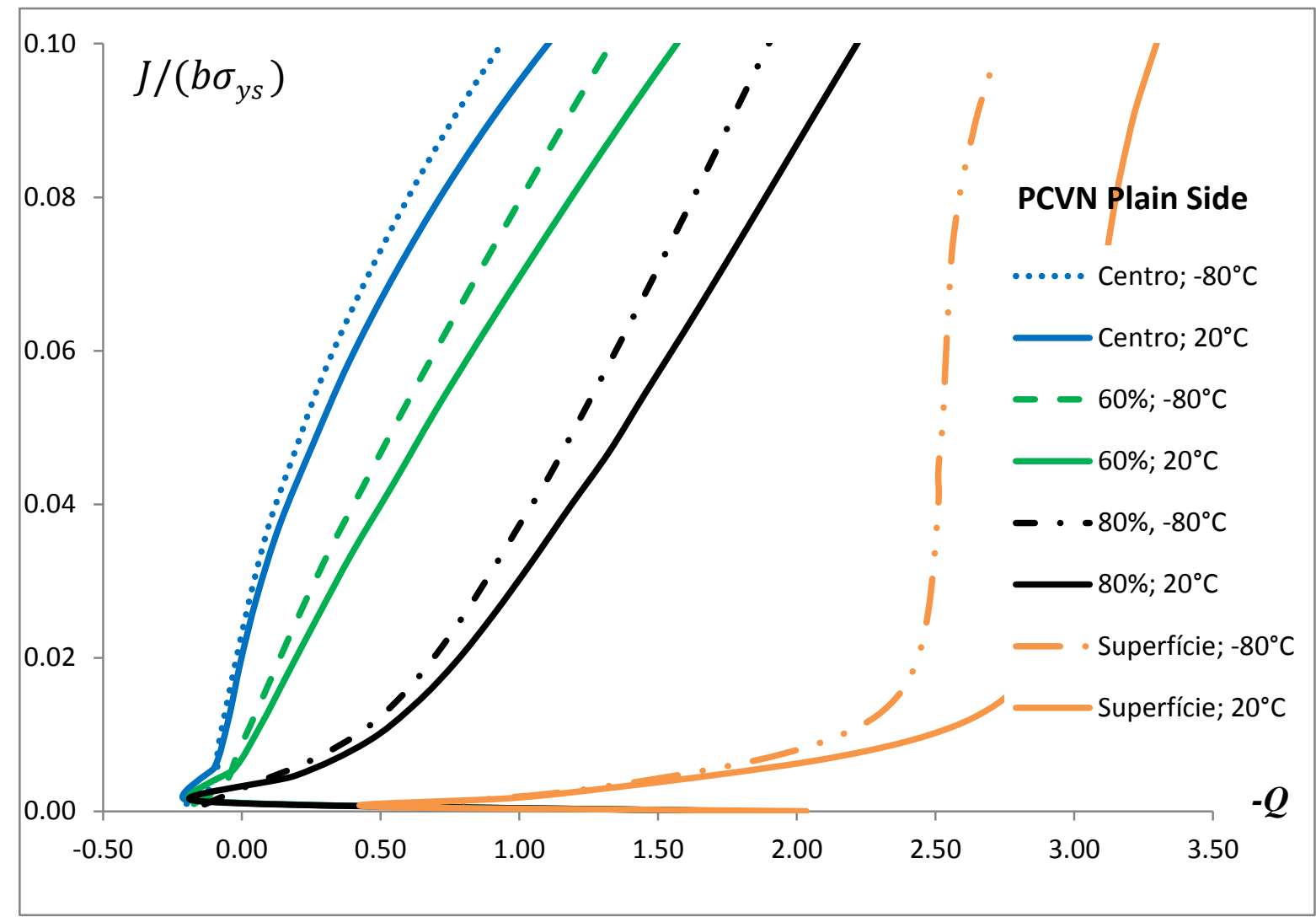

Figura 52. Efeito da temperatura sobre os valores de $J$-Q. Corpo de prova PCVN sem entalhe lateral. 
A variação de temperatura não altera significativamente a trajetória das curvas. Nota-se apenas que, para temperaturas mais baixas, $T=-80^{\circ} \mathrm{C}$ (curvas pontilhadas), essas são deslocadas para esquerda, indicando que possuem, a restrição plástica na frente de trinca aumentada.

Esse deslocamento para a esquerda é de valor constante em praticamente toda a extensão da frente de trinca. Porém, como as análises das trajetórias $J-Q$ são de natureza qualitativa e de forma a manter o padrão estabelecido nas análises feitas no tópico anterior, os resultados apresentados a seguir foram gerados a partir de análises numéricas adotando-se propriedades mecânicas do material a temperatura de $20^{\circ} \mathrm{C}$.

No gráfico da Figura 53 são mostradas as trajetórias $J$-Q adimensionalizadas para os corpos de prova PCVN-PS e SE(B)-1T com trinca profunda. A perda de restrição plástica do PCVN-PS, representado pelas curvas tracejadas e pontilhadas, é no geral menor do que a observada para o SE(B)-1T, pois todas as suas curvas estão deslocadas ligeiramente para uma porção mais à esquerda do gráfico do que as curvas para o SE(B)-1T.

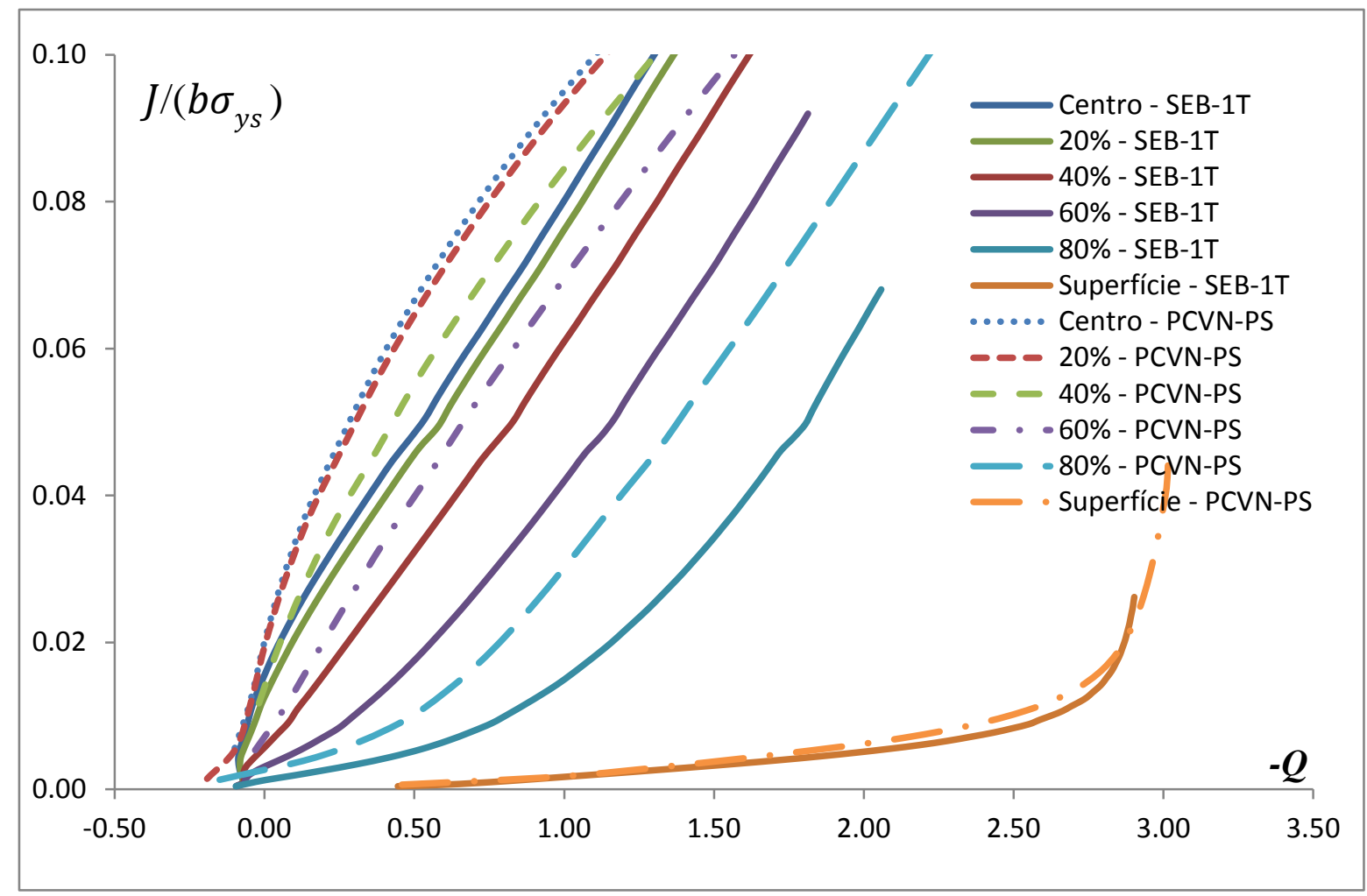

Figura 53. Gráfico comparativo das trajetórias $J-Q$ ao longo da espessura do corpo de prova para as geometrias SE(B)-1T e PCVN. 
Este resultado é relevante, pois se contrapõe ao argumento de que os altos valores de tenacidade à fratura obtidos para o PCVN em programas experimentais são decorrentes da alta perda de restrição plástica comumente observada em corpos de prova com dimensões reduzidas, [75 - [77]. Evidencia-se pelos resultados da Figura 53 que o aumento da tenacidade à fratura para o PCVN quando comparado ao SE(B)-1T não pode ser totalmente atribuído aos níveis de triaxialidade de tensões desenvolvidos na frente de trinca, mesmo sendo notável a variação de tais níveis em relação ao centro do corpo de prova onde o valor é máximo.

Conforme dito anteriormente, a introdução de entalhes laterais no espécime PCVN tem por objetivo reduzir a variação da restrição plástica na frente de trinca recuperando assim os níveis de triaxialidade de tensões observados no centro do corpo de prova. O gráfico da Figura 54 ilustra com clareza o efeito obtido com os entalhes laterais (linhas pontilhadas).

Portanto, elevando-se os níveis de restrição plástica em toda a espessura do corpo de prova espera-se conseguir a diminuição nos valores experimentais de tenacidade à fratura, contribuindo assim, para o atingimento dos requisitos relativos a $J_{\text {limite }}$ estabelecidos pela norma ASTM E1921 [14] para a determinação da temperatura referência, $T_{0}$. 


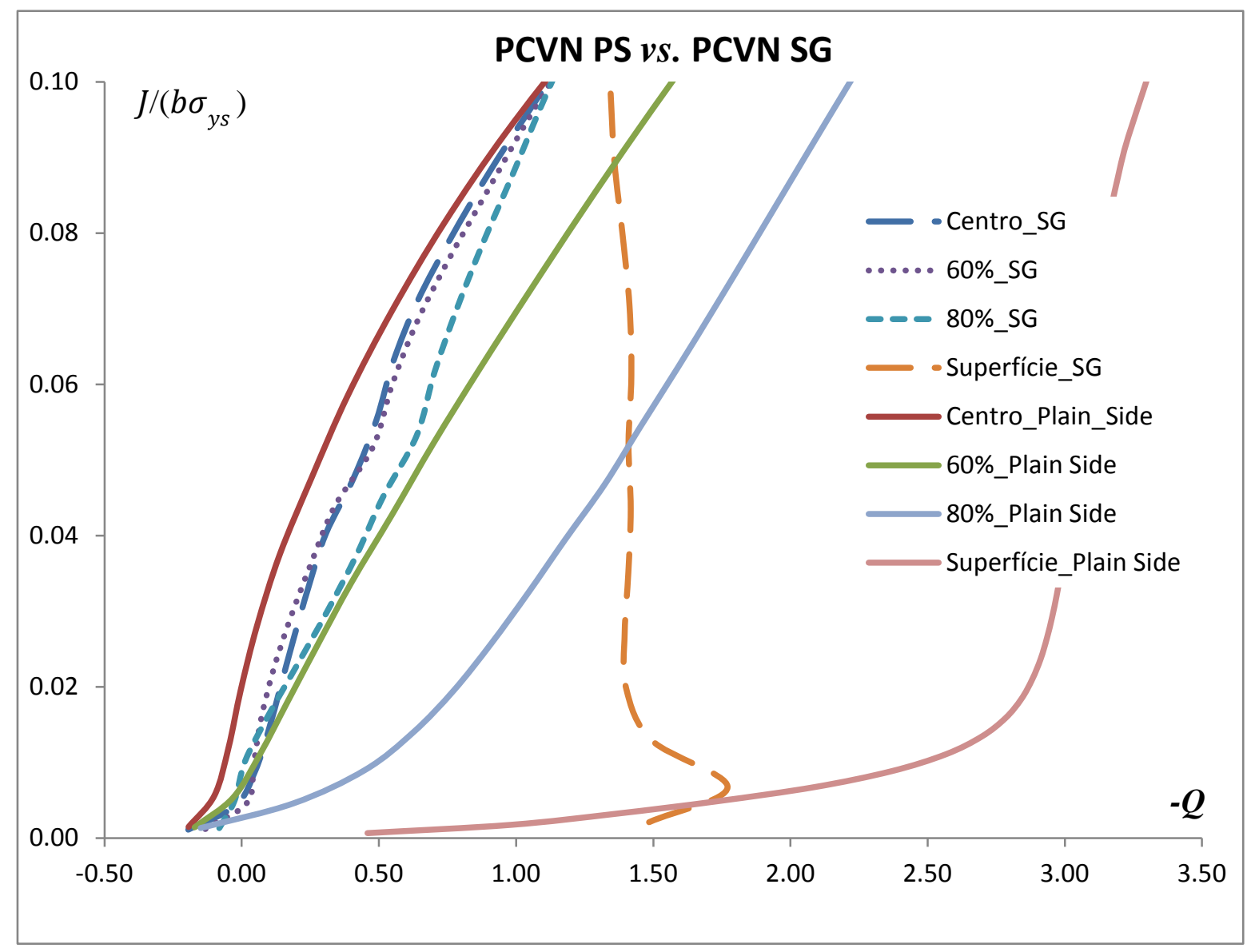

Figura 54. Gráfico comparativo das trajetórias $J-Q$ ao longo da espessura do corpo de prova para as geometrias PCVN sem entalhe lateral ("Plain Side") e PCVN com entalhes laterais ("Side Grooved') e ausência de raio de ponta.

Mesmo tendo nas análises anteriores argumentos para descartar a utilização de espécimes PCVN com entalhes laterais sem raio de ponta, em decorrência dos seus efeitos sobre o perfil de $J$ na frente de trinca, foi realizada a análise da influência desta variação de entalhe, sem/com raio de ponta, sobre os níveis de restrição plástica, conforme ilustra o gráfico da Figura 55. Os resultados comparativos entre os espécimes com e sem raio de ponta mostram que, mesmo próximo à superfície livre os níveis de restrição plástica são muito parecidos e também não apresentam alterações significativas ao longo da espessura. Assim sendo, a existência ou não do raio de ponta não influência os níveis de restrição plástica dos corpos de prova PCVN com entalhe lateral. 


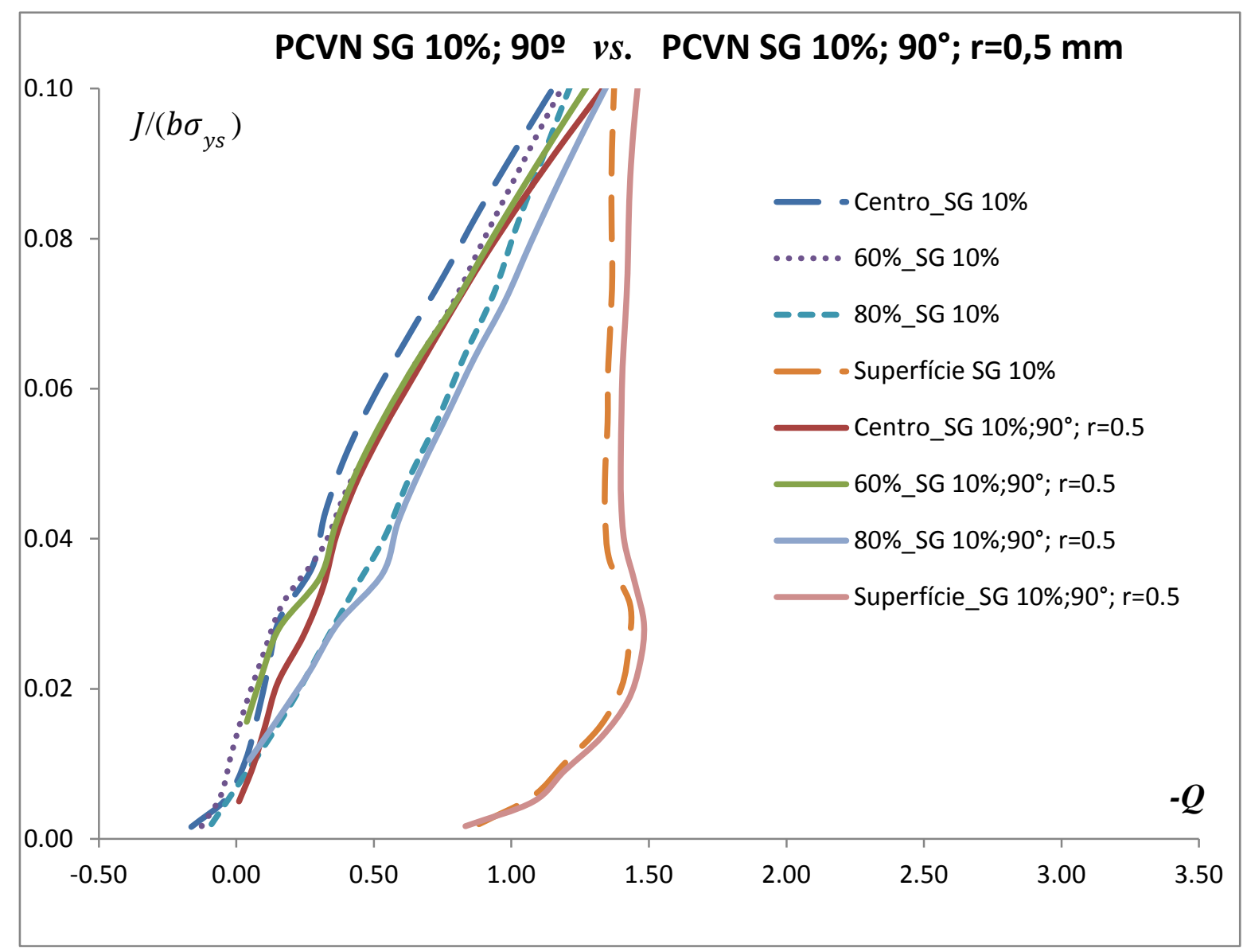

Figura 55. Gráfico comparativo das trajetórias $J-Q$ ao longo da espessura do corpo. Geometrias PCVN-SG ("Side Grooved") com e sem raio de ponta.

No gráfico Figura 56 são mostradas as trajetórias $J-Q$ para as duas geometrias de entalhe lateral que proporcionaram a distribuição mais constante de $J$ em toda a extensão da frente de trinca. A configuração com profundidade de $10 \%$ da espessura por lado, ângulo de abertura do entalhe de $45^{\circ}$ e raio de ponta de 0,5 (linha tracejadas) apresenta um pequeno deslocamento do conjunto de curvas para a esquerda concentrando-as próximas aos valores de $J$-Q obtidos na porção central do espécime evidenciando ser esta a geometria de entalhe lateral mais promissora para ser adotada nas atividades experimentais. 


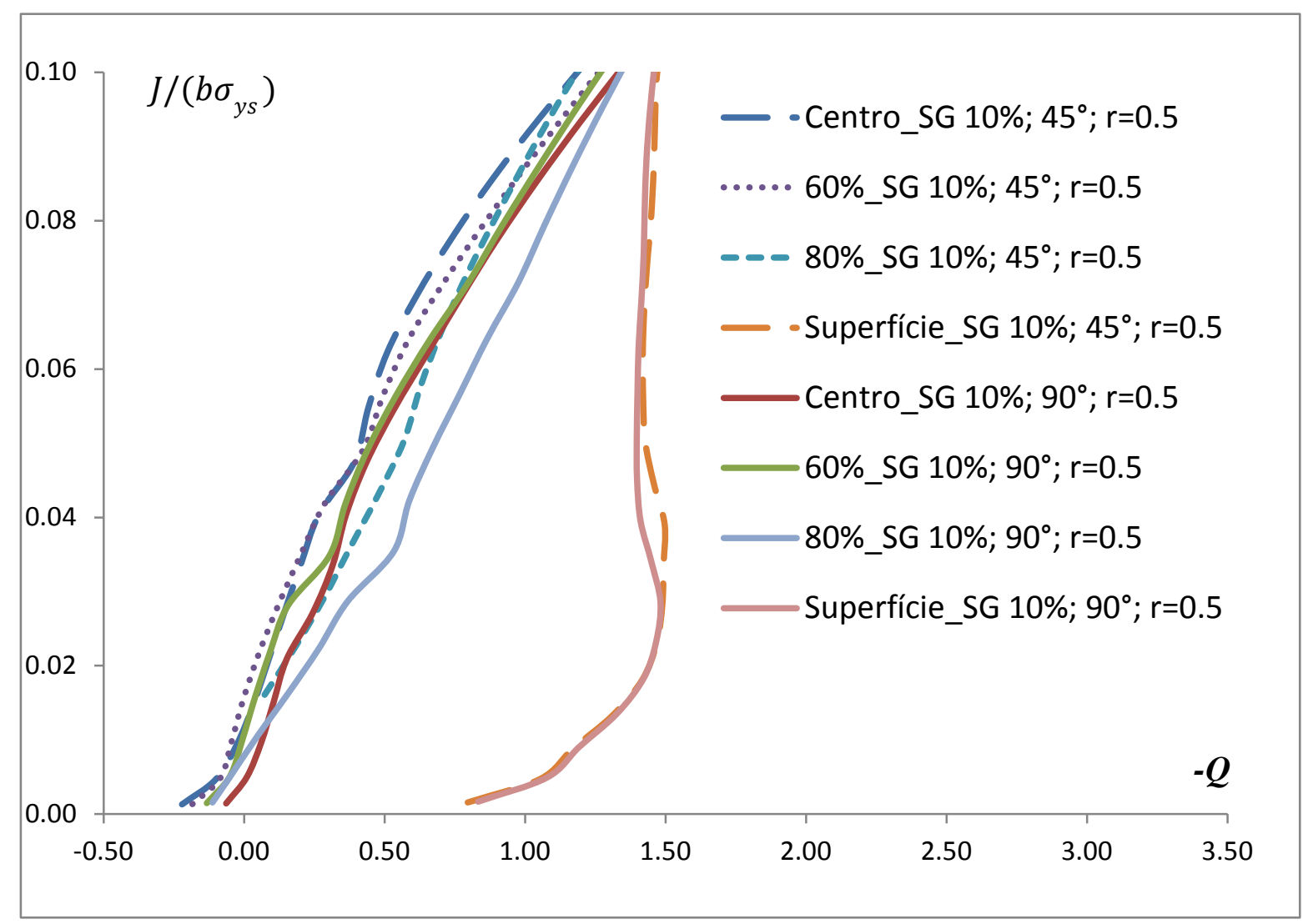

Figura 56. Gráfico comparativo das trajetórias $J-Q$ ao longo da espessura do corpo de prova. Geometrias PCVN-SG ("Side Grooved") variando o ângulo de abertura do entalhe.

Finalmente o gráfico da Figura 57 mostra uma comparação dos resultados do PCVN-SG, referente à melhor geometria, aos obtidos para corpo de prova $\mathrm{SE}(\mathrm{B})$ $1 T$, estabelecido como o padrão para as atividades experimentais. Conclui-se que os níveis de restrição plástica do PCVN-SG são corrigidos para valores muito próximos ao encontrado no centro do espécime $\mathrm{SE}(\mathrm{B})-1 \mathrm{~T}$. Esta correção se manifesta no deslocamento para a esquerda de todas as trajetórias $J$-Q (linhas contínuas) obtidas nos pontos de interesse da frente de trinca, com uma única exceção para camada mais próxima à superfície livre. 


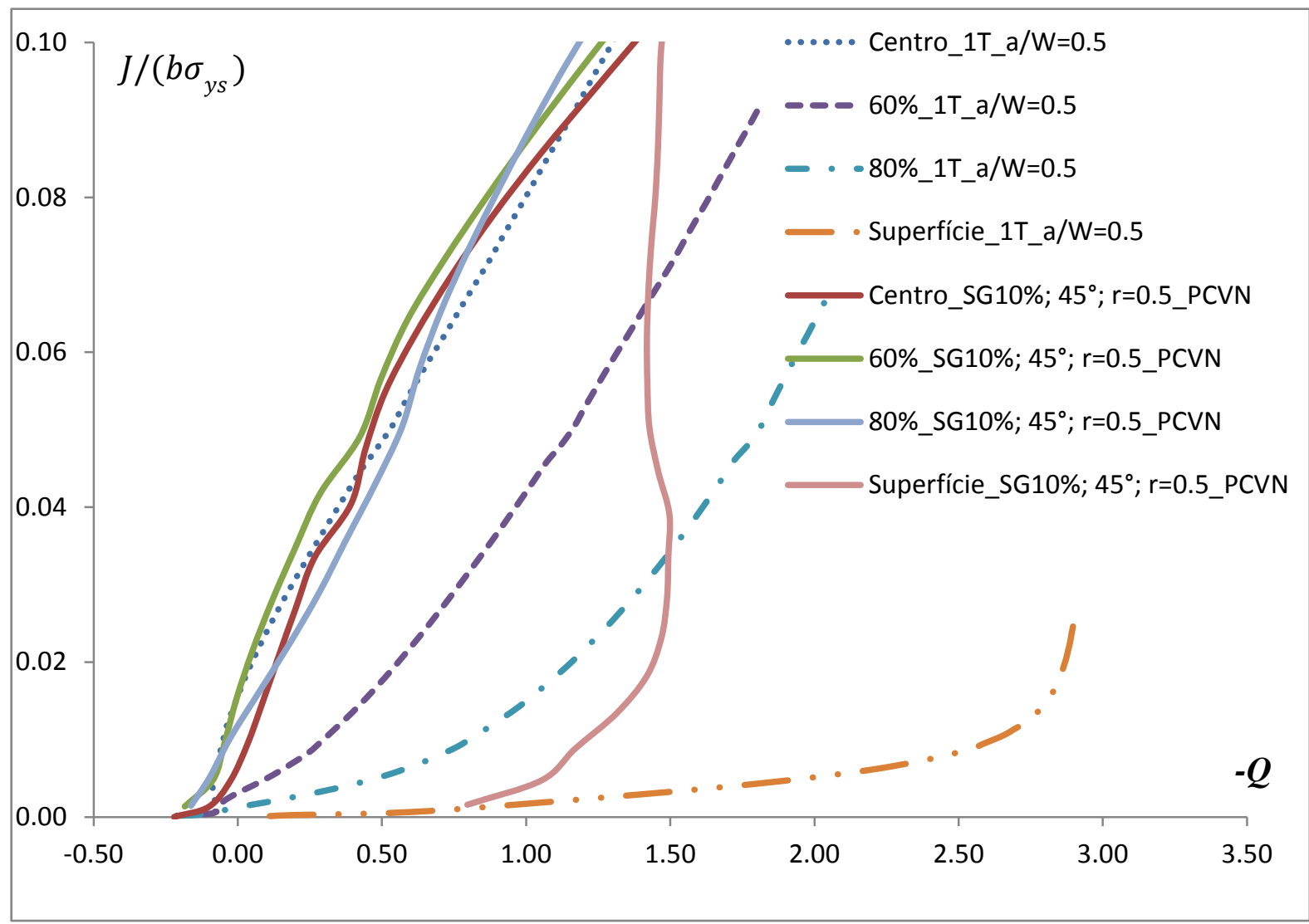

Figura 57. Gráfico comparativo das trajetórias $J-Q$ ao longo da espessura do corpo de prova para as geometrias SE(B)-1T e PCVN com entalhes laterais ("Side Grooved").

\subsubsection{Comparação das Zonas de Processo de Fratura (ZPF)}

Finalmente, como tentativa de explicar a grande diferença entre os valores de tenacidade observados para as duas principais geometrias utilizadas na determinação da temperatura de referência $T_{0}$, foram geradas imagens dos contornos da zona de processo de fratura (ZPF) desenvolvida nesses espécimes. As franjas observadas na Figura 58 delimitam a ZPF para o critério de $\sigma_{1} \geq 2 \sigma_{y s}$, onde $\sigma_{1}$ é a máxima tensão principal [83] e os dois tons observados nas imagens decorrem dos níveis de carregamento impostos. Tais níveis têm como base o Limite de Deformação Plástica, representada pela mancha escura, $M=60$, onde as condições SSY estão bem garantidas e pela mancha clara, $M=30$, onde se tem o limite para o início da condição de escoamento de grande monta ("Large Scale Yield" (LSY)). 


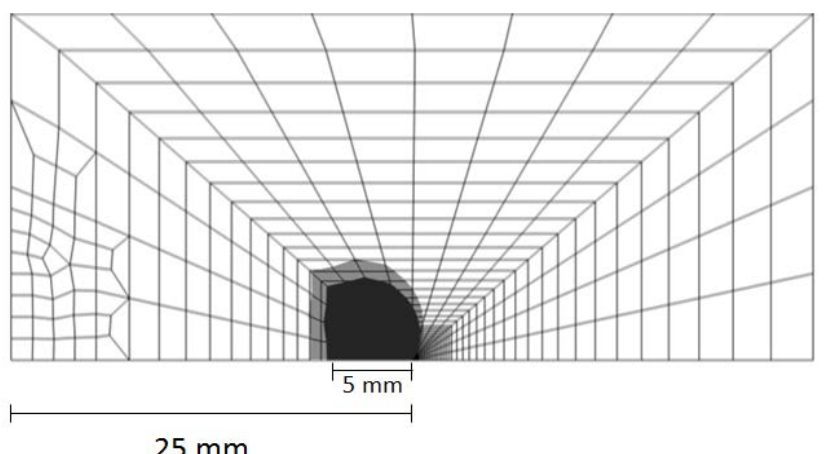

$25 \mathrm{~mm}$

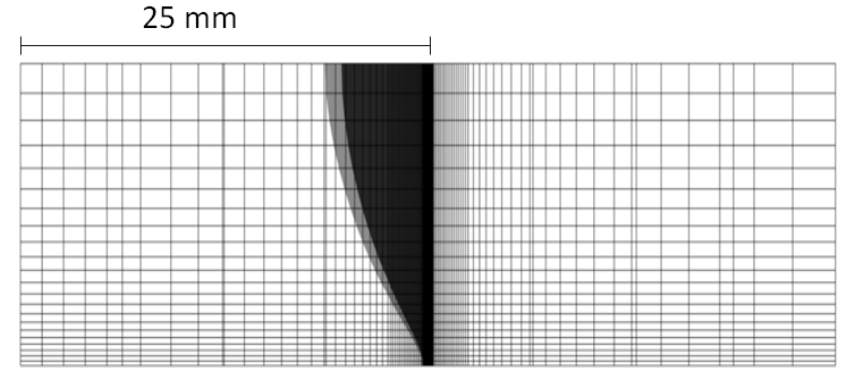

(a)

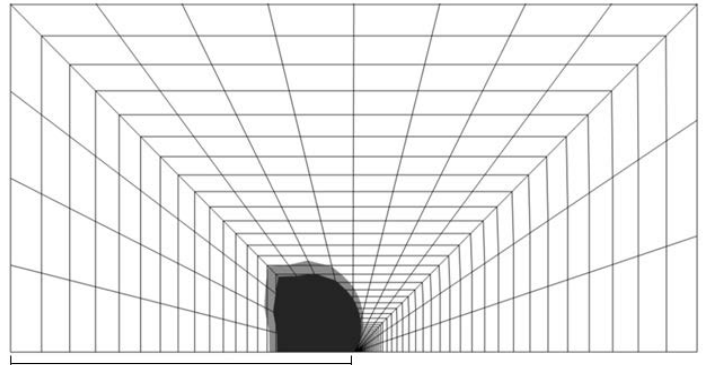

$5 \mathrm{~mm}$

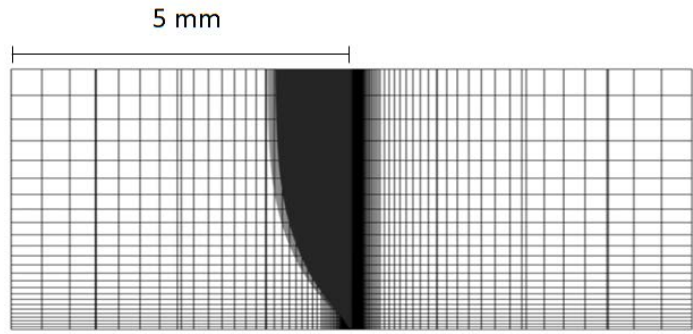

(b)

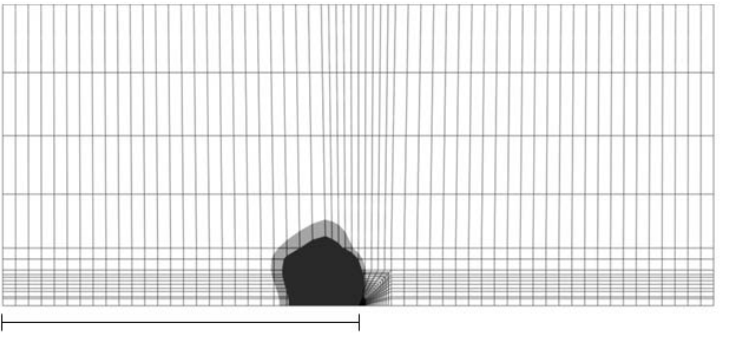

$5 \mathrm{~mm}$

$5 \mathrm{~mm}$

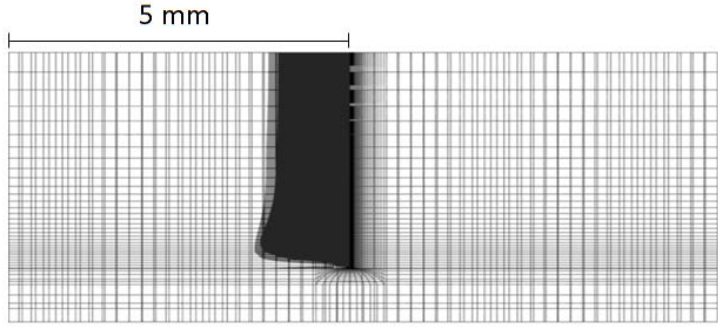

(c)

Figura 58. Imagens representativas das franjas que delimitam a Zona de Processo de Fratura desenvolvidas na frente da trinca para os corpos de prova com a geometria: (a) $S E(B)-1 T$ trinca profunda plano $X Y$ e $X Z$, (b) PCVN sem entalhes laterais plano XY e XZ e (c) PCVN com entalhes laterais plano $X Y$ e $X Z$. Zona Escuras $M=60$ e Zona Clara $M=30$. 
Portanto, enquanto os resultados observados na seção anterior, trajetórias $J-Q$, demonstram haver similaridades no comportamento mecânico dos três espécimes não justificando a grande diferença de tenacidade obtida nos resultados experimentais, neste caso observa-se uma grande diferença no tamanho das ZPF. Este pode ser um forte argumento para justificar o aumento da tenacidade à fratura do espécime PCVN.

Para o SE(B) trinca profunda, Figura 58 (a), a zona onde $\sigma_{1}$ excede $\sigma_{y s}$ é extensa na porção central do corpo de prova, porém não se mantém constante ao longo espessura do espécime, decaindo gradualmente até a superfície livre. Para os dois níveis de carregamento impostos observa-se um incremento próximo a $25 \%$ na extensão linear da ZPF quando $M=30$, esta diferença se mantém constante em relação à zona definida no carregamento menor $(M=60)$ em praticamente toda a extensão da frente de trinca, deixando de existir próximo à superfície.

Para o PCVN-PS, Figura 58 (b), tem-se um comportamento similar ao observado para o $\mathrm{SE}(\mathrm{B})$, sendo que os valores de $\sigma_{1}$ se mantêm constantes em uma porção ligeiramente maior da frente de trinca a partir do centro do espécime. Porém, com o aumento do carregamento, a análise qualitativa das imagens mostra não haver um incremento da ZPF nas mesmas proporções da encontrada para o seu comparativo, SE(B)-1T trinca profunda. Isto poderia explicar os altos níveis de $J$ exigidos para causar a falha no PCVN.

Com a introdução dos entalhes laterais, Figura 58 (c), altera-se o perfil de $\sigma_{1}$ e este passa a ser constante em toda a frente de trinca, a partir da imagem pode-se constatar o aumento da extensão linear da ZPF em relação ao PCVN-PS. Portanto, o maior volume da ZPF implica em uma maior probabilidade de que defeitos distribuídos na matriz do material tornem-se microtrincas críticas, podendo assim evoluir para uma fratura por clivagem em níveis de carregamento mais baixos, como o constatado no programa experimental. 


\section{CONCLUSÕES E SUGESTÕES PARA ESTUDOS FUTUROS}

\subsection{Comentários Finais}

A caracterização da tenacidade à fratura por clivagem na região TDF, utilizando espécimes $1 \mathrm{~T}$ com trinca profunda, gerou temperaturas de referência, $T_{0}$, precisas e confiáveis para balizar os resultados obtidos com o corpo de prova PCVN, pois:

- Em todos os ensaios realizados com o espécime 1T não se observou indícios de desenvolvimento de plasticidade além dos limites permitidos, caracterizando um processo de fratura por clivagem controlado por tensão.

- A distribuição teórica de Weibull com módulo $\alpha=2$ descreveu com precisão a distribuição dos valores experimentais de tenacidade à fratura $\left(J_{c}\right)$.

- A capacidade de carga suportada pelos espécimes $1 T$ é bastante alta e os valores experimentais de $J_{c}$ ficaram distantes do valor limite, $J_{\text {Limite, }}$ que se fosse superado, haveria violação da condição de escoamento de pequena monta, SSY, censurando os resultados.

A geometria PCVN é de grande importância, pois há situações onde os procedimentos de avaliação de integridade estrutural só se fazem viáveis com o uso de espécimes reduzidos. Estes espécimes proporcionam vantagens significativas na prática experimental, já citadas anteriormente, porém exigem um protocolo de ensaio diferente daquele utilizado para o corpo de prova com espessura 1T.

Os resultados experimentais com o PCVN indicam que a capacidade de medição das propriedades de tenacidade à fratura, em regime dúctil-frágil de aços de resistência moderada, pode ser comprometida. Na configuração sem entalhes laterais, esses apresentaram valores de tenacidade característica, $J_{0}$, de 2 a 4 vezes maiores do que aqueles obtidos com os espécime SE(B)-1T com trinca profunda. 
Tais resultados inviabilizam a geração de valores válidos de tenacidade à fratura, segundo os critérios da norma ASTM E 1921 [14]. Além disso, apenas a redução da temperatura de teste para a obtenção de resultados válidos, não é recomendada, pois isso exigiria temperaturas extremamente baixas o que impactaria fortemente a correta determinação da $T_{0}$.

Os ensaios experimentais mostraram haver um efeito combinado entre a geometria do corpo de prova e a temperatura de ensaio sobre os valores de tenacidade à fratura. A diminuição da temperatura de teste e a utilização do PCVN-SG resultaram em uma distribuição de probabilidade de falha muito próxima daquela obtida com o corpo de prova padrão SE(B)-1T trinca profunda.

Os entalhes laterais reduziram sensivelmente os valores de tenacidade à fratura, e a geometria sugerida de entalhe, além de uniformizar a distribuição de $J$ em toda a frente de trinca, gerou níveis de restrição plástica no PCVN-SG similares ao encontrado no centro do espécime SE(B)-1T. Dessa forma, a utilização de entalhes laterais mostrou ser uma condição obrigatória, porém não suficiente, para a obtenção de valores válidos de $J_{c}$.

Ainda sobre a geometria PCVN-SG, quando for realizada a correção da tenacidade pelo efeito da espessura, sugere-se adotar o valor efetivo da frente de trinca $(B=$ $B_{n}$ ), pois os resultados assim obtidos são mais próximos à $T_{0}$ de referência, calculada com o espécime padrão, SE(B)-1T.

Portanto, o conjunto dos resultados apresentados proporciona embasamento consistente para a utilização do PCVN, com entalhes laterais, para caracterização da tenacidade à fratura de aços ferríticos de resistência moderada, na região TDF, por meio da metodologia da Curva Mestra. 


\subsection{Sugestões para Estudos Futuros}

Apesar de, na presente tese, ter sido realizado um grande esforço experimental, explorado o comportamento mecânico de corpos de prova com dimensões reduzidas e a sua aplicação na determinação da Curva Mestra, alguns pontos relevantes não puderam ser abordados e, portanto, serão listados como sugestões para estudos futuros:

- Os dois materiais utilizados no programa experimental apresentaram propriedades mecânicas similares, principalmente quanto ao nível de encruamento, $n \sim 5$. Sugere-se então a repetição destas análises utilizando materiais com capacidade de encruamento diferentes, $n>10$, com posterior validação do uso de PCVN-SG para a determinação da temperatura de referência $T_{0}$, bem como a avaliação do limite de deformação plástica, $M$, para esta geometria.

- $\quad$ Aplicar uma abordagem com escopo metalúrgico para estudar o fenômeno da fratura frágil utilizando-se espécimes PCVN. Apesar de violarem os valores limites de tenacidade estabelecidos por norma, o aspecto visual das frentes de trinca não mostram evidências claras de desenvolvimento de plasticidade, portanto, análises fractográficas poderiam ser realizadas nesta avaliação, para verificação de um possível excesso de conservadorismo no critério da norma ASTM E1921 para o $K_{J c-l i m i t e}$ permitido para os corpos de prova PCVN.

- Expandir as análises desta tese para uma maior variedade de aços buscando validar o uso do PCVN-SG na determinação da Curva Mestra. 


\subsection{Trabalhos Publicados}

- Ruggieri, C.; Savioli, R. G.; Dodds, R. H.. An Engineering Methodology for Constraint Corrections of Elastic-Plastic Fracture Toughness - Part II: Effects Of Specimen Geometry And Plastic Strain On Cleavage Fracture Predictions. Engineering Fracture Mechanics, v. 146, p. 185-209, 2015.

- Savioli, R. G., Ruggieri, C.. Experimental Study on the Cleavage Fracture Behavior of an ASTM A285 Grade C Pressure Vessel Steel. Journal of Pressure Vessel Technology, v. 137, p. 1-7, 2014.

- Ruggieri, C.; Savioli, R. G.; Dodds, R. H.. Fracture Toughness Predictions Using the Weibull Stress Model with Implications for Estimations of the $T_{0}$ Reference Temperature. In: 13th International Conference on Fracture, 2013, Beijing. Proceeding of the 13th International Conference on Fracture, 2013.

- Savioli, R. G.; Ruggieri, C.. A Micromechanics Approach for Assessing the Applicability of Precracked Charpy Specimens to Determine the $T_{0}$ Reference Temperature. In: ASME 2013 Pressure Vessels \& Piping Division Conference, 2013, Paris. Proceedings of the ASME 2013 Pressure Vessels \& Piping Division Conference (PVP 2013), 2013.

- Ruggieri, C.; Savioli, R. G.. Previsão da Temperatura de Referência $T_{0}$ e Análise da Curva Mestra em Aços Ferríticos: Uma Abordagem Micromecânica. In: 68 Congresso ABM Internacional, 2013, Belo Horizonte. Anais do 68 Congresso ABM Internacional, 2013.

- Ruggieri, C.; Savioli, R. G.; Hippert Jr, E.. A Weibull Stress Model to Determine the $\mathrm{T}_{0}$ Reference Temperature Applicable to $\mathrm{CO} 2$ Transmission Pipelines. In: Rio Pipeline 2013 Conference \& Exposition, 2013, Rio de Janeiro. Proceedings of Rio Pipeline 2013 Conference \& Exposition, 2013.

- Ruggieri, C.; Savioli, R. G.. A Micromechanics Approach to Predict the $T_{0}$ Reference Temperature in Pressure Vessel Steels. In: 22nd International Congress of Mechanical Engineering (COBEM 2013), 2013, Ribeirão Preto - SP. Proceedings of 22nd International Congress of Mechanical Engineering (COBEM 2013), 2013. 


\section{REFERÊNCIAS BIBLIOGRÁFICAS}

[1]. Hansen D. A., Puyear R. B., Materials Selection for Hydrocarbon and Chemical Plants, MarcelDekker, Inc., New York, N. Y., 1996.

[2]. ASM International, ASM Handbook - Volume 11: Failure Analysis and Prevention, ASM International, Materials Park, OH, 2002.

[3]. Bednar H. H., Pressure Vessel Design Handbook, Krieger Publishing, Malabar, Florida, 1991.

[4]. American Society for Testing and Materials, Standard Specification for Pressure Vessel Plates, Carbon Steel, Low- and Intermediate-tensile strength, ASTM A285, 2012.

[5]. American Society for Testing and Materials, Standard Specification for Pressure Vessel Plates, Carbon Steel, for Intermediate- and Higher-Temperature Service ASTM A515, 2010.

[6]. Duncan A. J., Subramanian K. H., Sindelar R. L., Miller K., Reynolds A. P., Y. Chao J., Development of Mechanical Properties Database of A285 Steel for Structural Analysis of Waste Tanks, in: R. Chona (Ed.), Fatigue and Fracture Mechanics, Vol. 32, p. 399_409, ASTM STP 1406, American Society for Testing and Materials, Philadelphia, 2002.

[7]. British Standard Institution., "Guide on Methods for Assessing The Acceptability of Flaws In Metallic Structures", BS7910,1999. 
[8]. American Petroleum Institute. "Recommend Practice for Fitness-for-Service." API-RP-579, 2000.

[9]. American Society for Testing and Materials, "Standard Test Method for Measurement of Fracture Toughness.", ASTM E1820, 2011.

[10]. Wallin K., Irradiation damage effects on the fracture toughness transition curve shape for reactor pressure vessel steels, International Journal of Pressure Vessel and Piping, vol. 55, p. 61-79, 1993.

[11]. Wallin, K., "The Master Curve Method: A New Concept for Brittle Fracture", International Journal of Materials and Product Technology, Vol. 14, p. 342 - 354, 1999.

[12]. Wallin K., Fracture toughness transition curve shape for ferritic structural steels, in: S. H. S.H. Teoh, K. H. Lee (Eds.), Joint FEFG/IICF International Conference on Fracture of Engineering Materials and Structures, p. 83-88, Singapore, 1999.

[13]. Wallin K.; "Master Curve analysis of the "Euro" Fracture Toughness Dataset." Engineering Fracture Mechanics, vol. 69, p 451-481, 2002.

[14]. American Society For Testing And Materials, Standard Test Method For Determination Of Reference Temperature, $T_{0}$, For Ferritic Steels In The Transition Temperature, ASTM E1921-08 (2008).

[15]. Beremin F. M., "A Local Criterion for Cleavage Fracture of a Nuclear Pressure Vessel Steel", Metallurgical Transaction, Vol. 14A, p. 2277-2287, 1983. 
[16]. Hohe J., Hebel J., Friedmann V., Siegele D., "Probabilistic Assessment Of Ferritic Steels Using the Master Curve Approach Including Constraint Effects", Engineering Fracture Mechanics, Vol 74, p. 1274 - 1292, Freiburg, 2007

[17]. Cogswell D., "Statistical Modelling of the Transition Toughness Properties of Low Alloy Pressure Vessel Steels." University of Birmingham, Vol. I: Main Body, Birmingham, 2010.

[18]. Cogswell D., "Statistical Modelling of the Transition Toughness Properties of Low Alloy Pressure Vessel Steels." University of Birmingham, Vol. II: Appendices, Birmingham, 2010.

[19]. Viehrig H. W., Boehmert J., Dzugan J., "Some Issues by Using the Master Curve Concept." Nuclear Engineering and Design, Vol. 212, p. 115 - 124, Dresden, 2002.

[20]. Anderson, T. L., "Fracture Mechanics: Fundaments and Applications" - 3nd Edition, CRC Press, New York, 1995.

[21]. Irwin, G. R., "Analysis Of Stresses and Strains Near the End of Crack Traversing Plate." Journal of Applied Mechanics Vol. 24, 1957, pp. 361-364.

[22]. Williams, M. L., "Stress Singularities Resulting from Various Boundary Conditions in Angular Corner Plates in Extension." Journal of Applied Mechanics Vol. 19, 1952, pp. 526-528.

[23]. Williams, M. L., "On the Stress Distribution at the Base of Stationary Crack." Journal of Applied Mechanics Vol. 24, 1957, pp. 109-114. 
[24]. American Society for Testing and Materials, "Standard Test Method For Plane Strain Fracture Toughness Of Metalic Materials", ASTM E399, Philadelphia, 1991.

[25]. Rice, J.R., "A Path Independent Integral And The Approximate Analysis of a Strain Concentration by Notches And Cracks.", Journal Of Applied Mechanics, Vol. 35, 1968, pp. 379-386.

[26]. Donato, G. H. B, "Efeitos de Heterogeneidades Mecânicas Sobre Forças Motrizes de Trinca em Juntas Soldadas: Determinação Experimental de Tenacidade e Extensão de Metodologias de Avaliação de Criticidade de Defeitos", Tese de Doutorado, Escola Politécnica da Universidade de São Paulo, 2008.

[27]. Griffith A. A., "The Phenomena of Rupture and Flow in Solids" Philosophical Transactions, Series A, Vol. 221, 1920, pp. 163-198

[28]. Hutchinson, J. W., "A Singular Behavior at the end of a Tensile Crack Tip in a Hardening Material." Journal Of The Mechanics And Physics Of Solids, Vol.16, 1968, pp. 379-386.

[29]. Rice, J. R.; Rosengren, G. F., "Plane Strain Deformation Near The Crack Tip In A Power-Law Hardenig Material." Journal of the Mechanics And Physics of Solids, Vol.16, 1968, pp. 1-12.

[30]. Anderson, T. L.; Dodds, R. H., Specimen Size Requirements For Fracture Testing In Transition Region. Journal Of Testing And Evaluation, Vol.19, P. 123$134,1991$. 
[31]. Nevalainen, M.; Dodds, R. H.; "Numerical Investigation of 3-D Constraint Effects on Brittle Fracture in SE(B) and C(T) Specimens". International Journal of Fracture, V. 74, P 131-161, 1995.

[32]. Silva, L. A. I., "Avaliação De Defeitos Em Dutos e Risers Utilizando Corpos de Prova Mecanicamente Similares: Extensão 3D da Metodologia J-Q", Dissertação de Mestrado, Escola Politécnica da Universidade de São Paulo, 2006.

[33]. O'Dowd, N.P., Shih, C.F., "Family of Crack-Tip Fields Characterized by a Triaxiality Parameter: Part I - Structure of Fields," Journal of the Mechanics and Physics of Solids, Vol. 39, p. 989-1015, 1991.

[34]. O'Dowd, N.P., Shih, C.F., "Family Of Crack-Tip Fields Characterized By A Triaxiality Parameter: Part II - Fracture Applications." Journal of the Mechanics and Physics of Solids, Vol. 40, p. 939-963, 1992.

[35]. Ruggieri C., "Fractus 2D: Cálculo Numérico de Parâmetros de Mecânica da Fratura em Componentes Estruturais 2D Contendo Trincas." Escola Politécnica da Universidade de São Paulo, Departamento de Engenharia Naval e Oceânica, 2010.

[36]. Cravero S., "Metodologia Biparamétrica para Análise de Efeitos de Restrição sobre a Fratura de Componentes Estruturais e Aplicações à Avaliação de Defeitos em Dutos." Dissertação de Mestrado, Escola Politécnica da Universidade de São Paulo, 2007.

[37]. Sumpter J. D. G., e Turner C. E., "Method For Laboratory Determination Of $J_{c}$ " Crack and Fracture, ASTM STP 601, American Society or Testing and Materials, p. 3-18, 1976. 
[38]. SINTAP: Structural Integrity Assessment Procedure for European Industry.Final Procedure, 1999.

[39]. Det Norske Veritas. "Submarine Pipeline Systems." DNV-OS-F101, 2007.

[40]. R6, "Assessment of the Integrity of Structures Containing Defects", Report R6 revision 4, British Energy Generation, Gloucester, UK, 2000.

[41]. Kanninen, M. F., Popelar, C. H., "Advanced Fracture Mechanics", Oxford Engineering Science Series 15, Clarendon Press, 1985.

[42]. Souza R. F, Ruggieri C, Revised $\eta$-factors and J-CTOD Relationships for SE(B) Fracture Specimens Including 3-D Effects and Implications for Fracture Toughness Measurements, Materials Performance and Characterization (2014).

[43]. Ruggieri C.; "A Local Approach to Elasto-plastic Analysis of Crack and Applications o Cleavage Fracture." 1994. 98p. Tese (Doutorado). Departament of Welding and Production engineering. Osaka University. Osaka, 1994.

[44]. Kapur K. C., Lamberson L. R.; "Reliability in Engineering Design". John Wiley \& Sons, New York, 1977.

[45]. Reliability Hot Wire: The eMagazine for Reliability Professional, "Reliability Basics: Extreme Value Distributions" Issue 128, 2011, Disponível em: http://www.weibull.com/hotwire/issue128/relbasics128.htm, Acesso em 26 nov. 2015.

[46]. Weibull, W., "A Statistical Theory of the Strength of Materials", Royal Swedish Institute for Engineering Research., vol. 151, 1939. 
[47]. Landes, J., Schaffer, D., "Statistical characterization of fracture in the transition region"; ASTM STP 700, p.368-382, 1980.

[48]. Landes J. D., McCabe D. E., "Effect of Section Size on Transition Temperature Behavior of Structure Steel." ASTM STP 833, p 378-392, American Society for Testing and Material, 1984.

[49]. Wallin K., "The Scatter in $K_{I c}$ Results", Engineering Fracture Mechanics 19, pp. 1085_1093, 1984.

[50]. Ruggieri C.; "Análise Probabilística da Fratura em Regiões Heterogêneas e Sua Extensão à Análise de Falhas de Estruturas Soldadas." 1989. 198p. Dissestação (Mestrado). Escola Politécnica. Universidade de São Paulo. São Paulo, 1989.

[51]. Wallin, K., Saario, T., Törrönen, K., "A statistical model for carbides induced brittle fracture in steels", Metal Science, Vol. 18, 1984.

[52]. Wallin, K., "Structural integrity assessment aspects of the Master Curve methodology", Engineering Fracture Mechanics, Vol. 77, p. 285-292, 2010.

[53]. McCabe D. E., Merkle J. G., Wallin K.; "An Introduction to the Development and Use of the Master Curve Method" ASTM MNL52, American Society for Testing and Materials, 2005.

[54]. ASME Boiler \& Pressure Vessel Code Section XI. "Rules for In Service Inspection of Nuclear Power Plant Components". American Society of Mechanical Engineers. New York, 1992. 
[55]. Server W., Cipolla R., "Direct Use of The Fracture Toughness Master Curve in ASME Code, Section XI, Applications" Proceedings of the ASME 2013 Pressure Vessels and Piping Conference, 2013, Paris, France

[56]. ASME Boiler and Pressure Vessel Code, "Code Case N-631: Use of Fracture Toughness Test Data to Establish Reference Temperature for Pressure Retaining Materials Other Than Bolting for Class 1 Vessels", Section III, Division 1, ASME, New York, 1998.

[57]. ASME Boiler and Pressure Vessel Code, "Code Case N-629: Use of Fracture Toughness Test Data to Establish Reference Temperature for Pressure Retaining Materials", Section XI, Division 1, ASME, New York, 1998.

[58]. Wallin, K., "Statistical Re-evaluation of the ASME $K_{I C}$ and $K_{I R}$ Fracture Toughness Reference Curves", Nuclear Engineering and Design, Vol 193, p. 317 326, 1999.

[59]. Wallin, K., "Irradiation Damage on the Fracture Toughness Transition Curve Shape for Reactor Pressure Vessel Steels", International Journal of Pressure Vessels and Piping, Vol 55, p. 61 - 79, 1993.

[60]. Sokolov M. A., Nanstad R. K. "Comparison of Irradiation-Induced Shifts of KJc and Charpy Impact Toughness for Reaction Pressure Vessel Steels", ASTM STP 1325, p. 167 - 190, American Society for Testing and Materials, 1999.

[61]. Sokolov M. A., Nanstad R. K., Miller M.K., "Fracture Toughness Characterization of a Highly Embrittled RPV Weld", ASTM STP 1447, ASTM International, 2004.

[62]. Nanstad R. K., Bass B. R., Rosseel T. M., Merkle J. G., Sokolov M. A., "Heavy-Section Steel Technology and Irradiation Programs Retrospective and 
Prospective Views" Proceedings of the ASME 2007 Pressure Vessels \& Piping Division Conference, Texas, 2007

[63]. Planman T., Server W., "Fracture Toughness Mater Curve of BBC Steels," Comprehensive Nuclear Materials: Radiation Effects in Structural Functional Materials for Fission and Fusion, Vol. 4, Amsterdam, 2012.

[64]. Wallin, K., Nevasmaa P., Laukkanen A., Planman T., "Master Curve Analysis of Inhomogeneous Ferritic Steels", Engineering Fracture Mechanics, Vol. 77, p. 2329-2346, 2004.

[65]. Scibetta M., "Master Curve Analysis of Potentially Inhomogeneous Materials", Engineering Fracture Mechanics, Vol. 94, p. 56-70, 2012.

[66]. Choi S. B., Choi S., Choi J. B., Chang Y. S., Kim M. C., Lee B. S., "Enhancement of Master Curve Method for Inhomogeneous Materials", Journal of Mechanichal Science and Technology, Vol. 26, p. 2727-2734, 2012.

[67]. Heerens J., Ainsworth R. A., Moskovic R., Wallin K., "Fracture Toughness Characterization in the Ductile to Brittle Transition Upper Shelf Regimes Usind Precracked Charpy Single-edge Bend Specimens", International Journal of Pressure Vessels and Piping, Vol. 82, p. 649 - 667, 2004.

[68]. Imai Y., Matake T., "Effect of Side Groove on the Elastic-Plastic Stress State of Fracture Toughness Specimens - Three-Dimensional Finite Element Analysis", Engineering Fracture Mechanics, Vol. 16, p. 659 - 668, 1982.

[69]. Anderson T. L., Dodds R. H., "Specimen Size Requirements for Fracture Toughness Testing in the Transition Region", Journal of Testing and Evaluation, Vol. 19, p. $123-134,1991$. 
[70]. Nevalainen M., Dodds R. H., "Numerical Investigation of 3D Constraint Effects on Brittle Fracture in SE(B) and C(T) Specimens", Structural Research Series No. 598, University of Illinois, 1995.

[71]. Wallin, K., "Validity of Small Specimen Fracture Toughness Estimates Neglecting Constraint Corrections, Constraint Effects in Fracture: Theory and Applications,” ASTM STP 1244, p. 519-537, Philadelphia, 1995.

[72]. Joyce J. A., Link R. E.; "Ductile-to-brittle Transition Characterization Using Surface Crack Specimens Loaded in Combined Tension and Bending." Fatigue and Fracture Mechanics: $28^{\text {th }}$ Volume, ASTM STP 13221, American Society for Testing and Materials, 1997.

[73]. Sokolov M. A.; Wallin K.; McCabe D. E.; "Application of Small Specimens to Fracture Mechanics Characterization of Irradiated Vessel Steels." Fatigue and Fracture Mechanics Charactherization of Irradiated Pressure Vessel Steels: $28^{\text {th }}$ Volume, ASTM STP1321, 1997.

[74]. Wallin K., Planman T., Valo M., Rintamaa R., "Applicability of Miniature Size Bend Specimens to Determine Reference Temperature $T_{0}$ " Engineering Fracture Mechanics, Vol. 68, p 1256 - 1296, 2001.

[75]. Rathbun H. J., Odette G. R., Yamamoto T., Lucas G. E., "Influence of Statistical and Constraint Loss Size Effects on Cleavage Fracture Toughness in the Transition - A Single Variable Experiment and Database", Engineering Fracture Mechanics, Vol. 73, p. 134 - 158, Santa Barbara, 2006.

[76]. Rathbun H. J., Odette G. R., Yamamoto T., "Influence of Statistical and Constraint Loss Size Effects on Cleavage Fracture Toughness in the Transition - A 
Model Based Analysis", Engineering Fracture Mechanics, Vol. 73, p. 2723 - 2747, Santa Barbara, 2006.

[77]. Nanstad R. K., Scibetta M., "IAEA Coordinated Research Project on Master Curve Approach to Monitor fracture Toughness of RPV Steels: Effects of Bias Constraint and Geometry" Proceedings of the ASME 2007 Pressure Vessels \& Piping Division Conference, Texas, 2007.

[78]. Nanstad R. K., McCabe E. D., Sokolov M. A., Merkle J. G., "Experimental Evaluation of Deformation and Constraint Characteristics in Precracked Charpy and other Three-Point Bend Specimens", Proceedings of the ASME 2007 Pressure Vessels \& Piping Division Conference, Texas, 2007

[79]. Nanstad R. K., Brumovsky M., Callejas R.H., Gillemot F., Korshuov M., Lee B. S., Scibetta E. L. M., Nilsson K., Minnebo P., Miura N., Onizawa K., Planman T., Burgos W. S. B., Serrano M., "IAEA Coodinated Research Project on Master Curve Approach to Monitor Fracture Toughness of RPV Steels: Final Result of the Experimental Exercise to Support Constraint Effects", Proceedings of the ASME 2009 Pressure Vessels \& Piping Division Conference, Prague, 2009.

[80]. Strail L., Kozák V., Hadraba H., Dlouhy I., "Stress State Analysis of SubSized Pre-Cracked Three-Point-Bend Specimen", Engineering Mechanics, Vol. 19, p. $121-129,2012$.

[81]. Sobotka J. C., Dodds R. H., "Side-Groove effects in Three-dimensional Small Scale Yielding: A Load and Thickness-scaling Model", Engineering Fracture Mechanics, Vol. 102, p. 218 - 234, 2013.

[82]. Savioli, R. G.; Ruggieri, C., "A Micromechanics Approach for Assessing the Applicability of Precracked Charpy Specimens to Determine the T0 Reference 
Temperature", Proceedings of the ASME 2013 Pressure Vessels \& Piping Division Conference, Paris, 2013

[83]. Ruggieri C., Savioli R. G., Dodds R H., "An Engineering Methodology for Corrections of Elasto-Plastic fracture Toughness - Part II: Effects os specimens geometry and plastic Strain on Cleavage Fracture Predictions", Engineering Fracture Mechanics, Vol. 146, p. 185 - 209, 2015.

[84]. American Society For Testing And Materials, Standard Test Methods For Tension Testing Of Metallic Materials, ASTM E8-11 (2011).

[85]. Tagawa T., Kayamori Y., Ohata M., Handa T., Kawabata T., Yamashita Y., Tsutsumi K., Yoshinari H., Aihara S., Hagihara Y.,"Comparison of CTOD Standards: BS 7448-Part 1 and revised ASTM E1290." Engineering Fracture Mechanics, Vol. 77, p 327-336, 2010.

[86]. American Society For Testing And Materials, Standard Test Method For Notched Bar Impact Testing Of Metallic Materials, ASTM E23-07 (2007).

[87]. Curry, D.A., Knott, J.F., "The Relationship between Fracture Toughness and Microstructure in the Cleavage Fracture of Mild Steel", Metal Science, Vol. 10, p. 1$6,1976$.

[88]. Ericksonkirk M. T., Shaikh A., Ericksonkirk M. A., "Insights And Observations Arising from Curve-Fitting the Charpy V-Notch and Tensile Data Contained Within the United States Light Water Reactor Surveillance Database", ASME PVP 2008 Pressure Vessel And Piping Division Conference, American Society Of Mechanical Engineers, Chicago, 2008. 
[89]. Hackett E. M., Schwalbe K. H., Dodds R. H., " Constraint Effects in Fracture". STP 1171, Baltimore, 1993.

[90]. ABAQUS Analysis User's Manual, Simulia. Dassault Systèmes, 2011.

[91]. MSC Patran Reference Manual, Disponível em: http://mscsoftware.com.

[92]. Healy B., Gullerud A., Koppenhoefer K., Roy A., RoyChowdhury S., Petti J., Walters M., Bichon B., Cochran K., Carlyle A., Sobotka J., Messner M., Dodds R. H., "WARP3D: 3-D Dynamic Nonlinear Fracture Aanalyses of Solids Using Parallel Computers", Structural Research Series (SRS 607) UILU-ENG-95-2012, University of Illinois at Urbana-Champaign, http://code.google.com/p/warp3d (2013).

[93]. Moran, B., and Shih, C. F., "Crack Tip and Associated Domain Integrals from Momentum and Energy Balance", Engineering Fracture Mechanics, Vol. 27, pp. 615 $642,1978$.

[94]. Moran,B., and Shih,C.F.,"A General Treatment of Crack Tip Contour Integrals", International Journal of Fracture, Vol. 35, pp. 295 310, 1987. 


\section{ANEXOS}

\section{A. Correção da Tenacidade Pelo Efeito de Espessura}

As variações nos valores de tenacidade à fratura decorrentes da modificação da espessura dos corpos de prova são causadas pela mudança do volume da zona de processo de fratura desenvolvida nas frentes de trinca. Portanto quanto maior for este volume maior é a probabilidades de uma microtrinca crítica ser solicitada e assim, disparar o processo de falha.

A correção da tenacidade, devido aos efeitos de espessura, pode ser realizada de forma comparativa entre dois corpos de prova, conhecendo-se a distribuição dos valores de tenacidade para um determinado comprimento de trinca.

Para o caso específico da Curva Mestra o método para a correção da tenacidade deriva diretamente da Teoria do Elo Mais Fraco (WLM) e da distribuição de probabilidade de Weibull, sendo utilizado aqui o modelo de distribuição triparamétrico.

O WLM estabelece a possibilidade da divisão da frente de trinca em seções menores, conforme ilustra a Figura 59, e, portanto, avaliando-se a tenacidade de cada uma dessas seções determina-se que o menor valor obtido de tenacidade à fratura deverá ser equivalente ao valor da tenacidade à fratura para seção completa, ou seja, para o componente em sua totalidade.

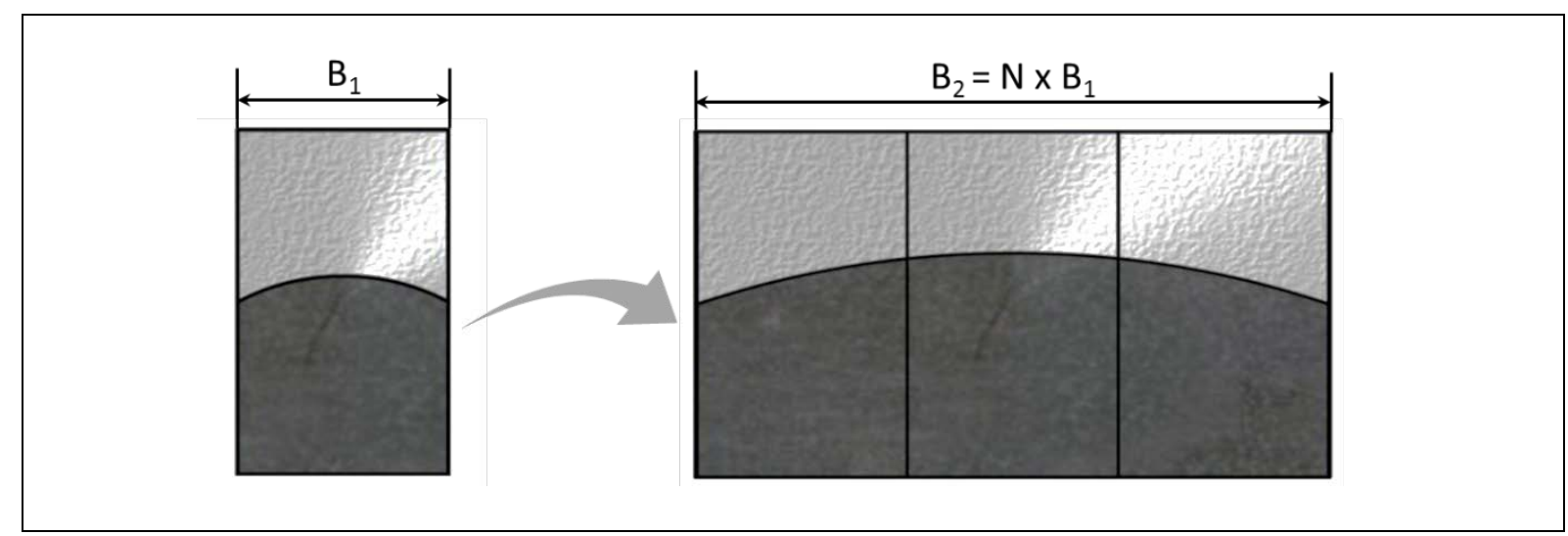

Figura 59. Representação da correção pelo efeito de espessura baseado no Weakest Link Model para um componente com espessura $B_{x}$ e três seções menores com espessura $B_{1}$. 
Resumidamente, uma frente de trinca genérica pode ser descrita como a coleção de pequenos comprimentos de trinca e a falha de um destes pequenos comprimentos de trinca levará ao colapso toda a estrutura. Com base na Figura 59 e considerando a probabilidade de falha de cada bloco independente e igual, a correção pelo efeito de espessura pode ser dada como:

$$
F\left(B_{2}\right)=1-S\left(B_{2}\right)
$$

Onde:

$F\left(B_{2}\right)$ : Probabilidade de falha do componente

$S\left(B_{2}\right)$ : Probabilidade de sobrevivência do componente

A probabilidade de sobrevivência do componente pode ser estabelecida como a produtória das probabilidades de sobrevivência das três seções menores,

$$
\begin{gathered}
S\left(B_{2}\right)=\prod_{n=1}^{3}\left[S^{n}\left(B_{1}\right)\right] \\
S\left(B_{2}\right)=S\left(B_{1}\right) * S\left(B_{1}\right) * S\left(B_{1}\right)=S\left(B_{1}\right)^{3}
\end{gathered}
$$

Generalizando para $n$ seções, temos:

$$
F\left(B_{2}\right)=1-S\left(B_{1}\right)^{n}
$$




$$
\begin{gathered}
1-S\left(B_{2}\right)=1-S\left(B_{1}\right)^{n} \\
S\left(B_{2}\right)=S\left(B_{1}\right)^{n}
\end{gathered}
$$

onde $n$ é o número de seções com probabilidade de falha conhecida, dado por:

$$
n=\frac{B_{1}}{B_{2}}
$$

Substituindo na equação (A.6) as expressões de uma distribuição de Weibull triparamétrica, obtem-se a equação (A.8) e após alguma manipulação é possível obter a expressão para correção da tenacidade por efeito de espessura, equação (A.12):

$$
\begin{gathered}
e^{-\left(\frac{J_{B_{2}}-J_{\min }}{\beta}\right)^{\alpha}}=\left(e^{\left.-\left(\frac{J_{B_{1}}-J_{\min }}{\beta}\right)^{\alpha}\right)^{\frac{B_{1}}{B_{2}}}}\right. \\
e^{-\left(\frac{J_{B_{2}}-J_{\min }}{\beta}\right)^{\alpha}}=e^{-\frac{B_{1}}{B_{2}}\left(\frac{J_{B_{1}}-J_{\min }}{\beta}\right)^{\alpha}} \\
e^{\left(\frac{J_{B_{2}}-J_{\min }}{\beta}\right)^{\alpha}}=e^{\left(\frac{\left(J_{B_{1}}-J_{\min }\right)\left(\frac{B_{1}}{B_{2}}\right)}{\beta}\right)^{\alpha}} \\
J_{B_{2}-J_{\min }}=\left(J_{B_{1}}-J_{\min }\right)\left(\frac{B_{1}}{B_{2}}\right)^{\frac{1}{\alpha}} \\
J_{B_{2}}=J_{\min }+\left(J_{B_{1}}-J_{\min }\right)\left(\frac{B_{1}}{B_{2}}\right)^{\frac{1}{\alpha}}
\end{gathered}
$$




\section{B. Ensaios de Tração a Baixa Temperatura}

Com os recursos laboratoriais disponíveis não foi possível realizar uma sujeição adequada do corpo de prova com seção de $12,5 \mathrm{~mm}$ ao equipamento de teste e ao mesmo tempo mantê-lo resfriado de forma controlada durante todo o experimento. Portanto, foi construído um pequeno aparato experimental para ensaiar os espécimes de seção reduzida de $6 \mathrm{~mm}$, ilustrado na Figura 60. Os resultados obtidos não foram satisfatórios, porém o desenvolvimento de tal aparato e utilização destes espécimes reduzidos proporcionaram uma experiência importante para o grupo de pesquisa.

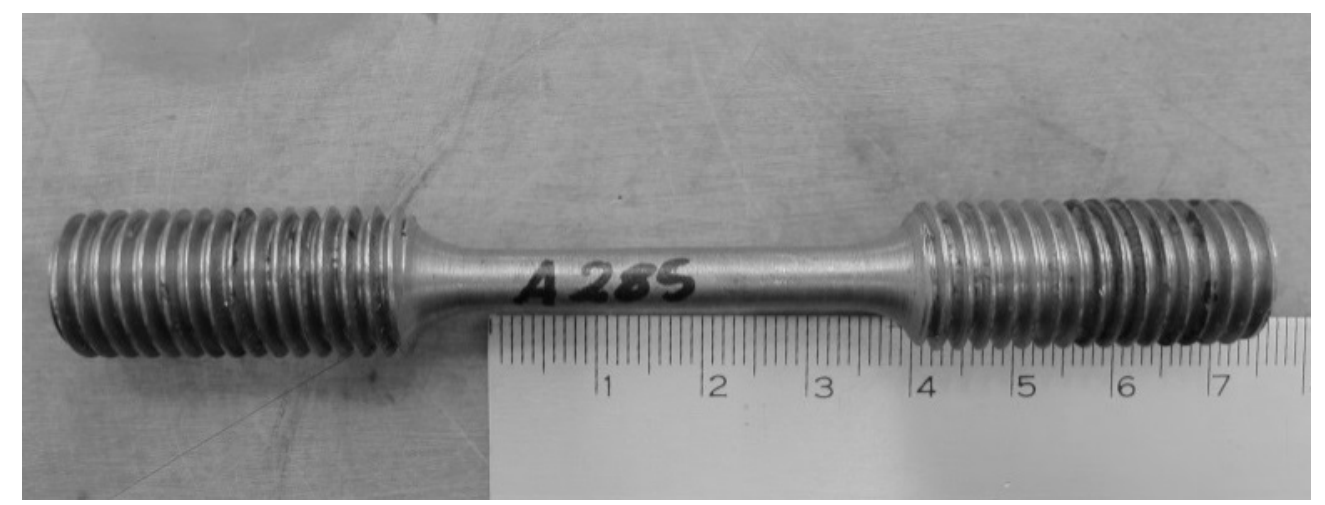

Figura 60. Corpos de tração para ensaios a baixa temperatura com dimensões reduzidas e previstas na norma ASTM E8/E8M-11.

Os ensaios de tração à baixa temperatura exigiram a confecção de uma cuba refrigerada e isolada termicamente. E corpos de tração com dimensões reduzidas, sujeitados por rosca facilitavam o projeto do aparato experimental, facilitavam a montagem do aparato na máquina de ensaios universal e reduziam os custos de fabricação da cuba.

A refrigeração dos espécimes foi feita por imersão em banho de álcool etílico + nitrogênio líquido (NL). Entretanto, esta configuração do aparato experimental não permitia a fixação do extensômetro ao corpo de prova, pois o fabricante do 
equipamento de medição não recomenda que este trabalhe mergulhado no banho refrigerante.

Como consequência destas dificuldades experimentais o ensaio foi realizado sem este equipamento e o deslocamento foi medido apenas com base no LVDT $^{5}$ (Linear Variable Differential Transformer) da máquina de testes. Apesar da alta precisão do LVDT, $\pm 0,0005 \mathrm{~mm}$, era conhecida a possibilidade de erros na medição de algumas propriedades mecânicas, geralmente obtidas no início do ensaio como, por exemplo, o Módulo de Elasticidade.

Imaginou-se então ser possível compor uma curva de tração confiável juntando-se dois conjuntos de dados:

- Dados no regime elástico do material, obtidos à temperatura ambiente e medidos com o extensômetro.

- Dados no regime plástico do material, obtidos à baixa temperatura e medidos com o LVDT.

Entretanto, este método não se mostrou adequado.

A Figura 61 ilustra o ensaio à baixa temperatura descrito acima para o aço A285 sem a utilização do extensômetro, acoplado ao corpo de prova nos instantes iniciais do teste, e o controle de temperatura do banho refrigerante utilizando-se o termômetro digital Minipa MT-455 com termopares do tipo K.

\footnotetext{
${ }^{5}$ Componente responsável pelo controle automático do deslocamento do atuador hidráulico da máquina universal de ensaios
} 

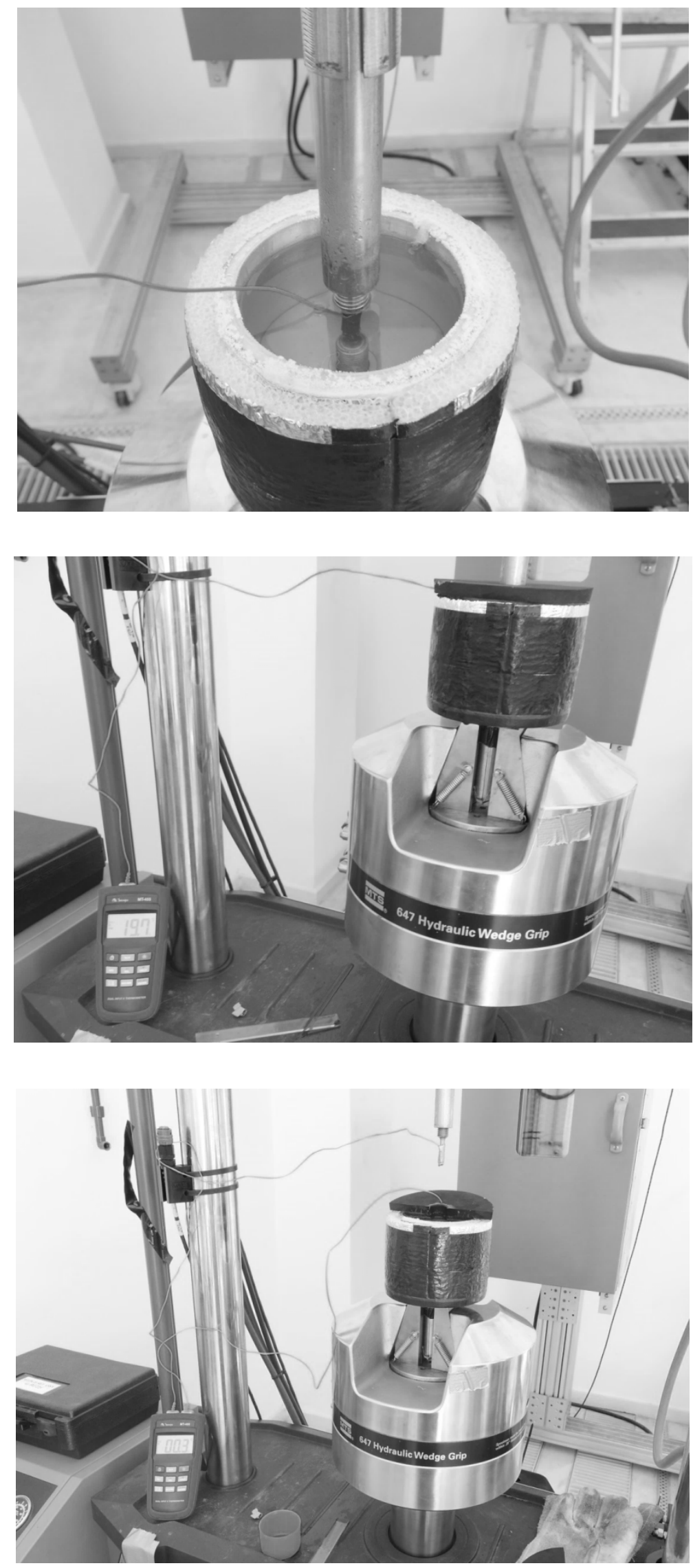

Figura 61. Imagens ilustrativas do ensaio de tração a baixa temperatura sem extensômetro. 
Devido à possibilidade de obtenção de valores imprecisos para o Módulo de Elasticidade, decorrente da não utilização do extensômetro nas etapas iniciais do ensaio, foi explorada uma nova configuração para o arranjo experimental nos ensaios do aço A515 de tal forma a permitir o uso do extensômetro. Substituiu-se o banho de álcool etílico + NL por uma atmosfera refrigerada obtida a partir da evaporação do nitrogênio líquido, conforme ilustra a Figura 62.

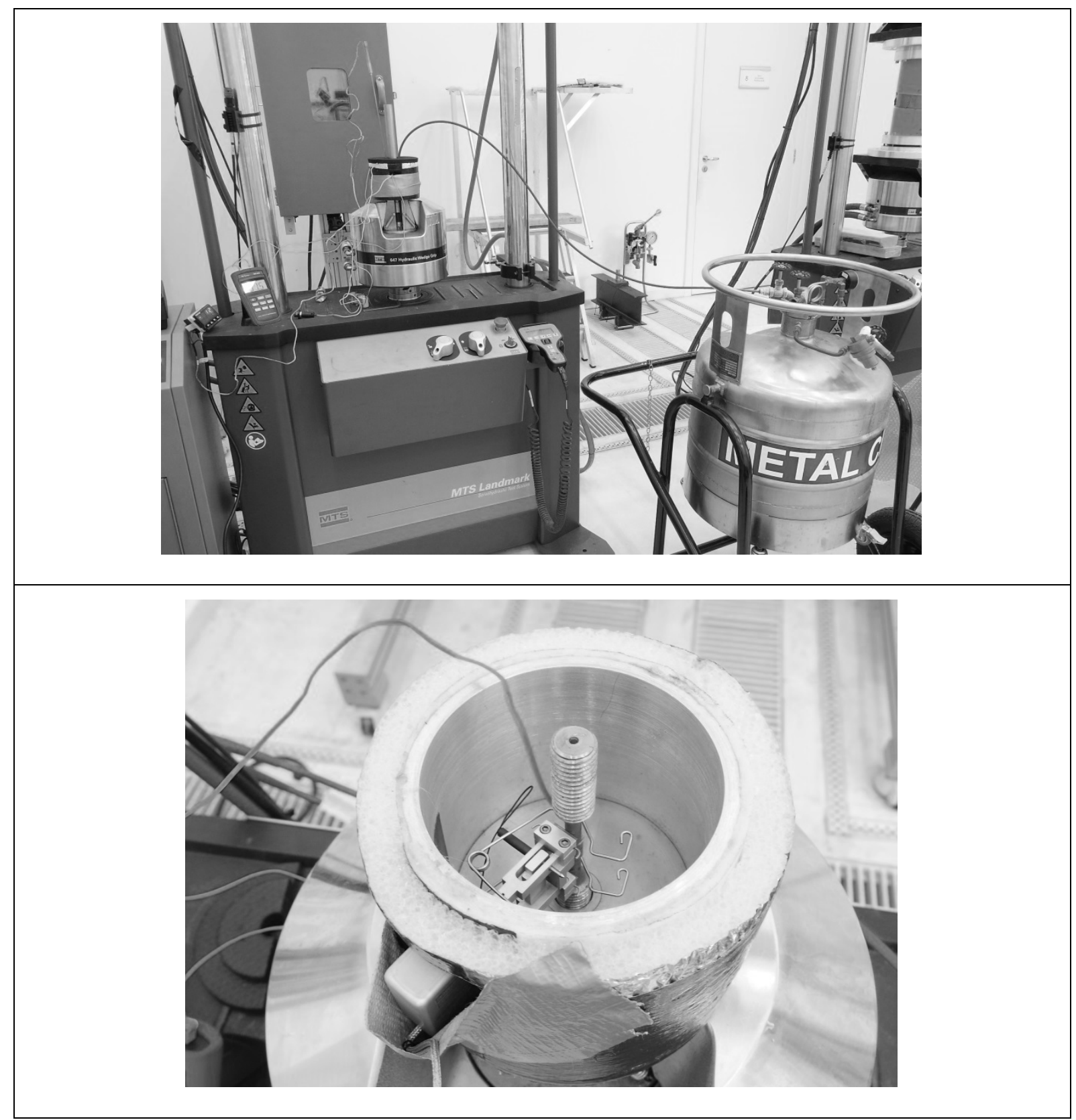

Figura 62. Tentativa de ensaio de tração do aço A515 em atmosfera refrigerada. 
A configuração com atmosfera refrigerada também não se mostrou satisfatória por uma série de motivos, dentre os quais vale destacar a difícil manutenção da temperatura de ensaio. Esta sofreu grandes variações, principalmente, quando medida com o termopar na superfície do corpo de prova.

Portanto, em decorrência do escopo do trabalho de pesquisa e da escassez de tempo optou-se pela determinação analítica das propriedades mecânicas a baixa temperatura para ambos os aços, A285 Gr C e A515 Gr 65.

\section{Detalhes Operacionais para Execução dos Ensaios de Tenacidade à Fratura}

\section{C.1. Processo de Nucleação de Pré-Trinca por Fadiga}

A etapa de nucleação das pré-trincas por fadiga é extremamente importante, demandando grande investimento de tempo e cuidados. Os corpos de prova com espessura $1 T$ e comprimento de trinca $a / W=0,5$ tendem a passar por este processo mais rapidamente necessitando de $100 \mathrm{mil}$ a 200 mil de ciclos para atingir o comprimento desejado. As demais geometrias ( $\mathrm{SE}(\mathrm{B})$ trinca rasa e $\mathrm{PCVN}$ ) em média necessitam de aproximadamente 350 mil a 600 mil ciclos.

$O$ processo de abertura de pré-trinca foi feito à temperatura ambiente e as determinações da norma ASTM E1921 [14] foram seguidas estritamente. Porém em alguns casos o baixíssimo nível de carregamento aplicado nos PCVN's, para manter $K$ próximo a $17 M P a \sqrt{m}$, não era suficiente para a propagação da prétrinca e sucessivos incrementos de carga precisaram ser realizados.

Alguns corpos de prova PCVN foram perdidos durante este processo. Por terem dimensões reduzidas, permitem uma faixa de carregamento muito estreita, entre a 
não propagação da trinca por fadiga e a perda do corpo de prova por deformações irreversíveis causadas pelo excesso de carga.

O processo de abertura de pré-trinca se encerra quando a razão $a / W$ desejada é atingida. A medição da propagação é feita pelo método da flexibilidade elástica executado no programa de controle da máquina de ensaios universal. Para maiores detalhes sobre o método consultar a norma ASTM E1820, [9].

\section{C.2. Determinação da Temperatura de Ensaio}

Para o início dos ensaios de tenacidade à fratura, seguindo as recomendações da norma ASTM E1921 [14], é preciso abaixar a temperatura dos corpos de prova para valores de temperatura próximos à temperatura de referência estimada, $T_{0}$. $\mathrm{A}$ norma sugere um procedimento para a estimativa inicial da temperatura de ensaio, $T_{\text {ensaio }}$, tendo como referência valores de tenacidade obtidos do ensaio de Impacto Charpy a 28 Joules ou 41 Joules. A equação abaixo mostra como a norma citada, [14], estima esta aproximação da temperatura de ensaio, $T_{\text {ensaio }}$,

$$
T_{\text {ensaio }}=T_{C V N}-C
$$

Na equação acima $C$ é uma constante obtida na Tabela 19 abaixo em função da energia absorvida e do tamanho do corpo de prova.

Tabela 19 Valores para a constante $C$

\begin{tabular}{ccc}
$\begin{array}{c}\text { Tamanho do } \\
\text { Corpo de Prova }\end{array}$ & \multicolumn{2}{c}{$\begin{array}{c}\text { Constante C } \\
\left({ }^{\circ} \mathbf{C}\right)\end{array}$} \\
\hline 28 J $~$ & $\mathbf{~ J 1}$ \\
\hline PCVN & -50 & -56 \\
0,4T & -32 & -38 \\
0,5T & -28 & -34 \\
1T & -18 & -24 \\
2T & -8 & -14 \\
3T & -1 & -7 \\
4T & 2 & -4 \\
\hline
\end{tabular}


Os espécimes são então posicionados no dispositivo de ensaio por flexão três pontos e mergulhados no banho refrigerante à temperatura desejada por aproximadamente 20 minutos, na sequência é acoplado o "clip-gage" na "boca" da trinca e a aplicação de carga é iniciada. A máquina de ensaios registra os dados de carga e deslocamento (CMOD) até a falha do corpo de prova. O ensaio é então interrompido e a superfície fraturada é analisada para verificação de crescimento sub-crítico da trinca e medição do comprimento inicial, $a_{0}$.

Para a determinação de $a_{0}$ foi utilizada a medição de 5 pontos na frente de trinca, estimando-se a média dos três pontos centrais, procedimento análogo ao da ASTM E1820 [9].

Todos os ensaios foram realizados com aplicação monotônica de carga e com taxas de carregamento diferentes para cada uma das configurações geométricas $(a / W=0,5, a / W=0,2$ e PCVN). As taxas de carregamento devem ser lentas o suficiente para não influenciar os valores de $J_{c}$, mas elevadas o suficiente para que a temperatura do ensaio não sofra variações superiores a $\pm 2^{\circ} \mathrm{C}$, a Tabela 20 mostra as taxas de carregamento aplicadas nos ensaios para cada tipo de geometria. A tentativa de adição de nitrogênio líquido para corrigir a temperatura durante o ensaio provoca perturbações no dispositivo que mede o CMOD e por isso não é recomendada.

Tabela 20 Taxa de aplicação de carga no ensaio de tenacidade

\begin{tabular}{cccc}
\hline & \multicolumn{3}{c}{ Corpo de Prova } \\
\cline { 2 - 4 } Taxa & PCVN & $a / W=0,2$ & $a / W=0,5$ \\
{$[\mathrm{~N} / \mathrm{s}]$} & 8 & 125 & 70 \\
\hline
\end{tabular}

Com base na temperatura de transição Charpy a 28 Joules, utilizando a equação (C.1), tem-se a primeira estimativa de temperatura de ensaio. Como procedimento interno, desenvolvido no grupo de pesquisa NAMEF, primeiramente são testados 3 espécimes $\mathrm{SE}(\mathrm{B})$ com trinca profunda $(a / W=0,5)$ para verificar se essa estimativa inicial é adequada. A partir desses testes é observado se há dispersão nos valores de $J_{c}$. 
Havendo dispersão, determina-se o valor do módulo de Weibull, $\alpha$, e caso esse esteja próximo ao valor teórico de 2 (em unidade de integral $J$ ), tem-se um bom indicativo de que a temperatura de teste é adequada. Já caso não haja dispersão, ou $\alpha$ seja muito diferente de 2 , a temperatura deve ser modificada e o processo repetido.

No ensaio de tenacidade, quando se abaixa em demasia a temperatura de aços ferríticos, há o risco de que os efeitos geométricos e estatísticos sobre os valores de $J_{c}$ sejam eliminados ou diminuídos, pois o material pode não estar mais na região TDF e o processo de clivagem passa a ser controlado apenas por propagação. Portanto, a temperatura deve ser alterada de forma a preservar os efeitos acima descritos. 


\section{C.3. Medição de $a_{0}$ e Determinação do $\Delta a_{p}$}

Após o término do ensaio de tenacidade à fratura, algumas análises devem ser feitas na superfície fraturada. As análises têm como objetivo verificar o real comprimento de trinca inicial, $a_{0}$, e medir o crescimento estável da trinca, caso este tenha ocorrido. Estes dois dados servirão para o cálculo da força motriz, $J_{c}$, e para censurar ensaios de tenacidade que tenham excedido o crescimento estável permitido pela norma ASTM E1921 [14].

O processo de análise, apesar de trabalhoso devido à quantidade de amostras, é bastante simples. As frentes de trinca são preparadas conforme ilustra a Figura 63 (a) e (b). Em seguida, com o auxilio de um estéreo microscópio (Zeiss Discovery $12 \mathrm{~V}$, aumento de 10X), verifica-se a ocorrência de crescimento estável e digitalizase cada uma das superfícies de fratura. As imagens são tratadas graficamente para a realização da medição digital de $a_{0}$ e $\Delta \mathrm{a}_{\mathrm{p}}$ por meio do programa Plot Digitizer. A Figura 63 (c) e (d) e a Figura 64 ilustram estas etapas. 

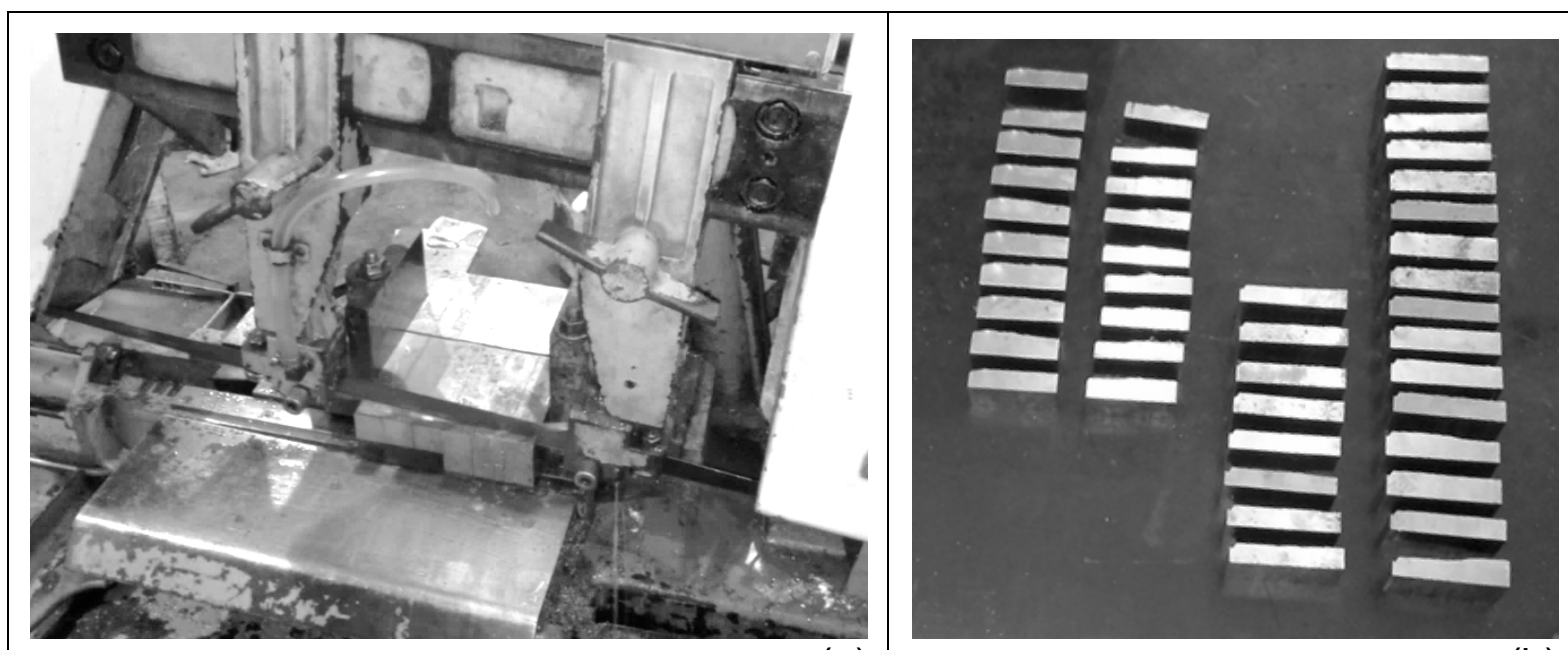

(a)

(b)

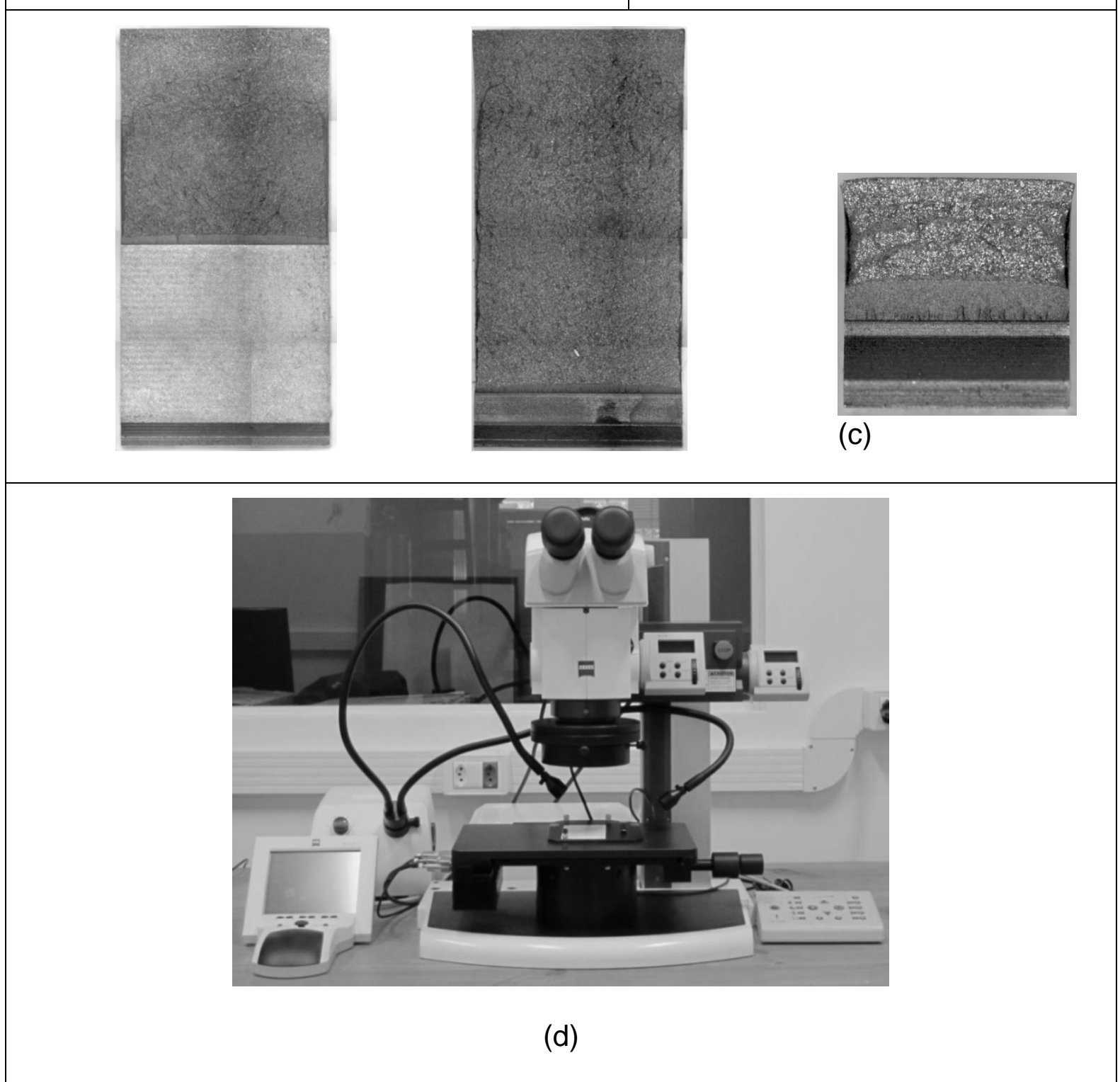

Figura 63. (a) e (b) Processo de corte e preservação da frente de trinca; (c) Digitalização das superfícies de fratura para as diferentes configurações de corpos de prova; (d) Estéreo microscópio. 


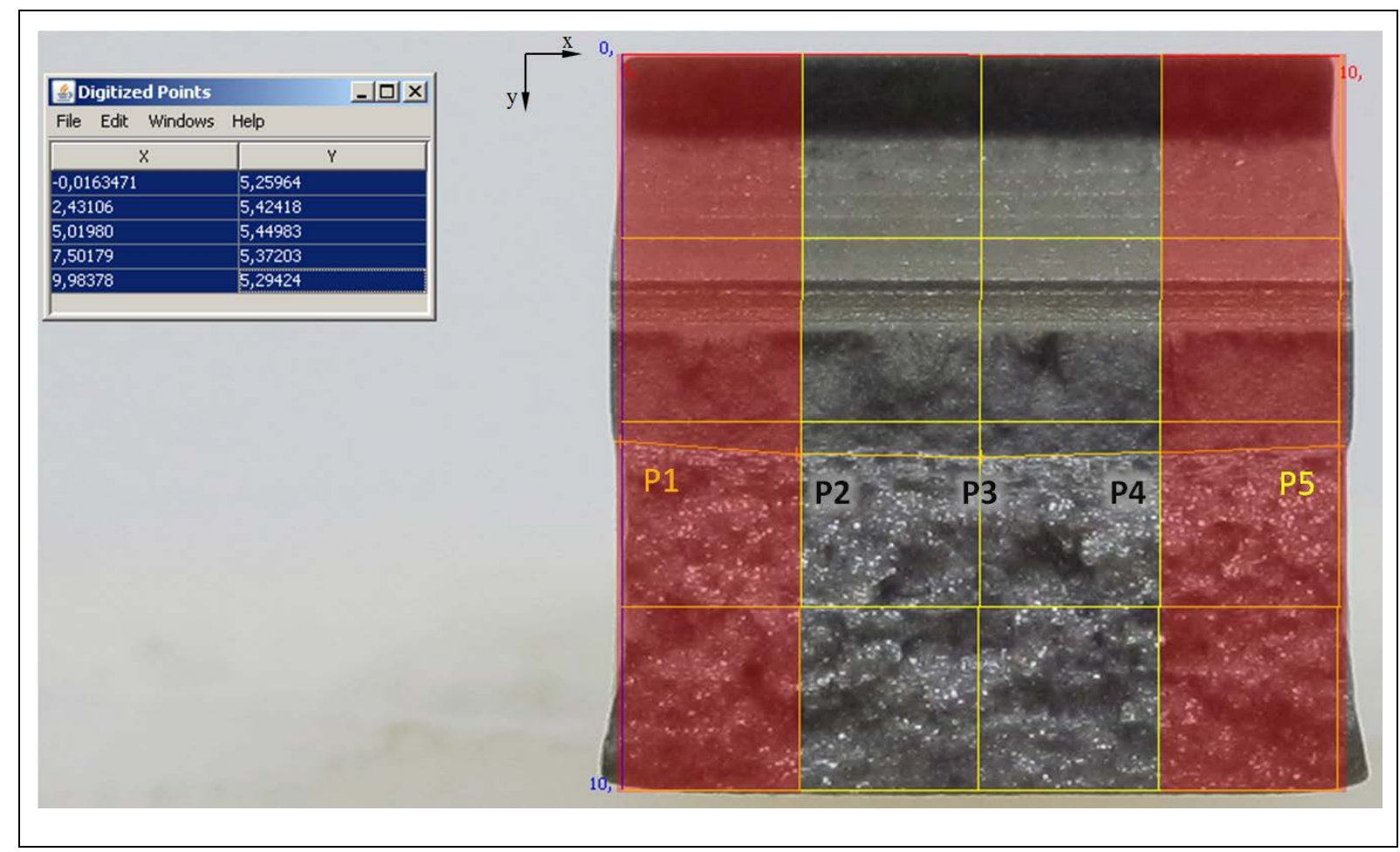

Figura 64. Pontos para a medição do comprimento de trinca inicial e verificação de possível crescimento estável da trinca.

Neste trabalho as medições de $a_{0}$ seguiram um procedimento análogo ao recomendado pela norma ASTM E1921 [14], porém com uso de menos pontos na frente de trinca, para a determinação dos comprimentos. Decidiu-se por utilizar menos pontos, pois:

- As pré-trincas nucleadas pelo processo de fadiga não apresentaram tunelamento significativo ou outros tipos de desvio;

- Não houve indícios de crescimento estável de trinca nos ensaios de tenacidade à fratura;

- O processo de clivagem transgranular é um processo controlado por tensão e esta ocorre em maior magnitude no centro do corpo de prova, justificando a eliminação dos pontos referentes à superfície do espécime, onde a tendência é de estado plano de tensões.

Portanto, neste procedimento foram considerados 5 ao invés de 9 pontos na frente de trinca. Os pontos referentes à superfície foram eliminados e $a_{0}$ é obtido da média aritmética dos 3 pontos centrais. A Figura 64 mostra como são definidos e medidos estes 5 pontos. 


\section{Procedimentos Computacionais}

A análise numérica computacional não é o escopo principal deste trabalho de pesquisa, porém um estudo comparativo foi realizado utilizando o método de elementos finitos e modelos computacionais dos corpos de prova. Tal estudo permitiu explorar o comportamento dos campos de tensões desenvolvidos nas frentes de trinca e avaliar os níveis de restrição plástica desenvolvidos para cada geometria de corpo de prova.

Por meio das análises numéricas foi possível estimar o efeito da introdução de entalhes laterais sobre os níveis de triaxialidade de tensões na ponta da trinca e a possibilidade de equalizar os níveis de força motriz, integral $J$, nesta mesma região para os corpos de prova com geometria PCVN. Ao término das análises computacionais definiu-se a configuração geométrica de entalhe lateral mais promissora para obtenção de resultados experimentais de tenacidade à fratura válidos para aplicação da metodologia da Curva Mestra.

\section{D.1. Modelos Computacionais dos Corpos de Prova}

Os modelos computacionais desenvolvidos simulam os corpos de prova carregados em flexão três pontos, $\mathrm{SE}(\mathrm{B})-1 \mathrm{~T}$ com seção retangular, $W=2 B$, e PCVN com seção quadrada, $W=B$, conforme ilustra a Figura 65 . Esses modelos reproduzem todas as configurações geométricas significativas dos corpos de prova reais, utilizadas na parte experimental, tais como a geometria da seção, comprimento de trinca, espessura e geometria dos entalhes laterais quando aplicável. 


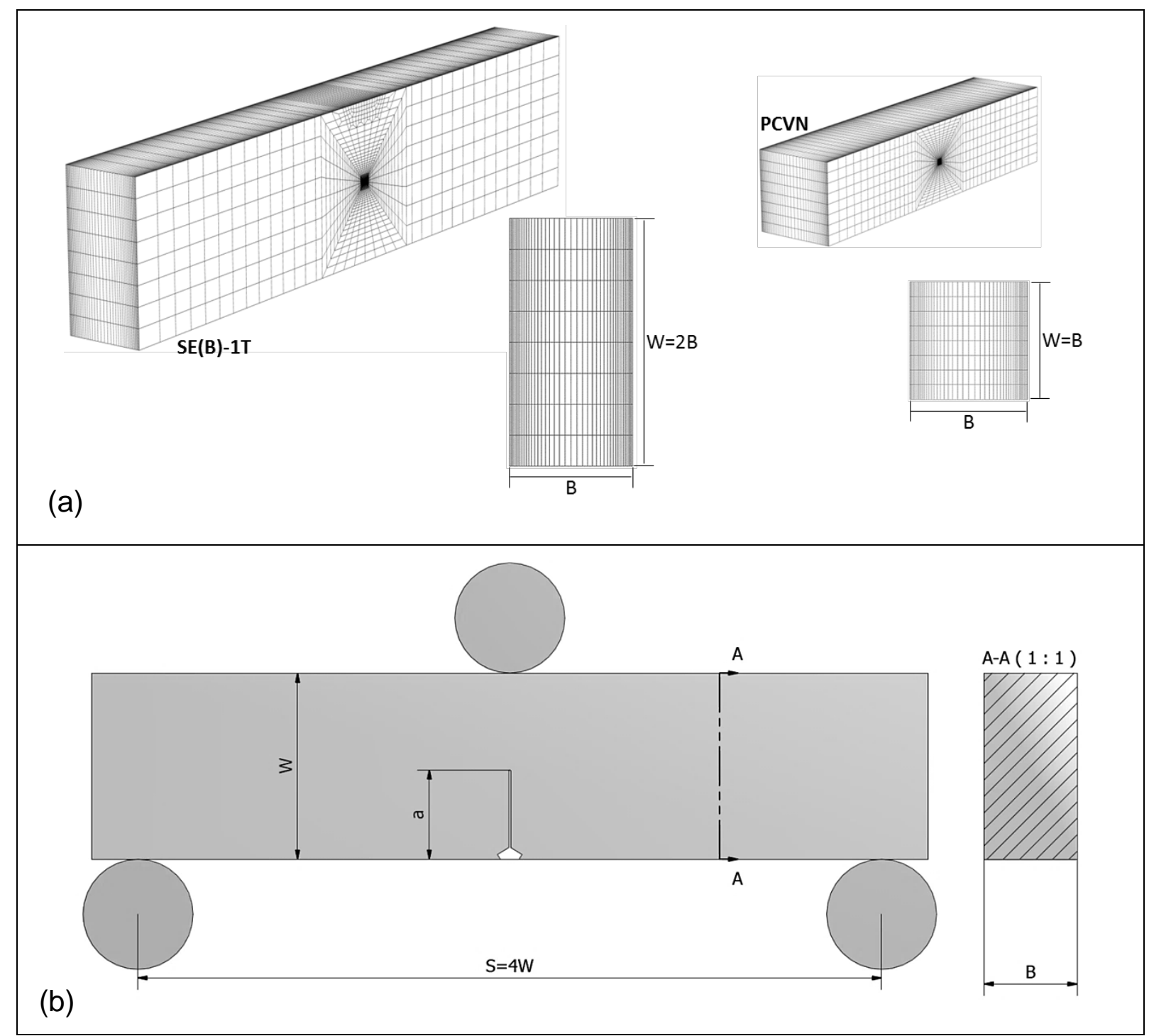

Figura 65. Modelos computacionais SE(B)-1T e PCVN (a). Representação das dimensões significativas dos corpos de prova (b).

A matriz de análise da Tabela 21 foi desenvolvida com o objetivo de estudar o comportamento dos campos de tensão na ponta da trinca com a evolução do nível de carregamento global para comparação entre os resultados obtidos com as diversas geometrias de corpos de prova. Para os corpos de prova com geometria PCVN além da configuração sem entalhe lateral, mostrada na Figura 66 (a), 6 diferentes configurações de geometria de entalhe foram analisadas, variando-se 0 ângulo de abertura, a profundidade do entalhe e a presença ou não do raio de ponta, conforme as Figuras 66 e Figura 67 ilustram. 
Tabela 21 Matriz de análise e dimensões dos corpos de prova SE(B) e PCVN.

\begin{tabular}{|c|c|c|}
\hline & PCVN & SEB \\
\hline a/W & 0,5 & 0,$2 ; 0,5$ \\
\hline Temperatura & $20^{\circ} \mathrm{C} ;-80^{\circ} \mathrm{C}$ & $20^{\circ} \mathrm{C} ;-60^{\circ} \mathrm{C} ;-80^{\circ} \mathrm{C}$ \\
\hline "Plain Side" & $\operatorname{sim}$ & $\operatorname{sim}$ \\
\hline “Side Grooved" & $\operatorname{sim}$ & não \\
\hline Raio do Entalhe & sem Raio $; 0,5 \mathrm{~mm}$ & \\
\hline Ângulo de Abertura & $90^{\circ} ; 45^{\circ}$ & \\
\hline Profundidade & $20 \% ; 10 \%$ (por lado) & \\
\hline
\end{tabular}

A título de nomenclatura corpos de prova sem entalhes laterais por vezes são tratados no texto pelos termos PCVN ou PCVN-PS, no qual "PS" abrevia o termo em inglês "Plain Side" e corpos de prova PCVN com entalhes laterais são tratados pelo termo PCVN-SG sendo "SG" a abreviatura do termo em inglês "Side Grooved". 


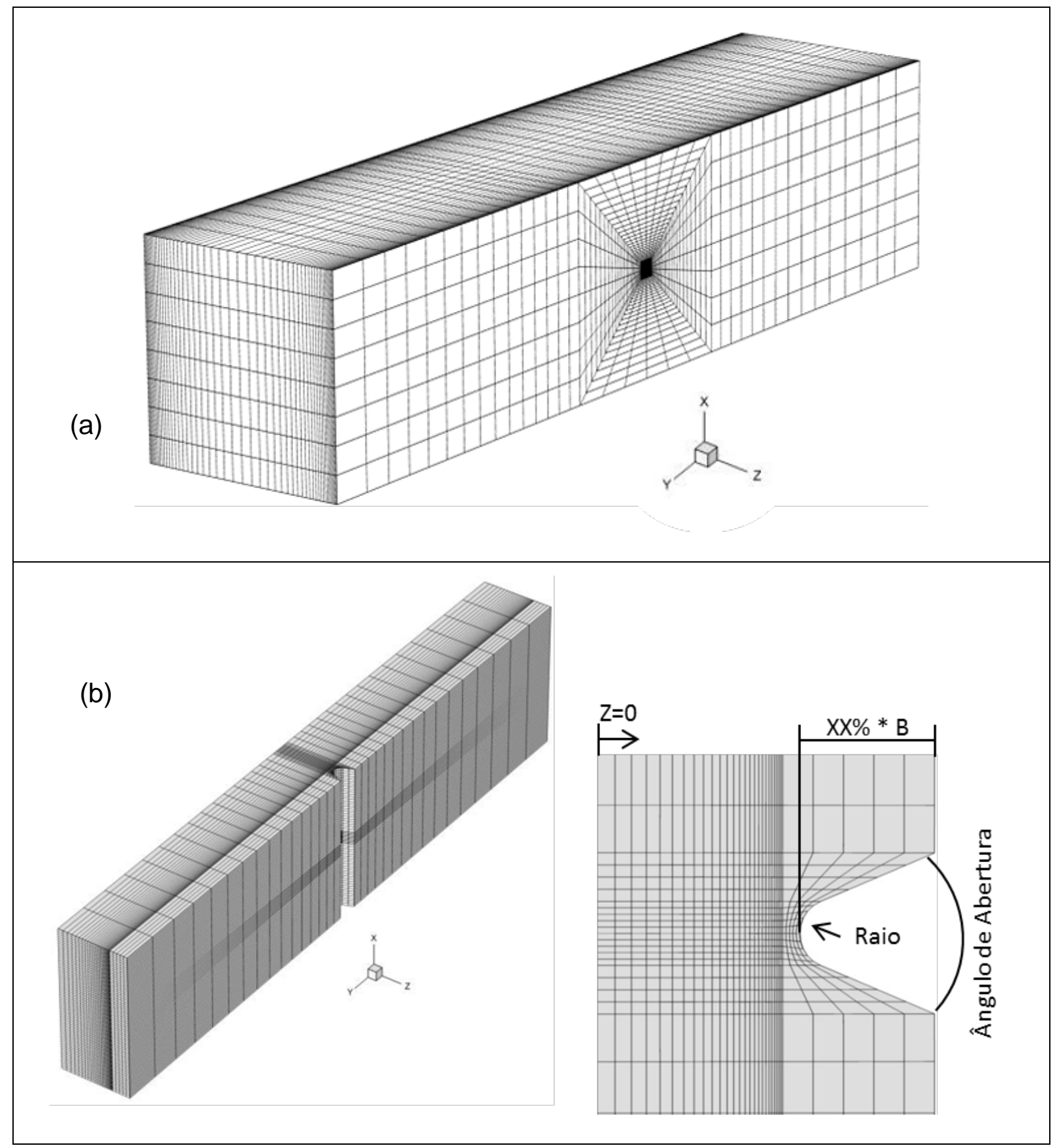

Figura 66. Modelos numéricos e representação das configurações geométrica dos corpos de prova com geometria PCVN. 
(a)
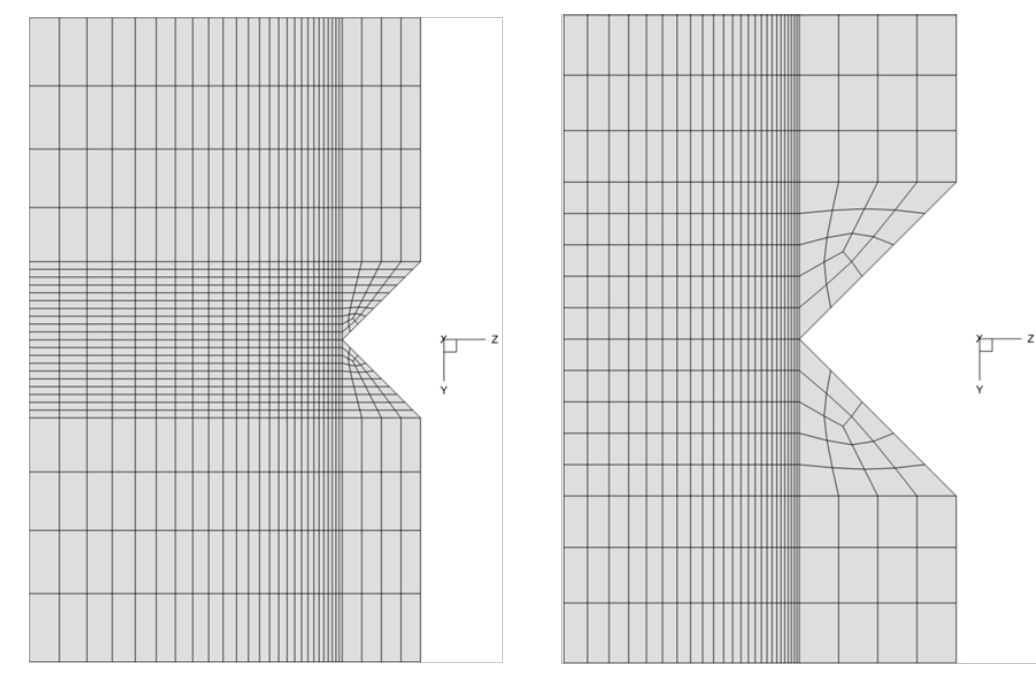

PCVN_SG $10 \% ; 90^{\circ}$

PCVN_SG 20\%; $90^{\circ}$

(b)
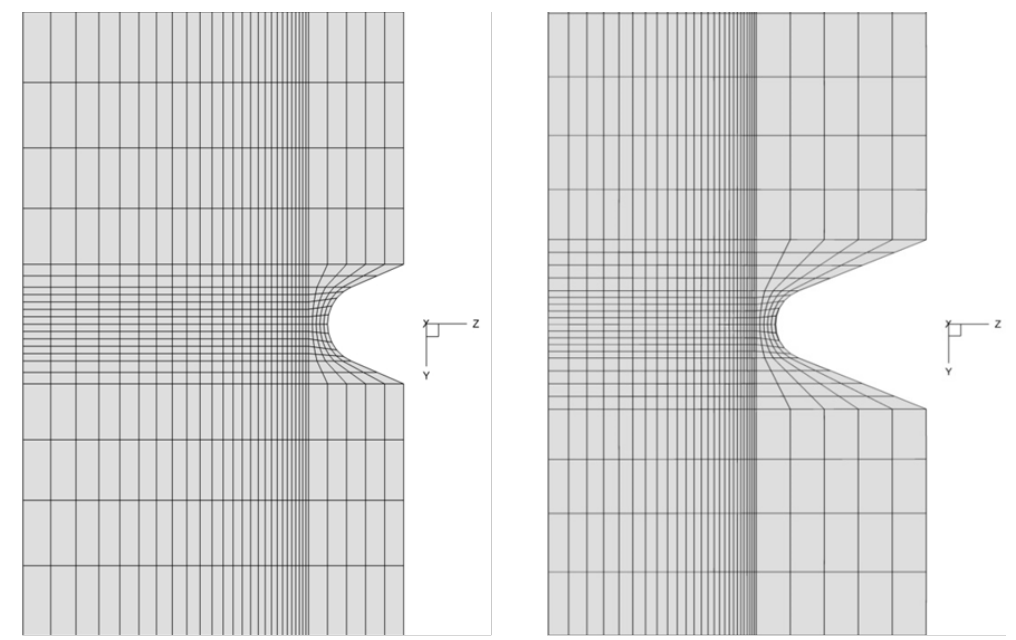

PCVN_SG $10 \% ; 45^{\circ} ; r=0,5$

PCVN_SG $20 \% ; 45^{\circ} ; r=0,5$
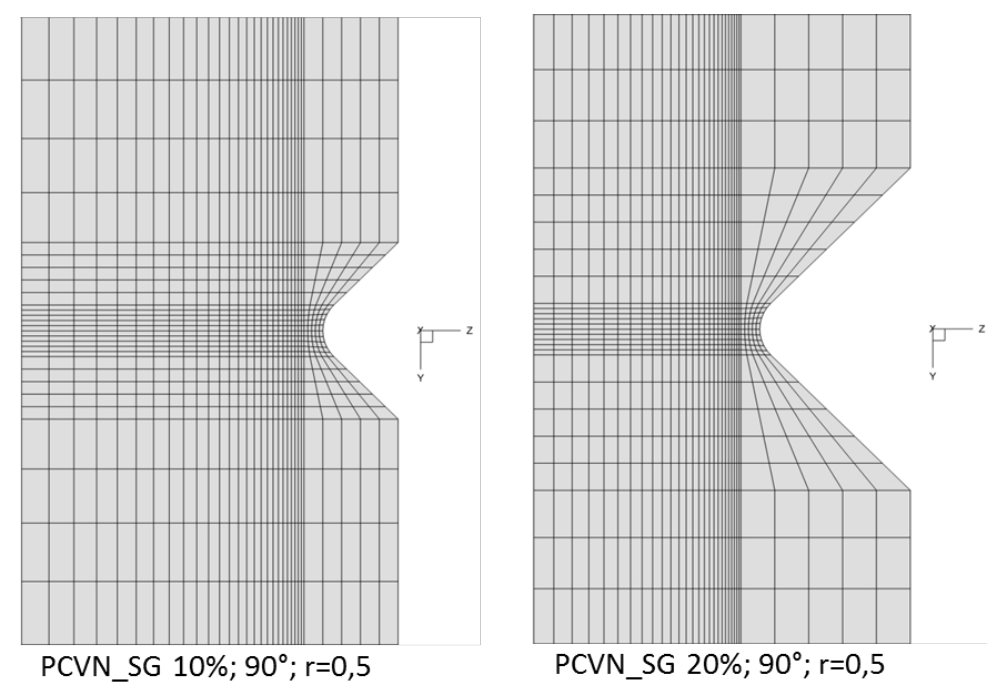

Figura 67. Modelos numéricos das diversas variações de corpos de prova com geometria PCVN. 
Para modelagem computacional dos corpos de prova, SE(B)-1T e PCVN, foram utilizados os programas ABAQUS [90] e MSC PATRAN [91] como pré e pósprocessador. Devido à simetria dos espécimes, as condições de contorno impostas nos planos de simetria permitem que apenas um quarto do modelo de elementos finitos seja construído, reduzindo assim o esforço computacional das análises numéricas.

$\mathrm{Na}$ modelagem da trinca um pequeno raio $(\rho=0,0025)$ é utilizado para simular o "blunting" ou arredondamento observado em corpos de prova reais, como mostrado na Figura 68. Além disto, este raio facilita a convergência das análises numéricas, tornando mais rápida a simulação.

A aplicação do carregamento se dá por meio de passos incrementais de deslocamento. O programa utilizado para o processamento das análises, WARP3D [93], permite a simulação de contato, realizada de forma similar para todos os modelos, por meio de um rolete com diâmetro definido conforme a norma ASTM E1921 [14] localizado a uma distância $2 W$ em relação ao centro do entalhe, conforme ilustrado na Figura 68.

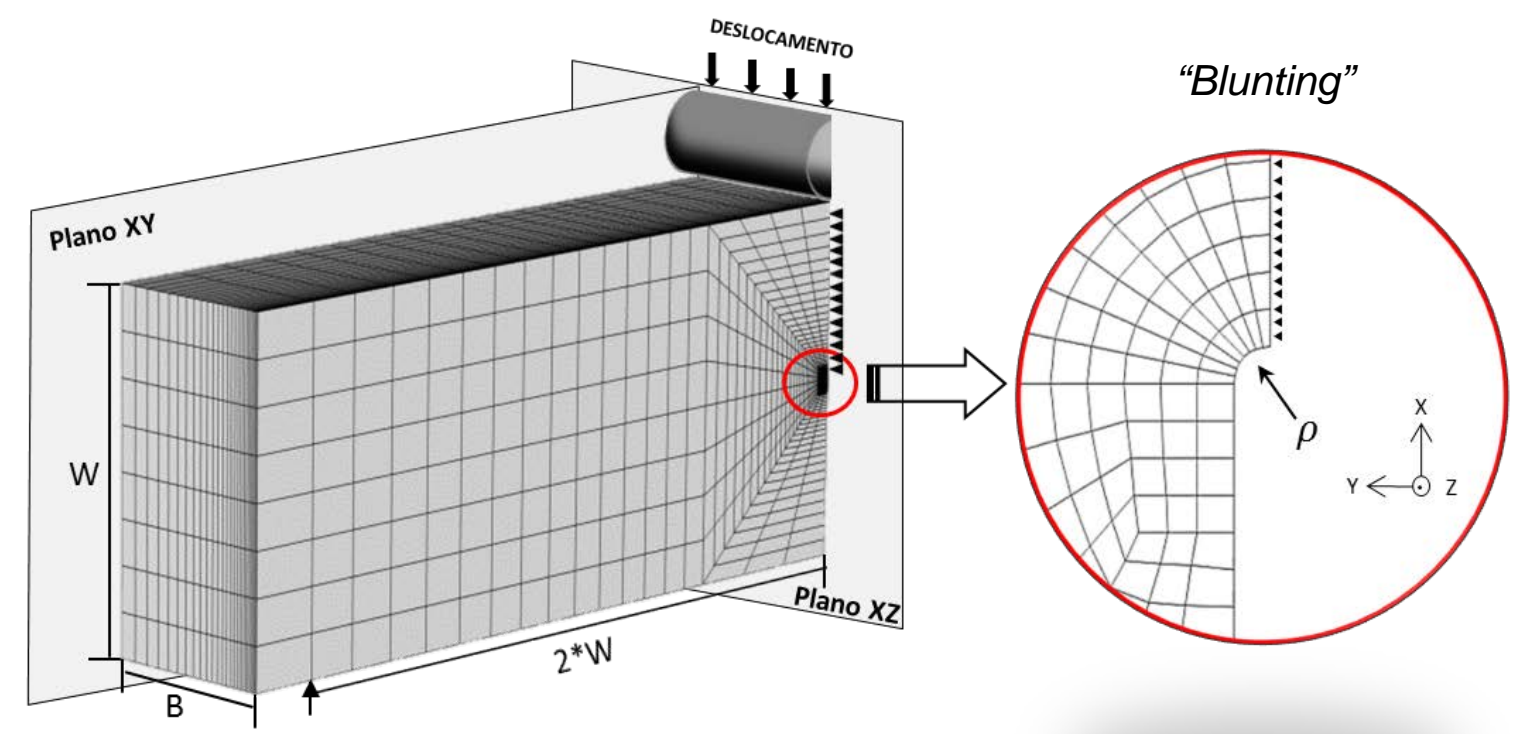

Figura 68. Representação da simetria do corpo SE(B) utilizada nos modelos para simulação e representação da ponta da trinca arredondada. 
A malha dos modelos numéricos apresenta refinamento progressivo nas camadas que constituem a espessura do corpo de prova sendo este refinamento crescente a partir do centro, $Z=0$, até à superfície livre do mesmo, $Z=B / 2$, na razão de $6,5: 1$ nos modelos com menor número de camadas e na razão de $10: 1$ nos modelos com maior número de camadas. Para as geometrias com superfície livre plana, ou seja, sem entalhes laterais, os modelos possuem aproximadamente 25 camadas, 30000 nós e 27000 elementos hexaédricos de 8 nós. Para os modelos com entalhes laterais o refinamento da malha é maior, pois o gradiente de tensão próximo à superfície livre do corpo de prova poderia ser acentuado em decorrência da presença do entalhe lateral, com isso estes modelos apresentam 31 camadas, 80000 nós e 75000 elementos hexaédricos de 8 nós.

\section{D.2. Análise Pelo Método dos Elementos Finitos}

Como já mencionado as análises computacionais deste trabalho visam simular numericamente os campos de tensões desenvolvidos nos corpos de prova com trinca central passante em regime elásto-plástico. Aos modelos numéricos foram atribuídas propriedades mecânicas similares às obtidas nos ensaios de caracterização do material, realizados na parte experimental. Tais propriedades mecânicas são bastante representativas dessa classe de aços ferríticos, comumente empregados na construção de vasos de pressão.

As soluções numéricas dos modelos tridimensionais estudados foram conduzidas utilizando o código WARP3D [92]. Este código foi concebido para modelagens numéricas não-lineares em sólidos 3D com comportamento elasto-plástico e incorpora o modelo constitutivo Mises (J2). O comportamento mecânico em tração uniaxial do material adotado no modelo numérico é caracterizado por uma lei de potência conforme as equações (D.1) e (D.2). 


$$
\varepsilon=\frac{\sigma}{E} ; \sigma \leq \sigma_{y s}
$$

$$
\frac{\varepsilon}{\varepsilon_{y s}}=\left(\frac{\sigma}{\sigma_{y s}}\right)^{n} ; \sigma \geq \sigma_{y s}
$$

A integral $J$, usada para a avaliação local da taxa de liberação de energia, em toda a extensão da frente de trinca é obtida da seguinte expressão:

$$
J=\lim _{\Gamma \rightarrow 0} \int_{\Gamma}\left(W n_{1}-\sigma_{i j} \frac{\partial u_{i}}{\partial x 1} n_{j}\right) d \Gamma
$$

Onde $\Gamma$ define, na configuração ainda não deformada, o contorno fechado normal ao plano da trinca, percorrido em sentido anti-horário, iniciando na face inferior e terminando na face superior da mesma, $n_{j}$ é o vetor normal ao contorno $\Gamma, W$ é a energia de deformação por unidade de volume indeformado, $\sigma_{i j}$ e $u_{i}$ são as componentes cartesianas do tensor de tensões e de deslocamentos no sistema de coordenadas localizado na frente da trinca. Por meio de integração de domínios [93 - [94] o código WARP3D [92] pode calcular de forma numérica o valor da integral $J$ em locais pontuais na frente de trinca ou determinar valores médios de integral $J$ ao longo de toda a espessura do espécime simulado. Os valores médios de tenacidade determinados numericamente tem boa aderência com os valores de tenacidades estimados experimentalmente, utilizando-se a metodologia baseada em fatores- $\eta$ [20]. 


\section{D.3. Trajetória $J-Q$}

A medição da triaxialidade na ponta da trinca, por meio da metodologia $J-Q$ foi realizada com auxílio do código de pesquisa Fractus 2D [35]. Para a obtenção das trajetórias $J-Q$ as equações (D.4) e (D.5) são resolvidas ponto a ponto computacionalmente calculando-se a diferença de tensões sob Modo I de carregamento a uma distância fixa da ponta da trinca, geralmente adota-se $r=J 2 / \sigma_{0}$, entre o componente estrutural, neste trabalho representado por corpo de prova solicitado em flexão três pontos e a solução de referência representada por uma placa infinita contendo uma trinca, representados pela Figura 68 (a) e (b) respectivamente.

$$
\begin{gathered}
\sigma_{i j}=\left(\sigma_{i j}\right)_{R e f}+Q \sigma_{0} \delta_{i j} ; \text { para } \quad r>\frac{\mathrm{J}}{\sigma_{0}}, \quad|\theta| \leq \frac{\pi}{2} \\
Q \equiv \frac{\sigma_{y y}-\left(\sigma_{y y}\right)_{R e f}}{\sigma_{0}} ; \quad r=J \frac{2}{\sigma_{0}}
\end{gathered}
$$




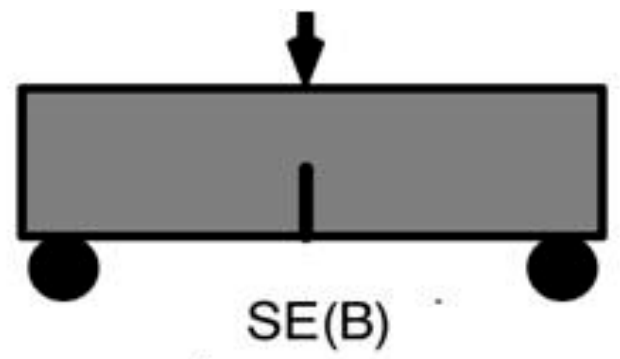

(a)

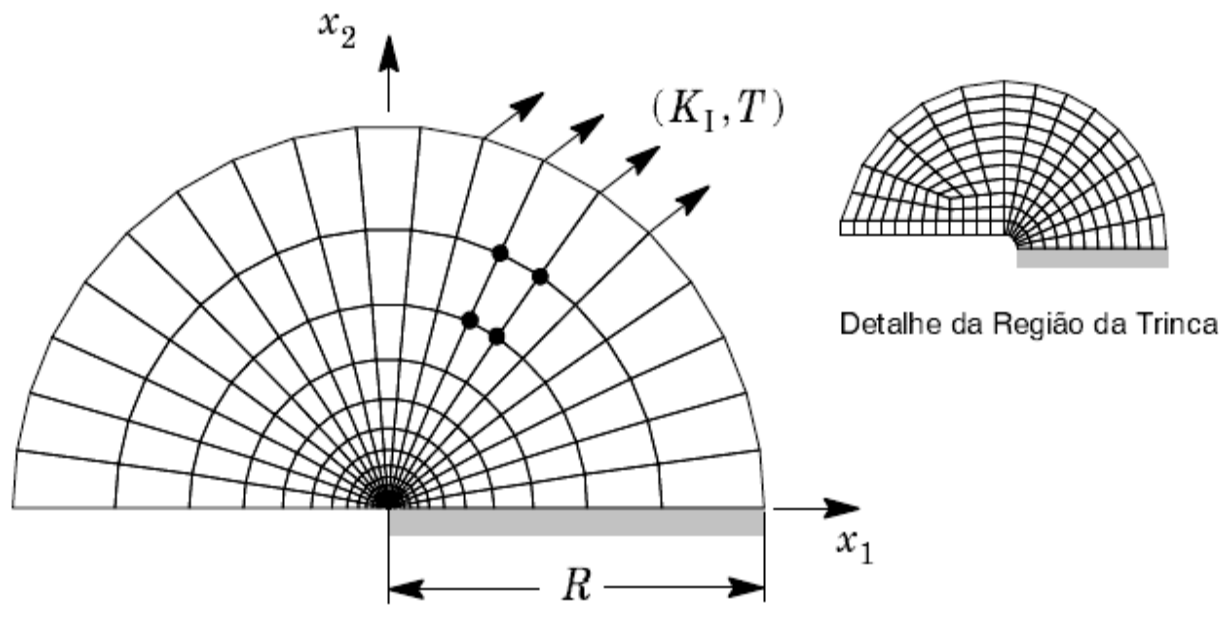

(b)

Figura 69. Representação de um corpo de prova com geometria SE(B), (a) solicitado sob Modo I de carregamento. (b) Representação do modelo MBL.

O gráfico da Figura 69 representa a diferença entre os campos de tensão, $Q * \sigma_{0}$, onde é plotada a tensão de abertura adimensionalizada pela tensão de escoamento $\left(\sigma_{y y} / \sigma_{0}\right)$ do material vs. distância adimensional em relação à ponta da trinca $\left(\lambda=r /\left(J / \sigma_{0}\right)\right)$. A linha tracejada representa a solução de referência e as linhas cheias referem-se ao componente estrutural objeto de estudo com diferentes níveis de carregamento $(J)$. 


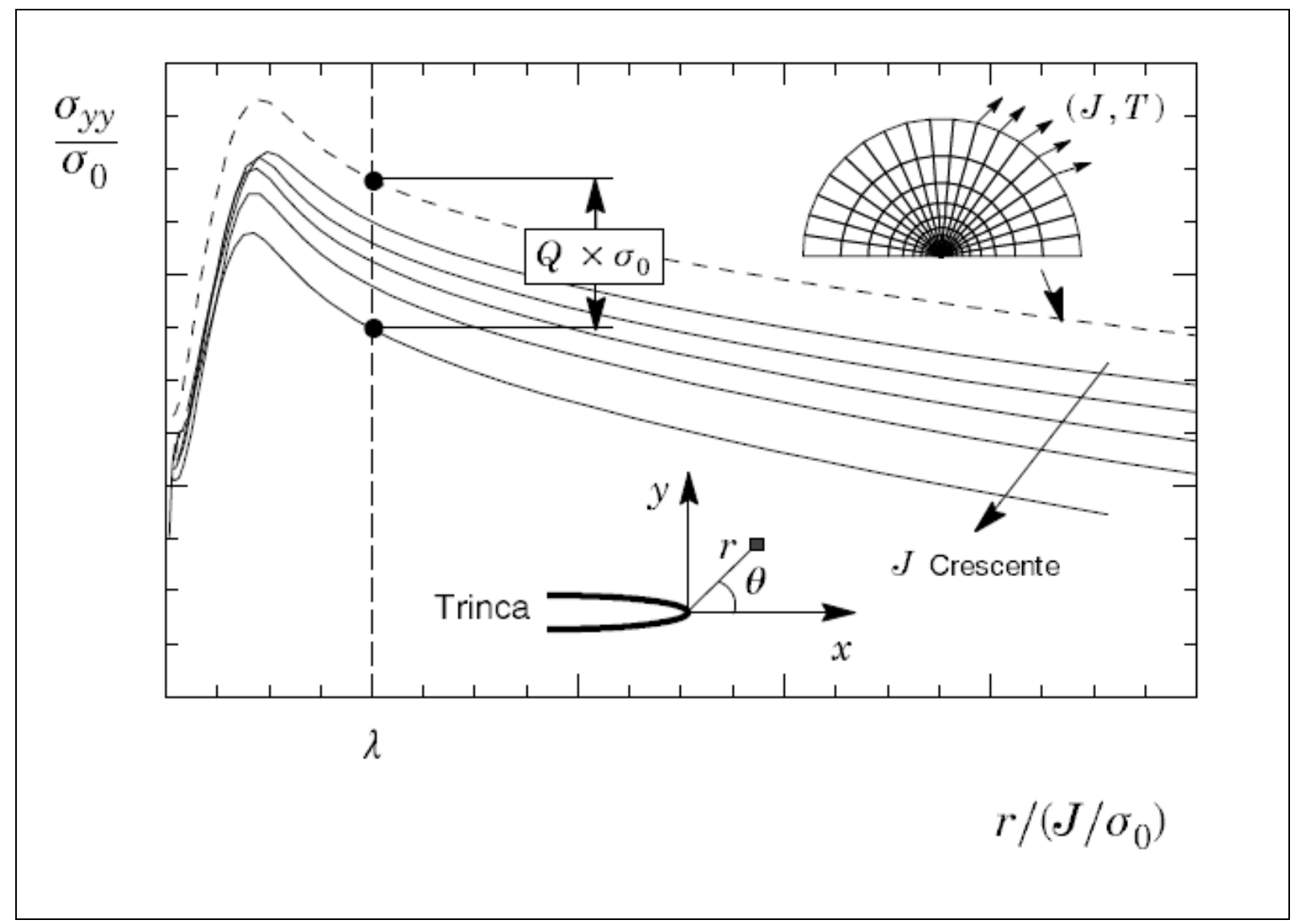

Figura 70. Representação da tensão de abertura adimensional vs. distância adimensional para a solução de referência MBL e um componente estrutural genérico [35]. 